Florida International University FIU Digital Commons

$11-7-2016$

\title{
Kinetics and Reaction Mechanisms for Methylidyne Radical Reactions with Small Hydrocarbons
}

Joao Marcelo Lamim Ribeiro

Florida International University, jribe003@fiu.edu

DOI: 10.25148 /etd.FIDC001210

Follow this and additional works at: https://digitalcommons.fiu.edu/etd

Part of the Physical Chemistry Commons

\section{Recommended Citation}

Ribeiro, Joao Marcelo Lamim, "Kinetics and Reaction Mechanisms for Methylidyne Radical Reactions with Small Hydrocarbons" (2016). FIU Electronic Theses and Dissertations. 3023.

https://digitalcommons.fiu.edu/etd/3023 


\section{FLORIDA INTERNATIONAL UNIVERSITY}

Miami, Florida

\section{KINETICS AND REACTION MECHANISMS FOR METHYLIDYNE RADICAL REACTIONS WITH SMALL HYDROCARBONS}

A dissertation submitted in partial fulfillment of the

requirements for the degree of

DOCTOR OF PHILOSOPHY

in

CHEMISTRY

by

Joao Marcelo Lamim Ribeiro

2016 
To: Dean Michael R. Heithaus

College of Arts, Sciences and Education

This dissertation, written by Joao Marcelo Lamim Ribeiro, and entitled Kinetics and Reaction Mechanisms for Methylidyne Radical Reactions with Small Hydrocarbons, having been approved in respect to style and intellectual content, is referred to you for judgment.

We have read this dissertation and recommend that it be approved.

\begin{tabular}{rr}
\hline John Zweibel \\
\hline Kevin O'Shea \\
\hline Jeffrey Joens
\end{tabular}

David C. Chatfield

Alexander M. Mebel, Major Professor

Date of Defense: November 7, 2016

The dissertation of Joao Marcelo Lamim Ribeiro is approved.

Dean Michael R. Heithaus

College of Arts, Sciences and Education

Andres G. Gil

Vice President for Research and Economic Development and Dean of the University Graduate School

Florida International University, 2016 


\section{ABSTRACT OF THE DISSERTATION \\ KINETICS AND REACTION MECHANISMS FOR METHYLIDYNE RADICAL REACTIONS WITH SMALL HYDROCARBONS}

by

Joao Marcelo Lamim Ribeiro

Florida International University, 2016

Miami, Florida

\section{Professor Alexander M. Mebel, Major Professor}

The chemical evolution with respect to time of complex macroscopic mixtures such as interstellar clouds and Titan's atmosphere is governed via a mutual competition between thousands of simultaneous processes, including thousands of chemical reactions. Chemical kinetic modeling, which attempts to understand their macroscopic observables as well as their overall reaction mechanism through a detailed understanding of their microscopic reactions and processes, thus require thousands of rate coefficients and product distributions. At present, however, just a small fraction of these have been well-studied and measured; in addition, at the relevant low temperatures, such information becomes even more scarce. Due to the recent developments in both theoretical kinetics as well as in $a b$ initio electronic structure calculations, it is now possible to predict accurate reaction rate coefficients and product distributions from first-principles at various temperatures, often in less time, than through the running of an experiment. Here, the results of a first principles theoretical investigation into both the reaction rate coefficients as well as the final product distributions for the reactions between the ground state $\mathrm{CH}$ radical $\left(\mathrm{X}^{2} \Pi\right)$ and various $\mathrm{C} 1$ - 
C3 hydrocarbons is presented; together, these constitute a set of reactions important to modeling efforts relevant to mixtures such as interstellar clouds and Titan's atmosphere. 


\section{TABLE OF CONTENTS}

CHAPTER

PAGE

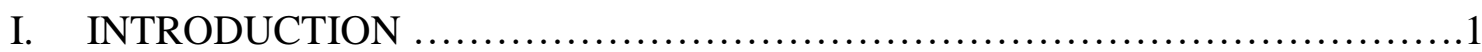

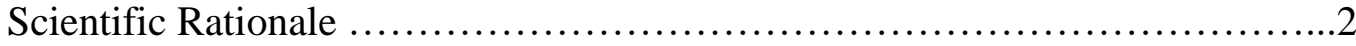

Chemical Kinetic Modeling ............................................

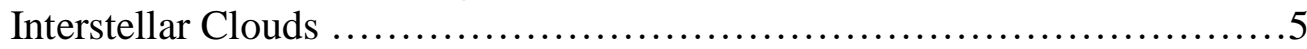

Atmosphere of Titan ...............................................

CH Radical Reactions Literature Review ................................9

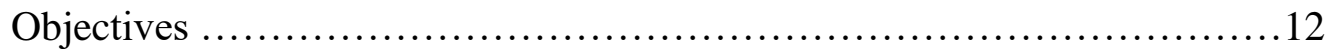

Theoretical Background and General Method ................................14

Potential Energy Surface (PES) ....................................... 14

Master Equation (ME) ...............................................

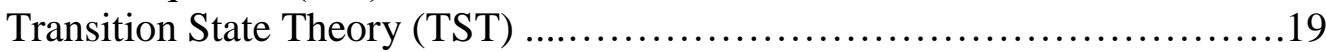

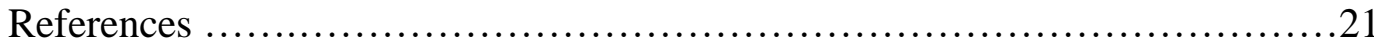

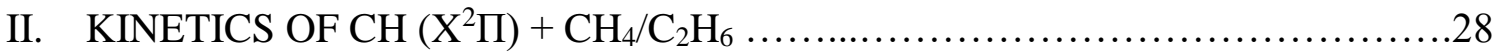

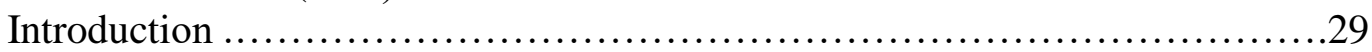

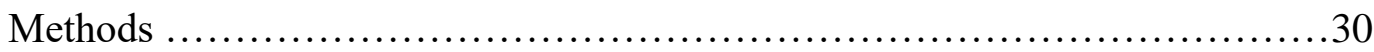

Results and Discussion ........................................................

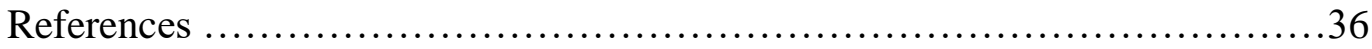

III. REACTION MECHANISM OF CH $\left(\mathrm{X}^{2} \Pi\right)+\mathrm{C}_{3} \mathrm{H}_{8}$ AND $\mathrm{C}_{4} \mathrm{H}_{9}$ PES ..............51

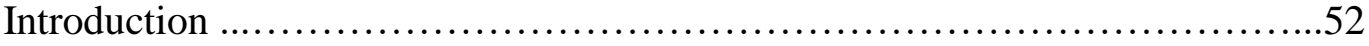

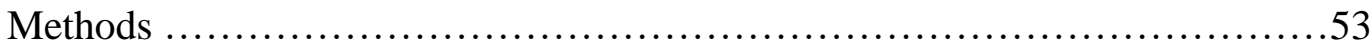

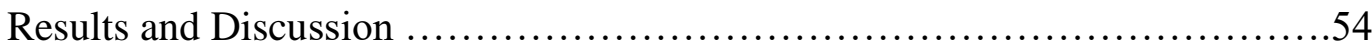

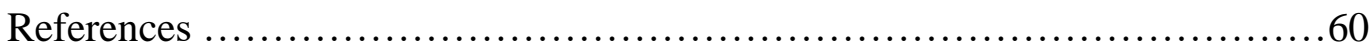

IV. REACTION MECHANISM OF CH $\left(\mathrm{X}^{2} \Pi\right)+\mathrm{C}_{3} \mathrm{H}_{6}$ AND $\mathrm{C}_{4} \mathrm{H}_{7}$ PES ..............72

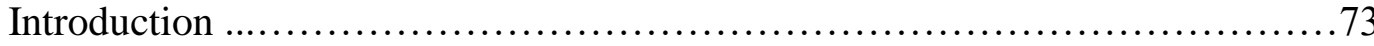

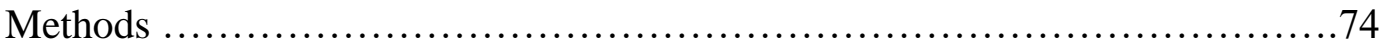

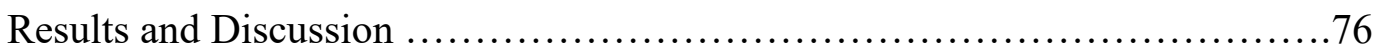

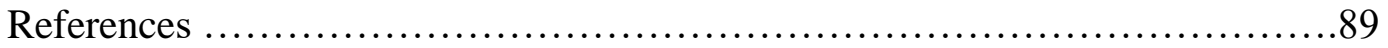

V. REACTION MECHANISM OF CH $\left(\mathrm{X}^{2} \Pi\right)+\mathrm{C}_{3} \mathrm{H}_{4}$ AND $\mathrm{C}_{4} \mathrm{H}_{5}$ PES ..............108

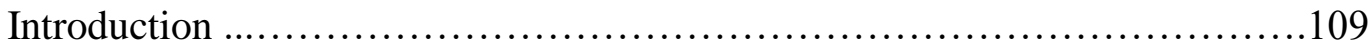

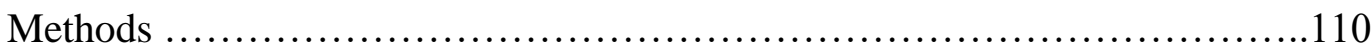

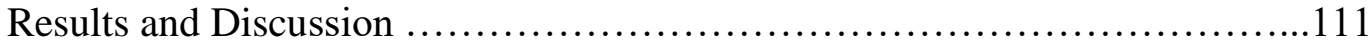

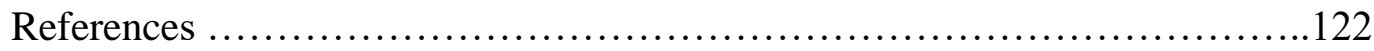

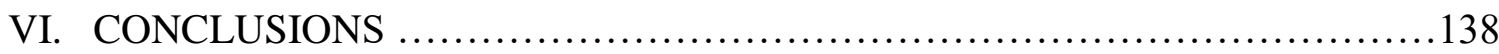

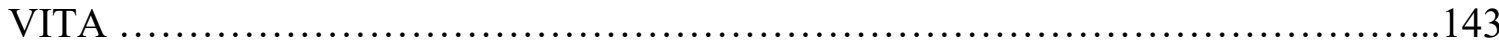




\section{LIST OF TABLES}

TABLE

PAGE

2.1 A Comparison of Geometries and Frequencies

2.2 A Comparison of the Barrier Heights for Channels Available to $n-\mathrm{C}_{3} \mathrm{H}_{7}$ Radical ...41

2.3 Methane + CH Radical CCSD(T), CCSDT(Q), CCSDTQ(P) Energies

2.4 Ethane + CH Radical CCSD(T) and CCSDT(Q) Energies .43

3.1 Relative Energies for Select $\mathrm{C}_{4} \mathrm{H}_{9}$ Species .65

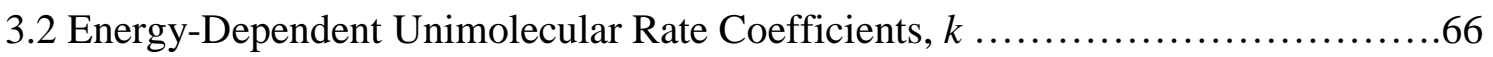

3.3 Propane $+\mathrm{CH}$ Radical Product Branching Ratio $(0 \mathrm{kcal} / \mathrm{mol}) \ldots \ldots \ldots \ldots \ldots \ldots . . .68$

3.4 Propane + CH Radical Product Branching Ratio $(1 \mathrm{kcal} / \mathrm{mol}) \ldots \ldots \ldots \ldots \ldots \ldots \ldots . \ldots 9$

4.1 Relative Energies for Select $\mathrm{C}_{4} \mathrm{H}_{7}$ Species ............................. 93

4.2 Energy-Dependent Isomerization Rate Coefficients, $k \ldots \ldots \ldots \ldots \ldots \ldots \ldots \ldots \ldots . \ldots 4$

4.3 Energy-Dependent Dissociation Rate Coefficients, $k \ldots \ldots \ldots \ldots \ldots \ldots \ldots \ldots \ldots \ldots . . . \ldots 6$

4.4 Propene $+\mathrm{CH}$ Radical Product Branching Ratio ............................. 97

5.1 Methylacetylene + CH Radical Unimolecular Rate Coefficients, $k \ldots \ldots \ldots \ldots \ldots . . .125$

5.2 Methylacetylene + CH Radical Product Branching Ratio .....................127

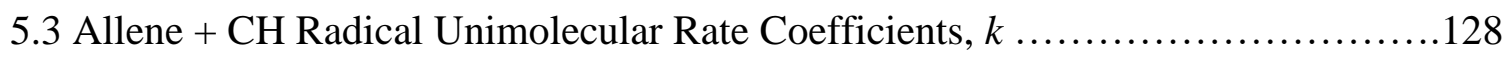

5.4 Allene + CH Radical Product Branching Ratio ............................ 129 


\section{LIST OF FIGURES}

FIGURE

PAGE

2.1 Methane + CH Radical "Rigid" vs. Optimized Potential ......................44

2.2 Methane $+\mathrm{CH}$ Radical Potential Describing $\mathrm{C}-\mathrm{H} \sigma$ Bond Insertion ..............45

2.3 Methane + CH Radical Total Rate Coefficients, $k$, as a Function of Temperature ..46

2.4 Ethane $+\mathrm{CH}$ Radical Potential Describing $\mathrm{C}-\mathrm{H} \sigma$ Bond Insertion ...............47

2.5 Ethane + CH Radical Potential Describing C-C $\sigma$ Bond Insertion .................48

2.6 Ethane $+\mathrm{CH}$ Radical Total Rate Coefficients, $k$, as a Function of Temperature ....49

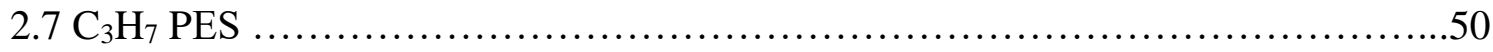

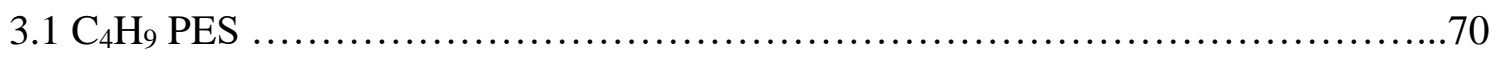

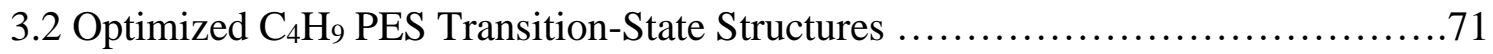

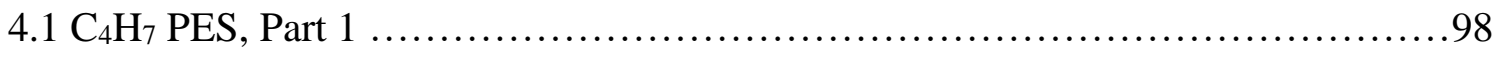

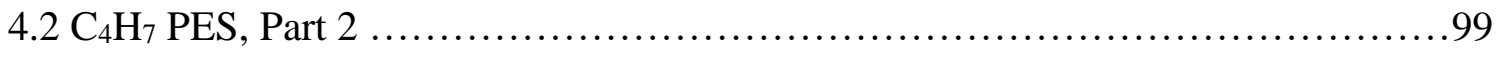

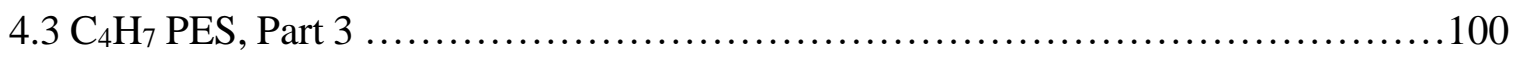

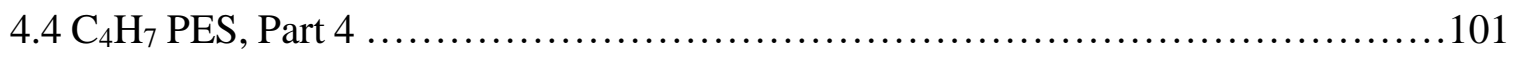

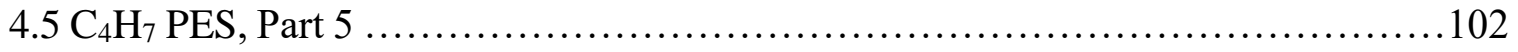

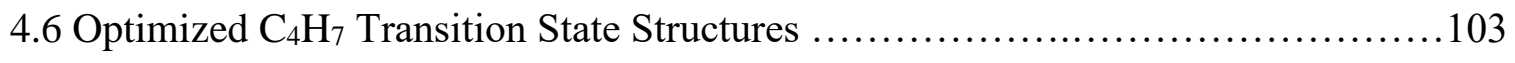

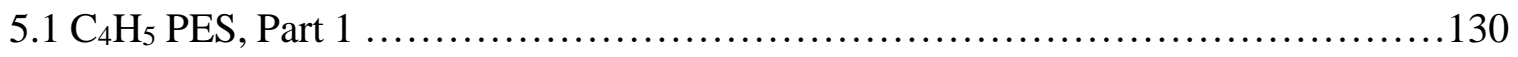

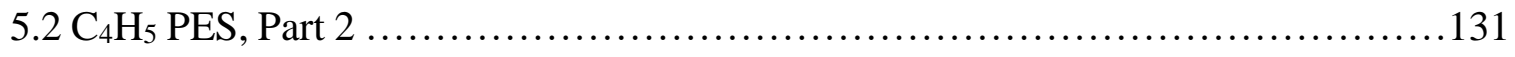

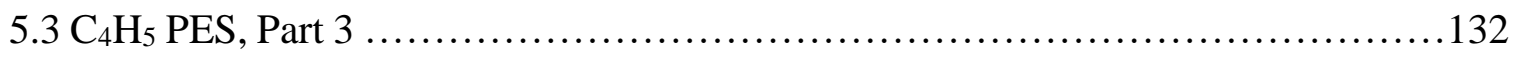

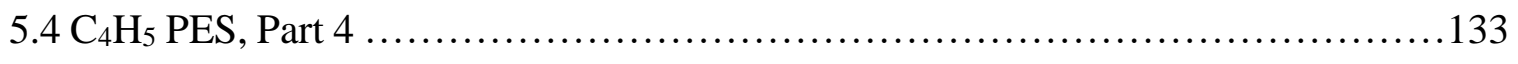

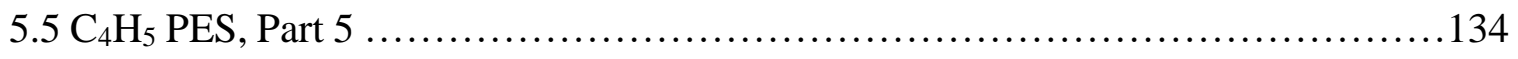

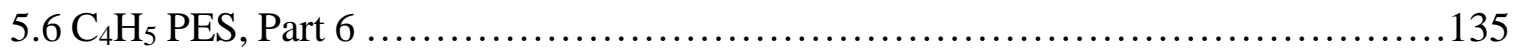


5.7 $\mathrm{C}_{4} \mathrm{H}_{5}$ PES, Part 7

5.8 $\mathrm{C}_{4} \mathrm{H}_{5}$ PES, Part 8 


\section{CHAPTER I}

INTRODUCTION 


\section{Scientific Rationale}

\section{Chemical Kinetic Modeling:}

In order to reach a quantitative understanding regarding the abundances of complex organic molecules observed in dense interstellar clouds, the atmospheres of moons and planets, and in combustion vessels, investigators make use of chemical kinetic models. In addition to predicting the concentration of various chemical species as a function of time, ${ }^{1-}$ ${ }^{7}$ chemical models can also reveal the processes and reactions which are most important in driving forward the overall evolution of the mixture. ${ }^{1,5,7,8}$ To create such a model, networks of interconnected processes and reactions which serve as the production and destruction paths available to each constituent in the mixture are established. ${ }^{1,5,6,9}$ Included in such networks are rate coefficients, one for each available path. ${ }^{1-3,5-9}$ The experiments and theoretical investigations aimed at elucidating, for a given reaction, the major products as well as the rate coefficients, thus provide important information to guide the building and/or optimizing of predictive models.

There exist two considerable challenges inherent to the modeling of interstellar clouds, low temperature atmospheres and combustion. The first of these is the sheer scope of the phenomena and, to illustrate this, take for instance the modeling of interstellar clouds: Here, 400 species and more than 4000 reactions coupling them might comprise the model. ${ }^{1}$ The need to understand the kinetics of thousands of reactions poses, in and of itself, a significant challenge. Second, meanwhile, are the ambient conditions: In certain regions of interstellar clouds, for instance, the temperature can be as low as $10 \mathrm{~K}^{1,2,4}$ and, in combustion, temperatures can reach a few thousand Kelvin (in addition to high pressures). ${ }^{6,7,9,10}$ The task of performing kinetic and mechanistic measurements under these 
conditions presents another significant challenge. As a result, the number of chemical/photochemical reactions whose product branching ratios and/or rate coefficients have been measured under the proper conditions make up a fraction of the total above. ${ }^{1}$ Regarding the modeling of Titan's atmosphere, less than 5\% of the branching ratios for reactions incorporated into models have been measured under the relevant conditions ${ }^{5}$ (the temperature on Titan's atmosphere is higher than in interstellar clouds but still lower than $190 \mathrm{~K}) .^{11}$

To circumvent the lack of direct available kinetic and mechanistic information, modelers must often use chemical intuition to determine, for unstudied reactions, the product distributions and rate coefficients. ${ }^{1}$ Meanwhile, when rate coefficients have been measured but under different conditions, extrapolation techniques are used to convert the coefficients to the proper temperature and pressure. ${ }^{1,5,7,8}$ A common situation is to have available room temperature rate coefficients which are then extrapolated to the lower temperatures of interstellar clouds and Titan's atmosphere. These extrapolations are based on modified Arrhenius laws. ${ }^{5,8}$ The assumption of Arrhenius behavior, however, has been found inadequate for various reactions ${ }^{12,13}$ which can lead to rather large uncertainties in the rate coefficients. ${ }^{14}$ The propagation of these uncertainties in turn leads to large uncertainties in the final model predictions, such that the uncertainties attached to the computed concentrations are much larger than the estimated uncertainties in the concentrations inferred from observations. ${ }^{1,15}$

In order to assist both experimental and theoretical kineticists in choosing which reactions to focus their efforts on, modelers are able to probe their models to reveal the most important reactions. ${ }^{5,8,14,16-18}$ These, at least in principle, should be prioritized and 
would have a maximum effect on modeling predictions. It is important to note that the definition of what constitutes an important reaction is not unambiguous, however, and will depend on what aspect of the model is being probed. ${ }^{5,8}$ Perhaps the most straightforward definition of an important reaction is that it is one which has a large influence on the concentration of a species (or of various different species), ${ }^{5,8}$ thus having a large impact on the overall evolution of the mixture. Another definition which has found extensive use, however, is that an important reaction is one whose attached uncertainties have a large effect on the final model uncertainties, ${ }^{5,8,14,16-18}$ such that it influences the overall precision of the model. Having a thorough understanding of the final predicted uncertainties is important for a proper comparison with the abundances inferred from direct observations. ${ }^{1}$ The former definition will be termed an influential reaction and the latter a key reaction. 5,8 Theoretical investigations of chemical and photochemical reactions are useful in chemical kinetics modeling in several respects. Often, they are used as a complement to experiments to help with interpretation of the results, ${ }^{7}$ something which becomes even more crucial when there are experimental disagreements. ${ }^{7}$ Meanwhile, in pressure and temperature regimes that pose large difficulties to performing experiments, theoretical studies can be used to reveal both the branching ratios and rate coefficients of chemical reactions. ${ }^{19,20}$ Even in situations where experimentation is feasible, depending on the reaction, theoretical calculations can now provide accurate results in less time and a more cost effective manner. In fact, with the development of modern computers and newer theoretical methods the accuracy of the kinetics of reactions determined via theoretical studies can often rival that of experiments. ${ }^{20}$ Thus theoretical kinetics has now become vital 
to the modeling of complex phenomena and its contribution might be expected to increase even more so with future developments in computation.

Interstellar Clouds:

The interstellar medium contains gas-phase molecules distributed in a heterogeneous fashion which often congregate onto particular regions of interstellar space. ${ }^{3,4}$ Such interstellar regions with an enhancement in the number concentration are called interstellar clouds. ${ }^{4}$ Depending on their specific concentrations, interstellar clouds are characterized as diffuse or molecular, ${ }^{2,4}$ with diffuse clouds having a concentration of less than $100 \mathrm{~cm}^{-3}$ and molecular clouds having a concentration of more than $100 \mathrm{~cm}^{-3} .4$ Within interstellar clouds, just as in the interstellar medium, the gas distribution is heterogeneous as a consequence of gravitation and turbulence ${ }^{2}$ and, in fact, it is gravitation and turbulence that leads the evolution of diffuse clouds towards a molecular cloud with a dense core. ${ }^{2}$ The dense core, with a number concentration of at least $10^{4} \mathrm{~cm}^{-3},{ }^{4}$ through gravitational collapse becomes a protostar and then a star. ${ }^{2,3,4}$ The surrounding disk, meanwhile, evolve into planets and other objects. ${ }^{3,21,22}$ The conditions within diffuse interstellar clouds and within the dense core can be quite different relative to one another. ${ }^{2-}$ ${ }^{4}$ Ultraviolet radiation, for instance, cannot penetrate into dense clouds such that its major species is $\mathrm{H}_{2} \cdot{ }^{2-4}$ Also, the ionization rate is not high since ionizing UV photons are not present. ${ }^{2}$ In diffuse clouds, meanwhile, penetrating UV radiation dissociates $\mathrm{H}_{2}$ and it coexists with $\mathrm{H}^{2}$ In addition, a larger fraction of ions is present in diffuse clouds. ${ }^{2}$ And while the temperature in dense clouds is $\sim 10 \mathrm{~K}$, in diffuse clouds it can range from 30-100 $\mathrm{K}$ because of the effect of UV photons upon the radiative balance. ${ }^{2}$ Regardless of the conditions, however, the major building blocks in both diffuse and dense interstellar clouds 
are the same relative to each other as well as to the interstellar medium, with $\mathrm{H}$ and $\mathrm{He}$ being the dominant building blocks, and with $\mathrm{O}, \mathrm{C}$ and $\mathrm{N}$ being available in trace amounts. ${ }^{1-}$ ${ }^{4,23}$ In addition, trace amounts of dust particles made up of silicates and carbonaceous material are present in interstellar clouds. ${ }^{2-4}$ These have an important role in the chemical evolution of interstellar clouds, providing a surface for numerous chemical reactions, ${ }^{2,3}$ the most important of which is $\mathrm{H}+\mathrm{H} \rightarrow \mathrm{H}_{2}{ }^{3}$

The detection and identification of molecules in the interstellar medium began in the 1940s when both the $\mathrm{CH}$ and $\mathrm{CN}$ radicals were identified. ${ }^{2,4}$ With the development of radio observations for astronomical purposes a large increase in the number of detected interstellar species took place in the 1960s and 1970s. ${ }^{1,2,4}$ A large fraction of these observed species are neutral molecules and also carbon-chain molecules. ${ }^{1,2}$ In fact, almost all complex molecules that have been detected are carbon-based molecules ${ }^{2}$ indicating that most of the chemistry in interstellar space is organic. ${ }^{2}$ There are some distinct and peculiar features exhibited by this organic chemistry, however, as a consequence of the low temperatures and lack of molecular collisions relative to terrestrial values. ${ }^{2}$ In a dense core with a number concentration of $10^{4} \mathrm{~cm}^{-3}$, a single collision between a neutral molecule and $\mathrm{H}_{2}$ will take place once a month ${ }^{4}$ allowing what are transient species on Earth to have longer lifetimes. ${ }^{2}$ Carbon-chain molecules with a high degree of unsaturation such as $\mathrm{CH}$, $\mathrm{C}_{2} \mathrm{H}, \mathrm{C}_{4} \mathrm{H}$ and $\mathrm{C}_{6} \mathrm{H}$ can thus be found in numerous interstellar clouds, ${ }^{2,4}$ and quite so during the earliest stages of dense cores. ${ }^{2,4}$ As a result of the low temperatures of interstellar clouds inhibiting reactions between two stable neutral molecules, ${ }^{1-4,23}$ these highly reactive neutral species might contribute to the production of complex organic molecules in interstellar clouds and it would be important to know if and how these species could contribute to 
increasing the carbon-skeleton. Overall, the pressure and temperature of interstellar clouds make it so that it is under complete kinetic control, "residing" far from a thermodynamically controlled equilibrium. ${ }^{2}$

Atmosphere of Titan:

Titan is the largest moon of Saturn and has a dense atmosphere with a surface pressure of 1.5 bar. ${ }^{11}$ In addition, its atmosphere is extensive, rising over $1000 \mathrm{~km} .{ }^{11}$ The atmosphere of Titan shows certain similarities to that of Earth's, one example being that the overall atmospheric structure is also composed of a troposphere, stratosphere, mesosphere and thermosphere, with both the stratosphere and thermosphere showing temperature inversion. ${ }^{11}$ The maximum atmospheric temperature on Titan lies close to the stratopause, where the temperature can rise to $\sim 190 \mathrm{~K} .{ }^{11}$ Another example, meanwhile, is that the main atmospheric component is also $\mathrm{N}_{2}, \sim 95-98 \%,{ }^{11,24}$ although this molecular nitrogen is in a somewhat reducing atmospheric environment on Titan ${ }^{11,25}$ while it is in an oxidizing one on Earth. This difference arises because methane is the second most abundant compound on Titan, with molecular mixing ratios of $\sim 0.015-0.050,{ }^{11,24}$ while on Earth it is $\mathrm{O}_{2}$. It is important to keep in mind, however, that the conditions on primordial Earth are thought to have been reducing and, also, that it is thought that Titan's atmosphere somewhat resembles that of primordial Earth. ${ }^{25,26,27}$ Thus Titan's atmosphere might provide some of the most direct information about Earth's own primordial atmosphere. Such a source of information is important to exobiologists, who are attempting to piece together how life developed and/or evolved given the conditions on primordial Earth. ${ }^{11}$ How molecular nitrogen is converted into nitrogen containing biological compounds, prior 
to bacterial fixation and within the reducing atmosphere of primordial Earth, might be one of the questions Titan and its atmosphere could help provide an answer. ${ }^{25}$

The chemical processes in Titan's atmosphere, these are initiated high in the atmosphere via photon and energetic electron bombardment of its two major constituents molecular nitrogen and methane, where the net effect is the degradation of inert molecules into reactive species primed to undergo reactions despite the low temperatures. ${ }^{11,28,29,30}$ The need to produce reactive species for low temperature reactions is illustrated well in the following example, which is the major reaction path towards ethane:

$$
\begin{gathered}
\mathrm{CH}_{4}+h v \rightarrow \cdot \mathrm{CH}_{3}+\cdot \mathrm{H} \\
\cdot \mathrm{CH}_{3}+\cdot \mathrm{CH}_{3} \rightarrow \mathrm{C}_{2} \mathrm{H}_{6}
\end{gathered}
$$

Thus the recombination of two reactive methyl radicals leads to the production of ethane. ${ }^{29}$ From a theoretical perspective, the requirement for chemical reactions to be feasible in the low temperature conditions of Titan's atmosphere, and at lower temperatures typical in interstellar clouds, is that they must not have energetic barriers along the reaction coordinate leading reactants towards products. ${ }^{1}$ Radical-radical reactions such as $\mathrm{CH}_{3}+$ $\mathrm{CH}_{3}$ are examples of such reactions. Another example are reactions between an ion and a neutral species (ion-neutral reactions) and these are important in Titan's ionosphere as well as interstellar clouds. ${ }^{28,30}$ In Titan's atmosphere, for instance, ion-neutral reactions may lead to efficient production of benzene. ${ }^{30}$

In addition to methyl radicals, the photolysis of methane can also lead to both methylene and methylidydne radical $\left(\mathrm{CH}_{2}\right.$ and $\mathrm{CH}$ respectively), ${ }^{11,29}$ and these too can contribute to the chemical evolution of Titan's atmosphere. ${ }^{29}$ In particular, the simple CH radical in the ground state, $X^{2} \Pi$, with a vacant nonbonding orbital as well as a singly 
occupied orbital on the carbon atom, ${ }^{31}$ has the interesting capability of reacting with closedshell neutral molecules without a barrier. ${ }^{31}$ In Titan's atmosphere, where some of the most abundant trace species are, in order from most concentrated to least, $\mathrm{C}_{2} \mathrm{H}_{6}, \mathrm{C}_{2} \mathrm{H}_{2}, \mathrm{C}_{2} \mathrm{H}_{4}$, $\mathrm{C}_{3} \mathrm{H}_{6}, \mathrm{C}_{3} \mathrm{H}_{8}$ and $\mathrm{C}_{3} \mathrm{H}_{4}, \mathrm{CH}$ radical reaction with hydrocarbons might be expected to play an important role it its chemical scheme. Therefore, the primary aim of this work is to investigate the kinetics and reaction mechanisms of $\mathrm{CH}$ radical reactions with methane and the $\mathrm{C} 2-\mathrm{C} 3$ hydrocarbons listed above.

\section{CH Radical Reactions Literature Review:}

Several investigations into the reactions of the ground state $\mathrm{CH}$ radical have been performed $^{31-49}$ and, in particular, methane reaction with $\mathrm{CH}$ has been the subject of various experiments. ${ }^{31-37}$ The extensive experimental interest stems from the reaction's influence on the chemical evolution of Titan's atmosphere, ${ }^{8,32}$ where, in fact, it is considered one of the most influential reactions. ${ }^{8}$ Unlike various other reactions in Titan's atmosphere, the reaction's influence appears to prevail at almost all altitudes. ${ }^{8}$ In addition, with regard to interstellar clouds, the reaction between methane and $\mathrm{CH}$ might also be of importance, leading to an increase in the length of the carbon-chain. ${ }^{32}$ Overall, these experiments have done much to reveal some of the reaction's most basic features. ${ }^{31-34,36,37}$ For instance, rate coefficients in the low temperature regime ranging from $23 \mathrm{~K}$ to $170 \mathrm{~K},{ }^{32,36}$ at room temperature, ${ }^{31,37}$ as well as at higher temperatures reaching $~ 800 \mathrm{~K}^{33,34}$ show that the reaction is fast even at low temperatures, reacting at almost all collisions, ${ }^{32}$ despite the inertness of methane, confirming that the reaction is indeed capable of occurring under the conditions present in Titan's atmosphere and within interstellar clouds. The measured rate coefficients, in addition, have shown that the reaction has a negative temperature 
dependence from $\sim 45 \mathrm{~K}$ up to $\sim 800 \mathrm{~K},{ }^{31-34,36,37}$ going through a maximum rate at $\sim 45 \mathrm{~K} .^{32}$ Theoretical studies, too, have been conducted for methane reaction with a $\mathrm{CH}$ molecule. ${ }^{31,35,43-46}$ Together these studies have provided strong evidence that the reaction produces an ethene molecule via $\mathrm{H}$ loss from an ethyl radical, ${ }^{31,46}$ where the ethyl radical must be formed via an initial insertion of the $\mathrm{CH}$ radical into one of the $\mathrm{C}-\mathrm{H}$ bonds of methane. ${ }^{31,35,46}$ On the other hand, it has proven much more difficult to make theoretical conclusions upon the mechanism of the bimolecular insertion entrance channel ${ }^{43-46}$ and to theoretically predict accurate rate coefficients for this reaction. ${ }^{35,46}$ In all cases, the insertion process was found to proceed through some exothermic "barrier,"31,35,43,46 although different relative energies for these "transition state structures" because of different optimization methods could lead to quite different rate coefficients. ${ }^{35,46}$

The reaction between ethane and $\mathrm{CH}$ has been suggested as an influential reaction in a chemical scheme towards benzene formation in dense molecular clouds like TMC- $1 .{ }^{50}$ Here, the path towards formation of benzene begins with an initial ethane reaction with $\mathrm{CH}$ expected to lead to propene. ${ }^{50}$ In addition, this reaction is also expected to be influential and contribute to the formation of both ethene and propene in Titan's atmosphere. ${ }^{5,29}$ The literature on ethane reaction with $\mathrm{CH}$ is much scarcer than that for the reaction between methane and $\mathrm{CH}$ but its rate coefficients have been measured..$^{32,37,38,51}$ The picture which emerged from the experiments shows that it shares some of the same qualitative features as the $\mathrm{CH}_{4}+\mathrm{CH}$ reaction, as the reaction is also fast at low temperatures ${ }^{32}$ and shows negative temperature dependence after an initial positive dependence at very low temperatures. ${ }^{32,37,38,51}$ While the situation regarding the bimolecular entrance channel is more difficult to describe than the previous reaction since it is now possible, in principle, 
for the $\mathrm{CH}$ molecule to insert into either ethane's $\mathrm{C}-\mathrm{H}$ bond and $\mathrm{C}-\mathrm{C}$ bond, experiments indicate that, is in the case of methane, insertion into the $\mathrm{C}-\mathrm{H}$ bond is the major entrance path and that insertion into the C-C bond is minor $^{32,38}(\sim 88 \%$ vs $\sim 12 \%)$. ${ }^{38}$ Regarding theoretical studies of the $\mathrm{C}_{2} \mathrm{H}_{6}+\mathrm{CH}$ reaction, one such investigation has been reported, ${ }^{38}$ although Miller et al. investigated rate coefficients for various association and dissociation reactions on the $\mathrm{C}_{3} \mathrm{H}_{7}$ PES. ${ }^{52}$ However, there has not been a detailed theoretical treatment for the rate coefficients the ethane reaction with $\mathrm{CH}$.

Meanwhile, the literature regarding the reactions between the $\mathrm{CH}$ radical and propane, butane, as well as larger saturated species is scarce and just a couple of experimental studies exist. ${ }^{53,54}$ In fact, after the $\mathrm{CH}_{4}+\mathrm{CH}$ and $\mathrm{C}_{2} \mathrm{H}_{6}+\mathrm{CH}$ reactions, the reactions for which there are several published studies involve small unsaturated hydrocarbon species. ${ }^{32,34-36,39-42,47-49}$ For these, several experimental rate coefficients for the reactions with $\mathrm{C}_{2} \mathrm{H}_{2}, \mathrm{C}_{2} \mathrm{H}_{4}, \mathrm{C}_{3} \mathrm{H}_{4}$ and $\mathrm{C}_{3} \mathrm{H}_{6}$ have shown that, like the reactions with saturated species, these are fast at low temperatures. ${ }^{32,34,36,39,41,42}$ In addition, the reactions show a negative temperature dependence, although the temperature dependence here appears to be less pronounced. ${ }^{32,36} \mathrm{~A}$ major difference between the reactions with unsaturated species, however, is that there is evidence that the major initial bimolecular entrance channel involves the addition of the $\mathrm{CH}$ radical to a double/triple bond, not an insertion process. ${ }^{40,42,49}$ The theoretical studies for the reactions between the $\mathrm{CH}$ radical and unsaturated species have tended to focus on describing the mechanism post entrance channel, attempting to describe the evolution of the possible initial complexes. ${ }^{47-49}$ In particular, the reaction mechanism for the reaction between $\mathrm{CH}$ and acetylene has been especially well studied theoretically. ${ }^{47-49}$ The reactions between $\mathrm{CH}+$ ethene, propene and 
methylacetylene have been much less well studied although there are aspects of the reaction which have been tackled by previous researchers.

\section{Objectives:}

- The influential reactions between methane/ethane and the $\mathrm{CH}$ radical are expected to have kinetics governed by the bimolecular insertion entrance channel and, furthermore, it is expected that these insertion entrance channels will not be endoergic. Thus the $\mathrm{CH}_{4}$ $+\mathrm{CH}$ and $\mathrm{C}_{2} \mathrm{H}_{6}+\mathrm{CH}$ reactions are expected to have fast rate coefficients.

- In order to have a proper theoretical description of the kinetics for methane/ethane reaction with the $\mathrm{CH}$ radical, a detailed and high level ab initio treatment of the bimolecular insertion entrance channels will be carried out. The rate coefficients for these reactions will then be calculated.

- The reaction between ethane and the $\mathrm{CH}$ radical is expected to be governed through a competition between two available bimolecular insertion entrance channels. Furthermore, it is expected that the insertion into a $\mathrm{C}-\mathrm{H} \sigma$ bond will be the major entrance channel since it seems the more facile process, while the $\mathrm{C}-\mathrm{C} \sigma$ bond insertion process is expected to be the minor process.

○ In order to understand the competition in the entrance channel for $\mathrm{C}_{2} \mathrm{H}_{6}+\mathrm{CH}$, a high level ab initio mapping of the minimum energy path (MEP) for each channel will be calculated such that the relative weight of each channel can be better understood.

- All the reactions involving the $\mathrm{CH}$ radical and hydrocarbons can further the growth of the carbon-chain at low temperatures or they can degrade it. It is expected that a competition between a $\mathrm{C}-\mathrm{H}$ bond $\beta$-scission and a $\mathrm{C}-\mathrm{C}$ bond $\beta$-scission governs the 
growth vs. degradation of the intermediate species formed from the bimolecular entrance channel reaction.

- There is no detailed theoretical investigation regarding the reaction between propane and the $\mathrm{CH}$ radical available in the literature. Thus the reaction mechanism will be investigated in order to understand the competition of the $\mathrm{C}-\mathrm{H}$ bond $\beta$-scission and a $\mathrm{C}-\mathrm{C}$ bond $\beta$-scission in this reaction. In addition, a final product distribution will be predicted and compared to the experimental product distribution to validate the mechanism. Furthermore, the same investigation will be performed on two unsaturated reactions, $\mathrm{C}_{3} \mathrm{H}_{6}+\mathrm{CH}$ and $\mathrm{C}_{3} \mathrm{H}_{4}+\mathrm{CH}$.

- The reactions between propene/allene/methylacetylene with the $\mathrm{CH}$ radical are expected to have numerous feasible bimolecular entrance channels. Although a $\mathrm{CH}$ radical addition entrance channel seems to be the favorable path, just what the relative weight for each possible entrance channel is has not been well understood to date.

- After generating a high level ab initio potential energy surface (PES), the product distribution for the $\mathrm{C}_{3} \mathrm{H}_{6}+\mathrm{CH}$ and $\mathrm{C}_{3} \mathrm{H}_{4}+\mathrm{CH}$ reactions will be calculated. Comparison of the theoretical product distribution with experimental results will be performed to see if it elucidates the complicated competition between the various bimolecular entrance channels that are, in principle, available. 


\section{Theoretical Background and General Method}

Potential Energy Surface (PES):

The PES is of extreme importance to the theoretical description of chemical reactions, from both practical and conceptual standpoints. ${ }^{55-57}$ The intuitive basis for the PES description of molecular motion, through the Born-Oppenheimer approximation, lies in the fact that there is large size difference between electrons and nuclei, such that there is an instantaneous electron response to changing atomic positions ${ }^{55.57}$ In this case, the original Schrodinger equation for the molecule can be reduced to an equation for the fixed nuclei, the electronic Schrodinger equation, such that solutions for all possible nuclear positions would present a potential energy function governing the motion of the nuclei. ${ }^{55-}$

${ }^{57}$ This Born-Oppenheimer approximation is often justified,${ }^{55,56}$ in the sense that errors due to it are often negligible. ${ }^{57}$ It can break down, however, in regions where different solutions to the electronic Schrodinger equation have similar energies, ${ }^{56,57}$ such that terms coupling different electronic states stemming from the original Schrodinger equation are nonzero. ${ }^{56,57}$ In addition to being accurate in numerous situations, from a conceptual point-ofview, the Born-Oppenheimer approximation introduces the useful chemist's picture of molecules and chemical reactions into the more general theoretical prescription, ${ }^{55-57}$ allowing us to ignore the "smeared" character of the nuclei and treat them as localized..$^{55-}$ 57

Since a PES describes all possible relative nuclear arrangements, it has 3N-6 coordinate dimensions due to exclusion of the degrees of freedom corresponding to overall translation and rotation. ${ }^{55-57}$ In the case of linear molecules, the coordinate dimensions are reduced to $3 \mathrm{~N}-5$ after additional exclusion of the rotation about the axis of the molecule. 
On a PES, stable molecules, which have long lifetimes and can thus be characterized in a lab, correspond to PES minima ${ }^{55}$ (wells on the PES). The mathematical requirement for such a surface minima is that the second derivatives of the potential energy with respect to all 3N-6 PES normal coordinates are positive ${ }^{57}$ in addition to the gradient being equal to zero. ${ }^{57}$ Meanwhile, traditional transition state structures connecting different PES minima are located on surface points with a zero gradient and a negative second derivative with respect to the reaction coordinate, ${ }^{57}$ which indicates that the potential energy along the reaction coordinate is at a maximum. ${ }^{57}$ The remaining coordinates orthogonal to this reaction coordinate the second derivatives are positive. ${ }^{57}$ The point on the PES corresponding to a transition state structure often represents a good approximation to the reaction bottleneck that controls the rate of a chemical reaction at lower temperatures. ${ }^{58}$

Various different methods were used to generate PES for the reactions of interest. Since different methods were used for different reactions, the particular methods used will be described in detail in each of the next chapters of this dissertation. What follows bellow is a brief outline of the main methods used to build the $\mathrm{C}_{2} \mathrm{H}_{5}, \mathrm{C}_{3} \mathrm{H}_{7}, \mathrm{C}_{4} \mathrm{H}_{9}, \mathrm{C}_{4} \mathrm{H}_{7}$ and $\mathrm{C}_{4} \mathrm{H}_{5}$ PES.

The optimization of the different relevant PES geometries needed to described the kinetics and/or the reaction mechanisms of the studied reactions used, in general, the B3LYP ${ }^{59,60}$ and B2PLYPD3 ${ }^{61,62}$ density functional methods. The B3LYP method combines Becke's three parameter exchange functional ${ }^{59}$ with the correlation treatment Lee, Yang and Parr. ${ }^{60}$ In general, the harmonic frequencies and zero point energies used for calculation of the rate coefficients and relative energies were produced at the same theoretical level as the optimizations; in other words, most often at the B3LYP or 
B2PLYPD3 levels. These harmonic frequencies also served to characterize the optimized structure as a PES minimum or saddle point.

The energies of all PES geometries that were optimized underwent further refinement, most often using the explicitly correlated coupled-cluster method with singles and doubles excitations, and a perturbative approximation to the triple excitations $(\mathrm{CCSD}(\mathrm{T})-\mathrm{F} 12) .{ }^{63,64}$ In the treatment of the entrance channels for the methane/ethane + $\mathrm{CH}$ reactions, coupled-cluster calculations up to full triple and quadruple excitations along with a perturbative approximation to the quintuple excitations were also completed ${ }^{65}$ In one particular instance, meanwhile, for certain portions of the $\mathrm{C}_{4} \mathrm{H}_{5} \mathrm{PES}$, it was deemed that multireference effects were not negligible and thus $(3 \times 3)$ CASPT2 ${ }^{66}$ calculations were used.

Master Equation (ME):

A proper treatment of the pressure and temperature dependence for a chemical reaction taking place on a multidimensional PES with various wells requires the solution of the chemical master equation. ${ }^{19,20,67}$ Often, reactive complexes have lifetimes long enough for them to undergo numerous collisions resulting in transitions between their rovibrational states. ${ }^{19,67}$ The coupling between the chemical transformations of the reactive complexes and collision induced transitions is encoded in the ME. ${ }^{19,20,67}$ As such, the ME governs the mutual competition between stabilization of a reactive complex within a well and the formation of bimolecular products as a function of pressure and temperature. ${ }^{19,20,67}$ It is instructive to see the expression for the ME in order to see how this information is encoded: 67

$$
A+B \rightleftharpoons \text { PRODUCTS }
$$




$$
\begin{array}{r}
\frac{d n_{i}(E)}{d t}=Z_{i} \int_{E_{0_{i}}}^{\infty} P\left(E \leftarrow E^{\prime}\right) n_{i}\left(E^{\prime}\right) d E^{\prime}-Z_{i} n_{i}(E)+\sum_{j} k_{i \leftarrow j} n_{j}(E)-\sum_{j} k_{j \leftarrow i} n_{i}(E) \\
\quad+k_{a_{i}}(E) n_{A} n_{B} \frac{\rho_{A B}(E) e^{-\beta E}}{Q_{A B}}-k_{d_{i}}(E) n_{i}(E)-\sum_{P R O D U C T S} k_{p_{i}}(E) n_{i}(E)
\end{array}
$$

where the lower case indices $i$ and $j$ represent different PES wells (i.e. complexes formed as a result of the $\mathrm{A}+\mathrm{B}$ bimolecular collision and their chemical isomers), the $n_{i}(E)$ and $n_{j}(E)$ represent the concentrations of the $i^{t h}$ and $j^{\text {th }}$ isomers with an energy between $E$ and $d E, Z_{i}$ is the collision rate of the $i^{t h}$ isomer, $P\left(E \leftarrow E^{\prime}\right)$ is the probability that a collision will transfer a molecule in a state of energy between $E^{\prime}$ and $E^{\prime}+d E^{\prime}$ into a state of energy between $E$ and $E+d E, k_{i \leftarrow j}$ is the unimolecular rate coefficient for the isomerization of the $j^{\text {th }}$ isomer into the $i^{t h}$ isomer, $k_{d_{i}}$ is the unimolecular rate coefficient for re-dissociation of the $i^{\text {th }}$ isomer into reactants, $k_{p_{i}}$ is the unimolecular rate coefficient for dissociation of the $i^{\text {th }}$ isomer into bimolecular products and $k_{a_{i}}$ is the bimolecular rate constant for the association of the reactants. Notice that the term describing the initial bimolecular association implies that the reactants are assumed to be under thermal equilibrium (i.e. Boltzmann distribution). Thus as can be seen above in the chemical ME, the time evolutions of the populations of chemical species with a certain energetic content is described in terms of a competition between the possible fluxes "in and out". Notice that the first two terms on the right hand side of the equation describe vertical transitions on the $\mathrm{PES},{ }^{20}$ that is, collision induced state transitions within a given well, while the remaining terms describe the PES horizontal transitions ${ }^{20}$ which represent chemical change. One approach to solving the equation involves a coordinate transformation which allows the ME to be written as a matrix equation with a well-known mathematical solution: ${ }^{19,67}$ These 
solutions are given in terms of eigenvectors of the transition matrix which correspond to equilibration between the different wells and also the equilibration between the energy levels within a well. ${ }^{19,67}$ Together these describe the relaxation towards complete thermal equilibrium. ${ }^{19-67}$ So long as the eigenvectors which represent chemical relaxation towards chemical equilibrium have eigenvalues much lower than the rest, methods have been developed that relate the eigenvectors and eigenvalues to the reaction's phenomelogical rate coefficients. ${ }^{19,20,67}$ All the $\mathrm{ME}$ calculations performed for the $\mathrm{CH}$ reactions in this dissertation were performed using the PAPER software package of Georgievskii and coworkers. $^{68}$

Last, it is important to mention that the above ME treatment to the chemical kinetics a multiple well reaction requires information regarding the kinetics of the individual unimolecular and bimolecular processes available. These, of course, appear in the form of the unimolecular and bimolecular rate coefficients, $k_{i \leftarrow j}, \ldots, k_{a_{i}}$ representing the probabilities per unit time for the interconversion of one isomer towards some different structural configuration. Often, it is sufficient to treat these using TST and RRKM theories, which will be discussed in the following section. In general, however, since the density of states for a given species within the TST and RRKM calculations are derived from a rigidrotor harmonic oscillator approximation, rotational constants and harmonic frequencies taken from electronic structure calculations were used, except for the loose normal modes corresponding to hindered rotations, which were treated using a hindered rotor model ${ }^{69}$ requiring, naturally, a potential describing the hindered rotation. For the collision induced transitions within a chemical well used in the ME calculations, an exponential down 
model $^{70}$ was used to treat the probabilities of inducing a given transition while the collisional frequencies were treated assuming a Lennard-Jones intermolecular potential. Transition State Theory (TST):

Transition State theory provides a useful and effective method for calculating reaction rate coefficients. Within the context of chemical kinetic modeling, with its thousands of competing reactions, the TST reduction of rate coefficient calculations from a global PES problem to a local one makes it an invaluable tool. ${ }^{71,72}$ In addition, modern TST implementations often give rate coefficients in good agreement with those obtained from dynamics simulations. ${ }^{73}$ Within the classical formulation of TST, the reduction from a global PES problem to a local one can be traced to the fundamental assumption of TST: A surface in phase space separating the reactant region from the region corresponding to the products exists; phase space trajectories through this surface do not re-cross back to reactants such that the flux of trajectories through the surface governs the reaction's kinetics. ${ }^{58,72}$ In other words, the phase space dividing surface acts as the dynamical bottleneck to reaction and the flux coefficient through the surface in the forward direction is equated to the rate coefficient. ${ }^{72}$ In conventional TST, which is applicable to reactions whose reaction coordinate contains an energetic barrier, the surface is placed on the top of the barrier, ${ }^{58,72,74}$ just on the product side, ${ }^{75}$ such that reactant molecules that reach the surface proceed to slide downhill into the product region where they are thermalized. ${ }^{72}$ In this case, the flux of trajectories through the dividing surface can be determined from the fraction of reactants that lie on it; ${ }^{75}$ using results from statistical mechanics leads to the following reaction temperature resolved TST rate coefficient, ${ }^{75,76}$ 


$$
k(T)=\sigma \frac{k_{B} T}{h} \frac{Q_{T S}}{Q_{A} Q_{B}} e^{\frac{-V^{\ddagger}}{k_{B} T}}
$$

where $\sigma$ is the ratio of rotational symmetry numbers for the reactants and the transition state, $k_{B}$ is Boltzmann's constant, $T$ is the temperature, $h$ is Planck's constant, $Q$ are the partition functions for the transition state and the reactants, and $V^{\ddagger}$ is the barrier height to reaction along the PES. Although it is this temperature dependent rate coefficient that results from the original TST formulations, modern treatments often make use of rate coefficients resolved at the $E$ and $J$ levels, where $J$ represents the total angular momentum. $^{72,77}$

Reactions for which there is not an energetic barrier along the reaction coordinate must make use of generalized TST approaches, ${ }^{72,74}$ for which the dividing surface location is allowed to vary so as to minimize the flux. ${ }^{72,74}$ A large variation in the location of the surface for barrierless reactions with respect to temperature is the result of a more pronounced competition between energetic and entropic effects. ${ }^{78}$ Two different variational approaches were used for the work in this publication: The first requires mapping a one dimensional MEP which leads the reactants to products and calculating a TST rate coefficient along different points on the reaction coordinate so as to locate the minimum rate coefficient ${ }^{72,74}$ (i.e. the reaction bottleneck); the second approach, meanwhile, involves treating the center-of-masses of the reacting molecules as the reaction path and decomposing the normal modes into conserved and transitional modes, whose contribution to the rate coefficient are treated in different manners. ${ }^{72}$ In the case of $\mathrm{CH}$ radical reactions with a saturated species, the former approach is quite useful for treating 
the initial bimolecular insertion processes at higher temperatures, while the latter is used in treating their low temperature rate coefficients.

\section{References:}

1.Wakelam, V.; Smith, I. W. M.; Herbst, E.; Troe, J.; Geppert, W.; Linnartz, H.; Oberg, K.; Roueff, E.; Agundez, M.; Pernot, P.; Cuppen, H. M.; Loison, J. C.; Talbi, D. Reaction Networks for Interstellar Chemical Modelling: Improvements and Challenges. Space Sci. Rev. 2010, 156, 13-72.

2.Wakelam, V.; Agundez, M. Chemistry of Dark Clouds: Databases, Networks and Models. Chem. Rev. 2013, 113, 8710-8737.

3.Aikawa, Y. Interplay of Chemistry and Dynamics in the Low-Mass Star Formation. Chem. Rev. 2013, 113, $8961-8980$.

4.Sakai, N.; Yamamoto, S. Warm Carbon-Chain Chemistry. Chem. Rev. 2013, 113, 89819015.

5.Dobrijevic, M.; Hebrard, E.; Plessis, S.; Carrasco, N.; Pernot, P.; Bruno-Claeys, M. Comparison of Methods for the Determination of Key Reactions in Chemical Systems: Application to Titan's Atmosphere. Adv. Space Res. 2010, 45, 77-91.

6.Westbrook, C. K.; Dryer, F. L. Chemical Kinetic Modeling of Hydrocarbon Combustion. Prog. Energy Combust. Sci. 1984, 10, 1-57.

7.Miller, J. A.; Kee, R. J.; Westbrook, C. K. Chemical Kinetics and Combustion Modeling. Annu. Rev. Phys. Chem. 1990, 41, 345-387.

8.Peng, Z; Dobrijevic, M.; Hebrard, E.; Nathalie, C.; Pernot, P. Photochemical Modeling of Titan Atmosphere at the "10 Percent Uncertainty Horizon." Faraday Discuss. 2010, $147,137-153$.

9.Simmie, J. M. Detailed Chemical Kinetic Models for the Combustion of Hydrocarbon Fuels. Prog. Energ. Combust. 2003, 29, 599-634.

10.Westbrook, C. K. Chemical Kinetics of Hydrocarbon Ignition in Practical Combustion Systems. Proc. Combust. Inst. 2000, 28, 1563-1577.

11.Raulin, F.; Brasse, C.; Poch, O.; Coll, P. Prebiotic-Like Chemistry on Titan. Chem. Soc. Rev. 2012, 41, 5380-5393. 
12.Smith, I.W.M. The Temperature-Dependence of Elementary Reaction Rates: Beyond Arrhenius. Chem. Soc. Rev. 2008, 37, 812-826.

13.Sabbah, H.; Biennier, L.; Sims, I. R.; Georgievskii, Y.; Klippenstein, S. J.; Smith, I. W. M. Understanding Reactivity at Very Low Temperatures: The Reactions of Oxygen Atoms with Alkenes. Science 2007, 317, 102-105.

14.Hebrard, E.; Pernot, P.; Dobrijevic, M; Carrasco, N; Bergeat, A.; Hickson, K. M.; Canosa, A.; Picard, S. D. L.; Sims, I. R. How Measurements of Rate Coefficients at Low Temperature Increase the Predictivity of Photochemical Models of Titan's Atmosphere. J. Phys. Chem. A 2009, 113, 11227-11237.

15.Hebrard, E.; Dobrijevic, M.; Benilan, Y.; Raulin, F. Photochemical Kinetics Uncertainties in Modeling Titan's Atmosphere: First Consequences. Planet. Space Sci. 2007, 55, 1470-1489.

16.Wakelam, V.; Herbst, E.; Selsis, F. The Effect of Uncertainties on Chemical Models of Dark Clouds. Astron. Astrophys. 2006, 451, 551-562.

17.Wakelam, V.; Selsis, F.; Herbst, E.; Caselli, P. Estimation and Reduction of the Uncertainties in Chemical Models: Application to Hot Core Chemistry. Astron. Astrophys. 2005, 444, 883-891.

18. Vasyunin, A.I.; Semenov, D.; Henning, T.; Wakelam, V; Herbst, E.; Sobolev, A. M. Chemistry in Protoplanetary Disks: A Sensitivity Analysis. Astrophys. J. 2008, 672, 629641.

19.Klippenstein, S. J.; Miller, J. A. From the Time-Dependent, Multiple-Well Master Equation to Phenomenological Rate Coefficients. J. Phys. Chem. A 2002, 106, 9267-9277.

20.Georgievskii, Y.; Miller, J. A.; Burke, M. P.; Klippenstein S. J. Reformulation and Solution of the Master Equation for Multiple-Well Chemical Reactions. J. Phys. Chem. A 2013, 117, $12146-12154$.

21.Henning, T.; Semenov, D. Chemistry in Protoplanetary Disks. Chem. Rev. 2013, 113, $9016-9042$.

22.van Dishoeck, E. F. Chemistry in Low-Mass Protostellar and Protoplanetary Regions. PNAS. 2006, 103, 12249-12256.

23.Oka, T. Interstellar $\mathrm{H}_{3}{ }^{+}$. PNAS. 2006, 103, 12235-12242. 
24.Kaiser, R. I.; Mebel, A. M. On the Formation of Polyacetylenes and Cyanopolyacetylenes in Titan's Atmosphere and their Role in Astrobiology. Chem. Soc. Rev. 2012, 41, 5490-5501.

25.Balucani, N. Elementary Reactions of N Atoms with Hydrocarbons: First Steps Towards the Formation of Prebiotic N-Containing Molecules in Planetary Atmospheres. Chem. Soc. Rev. 2012, 41, 5473-5483.

26.Sagan, C.; Thompson, W. R.; Khare, B. N. Titan: a laboratory for prebiological organic chemistry. Acc. Chem. Res. 1992, 25, 286-292.

27.Coustenis, A.; Taylor, F. W. Titan: the Earth-like Moon. World Scientific, Singapore, 1999.

28.Waite Jr., J. H.; Young, D. T.; Cravens, T. E.; Coates, A. J.; Crary, F. J.; Magee, B.; Westlake, J. The Process of Tholin Formation in Titan's Upper Atmosphere. Science 2007, 316, 870-875.

29.Bezard, B. Composition and Chemistry of Titan's Stratosphere. Phil. Trans. R. Soc. A 2009, 367, 683-695.

30.Vuitton, V.; Yelle, R. V.; Lavvas, P. Composition and Chemistry of Titan's Thermosphere and Ionosphere. Phil. Trans. R. Soc. A 2009, 367, 729-741.

31.Fleurat-Lessard, P.; Rayez, J. C.; Bergeat, A.; Loison, J. C. Reaction of Methylidyne $\mathrm{CH}\left(\mathrm{X}^{2} \Pi\right)$ Radical with $\mathrm{CH}_{4}$ and $\mathrm{H}_{2} \mathrm{~S}$ : Overall Rate Constant and Absolute Hydrogen Poduction. Chem. Phys. 2002, 279, 87-99.

32.Canosa, A.; Sims, I. R.; Travers, D.; Smith, I. W. M.; Rowe, B. R. Reactions of the Methylidyne Radical with $\mathrm{CH}_{4}, \mathrm{C}_{2} \mathrm{H}_{2}, \mathrm{C}_{2} \mathrm{H}_{4}, \mathrm{C}_{2} \mathrm{H}_{6}$ and but-1-ene Studied Between 23 and $295 \mathrm{~K}$ with a CRESU Apparatus. Astron. Astrophys.1997, 323,644-651.

33.Blitz, M. A.; Johnson, D. G.; Pesa, M.; Pilling, M. J.; Robertson S. H.; Seakins, P. W. Reaction of CH Radicals with Methaneisotopomers. J. Chem. Soc., Faraday Trans. 1997, 93, 1473-1479.

34.Thiesemann, H.; MacNamara, J.; Taatjes, C. A. Deuterium Kinetic Isotope Effect and Temperature Dependence in the Reactions of $\mathrm{CH}\left[{ }^{2} \Pi\right]$ with Methane and Acetylene. $J$. Phys. Chem. A 1997, 101, 1881-1886.

35.Taajtes, C. A.; Klippenstein, S. J. Kinetic Isotope Effects and Variable Reaction Coordinates in Barrierless Recombination Reactions. J. Phys. Chem. A 2001, 105, 85678578. 
36.Daugey, N.; Caubet, P.; Retail, B.; Costes, M.; Bergeat, A.; Dorthe, G. Kinetic Measurements on Methylidyne Radical Reactions with Several Hydrocarbons at Low Temperatures. Phys. Chem. Chem. Phys. 2005, 7, 2921-2927.

37.Loison, J. C; Bergeat, A.; Caralp, F.; Hannachi, Y. Rate Constants and H Atom Branching Ratios of the Gas-Phase Reactions of Methylidyne $\mathrm{CH}\left(\mathrm{X}^{2} \Pi\right)$ Radical with a Series of Alkanes. J. Phys. Chem. A 2006, 110, 13500-13506.

38.Galland, N.; Caralp, F.; Hannachi, Y.; Bergeat, A.; Loison, J. C. Experimental and Theoretical Studies of the Methylidyne $\mathrm{CH}\left(\mathrm{X}^{2} \Pi\right)$ Radical Reaction with Ethane $\left(\mathrm{C}_{2} \mathrm{H}_{6}\right)$ : Overall Rate Constant and Product Channels. J. Phys. Chem. A 2003, 107, 5419-5426.

39.Thiesemann, H.; Clifford, E. P.; Taatjes, C. A.; Klippenstein, S. J. Temperature Dependence and Deuterium Kinetic Isotope Effects in the $\mathrm{CH}(\mathrm{CD})+\mathrm{C}_{2} \mathrm{H}_{4}\left(\mathrm{C}_{2} \mathrm{D}_{4}\right)$ Reaction between 295 and 726 K. J. Phys. Chem. A 2001, 105, 5393-5401.

40.Zhang, F.; Maksyutenko, P.; Kaiser, R. I. Chemical dynamics of the $\mathrm{CH}\left(\mathrm{X}^{2} \Pi\right)+\mathrm{C}_{2} \mathrm{H}_{4}$ $\left(\mathrm{X}^{1} \mathrm{~A}_{1 \mathrm{~g}}\right), \mathrm{CH}\left(\mathrm{X}^{2} \Pi\right)+\mathrm{C}_{2} \mathrm{D}_{4}\left(\mathrm{X}^{1} \mathrm{~A}_{1 \mathrm{~g}}\right)$ and $\mathrm{CD}\left(\mathrm{X}^{2} \Pi\right)+\mathrm{C}_{2} \mathrm{H}_{4}\left(\mathrm{X}^{1} \mathrm{~A}_{1 \mathrm{~g}}\right)$, Reactions Studied Under Single Collision Conditions.

41.Loison, J. C; Bergeat, A. Rate Constants and the $\mathrm{H}$ Atom Branching Ratio of the Reactions of the Methylidyne $\mathrm{CH}\left(\mathrm{X}^{2} \Pi\right)$ Radical with $\mathrm{C}_{2} \mathrm{H}_{2}, \mathrm{C}_{2} \mathrm{H}_{4}, \mathrm{C}_{3} \mathrm{H}_{4}$ (Methylacetylene and Allene), $\mathrm{C}_{3} \mathrm{H}_{6}$ (Propene) and $\mathrm{C}_{4} \mathrm{H}_{8}$ (Trans-Butene). Phys. Chem. Chem. Phys., 2009, $11,655-664$.

42.Goulay, F.; Trevitt, A. J.; Meloni, G.; Selby, T. M.; Osborn, D. L.; Taatjes, C. A.; Vereecken, L.; Leone, S. R. Cyclic Versus Linear Isomers Produced by Reaction of the Methylidyne Radical (CH) with Small Unsaturated Hydrocarbons. J. Am. Chem. Soc. 2009, $131,993-1005$.

43.Wang, Z-X.; Huang, M. B.; Liu, R. Z. Theoretical Study on the Insertion Reaction of $\mathrm{CH}\left(\mathrm{X}^{2} \Pi\right)$ with $\mathrm{CH}_{4}$. Can. J. Chem. 1997, 75, 996-1001.

44.Yu, Z.; Chen, C.; Huang. M; An Ab Initio Study on the Reaction of $\mathrm{CH}\left(\mathrm{X}^{2} \Pi\right)$ with $\mathrm{CH}_{4}$ Can. J. Chem. 1993, 71, 512-519.

45.Wang, Z-X; Liu, R. Z.; Huang, M. B.; Yu, Z. An Ab Initio Study on the Insertion Reactions of $\mathrm{CH}\left(\mathrm{X}^{2} \Pi\right)$ with $\mathrm{NH}_{3}, \mathrm{H}_{2} \mathrm{O}$, and HF. Can. J. Chem. 1996, 74, 910-917.

46.Ribeiro, J. M.; Mebel, A. M. Reaction Mechanism and Rate Constants of the $\mathrm{CH}+\mathrm{CH}_{4}$ Reaction: A Theoretical Study. Mol. Phys. 2015, 113, 1865 - 1872.

47.Vereecken, L.; Pierloot, K.; Peeters, J. B3LYP-DFT characterization of the potential energy surface of the $\mathrm{CH}\left(\mathrm{X}^{2} \Pi\right)+\mathrm{C}_{2} \mathrm{H}_{2}$ Reaction. J. Chem. Phys. 1998, 108, 1068-. 
48.Vereecken, L.; Peeters, J. Detailed Microvariational RRKM Master Equation Analysis of the Product Distribution of the $\mathrm{C}_{2} \mathrm{H}_{2}+\mathrm{CH}\left(\mathrm{X}^{2} \Pi\right)$ Reaction over Extended Temperature and Pressure Ranges. J. Phys. Chem. A, 1999, 103, 5523-5533.

49.Nguyen, T. L.; Mebel, A. M.; Lin, S. H; Kaiser, R. I. Product Branching Ratios of the $\mathrm{C}\left({ }^{3} \mathrm{P}\right)+\mathrm{C}_{2} \mathrm{H}_{3}\left({ }^{2} \mathrm{~A}^{6}\right)$ and $\mathrm{CH}\left({ }^{2} \Pi\right)+\mathrm{C}_{2} \mathrm{H}_{2}\left({ }^{1} \Sigma_{\mathrm{g}}{ }^{+}\right)$Reactions and Photodissociation of $\left.\mathrm{H}_{2} \mathrm{CC}: \mathrm{CH}^{2}{ }^{2} \mathrm{~B}_{1}\right)$ at 193 and $242 \mathrm{~nm}$ : an ab Initio/RRKM Study. J. Phys. Chem. A, 2001, 105, 11549-11559.

50.Jones, B. M.; Zhang, F.; Kaiser, R. I.; Jamal, A.; Mebel, A. M.; Cordiner, M. A.; Charnley, S. B. Formation of Benzene in the Interstellar Medium. Proc. Natl. Acad. Sci. U. S. A. 2011, 108, $452-457$.

51.Berman, M. R.; Lin, M. C. Kinetics and Mechanisms of the Reactions of $\mathrm{CH}_{4}, \mathrm{C}_{2} \mathrm{H}_{6}$ and $\mathrm{C}_{4} \mathrm{H}_{10}$. Chem. Phys. 1983, 82, 435.

52.Miller, J. A.; Klippenstein, S. J. Dissociation of Propyl Radicals and Other Reactions on $\mathrm{a}_{3} \mathrm{H}_{7}$ Potential. J. Phys. Chem. A 2013, 117, 2718-2727.

53.Zabarnick, S.; Fleming, J. W.; Lin, M. C. Kinetics of CH ( $\left.\mathrm{X}^{2} \Pi\right)$ Radical Reactions with Propane, Isobutane and Neopentane. Chem. Phys. 1987, 112, 409-413.

54.Butler, J. E.; Fleming, J. W.; Goss, L. P.; Lin, M. C. Kinetics of CH Radical Reactions with Selected Molecules at Room Temperature. Chem. Phys. 1981, 56, 355-365.

55.Lewards, E. G. Computational Chemistry: Introduction to the Theory and Applications of Molecular and Quantum Mechanics. Springer: Netherlands, 2011.

56.Cramer, C. J. Essentials of Computational Chemistry: Theories and Models. Wiley: England, 2004.

57.Jensen, F.; Introduction to Computational Chemistry. Wiley: England, 2007.

58.Pechukas, P. Transition State Theory. Ann. Rev. Phys. Chem. 1981, 32, 159-177.

59.Becke, A. D. Density-Functional Thermochemistry. III. The Role of Exact Exchange. J. Chem. Phys. 1993, 98, $5648-5652$.

60.Lee, C.; Yang, W.; Parr, R. G. Development of the Colle-Salvetti Correlation-Energy Formula into a Functional of the Electron Density. Phys. Rev. B: Condens. Matter Mater. Phys. 1988, 37, 785 - 789. 
61.Grimme, S. Semiempirical Hybrid Density Functional with Perturbative Second-Order Correlation. J. Chem. Phys. 2006, 124, 1-16.

62.Grimme, S.; Antony, J.; Ehrlich, S.; Krieg, H. A Consistent and Accurate ab Initio Parametrization of Density Functional Dispersion Correction (DFT-D) for the 94 Elements H-Pu. J. Chem. Phys. 2010, 132, 1-19.

63.Purvis, G. D.; Bartlett, R. J. A Full Coupled-Cluster Singles and Doubles Model: The Inclusion of Disconnected Triples. J. Chem. Phys. 1982, 76, 1910- 1918.

64.Knizia, G.; Adler, T. B.; Werner, H.-J. Simplified CCSD(T)-F12 Methods: Theory and Benchmarks. J. Chem. Phys. 2009, 130, 054104.

65.Rolik, Z.; Kallay, M. A General-Order Local Coupled-Cluster Method Based on the Cluster-in-Molecule Approach. J. Chem. Phys. 2011, 135, 104111.

66.Werner, H. J. Third Order Multireference Perturbation Theory The CASPT3 Method. Mol. Phys. 1996, 89, 645-661.

67.Miller, J. A.; Klippenstein, S. J. Master Equation Methods in Gas Phase Chemical Kinetics. J. Phys. Chem. A 2006, 110, 10528-10544.

68.Y. Georgievskii, A.W. Jasper, J. Zador, J.A. Miller, M. P. Burke, C.F. Goldsmith, S.J. Klippenstein, PAPER v1 (2014).

69.Steinfeld, J.I.; Francisco, J.S.; Hase, W.L. Chemical Kinetics and Dynamics; PrenticeHall: Upper Saddle River, NJ, 1999.

70.Troe, J. Theory of Thermal Unimolecular Reactions at Low Pressures. 1. Solutions of the Master Equation. J. Chem. Phys. 1977, 66, 4745-4757.

71.Truhlar, D. G.; Hase, W. L.; Hynes, J. T. Current Status of Transition-State Theory. J. Phys. Chem. 1983, 87, 2664-2682.

72.Truhlar, D. G.; Garrett, B. C.; Klippenstein, S. J. Current Status of Transition-State Theory. J. Phys. Chem. 1996, 100, 12771-12800.

73.Georgievskii, Y.; Klippenstein, S. J. Variable Reaction Coordinate Transition State Theory: Analytic Results and Application to the $\mathrm{C}_{2} \mathrm{H}_{3}+\mathrm{H} \rightarrow \mathrm{C}_{2} \mathrm{H}_{4}$ Reaction. J. Chem. Phys. 2003, 118, 5442-5455.

74.Truhlar, D. G.; Garrett, B. C. Variational Transition State Theory. Ann. Rev. Phys. Chem. 1984, 35, 159-189. 
75.Mahan, B. H. Activated Complex Theory of Bimolecular Reactions. J. Chem. Edu. 1974, 51, 709-711.

76.Fernandez-Ramos, A.; Ellingson, B. A.; Meana-Paneda, R.; Marques, J. M. C.; Truhlar, D. G. Symmetry Numbers and Chemical Reaction Rates. Theor. Chem. Acc. 2007, 118, 813-826.

77.Garrett, B. G.; Truhlar, D. G. Generalized Transition State Theory: Classical Mechanical Theory and Applications to Collinear Reactions of Hydrogen Molecules. $J$. Phys. Chem. 1979, 83, 1052-1079.

78.Klippenstein, S. J. Variational Optimizations in the Rice-Ramsperger-Kassel-Marcus Theory Calculations for Unimolecular Dissociations with no Reverse Barrier. J. Chem. Phys. 1992, 96, 367-371. 
CHAPTER II

KINETICS OF CH $\left(\mathrm{X}^{2} \Pi\right)+\mathrm{CH}_{4} / \mathrm{C}_{2} \mathrm{H}_{6}$ 
Introduction:

Methane, the second most abundant species in Titan's atmosphere with a molecular mixing ratio of $\sim 1.5 \%$ in both the stratosphere ${ }^{1,2}$ and in upper atmospheric zones, ${ }^{1}$ serves an important role in its chemical evolution. Methane, together with energetic photons and electrons, photodissociates into different radical species that are primed to undergo further chemical reactions. ${ }^{1,2,3}$ It is the formation of $\mathrm{CH}_{3}, \mathrm{CH}_{2}$ and $\mathrm{CH}$ radicals through this photodissociation which initiates the carbon skeleton growth in the low temperature environment. ${ }^{1,2}$ To understand the initial growth of the carbon skeleton, the photofragmentation pattern of methane thus needs to be understood. There have been numerous experiments and theoretical studies aimed at understanding methane photodissociation. The earliest studies suggested that $\mathrm{CH}_{2}+\mathrm{H}_{2}$ was the major dissociation path. ${ }^{4,5,6,7}$ Later experiments, however, indicate that the $\mathrm{CH}_{3}+\mathrm{H}$ path could be dominant instead. ${ }^{8,9}$ More recently, experiments have indicated that both $\mathrm{CH}_{2}$ and $\mathrm{CH}_{3}$ are produced ${ }^{10}$ and that the relative yields show a significant dependence on the wavelength of the absorbed radiation. ${ }^{10}$ Furthermore, it was estimated that $\mathrm{CH}$ formation could be close to $10 \% .{ }^{10}$ Despite the fact that the $\mathrm{CH}$ radical is expected to be a minor product, it is capable of reacting with inert closed-shell neutral molecules even at low temperatures., ${ }^{2,11,12}$ Their reactions might help influence the growth of the carbon-chain on Titan's atmosphere ${ }^{2,11,12}$ and in interstellar clouds. ${ }^{11,13}$ In fact, recent chemical modeling studies have indicated that the reactions between $\mathrm{CH}$ and methane or ethane are influential reactions to both of these environments. ${ }^{14,15}$ Regarding the atmosphere of Titan, models indicate that the methane + $\mathrm{CH}$ reaction is one of the most influential reactions at almost all altitudes; ${ }^{14}$ in addition, the reaction between ethane and $\mathrm{CH}$ has been implicated in helping ethene production on 
Titan's atmosphere. ${ }^{14}$ With respect to interstellar clouds, recent modeling of dark molecular clouds similar to TMC-1 (Taurus Molecular Cloud 1) has indicated that ethane $+\mathrm{CH}$ is an important reaction, initiating a neutral-neutral reaction scheme leading to the first aromatic ring, benzene. ${ }^{15}$ Although there have been experimental studies of both reactions, ${ }^{16-21}$ there has not been a detailed theoretical treatment of the total rate coefficient of ethane $+\mathrm{CH}$ reaction and of the bimolecular insertion entrance channels which govern its kinetics. In regard to the methane $+\mathrm{CH}$ reaction, one such theoretical investigation was published ${ }^{22}$ and although the results were reasonable at lower temperatures, it began to break down at higher temperatures. Here we seek to provide a treatment of the kinetics that is consistent across all measured temperature ranges as well as a thorough treatment of the entrance channels that govern the kinetics of both reactions.

Methods:

The optimization of all PES minima and saddle points, as well as all the points along the bimolecular MEP, were performed using the B2PLYPD3 ${ }^{23,24}$ functional and the aug-cc-pVTZ basis set $^{25}$ (cc-pVTZ for propane $+\mathrm{CH}$ ). The choice to use the B2PLYPD3/aug-cc-pVTZ method for the optimizations was made after comparing parameters that are important to rate coefficient calculations with the more often used B3LYP ${ }^{26,27} / 6-311++G(d, p)^{28}$ method and the gold-standard "reference" $\operatorname{CCSD}(T)^{29} /$ augcc-pVTZ method. The latter method was taken as reference since all points do not appear to suffer from significant multireference effects (i.e. T1 diagnostics are less than 0.02). Table 2.1 summarizes the comparison for the different $\mathrm{C}_{2} \mathrm{H}_{5}$ structures and contains the dependence of the $\operatorname{CCSD}(\mathrm{T})-\mathrm{F} 12^{30} / \mathrm{CBS}$ relative energies on the level of the optimization, where the CBS limit was achieved using a two-point extrapolation technique on the cc- 
pVXZ-F12 ${ }^{31}(X=T, Q)$ basis set results and, in addition, contains the dependence for the harmonic frequencies. Regarding the results in Table 2.1, notice first that the B3LYP/6$311++\mathrm{G}(\mathrm{d}, \mathrm{p})$ method can introduce larger errors into the harmonic frequencies as can be seen at the endpoints of the bimolecular insertion MEP as well as for the transition state structure describing an ethyl radical $\mathrm{H}$ loss. Meanwhile, the B3LYP/6-311++G(d,p) method also tends to introduce a larger error into the $\mathrm{CCSD}(\mathrm{T})$-F12/CBS relative energies. This is especially so for the transition state describing an ethyl radical $\mathrm{H}$ loss, which introduces an error close to one $\mathrm{kcal} / \mathrm{mol}$. This can be explained from the fact that for the ethyl radical $\mathrm{H}$ loss transition state the B3LYP/6-311++G(d,p) method optimizes the transition state too far along the reaction coordinate.

Because the kinetics of the reactions between the $\mathrm{CH}$ radical with both methane, ethane and propane are expected to be controlled in the entrance channel, the geometries describing mutual fragment approach optimized at the B2PLYPD3/aug-cc-pVTZ level (B2PLYPD3/cc-pVTZ for propane $+\mathrm{CH}$ ) underwent further refinements in the energies so as to build a reliable potential for the available bimolecular insertion reactions. The first of these gave CCSD(T)-F12/CBS level energies, where the complete basis set (CBS) limit was achieved using the two-point extrapolation introduced above. The remaining refinements, meanwhile, were corrections to account for both the correlation of the core electrons and to account for higher order excitations into the coupled-cluster calculations. The exact method for calculating the energies of these entrance channel structures, for methane reaction with $\mathrm{CH}$ radical, was the following:

$$
\begin{gathered}
E=E_{C C S D(T)-F 12 / C B S}+\left(E_{C C S D(T), \text { Core Correlation } / C B S}-E_{C C S D(T) / C B S}\right) \\
+\left(E_{C C S D T Q(P) / V D Z(d / s)}-E_{C C S D(T) / V D Z(d / s)}\right)
\end{gathered}
$$


For the ethane $+\mathrm{CH}$ radical reaction, $\mathrm{CCSDT}(\mathrm{Q})$ calculations were used instead of $\operatorname{CCSDTQ}(\mathrm{P}) .{ }^{32}$ Meanwhile, for the propane $+\mathrm{CH}$ radical reaction, the $\mathrm{CCSDT}(\mathrm{Q})$ corrections were introduced in an ad hoc fashion based upon the calculations from ethane $+\mathrm{CH}$. While this potential is used in rate coefficient calculations, it governs the kinetics at high temperatures. At low temperatures an outer transition state acts as a reaction bottleneck; thus a two transition state approach was used for the rate coefficient calculations. Figure 2.1, for the $\mathrm{CH}_{4}+\mathrm{CH}$ reaction, gives the $\mathrm{CCSD}(\mathrm{T}) / \mathrm{cc}-\mathrm{pVTZ}$ potentials for the approach of rigid fragments as well as optimized ones, confirming that at separations greater than $3.0 \AA$, the reaction kinetics depends on center-of-mass relative motion with conserved (internal) modes while at separations less than $3.0 \AA$, the conserved modes assumption no longer applies. In the outer region, then, separation of the normal modes into conserved and transitional modes took place, and the transitional mode contribution to the reactive flux was calculated using the ROTD software package. ${ }^{33}$ Final rate coefficient calculations were performed using the PAPER software package. ${ }^{34,35}$ Here, the density of states for all species were calculated within the rigid-rotor harmonic oscillator approximation except for the inclusion of hindered rotations. ${ }^{36}$ Results and Discussion:

\section{Insertion into $C-H$ Bond of Methane:}

The potential along the MEP corresponding to the insertion of a $\mathrm{CH}$ radical into a $\mathrm{C}-\mathrm{H} \sigma$ bond of methane is given in Figure 2.2; overall, it shows much different results than the previous theoretical results, which all located an exothermic saddle point along the MEP. ${ }^{12,22,39,40}$ In these cases, $\mathrm{CH}$ approach of a methane molecule was found to be attractive until a fragment distance in which a bond began to cleave and the $\mathrm{H}$-atom migrate 
towards the $\mathrm{CH}$ radical, where a small increase in the potential led to a saddle point below the separated reactants. Past this saddle point, the potential became much more attractive, leading to a deep well on the PES. ${ }^{22}$ Here, however, it is clear that the potential shows no such saddle point. Furthermore, Figure 2.2 shows that the additional correction terms help to make the potential more attractive and monotonic. Also notice that while the correction terms for correlating the core electrons are small, the correction for the inclusion of higher order excitations into the coupled-cluster calculations are non-trivial, making the potential more attractive, about half a kcal/mol so. All of this latter correction, however, stems from inclusion of a full triples excitation and a perturbative estimation to the quadruples excitation, meaning that the energies along the MEP mostly converge beyond the $\operatorname{CCSDT}(\mathrm{Q})$ level.

Kinetics of the Methane + CH Reaction:

The bimolecular rate coefficients for the reaction between methane and the $\mathrm{CH}$ radical are given in Figure 2.3. The predicted rate coefficients are in general a factor of $\sim 2$ 2.5 faster than the experimental results, although at the lowest available temperatures the error is $\sim 75 \%$. All of the qualitative features of the experimental results are reproduced; however, beginning with the positive temperature dependence at the lowest temperatures, a similar steep negative dependence until $\sim 300 \mathrm{~K}$, and a "flattening out" of the rate coefficients after $\sim 300 \mathrm{~K}$. Further, theoretical results predict a slow positive dependence at high temperatures, for which there are no experimental results. Inspection of the rate calculations shows that below $400 \mathrm{~K}$ a long-range bottleneck governs the kinetics, while from 400 to $2000 \mathrm{~K}$ an inner transition state controls the reaction rate. 
Insertions into the $C-H$ Bond/C-C Bond of Ethane:

As for the case of methane $+\mathrm{CH}$, while there also exists a $\mathrm{C}-\mathrm{H} \sigma$ bond insertion, at least in principle it is also possible for an insertion of the $\mathrm{CH}$ radical into ethane's $\mathrm{C}-\mathrm{C} \sigma$ bond. The MEPs given in Figures 2.4 and 2.5 show the potential corresponding to these two entrance channel reactions. Notice first, from Figure 2.4, that as was the case with the previous reaction the insertion process into a $\mathrm{C}-\mathrm{H} \sigma$ bond is a monotonic, barrierless process. Furthermore, the potential is now more attractive, $\sim 3.5 \mathrm{kcal} / \mathrm{mol}$ so. From a qualitative point of view, this more attractive potential explains the larger rate coefficients for this reaction. The calculations used to create this potential were equivalent to the methane $+\mathrm{CH}$ reaction of the previous sections except that, due to convergence of the energies given in Table 2.3, higher-order excitation corrections were based on CCSDT(Q) results. Meanwhile, Figure 2.5 gives the MEP potential describing the insertion into ethane's C-C $\sigma$ bond. As can be seen, the potential energy at carbon-carbon distances greater than $2.7 \AA$ is greater than that of separated reactants, indicating that $\mathrm{CH}$ approach of ethane through the region between the two carbon atoms of ethane involves a repulsive potential. Thus a C-C $\sigma$ bond insertion is not expected to be feasible, such that the ethane $+\mathrm{CH}$ reaction is expected to proceed exclusively by $\mathrm{C}-\mathrm{H} \sigma$ bond insertion followed by the evolution of internally energized n-propyl radical.

Kinetics of Ethane + CH Reaction:

The total rate coefficients for ethane $+\mathrm{CH}$ reaction are given in Figure 2.6 and again these predict a faster reaction than experimental results. Here, however, the disagreements between the theoretical and experimental rate coefficients are much lower and much more uniform throughout the curve. At the lowest temperatures the maximum 
disagreement is $\sim 75 \%$ while at temperatures greater than $300 \mathrm{~K}$, this disagreement is reduced to $\sim 55 \%$ error. The qualitative features of this curve are similar to those describing the methane $+\mathrm{CH}$ reaction. The maximal rate coefficient is at a temperature of $\sim 50 \mathrm{~K}$. The reaction between ethane and $\mathrm{CH}$ has a long-range bottleneck below $900 \mathrm{~K}$ while from 1000 to $2000 \mathrm{~K}$ the reaction kinetics is controlled in the inner region.

\section{Mechanism of Ethane + CH Reaction:}

The reaction between ethane and $\mathrm{CH}$ was shown to be initiated via a $\mathrm{C}-\mathrm{H} \sigma$ bond insertion leading to the $n-\mathrm{C}_{3} \mathrm{H}_{7}$ radical. This process is $95.7 \mathrm{kcal} / \mathrm{mol}$ exothermic. There is one previous investigation into the evolution of this radical in the context of this reaction, ${ }^{20}$ where it was determined using RRKM rate constant calculations that the $n-\mathrm{C}_{3} \mathrm{H}_{7}$ radical will undergo $\mathrm{H}$ loss to produce propene much less often than $\mathrm{CH}_{3}$ loss. The $\mathrm{H}$ atom branching ratio was $12 \% .{ }^{20}$ Experimental results from the same publication measured the $\mathrm{H}$ atom branching ratio to $22 \pm 8 \%$ and the results were rationalized in terms of giving the proper weight to the $\mathrm{C}-\mathrm{C} \sigma$ bond insertion path to fit the results (i.e. $12 \% \mathrm{C}-\mathrm{C}$ insertion vs. 88\% C-H insertion). Based upon our results, however, allowing just for a $\mathrm{C}-\mathrm{H} \sigma$ bond insertion, the predicted $\mathrm{H}$ loss branching ratio is $20.5 \%$, well within the experimental error. The much greater $\mathrm{H}$ atom branching ratio in this work is due to slight changes in the barrier heights. These are shown in Table 2.2, along with the barrier heights from Miller et al. (QCISD(T)/CBS//CCSD(T)/cc-pVTZ). Notice that while the barrier heights for $\mathrm{CH}_{3}$ are consistent throughout, the barrier height for $\mathrm{H}$ loss used in this work and in Miller et al. is นhalf a $\mathrm{kcal} / \mathrm{mol}$ lower and that the barrier height for 1,2 $\mathrm{H}$ shift both here and in Miller et al. is one $\mathrm{kcal} / \mathrm{mol}$ lower as well. Together these lower barrier heights redistribute some of the $\mathrm{CH}_{3}$ loss products into $\mathrm{H}$ loss products. The previous theoretical prediction of $12 \%$ 
$\mathrm{H}$ loss could be an artifact of the B3LYP transition state optimization similar to what we described in the methods for $\mathrm{H}$ loss from the ethyl radical.

\section{References:}

1.Raulin, F.; Brasse, C.; Poch, O.; Coll, P. Prebiotic-Like Chemistry on Titan. Chem. Soc. Rev. 2012, 41, 5380-5393.

2.Bezard, B. Composition and Chemistry of Titan's Stratosphere. Phil. Trans. R. Soc. A 2009, 367, 683-695.

3.Waite Jr., J. H.; Young, D. T.; Cravens, T. E.; Coates, A. J.; Crary, F. J.; Magee, B.; Westlake, J. The Process of Tholin Formation in Titan's Upper Atmosphere. Science. 2007, $316,870-875$.

4.Karplus, S.; Bersohn, R. Photodissociation of Methane. J. Chem. Phys. 1969, 51, 20402050.

5.Gordon, M. S. Excited States and Photochemistry of Saturated Molecules. VI. Extended Basis Calculations on the ${ }^{1} \mathrm{~B}_{1}\left({ }^{1} \mathrm{~T}_{2}\right)$ State of Methane. Chem. Phys. Lett. 1977, 52, 161-167.

6.Gordon, M. S.; Caldwell, J. W. Excited States and Photochemistry of Saturated Molecules. VII. Potential Energy Surfaces in Excited Singlet States of Methane. J. Chem. Phys. 1979, 70, 5503-5514.

7.Lee, H. U.; Janoschek, R. Photolysis of Methane: Population Inversion in Methylene? Chem. Phys. 1979, 39, 271-277.

8.Mordaunt, D. H.; Lambert, I. R.; Morley, G. P.; Ashfold, M. N. R.; Dixon, R. N.; Western, C. M.; Schnieder, L.; Welge, K. H. Primary Product Channels in the Photodissociation of Methane at 121.6 nm. J. Chem. Phys. 1993, 98, 2054-2065.

9.Heck, A. J. R.; Zare, R. N.; Chandler, D. W. Photofragment imaging of methane. J. Chem. Phys. 1996, 104, 4019-4030.

10.Gans, B.; Boye-Peronne, S.; Broquier, M.; Delsaut, M.; Douin, S.; Fellows, C. E.; Halvick, P.; Loison, J.; Lucchese, R. R.; Gauyacq, D. Photolysis of Methane Revisited at $121.6 \mathrm{~nm}$ and at $118.2 \mathrm{~nm}$ : Quantum Yields of the Primary Products, Measured by Mass Spectrometry. Phys. Chem. Chem. Phys. 2011, 13, 8140-8152.

11.Canosa, A.; Sims, I. R.; Travers, D.; Smith, I. W. M.; Rowe, B. R. Reactions of the Methylidine Radical with $\mathrm{CH}_{4}, \mathrm{C}_{2} \mathrm{H}_{2}, \mathrm{C}_{2} \mathrm{H}_{4}, \mathrm{C}_{2} \mathrm{H}_{6}$, and But-1-ene Studied between 23 and $295 \mathrm{~K}$ with a CRESU Apparatus. Astron. Astrophys. 1997, 323, 644- 651. 
12.Lessard, P. F.; Rayez, J. C.; Bergeat, A.; Loison, J. C. Reaction of Methylidyne Radical with $\mathrm{CH}_{4}$ and $\mathrm{H}_{2} \mathrm{~S}$ : Overall Rate Constant and Absolute Atomic Hydrogen Production. Chem. Phys. 2002, 279, 87-99.

13.Winnewisser, G.; Herbst, E. Interstellar Molecules. Rep. Prog. Phys. 1993, 56, 12091273.

14.Peng, Z; Dobrijevic, M.; Hebrard, E.; Nathalie, C.; Pernot, P. Photochemical Modeling of Titan Atmosphere at the "10 Percent Uncertainty Horizon." Faraday Discuss. 2010, 147, 137-153.

15.Jones, B. M.; Zhang, F.; Kaiser, R. I.; Jamal, A.; Mebel, A. M.; Cordiner, M. A.; Charnley, S. B. Formation of Benzene in the Interstellar Medium. Proc. Natl. Acad. Sci. U. S. A. 2011, 108, $452-457$.

16.Blitz, M. A.; Johnson, D. G.; Pesa, M.; Pilling, M. J.; Robertson S. H.; Seakins, P. W. Reaction of CH Radicals with Methaneisotopomers. J. Chem. Soc., Faraday Trans. 1997, 93, 1473-1479.

17.Thiesemann, H.; MacNamara, J.; Taatjes, C. A. Deuterium Kinetic Isotope Effect and Temperature Dependence in the Reactions of $\mathrm{CH}\left[{ }^{2} \Pi\right]$ with Methane and Acetylene. $J$. Phys. Chem. A 1997, 101, 1881-1886.

18.Daugey, N.; Caubet, P.; Retail, B.; Costes, M.; Bergeat, A.; Dorthe, G. Kinetic Measurements on Methylidyne Radical Reactions with Several Hydrocarbons at Low Temperatures. Phys. Chem. Chem. Phys. 2005, 7, 2921-2927.

19.Loison, J. C; Bergeat, A.; Caralp, F.; Hannachi, Y. Rate Constants and H Atom Branching Ratios of the Gas-Phase Reactions of Methylidyne $\mathrm{CH}\left(\mathrm{X}^{2} \Pi\right)$ Radical with a Series of Alkanes. J. Phys. Chem. A 2006, 110, 13500-13506.

20.Galland, N.; Caralp, F.; Hannachi, Y.; Bergeat, A.; Loison, J. C. Experimental and Theoretical Studies of the Methylidyne $\mathrm{CH}\left(\mathrm{X}^{2} \Pi\right)$ Radical Reaction with Ethane $\left(\mathrm{C}_{2} \mathrm{H}_{6}\right)$ : Overall Rate Constant and Product Channels. J. Phys. Chem. A 2003, 107, 5419-5426.

21.Berman, M. R.; Lin, M. C. Kinetics and Mechanisms of the Reactions of $\mathrm{CH}$ with $\mathrm{CH}_{4}$, $\mathrm{C}_{2} \mathrm{H}_{6}$ and $n-\mathrm{C}_{4} \mathrm{H}_{10}$. Chem. Phys. 1983, 82, 435.

22.Ribeiro, J. M.; Mebel, A. M. Reaction Mechanism and Rate Constants of the $\mathrm{CH}+\mathrm{CH}_{4}$ Reaction: A Theoretical Study. Mol. Phys. 2015, 113, 1865 - 1872.

23.Grimme, S. Semiempirical Hybrid Density Functional with Perturbative Second-Order Correlation. J. Chem. Phys. 2006, 124, 1-16. 
24.Grimme, S.; Antony, J.; Ehrlich, S.; Krieg, H. A Consistent and Accurate ab Initio Parametrization of Density Functional Dispersion Correction (DFT-D) for the 94 Elements H-Pu. J. Chem. Phys. 2010, 132, 1-19.

25.Dunning, T. H. Gaussian Basis Sets for Use in Correlated Molecular Calculations. I. The Atoms Boron through Neon and Hydrogen. J. Chem. Phys. 1989, 90, 1007- 1023.

26.Becke, A. D. Density-Functional Thermochemistry. III. The Role of Exact Exchange. J. Chem. Phys. 1993, 98, 5648-5652.

27.Lee, C.; Yang, W.; Parr, R. G. Development of the Colle-Salvetti Correlation-Energy Formula into a Functional of the Electron Density. Phys. Rev. B: Condens. Matter Mater. Phys. 1988, 37, $785-789$.

28.Krishnan, R.; Frisch, M.; Pople, J. A. Contribution of Triple Substitutions to the Electron Correlation Energy in Fourth Order Perturbation Theory. J. Chem. Phys. 1980, $72,4244-4245$.

29.Purvis, G. D.; Bartlett, R. J. A Full Coupled-Cluster Singles and Doubles Model: The Inclusion of Disconnected Triples. J. Chem. Phys. 1982, 76, 1910- 1918.

30.Knizia, G.; Adler, T. B.; Werner, H.-J. Simplified CCSD(T)-F12 Methods: Theory and Benchmarks. J. Chem. Phys. 2009, 130, 054104.

31.Peterson, K . A.; Adler, T. B.; Werner, H.-J. Systematically Convergent Basis Sets for Explicitly Correlated Wavefunctions: The Atoms H, He, B-Ne, and Al-Ar. J. Chem. Phys. 2008, 128, 084102

32.Rolik, Z.; Kallay, M. A General-Order Local Coupled-Cluster Method Based on the Cluster-in-Molecule Approach. J. Chem. Phys. 2011, 135, 104111.

33. Georgievskii, Y.; Klippenstein, S. J. Transition State Theory for Multichannel Addition Reactions: Multifaceted Dividing Surfaces. J. Phys. Chem. A 2003, 107, 9776 - 9781.

34.Georgievskii, Y.; Miller, J. A.; Burke, M. P.; Klippenstein, S. J. Reformulation and Solution of the Master Equation for Multiple-Well Chemical Reactions. J. Phys. Chem. A 2013, 117, $12146-12154$.

35.Georgievskii, Y.; Jasper, A.W.; Zador, J.; Miller, J.A.; Burke, M. P.; Goldsmith, C.F.; Klippenstein, S. J. PAPER, v1; 2014. 
36.Steinfeld, J.I.; Francisco, J.S.; Hase, W.L. Chemical Kinetics and Dynamics; PrenticeHall: Upper Saddle River, NJ, 1999.

37.Jasper, A. W.; Miller, J. A. Lennard-Jones Parameters for Combustion and Chemical Kinetics Modeling from Full-Dimensional Intermolecular Potentials. Combust. Flame 2014, 161, $101-110$.

38.Troe, J. Theory of Thermal Unimolecular Reactions at Low Pressures. 1. Solutions of the Master Equation. J. Chem. Phys. 1977, 66, 4745- 4757.

39.Wang, Z-X.; Huang, M. B.; Liu, R. Z. Theoretical Study on the Insertion Reaction of $\mathrm{CH}\left(\mathrm{X}^{2} \Pi\right)$ with $\mathrm{CH}_{4}$. Can. J. Chem. 1997, 75, 996-1001.

40.Taajtes, C. A.; Klippenstein, S. J. Kinetic Isotope Effects and Variable Reaction Coordinates in Barrierless Recombination Reactions. J. Phys. Chem. A 2001, 105, 85678578 . 
Table 2.1: A Comparison of Geometries and Frequencies. It illustrates the effect that the level of optimization has on these (important) rate coefficient parameters. CCSD(T)/aug-cc-pVTZ geometries and frequencies are used as reference. In addition, the relative energies are given relative to methane and $\mathrm{CH}$ radical fragments at infinite separation, with all relative energies at the CCSD(T)-F12/CBS level and in units of $\mathrm{kcal} / \mathrm{mol}$.

\begin{tabular}{|c|c|c|c|c|}
\hline Structure & $\begin{array}{l}\mid \Delta E_{B 3 L Y P} \\
-\Delta E_{C C S D(T)} \mid\end{array}$ & $\begin{array}{l}\mid \Delta E_{B 2 P L Y P D 3} \\
-\Delta E_{C C S D(T)} \mid\end{array}$ & $\frac{\prod \text { Frequencies }_{B 3 L Y P}}{\prod \text { Frequencies }_{C C S D(T)}}$ & $\frac{\prod \text { Frequencies }}{\text { MFrPLYPD3 }}$ \\
\hline $\begin{array}{c}\mathrm{CH}_{4}+\mathrm{CH} \text { Radical, } \\
2.45 \AA\end{array}$ & 0.18 & 0.06 & 1.23 & 1.16 \\
\hline $\begin{array}{c}\mathrm{CH}_{4}+\mathrm{CH} \text { Radical, } \\
2.40 \AA\end{array}$ & 0.12 & 0.04 & 1.08 & 1.03 \\
\hline $\begin{array}{c}\mathrm{CH}_{4}+\mathrm{CH} \text { Radical, } \\
2.35 \AA \\
\end{array}$ & 0.08 & 0.03 & 1.02 & 0.97 \\
\hline $\begin{array}{c}\mathrm{CH}_{4}+\mathrm{CH} \text { Radical, } \\
2.30 \AA \\
\end{array}$ & 0.04 & 0.02 & 0.94 & 0.94 \\
\hline $\begin{array}{c}\mathrm{CH}_{4}+\mathrm{CH} \text { Radical, } \\
2.25 \AA\end{array}$ & 0.02 & 0.02 & 0.87 & 0.92 \\
\hline $\begin{array}{c}\mathrm{CH}_{4}+\mathrm{CH} \text { Radical, } \\
2.20 \AA\end{array}$ & 0.02 & 0.02 & 0.78 & 0.88 \\
\hline $\mathrm{C}_{2} \mathrm{H}_{5}$ Radical & 0.02 & 0.01 & 0.81 & 1.01 \\
\hline $\mathrm{C}_{2} \mathrm{H}_{5}$ Radical $\mathrm{H}$ loss TS & 0.84 & 0.02 & 0.57 & 1.21 \\
\hline
\end{tabular}


Table 2.2: A Comparison of the Barrier Heights for Channels Available to $n-\mathrm{C}_{3} \mathrm{H}_{7}$ Radical. Units are in $\mathrm{kcal} / \mathrm{mol}$.

\begin{tabular}{|c|c|c|c|}
\hline Structure & $V^{\ddagger \mathrm{a}}$ & $V^{\ddagger \mathrm{b}}$ & $V^{\ddagger \mathrm{c}}$ \\
\hline TS1 $(2,1$ H shift) & 37.6 & 37.9 & 39.0 \\
\hline $\mathrm{TS} 2$ (H loss) & 35.7 & 35.8 & 36.1 \\
\hline $\mathrm{TS} 3\left(\mathrm{CH}_{3}\right.$ loss $)$ & 30.9 & 30.7 & 30.9 \\
\hline
\end{tabular}

${ }^{\mathrm{a} C C S D}(\mathrm{~T})-\mathrm{F} 12 / \mathrm{CBS} / / \mathrm{B} 2 \mathrm{PLYPD} 3 /$ aug-cc-pVTZ. ${ }^{\mathrm{b}} \mathrm{QCISD}(\mathrm{T}) / \mathrm{CBS} / / \mathrm{CCSD}(\mathrm{T}) / \mathrm{cc}-\mathrm{p}-\mathrm{VTZ}$ from Miller et al. ${ }^{c} \mathrm{CCSD}(\mathrm{T}) / \mathrm{cc}-\mathrm{pVTZ//B3LYP/aug-cc-pVDZ} \mathrm{from} \mathrm{Galland} \mathrm{et} \mathrm{al.}$ 
Table 2.3: Methane + CH Radical CCSD(T), CCSDT(Q), CCSDTQ(P) Energies. Calculated using the cc-pVDZ $(\mathrm{d} / \mathrm{s})$ basis set and given in atomic units.

\begin{tabular}{|c|c|c|c|}
\hline Structure & CCSD $(\mathrm{T})$ & CCSDT(Q) & CCSDTQ(P) \\
\hline Methane & -40.34462 & -40.34511 & -40.34512 \\
\hline CH Radical & -38.36905 & -38.36959 & -38.36961 \\
\hline Methane + CH 2.450 & -78.71356 & -78.71503 & -78.71505 \\
\hline Methane + CH 2.425 & -78.71340 & -78.71488 & -78.71490 \\
\hline Methane + CH 2.400 & -78.71322 & -78.71472 & -78.71473 \\
\hline Methane + CH 2.375 & -78.71303 & -78.71453 & -78.71455 \\
\hline Methane + CH 2.350 & -78.71280 & -78.71432 & -78.71434 \\
\hline Methane + CH 2.325 & -78.71256 & -78.71409 & -78.71410 \\
\hline Methane + CH 2.300 & -78.71228 & -78.71384 & -78.71385 \\
\hline Methane + CH 2.275 & -78.71199 & -78.71356 & -78.71358 \\
\hline Methane + CH 2.250 & -78.71167 & -78.71327 & -78.71328 \\
\hline Methane + CH 2.225 & -78.71133 & -78.71296 & -78.71297 \\
\hline Methane + CH 2.000 & -78.71097 & -78.71264 & -78.71265 \\
\hline
\end{tabular}


Table 2.4: Ethane + CH Radical CCSD(T) and CCSDT(Q) Energies. Calculated using the cc-pVDZ $(d / s)$ basis set and given in atomic units.

\begin{tabular}{|c|c|c|}
\hline Structure & CCSD(T) & CCSDT(Q) \\
\hline Ethane & -79.51870 & -79.51966 \\
\hline CH Radical & -38.36905 & -117.89246 \\
\hline Ethane + CH 2.450 & -117.89045 & -117.89243 \\
\hline Ethane + CH 2.425 & -117.89039 & -117.89238 \\
\hline Ethane + CH 2.400 & -117.89031 & -117.89229 \\
\hline Ethane + CH 2.375 & -117.89020 & -117.89218 \\
\hline Ethane + CH 2.350 & -117.89007 & -117.89204 \\
\hline Ethane + CH 2.325 & -117.88990 & -117.89186 \\
\hline Ethane + CH 2.300 & -117.88963 & -117.89164 \\
\hline Ethane + CH 2.275 $\AA$ & -117.88937 & -117.89139 \\
\hline Ethane + CH 2.250 & -117.88907 & -117.89111 \\
\hline Ethane + CH 2.225 & -117.88873 & \\
\hline
\end{tabular}


Figure 2.1: Methane + CH Radical "Rigid" vs. Optimized Potential. It compares the CCSD(T)/cc-pVTZ MEP potential describing the mutual approach of methane and the $\mathrm{CH}$ radical (in black) with the potential describing the methane and $\mathrm{CH}$ radical approach rigid fragments (in red), each with their infinite separation equilibrium geometries. At separations greater than $3.0 \AA$, where the potentials converge, the reaction kinetics depends on center-of-mass relative motion with conserved (internal) modes.

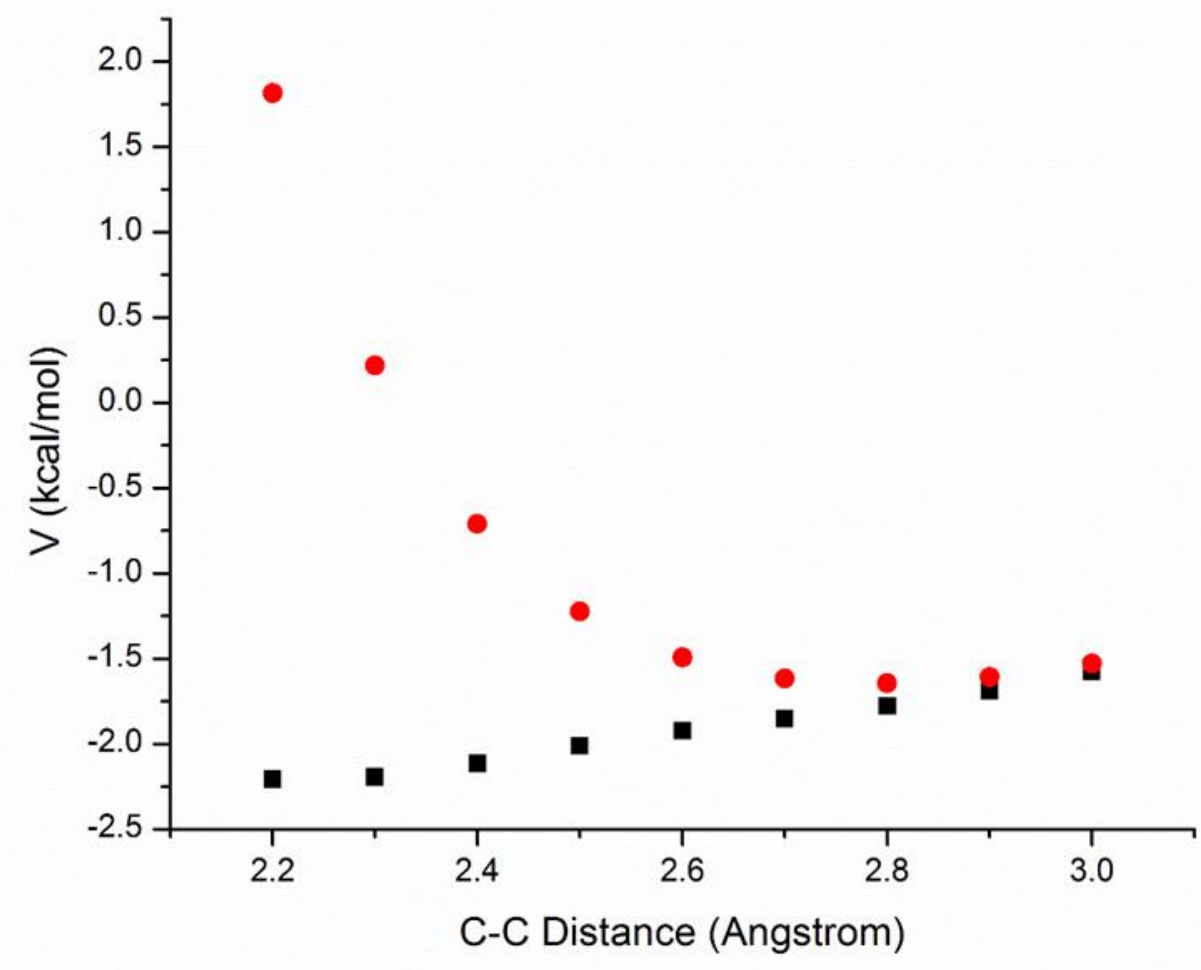


Figure 2.2: Methane $+\mathrm{CH}$ Radical Potential Describing $\mathrm{C}-\mathrm{H} \sigma$ Bond Insertion. The potential, $\mathrm{V}$, is along the MEP. The black curve is the $\operatorname{CCSD}(\mathrm{T})$ F12/CBS//B2PLYPD3/aug-cc-pVTZ potential. The red curve takes the black curve and includes a correction for allowing the core electrons to be included in the treatment of electronic correlation. The blue curve, meanwhile, also corrects for higher order excitations including full singles, doubles, triples and quadruples excitations plus a perturbative approximation for the quintuple excitation.

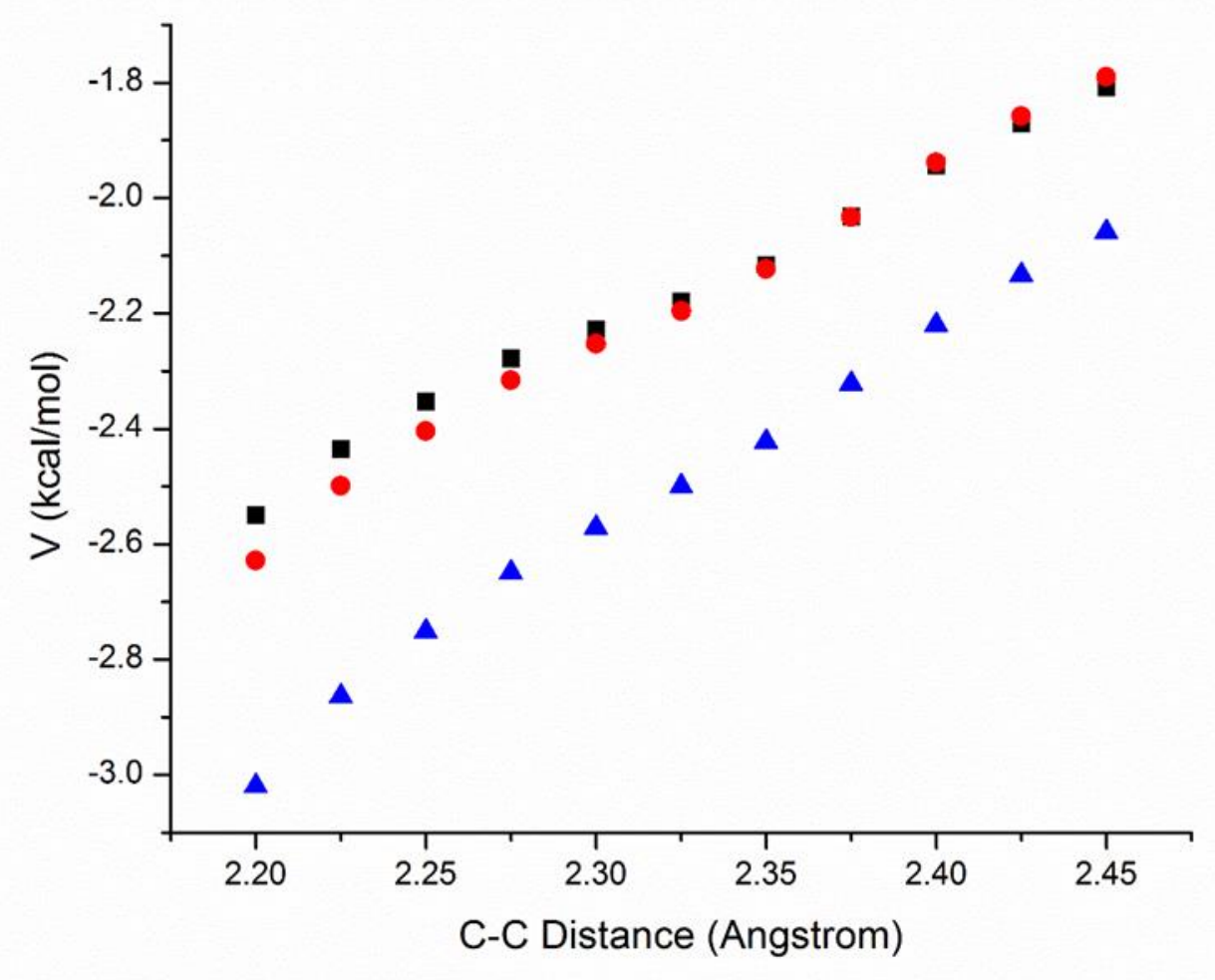


Figure 2.3: Methane + $\mathrm{CH}$ Radical Total Rate Coefficients, $k$, as a Function of Temperature.

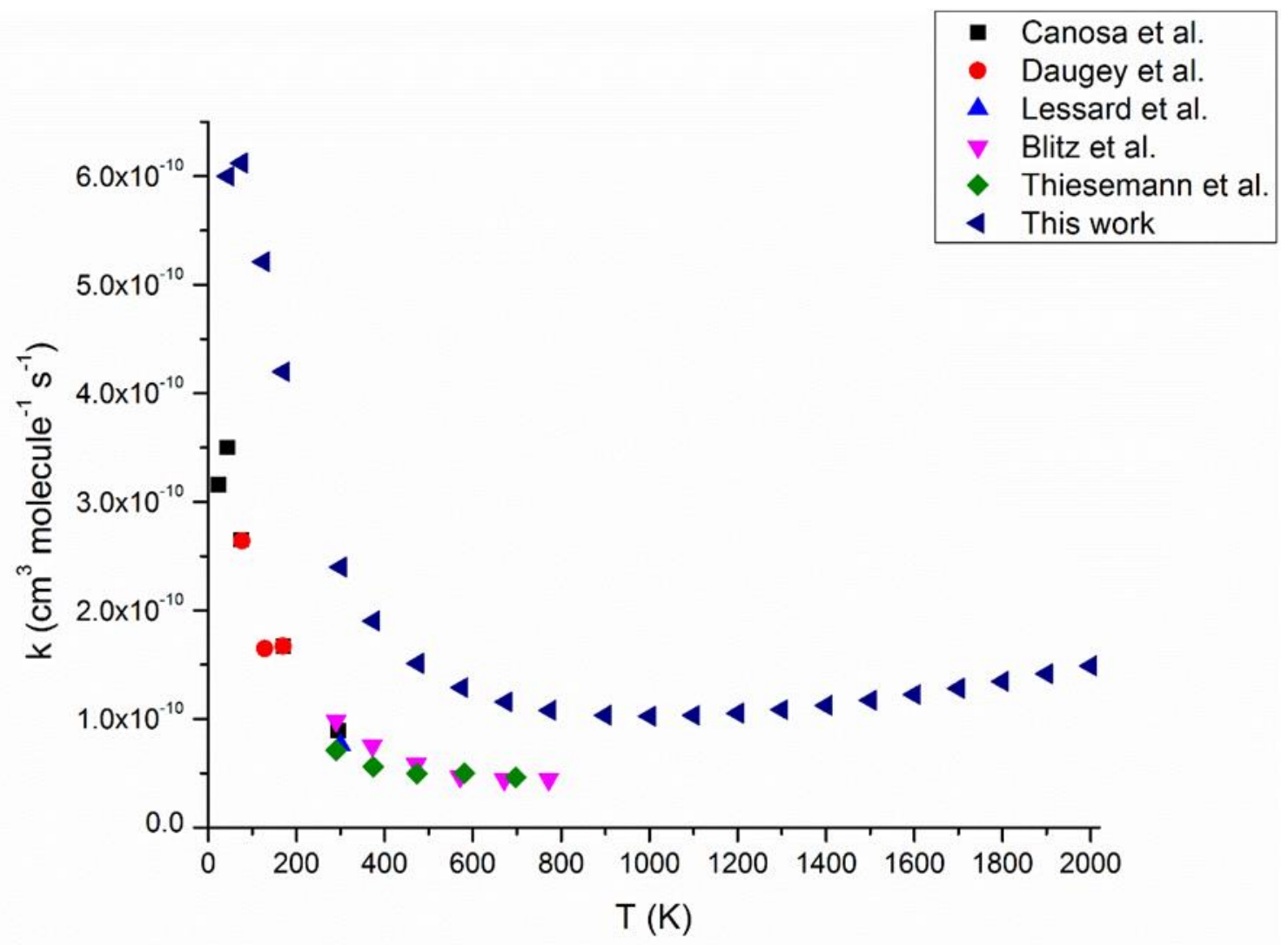


Figure 2.4: Ethane $+\mathrm{CH}$ Radical Potential Describing $\mathrm{C}-\mathrm{H} \sigma$ Bond Insertion. The potential, $\mathrm{V}$, is along the MEP. The black curve is the CCSD(T)-F12/CBS//B2PLYPD3/aug-ccpVTZ potential. The red curve takes the black curve and includes a correction for allowing the core electrons to be included in the treatment of electronic correlation. The blue curve, meanwhile, also corrects for higher order excitations including full singles, doubles and triples plus a perturbative approximation for the quadruple excitation.

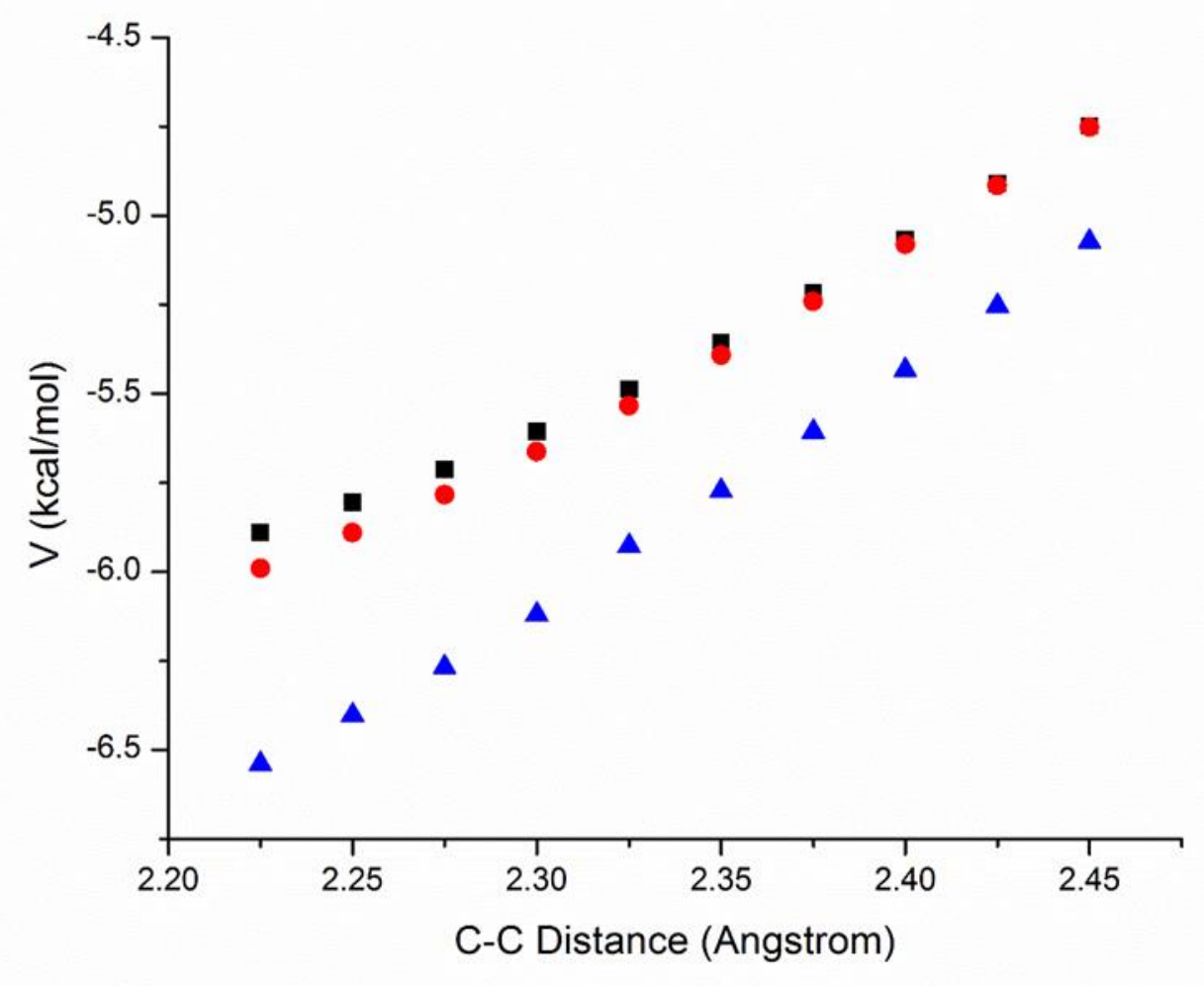


Figure 2.5: Ethane $+\mathrm{CH}$ Radical Potential Describing $\mathrm{C}-\mathrm{C} \sigma$ Bond Insertion. The potential, $\mathrm{V}$, is along the MEP. It is at the CCSD(T)-F12/CBS//B2PLYPD3/aug-cc-pVTZ level. Notice that for fragment separation greater than $1.7 \AA$, the points are located above the separated reactants.

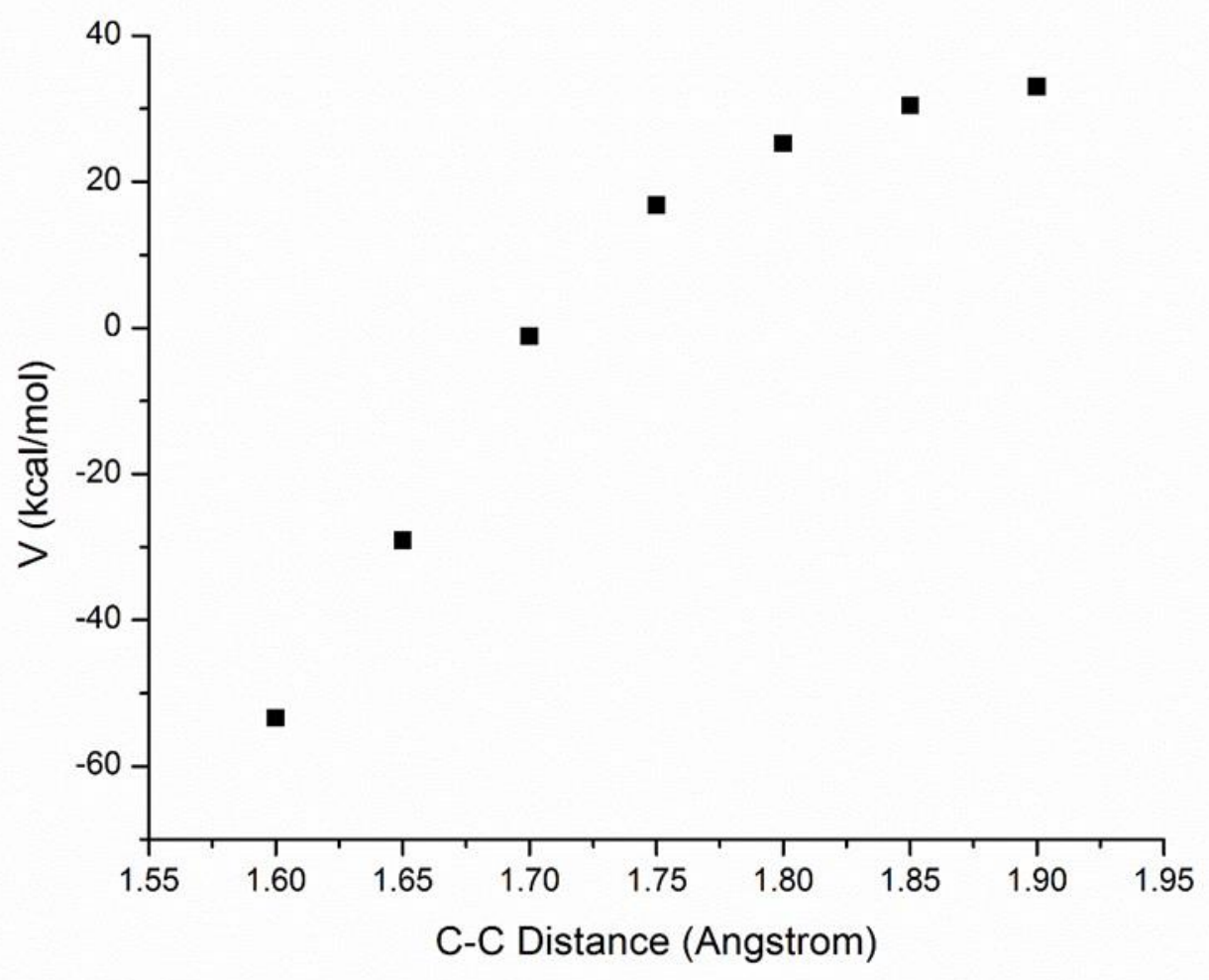


Figure 2.6: Ethane + CH Radical Total Rate Coefficients, k, as a Function of Temperature.

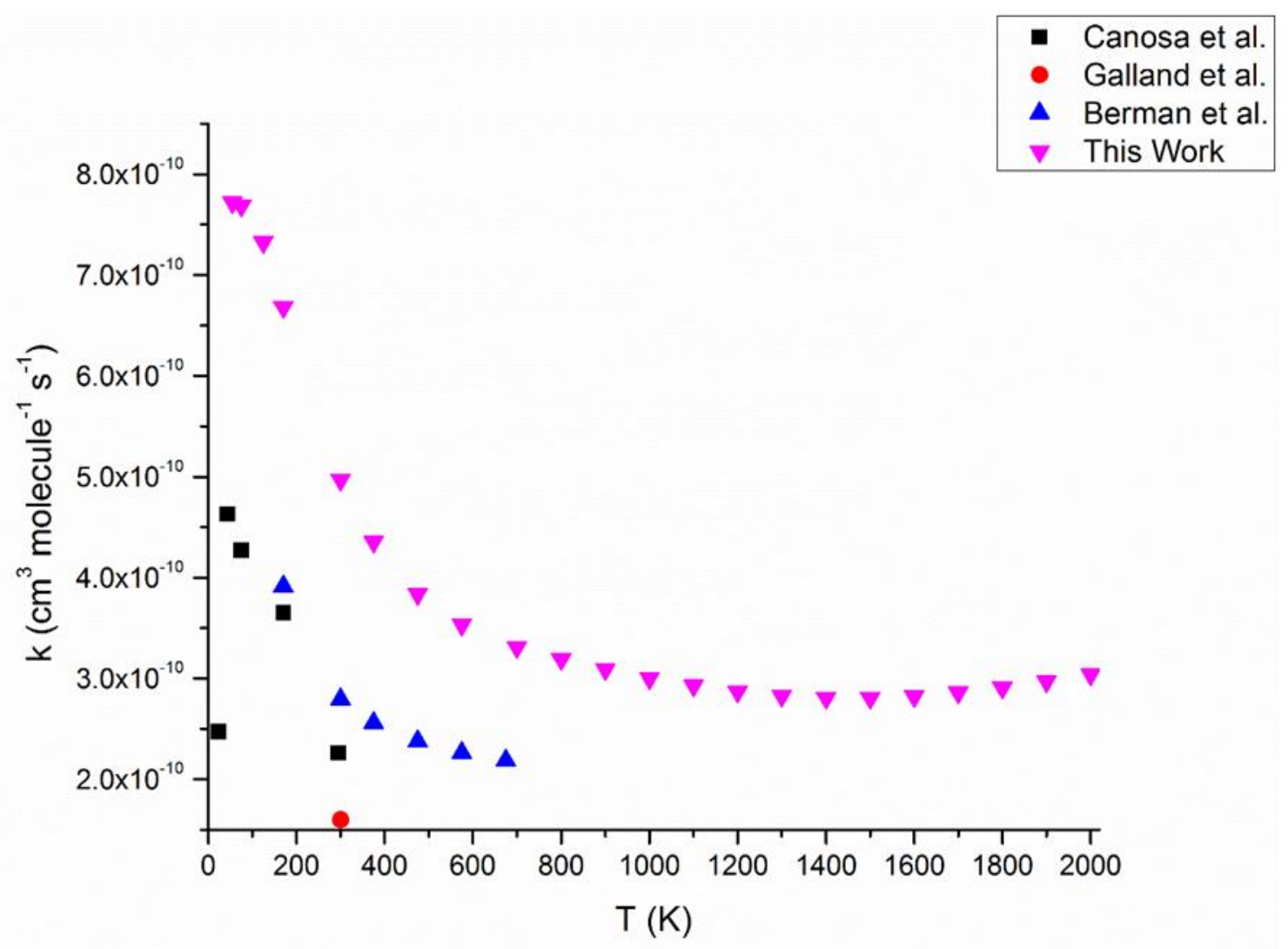


Figure 2.7: $\mathrm{C}_{3} \mathrm{H}_{7}$ PES. Surface was prepared at the CCSD(T)-F12/CBS//B2PLYPD3/augcc-pVTZ level.

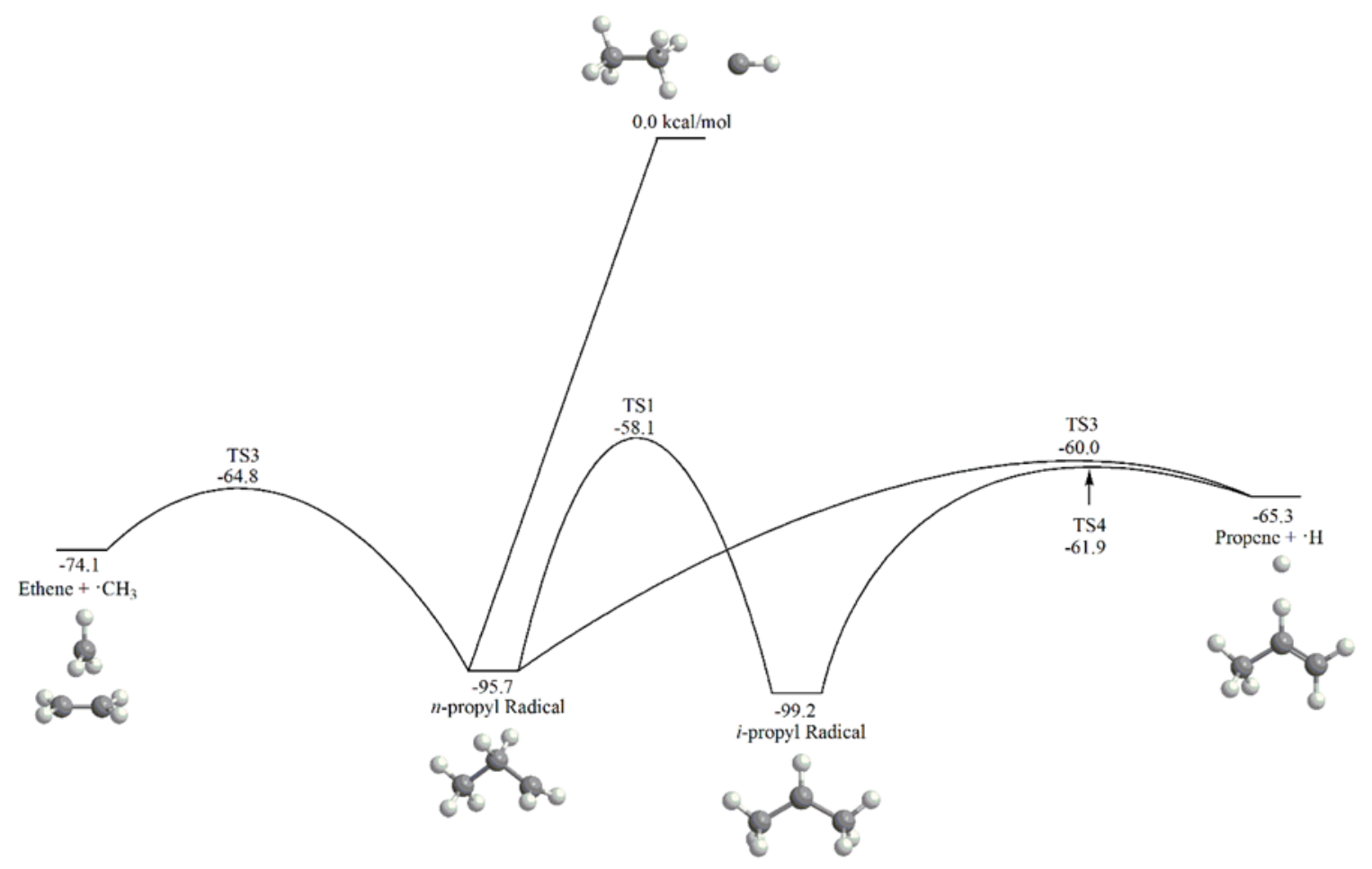




\section{CHAPTER III}

REACTION MECHANISM OF CH $\left(\mathrm{X}^{2} \Pi\right)+\mathrm{C}_{3} \mathrm{H}_{8}$ AND $\mathrm{C}_{4} \mathrm{H}_{9}$ PES 
Introduction:

Elucidation of the chemical reactions which drive the growth of the carbon-chain on Titan's atmosphere has attracted various experimental and theoretical investigations due to the possible shared characteristic of Titan's current atmosphere with that of primordial Earth. ${ }^{1,2,3,4}$ It is now understood that the growth of the carbon-chain on Titan is "kickstarted" upon photoirradiation of methane, ${ }^{3,5,6}$ which comprises $\sim 2 \%$ of Titan's upper atmosphere, ${ }^{3}$ to produce reactive radical species such as $\mathrm{CH}_{3}, \mathrm{CH}_{2}$ and $\mathrm{CH}$. Despite recent results suggesting that the ground-state $\mathrm{CH}$ radical $\left(\mathrm{X}^{2} \Pi\right)$ comprises just $\sim 7 \%$ of the photodissociation products at Lyman- $\alpha$ wavelengths, ${ }^{7} \mathrm{CH}$ is the most reactive species, capable of reacting with both inert closed-shell species ${ }^{8}$ as well as open-shell species. This particular characteristic of the $\mathrm{CH}$ molecule thus makes it important to the chemical evolution of Titan's atmosphere, ${ }^{9}$ as has been highlighted in opening pages of Chapters 1 and 2. Although there are still issues to be resolved in the case of reactions between $\mathrm{CH}$ and small $\mathrm{C} 1$ and $\mathrm{C} 2$ hydrocarbon species, a couple of which were treated in the previous chapter, there have been numerous studies with different emphasis and scope performed on these particular systems. ${ }^{8,10-24} \mathrm{CH}$ radical reactions with the $\mathrm{C} 3$ species have been much less studied, however. In particular, the literature on the reaction between $\mathrm{CH}$ and propane remains scarce, as there is but one experimental investigation, a room temperature measurement of the overall rate coefficient and of the $\mathrm{H}$ atom branching ratio; ${ }^{8}$ here, a partial theoretical investigation was also included to provide a comparison with the experimental $\mathrm{H}$ atom branching ratio, but no details of the reaction PES were given. ${ }^{8}$ Meanwhile, this scarcity exists despite the fact that propane exists on Titan's atmosphere in greater amounts than ethene $e^{3,25}$ and its reaction with other (larger) reactive radicals such 
as the $\mathrm{C}_{2} \mathrm{H}$ and $\mathrm{C}_{4} \mathrm{H}$ radicals have been studied at low temperatures. ${ }^{26-28}$ The present work thus seeks to expand the initial theoretical investigation in order to, first, map out the relevant minima and saddle points on the $\mathrm{C}_{4} \mathrm{H}_{9}$ potential energy surface (PES), second, determine the unimolecular rate coefficients for isomerization and decomposition paths available to the butyl radical, and, third, determine the product distribution for the $\mathrm{CH}$ $\left(\mathrm{X}^{2} \Pi\right)+$ propane reaction.

Methods:

All geometries for the reactants, transition states, isomers and products were optimized using the Gaussian 09 software, ${ }^{29}$ using the B3LYP hybrid density functional $(\mathrm{DFT})^{30,31}$ and the 6-311G $(\mathrm{d}, \mathrm{p})^{32}$ basis set. However, since the B3LYP functional is known, to sometimes underestimate reaction barriers, transition state structures that could not be optimized were further investigated at the QCISD method. ${ }^{33}$ Three saddle points were located using the QCISD/6-311G(d,p), two describing $\mathrm{H}$ loss from a $\mathrm{CH}_{3}$ group and one describing a 2-butyl radical internal rotation interconverting the trans and the cis isomers. Also, one isomer was located using this method, the cis-2-butyl radical. To characterize the nature of the stationary points, harmonic frequencies were calculated for all optimized structures. These also yielded zero-point energy corrections (ZPE) for all species. All harmonic frequencies were calculated at the B3LYP level except for the four structures described above, whose frequencies were calculated at the QCISD level. The QCISD level ZPE were scaled by the factor $0.9812 .^{34}$

To refine the energies of all B3LYP and QCISD minima and transition states, the Molpro 2010 package was used. ${ }^{35}$ This refinement was achieved through a three-point 
complete basis set extrapolation ${ }^{36}$ using Dunning's cc-pVnZ basis sets (in particular, ccpVDZ, cc-pVTZ, and cc-pVQZ) ${ }^{37}$ at the $\operatorname{CCSD}(\mathrm{T})$ level. $^{38}$

In order to calculate the relevant unimolecular rate constants for isomerization and dissociation of the different $\mathrm{C}_{4} \mathrm{H}_{9}$ radicals, Rice-Ramsperger-Kassel-Marcus (RRKM) theory was used. ${ }^{39}$ The calculations were performed for single-collision conditions relevant to the low pressures of Titan's upper atmosphere. The relevant RRKM equation from which we extract the rate coefficient at a given internal energy, $E$, is the following:

$$
k(E)=\frac{\sigma W^{\ddagger}\left(E-E^{\ddagger}\right)}{h \rho}
$$

Here, $\sigma$ is the reaction path degeneracy, $h$ is Planck's constant, $W^{\ddagger}\left(E-E^{\ddagger}\right)$ is the total number of states of the transition state, and $\rho(E)$ represents the density of states of the energized reactants. The internal energy was taken as a sum of the energy of chemical activation in the $\mathrm{CH}+\mathrm{C}_{3} \mathrm{H}_{8}$ reaction and a collision energy, assuming that a dominant fraction of the latter is converted to the internal vibrational energy. The calculated harmonic frequencies were used to determine the total numbers and densities of states. Product branching ratios were evaluated by solving first-order kinetic equations for unimolecular reactions within the steady-state approximation, according to the kinetics schemes based on the ab initio potential energy diagrams.

Results and Discussion:

It was shown in Chapter 2 that an insertion of $\mathrm{CH}$ into a $\mathrm{sp}^{3} \mathrm{C}-\mathrm{H} \sigma$ bond is a barrierless process and, in addition, it was demonstrated that insertion into a $\mathrm{sp}^{3} \mathrm{C}-\mathrm{C} \sigma$ bond is repulsive at intermediate fragment separation for the reaction between ethane and the $\mathrm{CH}$ radical. It might thus be expected, for the reaction between propane and $\mathrm{CH}$, that 
an attractive endpoint region about each side of propane as well as an attractive region extending from its central carbon are separated by the presence of a repulsive potential between them from the $\mathrm{C}-\mathrm{C} \sigma$ bond insertion. Furthermore, Galland et al. ${ }^{24}$ suggested that such insertion for the $\mathrm{C}_{2} \mathrm{H}_{6}$ reaction may be sterically hindered and later, on these grounds, it was ruled out by Loison et al. ${ }^{8}$ for $\mathrm{CH}$ reactions with larger alkanes. The approach in the present work is to thus consider two initial $\mathrm{C}_{4} \mathrm{H}_{5}$ intermediates to be accessible through the $\mathrm{C}-\mathrm{H} \sigma$ bond insertions when comparing product branching ratios with experimental work, namely, the 1-butyl and $i$-butyl radical. Our description of the $\mathrm{C}_{4} \mathrm{H}_{9} \mathrm{PES}$ and its unimolecular kinetics is more general, however, as these could be useful in other contexts. The overall $\mathrm{C}_{4} \mathrm{H}_{9} \mathrm{PES}$ is given in Figure 3.1; in what follows, only the most important features will be mentioned.

The C-C insertion adduct, the trans-2-butyl radical, appears to be the thermodynamically favored adduct. The terminal $\mathrm{C}-\mathrm{H}$ insertion produces the 1-butyl radical and is thermodynamically least favorable, whereas the central $\mathrm{C}-\mathrm{H}$ insertion gives the isobutyl radical, which is less stable than trans-2-butyl but more stable than 1-butyl. Nevertheless, all three initial adducts reside in a narrow energy range between -99.4 and $96.7 \mathrm{kcal} / \mathrm{mol}$ relative to the initial reactants. The trans-2-butyl radical can isomerize to the 1-butyl radical through a 1,2-H shift (via TSa) or through a 2,4-H shift (via TSb), although the barrier associated with the latter $\mathrm{H}$-shift is $\sim 1 \mathrm{kcal} / \mathrm{mol}$ higher. The trans-2-butyl radical adduct can also isomerize to the isobutyl radical through a 2,3- $\mathrm{CH}_{3}$ shift (via TSc) but the corresponding barrier is greater than its $\mathrm{H}$-shift barriers by $\sim 20 \mathrm{kcal} / \mathrm{mol}$. There is a small rotational barrier (TSm) separating the trans and cis 2-butyl radicals. As for the 1-butyl radical, there does not exist a direct connection for its rearrangement to the isobutyl radical 
and in fact it cannot isomerize to any other low-energy species except the trans-2-butyl radical. Finally, through a 1,2-H shift (via TSd) the isobutyl radical can form the most stable $\mathrm{C}_{4} \mathrm{H}_{9}$ isomer, the tert-butyl radical, and this occurs with the lowest isomerization barrier of $36.0 \mathrm{kcal} / \mathrm{mol}$. Comparison of the calculated energies for the adducts with experimental data ${ }^{40,41}$ is shown in Table 3.1, where available, showing that the smallest absolute deviation of $1.1 \mathrm{kcal} / \mathrm{mol}$ is for trans-2-butyl radical and the highest absolute deviation of $2.4 \mathrm{kcal} / \mathrm{mol}$ is for the tert-butyl radical. The unimolecular rate constants for the isomerization reactions are included in Table 3.2 at both $0 \mathrm{kcal} / \mathrm{mol}$ and $1 \mathrm{kcal} / \mathrm{mol}$ collision energies, which are relevant to the temperature range of $0-335 \mathrm{~K}$. This temperature range covers the reaction conditions from those typical for the interstellar medium to planetary atmospheres (Pluto and Titan) to ambient conditions. Just about all of the rate constants reflect what is to be expected from the energetics of the PES in Figure 3.1, showing that rotation takes place much more quickly than all the different $\mathrm{H}$-shifts and that $\mathrm{CH}_{3}$-migration is much slower than all the $\mathrm{H}$-shifts. The fact that tert-butyl radical isomerization to the isobutyl radical is comparable to its "forward" reaction can in large part be attributed to the highly symmetric nature of the tert-butyl radical as a reacting species.

The PES shows that in general the H-loss channels are both kinetically and thermodynamically unfavorable relative to their methyl/ethyl-loss counterparts. The formation of propene and methyl radical can occur via two low barrier $\mathrm{CH}_{3}$-loss channels, one resulting from the chain trans-2-butyl radical (via TSe) and another from the branched isobutyl radical (via TSf). The barrier heights for both $\mathrm{CH}_{3}$-loss channels are approximately equal, 31.2 and $31.5 \mathrm{kcal} / \mathrm{mol}$. Through the breaking of its middle $\mathrm{C}-\mathrm{C}$ single bond the 1 - 
butyl radical can lead to the formation of ethene and ethyl radical, a channel that proceeds through TSg and with the associated barrier height of $30.2 \mathrm{kcal} / \mathrm{mol}$. Due to the fact that the 1-butyl radical is a terminal radical, it has one possible H-loss channel leading to the formation of 1-butene and $\mathrm{H}$-atom, although the barrier that must be overcome along this reaction path is $36.4 \mathrm{kcal} / \mathrm{mol}$ (TSi). The trans-2-butyl radical, however, because of its internal radical location, can proceed along two possible $\mathrm{H}$-loss channels, terminal $\mathrm{H}$-loss and internal H-loss. Terminal H-loss proceeds through the transition structure TSh with a barrier height of $37.1 \mathrm{kcal} / \mathrm{mol}$ and also leads to 1-butene and $\mathrm{H}$-atom. Internal H-loss, which is the kinetically favored trans-2-butyl radical H-loss channel, proceeds through TSn with its barrier being $34.9 \mathrm{kcal} / \mathrm{mol}$, and leads to the trans-2-butene and $\mathrm{H}$-atom products. The formation of cis-2-butene and $\mathrm{H}$-atom proceeds through a slightly higher barrier of $35.6 \mathrm{kcal} / \mathrm{mol}$ (TSo) and is thermodynamically unfavorable by $1 \mathrm{kcal} / \mathrm{mol}$ relative to its trans counterpart. Finally, the formation of the most stable H-loss products, isobutene and $\mathrm{H}$-atom, can take place via two channels, $\mathrm{H}$-loss from isobutyl radical and $\mathrm{H}$-loss from tertbutyl radical. The barrier heights for these two channels are $34.6 \mathrm{kcal} / \mathrm{mol}(\mathrm{TSj})$ and 36.1 $\mathrm{kcal} / \mathrm{mol}(\mathrm{TSl})$ respectively. The relative energies of all products have also been compared to experimental data as can be seen in Table 3.1 and the agreement is better than that of adducts as the largest absolute deviation, for ethene + ethyl radical, is below $1 \mathrm{kcal} / \mathrm{mol}$. Table 3.2 shows the unimolecular rate constants for these different product formation channels at collision energies of 0 and $1 \mathrm{kcal} / \mathrm{mol}$.

Absent from the above discussion (and calculations) are the direct $\mathrm{H}$-abstraction channels leading to either isopropyl radical + methylene or n-propyl radical + methylene. These reactions are slightly exothermic or nearly isoergic in nature and in principle might 
be relevant in the interstellar medium and under Titan or Pluto atmospheric conditions and also in combustion. For instance, the isopropyl radical + methylene products together are $2.9 \mathrm{kcal} / \mathrm{mol}$ lower in energy than the reactants, whereas n-propyl radical + methylene are $0.1 \mathrm{kcal} / \mathrm{mol}$ higher in energy than $\mathrm{CH}+\mathrm{C}_{3} \mathrm{H}_{8}$. However, a careful search of direct $\mathrm{H}$ abstraction transition states has failed; a transition state for either of these reactions could not be located as different starting geometries tended to lead to dissociated reactants or toward the insertion reaction channel. This result can be attributed to the fact that the insertion channels are much more favorable energetically, and hence, no pathways to the direct $\mathrm{H}$-abstraction products going from the reactants via a first-order saddle point exist; when a $\mathrm{CH}$ radical approaches propane, it tends to insert into $\mathrm{CH}$ or $\mathrm{CC}$ bonds rather than to abstract a hydrogen atom. The formal $\mathrm{H}$ abstraction products, isopropyl + methylene and n-propyl + methylene, can be formed by cleavage of a $\mathrm{CH}_{2}$ group from isobutyl and 1butyl radicals, respectively. However, these dissociation channels are much less favorable compared to $\mathrm{H}$ and $\mathrm{C}_{2} \mathrm{H}_{5}$ eliminations from these radicals and therefore are not anticipated to be competitive.

Tables 3.3 and 3.4 contain the product branching ratios for $\mathrm{CH}+\mathrm{C}_{3} \mathrm{H}_{8}$ at 0 and 1 $\mathrm{kcal} / \mathrm{mol}$ collision energies, the $0 \mathrm{kcal} / \mathrm{mol}$ collision energy being relevant to Titan and Pluto atmospheric conditions and the $1 \mathrm{kcal} / \mathrm{mol}$ collision energy being included to aid comparison to the room-temperature experiment discussed in Ref. 8. In both tables columns two through four are the percentages of products formed should all $\mathrm{CH}+\mathrm{C}_{3} \mathrm{H}_{8}$ reacting systems proceed exclusively along the one entrance channel indicated. Columns five and six, meanwhile, average the product yields of the different entrance channels giving equal weights to all single bonds available for $\mathrm{CH}$ radical to insert into (two $\mathrm{C}-\mathrm{C}$, 
six terminal $\mathrm{C}-\mathrm{H}$, and two central $\mathrm{C}-\mathrm{H}$ ) but differ in that column five assumes that the $\mathrm{C}$ $\mathrm{C}$ insertion is viable while column six assumes that the $\mathrm{C}-\mathrm{C}$ insertion does not contribute. In all cases the formation of carbon-chains smaller than four-carbons in length (via a C-C bond cleavage in the $\mathrm{C}_{4} \mathrm{H}_{9}$ radicals) will dominate over the formation of butene $+\mathrm{H}$, as can be expected from the H-loss barrier heights described by the PES. For instance, the terminal $\mathrm{C}-\mathrm{H}$ insertion should result in the preferable formation of ethene + ethyl radical, whereas the mid $\mathrm{C}-\mathrm{H}$ insertion and the $\mathrm{C}-\mathrm{C}$ insertion (to a lesser extent) favor the formation of propene + methyl radical. The inclusion of the $\mathrm{C}-\mathrm{C}$ insertion in the product branching ratio calculations does cause the H-loss channels (carbon-skeleton growth channels) to factor in at close to double their overall branching ratio as opposed to when it is not included, driving down formation of propene and methyl radical as well as ethene and ethyl radical by a combined amount of about $6 \%$. This inclusion results in the $\mathrm{H}$-loss products making up $13.51 \%$ of the products at $0 \mathrm{kcal} / \mathrm{mol}$ collision energy and $13.68 \%$ of the products at 1 $\mathrm{kcal} / \mathrm{mol}$ collision energy. The exclusion of the $\mathrm{C}-\mathrm{C}$ insertion channel causes the $\mathrm{H}$-loss to have a diminished role in product formation, driving the $\mathrm{H}$-loss products to make up only $8.00 \%$ of products at $0 \mathrm{kcal} / \mathrm{mol}$ collision energy and $8.12 \%$ at $1 \mathrm{kcal} / \mathrm{mol}$ collision energy. To explain the product distribution deviation from experimentally determined ones, it is possible that steric hindrance of $\mathrm{C}-\mathrm{C}$ insertion might reduce the rate of formation of bimolecular $\mathrm{C}-\mathrm{C}$ insertion adducts while not necessarily excluding them completely from participation in which case the H-loss product branching ratio is likely to fall in between the ranges described above when the proper weights are assigned to the channels. The experimental value of $\mathrm{H}$-loss product branching ratio is $19 \pm 7 \%$, however, so that inclusion of $\mathrm{C}-\mathrm{C}$ insertion into calculations makes the $\mathrm{H}$-atom production fall within the 
experimental result. Loison et al. ${ }^{25}$ attributed the fact that the experimental $\mathrm{H}$-atom yield is higher than their theoretical value computed with exclusion of the $\mathrm{C}-\mathrm{C}$ insertions to secondary prompt decomposition of the $\mathrm{C}_{2} \mathrm{H}_{5}$ product at their experimental conditions. Alternatively, we can see that the experimental $\mathrm{H}$-atom yield can be explained if the $\mathrm{C}-\mathrm{C}$ insertion is included. Another likely explanation, which would make the propane $+\mathrm{CH}$ reaction conform with all the behaviors of the similar methane/ethane $+\mathrm{CH}$ reactions, is that the C-C $\sigma$ bond insertion does not happen and that the B3LYP method used in the optimizations is not optimal to describe the $\mathrm{H}$ loss transition states and their barrier heights. This inadequacy of the B3LYP functional was seen on both the $\mathrm{C}_{2} \mathrm{H}_{5} \mathrm{PES}$ and $\mathrm{C}_{3} \mathrm{H}_{7} \mathrm{PES}$ of the previous chapter and it could very well shift the product branching distributions and reconcile them with experimental values. This being the case, the properties of the reactions between the $\mathrm{CH}$ radical and methane/ethane/propane would show uniform behavior and tendencies as might be expected on the basis of their similar chemical structures. Experimentally, it would be useful to carry out this reaction in crossed molecular beams under single-collision conditions where only primary reaction products can be observed and thus the elementary reaction outcome could be further elucidated and compared with the theoretical branching ratios.

References:

1.Sagan, C.; Thompson, W. R.; Khare, B. N. Titan: a laboratory for prebiological organic chemistry. Acc. Chem. Res. 1992, 25, 286-292.

2.Coustenis, A.; Taylor, F. W. Titan: the Earth-like Moon. World Scientific, Singapore, 1999.

3.Raulin, F.; Brasse, C.; Poch, O.; Coll, P. Prebiotic-Like Chemistry on Titan. Chem. Soc. Rev. 2012, 41, 5380-5393. 
4.Balucani, N. Elementary Reactions of N Atoms with Hydrocarbons: First Steps Towards the Formation of Prebiotic N-Containing Molecules in Planetary Atmospheres. Chem. Soc. Rev. 2012, 41, 5473-5483.

5.Atreya, S. K.; Adams, E. Y.; Niemann, H. B.; Demick-Montelara, J. E.; Owen, T. C.; Fulchignoni, M.; Ferri, F.; Wilson, E. H. Titan's Methane Cycle. Planet. Space Sci. 2006, 54, 1177-1187.

6.Waite Jr., J. H.; Young, D. T.; Cravens, T. E.; Coates, A. J.; Crary, F. J.; Magee, B.; Westlake, J. The Process of Tholin Formation in Titan's Upper Atmosphere. Science 2007, $316,870-875$.

7.Gans, B.; Boye-Peronne, S.; Broquier, M.; Delsaut, M.; Douin, S.; Fellows, C. E.; Halvick, P.; Loison, J.; Lucchese, R. R.; Gauyacq, D. Photolysis of Methane Revisited at $121.6 \mathrm{~nm}$ and at $118.2 \mathrm{~nm}$ : Quantum Yields of the Primary Products, Measured by Mass Spectrometry. Phys. Chem. Chem. Phys. 2011, 13, 8140-8152.

8.Loison, J. C; Bergeat, A.; Caralp, F.; Hannachi, Y. Rate Constants and H Atom Branching Ratios of the Gas-Phase Reactions of Methylidyne $\mathrm{CH}\left(\mathrm{X}^{2} \Pi\right)$ Radical with a Series of Alkanes. J. Phys. Chem. A 2006, 110, 13500-13506.

9.Peng, Z; Dobrijevic, M.; Hebrard, E.; Nathalie, C.; Pernot, P. Photochemical Modeling of Titan Atmosphere at the "10 Percent Uncertainty Horizon." Faraday Discuss. 2010, $147,137-153$.

10.Canosa, A.; Sims, I. R.; Travers, D.; Smith, I. W. M.; Rowe, B. R.Reactions of the Methylidine Radical with CH4, C2H2, C2H4, C2H6, and But-1-ene Studied between 23 and $295 \mathrm{~K}$ with a CRESU Apparatus. Astron. Astrophys. 1997, 323, 644-651.

11.Maksyutenko, P.; Zhang, F.; Gu, X.; Kaiser, R. I. A Crossed Molecular Beam Study on the Reaction of Methylidyne Radicals $\left[\mathrm{CH}\left(\mathrm{X}^{2} \Pi\right)\right]$ with Acetylene $\left[\mathrm{C} 2 \mathrm{H} 2\left(\mathrm{X}^{1} \Sigma_{\mathrm{g}}{ }^{+}\right)\right]-$ Competing $\mathrm{C}_{3} \mathrm{H}_{2}+$ and $\mathrm{C}_{3} \mathrm{H}+\mathrm{H}_{2}$ Channels. Phys. Chem. Chem. Phys. 2011, 13, 240-252.

12.Zhang, F.; Maksyutenko, P.; Kaiser, R. I. Chemical dynamics of the $\mathrm{CH}\left(\mathrm{X}^{2} \Pi\right)+\mathrm{C}_{2} \mathrm{H}_{4}$ $\left(\mathrm{X}^{1} \mathrm{~A}_{1 \mathrm{~g}}\right), \mathrm{CH}\left(\mathrm{X}^{2} \Pi\right)+\mathrm{C}_{2} \mathrm{D}_{4}\left(\mathrm{X}^{1} \mathrm{~A}_{1 \mathrm{~g}}\right)$ and $\mathrm{CD}\left(\mathrm{X}^{2} \Pi\right)+\mathrm{C}_{2} \mathrm{H}_{4}\left(\mathrm{X}^{1} \mathrm{~A}_{1 \mathrm{~g}}\right)$, Reactions Studied Under Single Collision Conditions. Phys. Chem. Chem. Phys. 2012, 14, 529-537.

13.Goulay, F.; Trevitt, A. J.; Meloni, G.; Selby, T. M.; Osborn, D. L.; Taatjes, C. A.; Vereecken, L.; Leone, S. R. Cyclic Versus Linear Isomers Produced by Reaction of the Methylidyne Radical (CH) with Small Unsaturated Hydrocarbons. J. Am. Chem. Soc. 2009, 131, 993-1005.

14.Wang, Z-X.; Huang, M. B.; Liu, R. Z. Theoretical Study on the Insertion Reaction of $\mathrm{CH}\left(\mathrm{X}^{2} \Pi\right)$ with $\mathrm{CH}_{4}$. Can. J. Chem. 1997, 75, 996-1001. 
15.Yu, Z.; Chen, C.; Huang. M; An Ab Initio Study on the Reaction of $\mathrm{CH}\left(\mathrm{X}^{2} \Pi\right)$ with $\mathrm{CH}_{4}$ Can. J. Chem. 1993, 71, 512-519.

16.Wang, Z-X; Liu, R. Z.; Huang, M. B.; Yu, Z. An Ab Initio Study on the Insertion Reactions of $\mathrm{CH}\left(\mathrm{X}^{2} \Pi\right)$ with $\mathrm{NH}_{3}, \mathrm{H}_{2} \mathrm{O}$, and HF. Can. J. Chem. 1996, 74, 910-917.

17.Fleurat-Lessard, P.; Rayez, J. C.; Bergeat, A.; Loison, J. C. Reaction of Methylidyne $\mathrm{CH}\left(\mathrm{X}^{2} \Pi\right)$ Radical with $\mathrm{CH}_{4}$ and $\mathrm{H}_{2} \mathrm{~S}$ : Overall Rate Constant and Absolute Hydrogen Production. Chem. Phys. 2002, 279, 87-99.

18.Taajtes, C. A.; Klippenstein, S. J. Kinetic Isotope Effects and Variable Reaction Coordinates in Barrierless Recombination Reactions. J. Phys. Chem. A 2001, 105, 85678578 .

19.Guadagnini, R.; Schatz, G. C.; Walch, S. P. Ab Initio and RRKM Studies of the Reactions of $\mathrm{C}, \mathrm{CH}$, and ${ }^{1} \mathrm{CH}_{2}$ with Acetylene. J. Phys. Chem. A 1998, 102, 5857-5866.

20.Vereecken, L.; Pierloot, K.; Peeters, J. B3LYP-DFT characterization of the potential energy surface of the $\mathrm{CH}\left(\mathrm{X}^{2} \Pi\right)+\mathrm{C}_{2} \mathrm{H}_{2}$ Reaction. J. Chem. Phys. 1998, 108, 1068-1080.

21.Vereecken, L.; Peeters, J. Detailed Microvariational RRKM Master Equation Analysis of the Product Distribution of the $\mathrm{C}_{2} \mathrm{H}_{2}+\mathrm{CH}\left(\mathrm{X}^{2} \Pi\right)$ Reaction over Extended Temperature and Pressure Ranges. J. Phys. Chem. A, 1999, 103, 5523-5533.

22.Nguyen, T. L.; Mebel, A. M.; Lin, S. H; Kaiser, R. I. Product Branching Ratios of the $\mathrm{C}\left({ }^{3} \mathrm{P}\right)+\mathrm{C}_{2} \mathrm{H}_{3}\left({ }^{2} \mathrm{~A}^{6}\right)$ and $\mathrm{CH}\left({ }^{2} \Pi\right)+\mathrm{C}_{2} \mathrm{H}_{2}\left({ }^{1} \Sigma_{\mathrm{g}}{ }^{+}\right)$Reactions and Photodissociation of $\mathrm{H}_{2} \mathrm{CC}: \mathrm{CH}\left({ }^{2} \mathrm{~B}_{1}\right)$ at 193 and $242 \mathrm{~nm}$ : an ab Initio/RRKM Study. J. Phys. Chem. A, 2001, 105, 11549-11559.

23.Thiesemann, H.; Clifford, E. P.; Taatjes, C. A.; Klippenstein, S. J. Temperature Dependence and Deuterium Kinetic Isotope Effects in the $\mathrm{CH}(\mathrm{CD})+\mathrm{C}_{2} \mathrm{H}_{4}\left(\mathrm{C}_{2} \mathrm{D}_{4}\right)$ Reaction between 295 and 726 K. J. Phys. Chem. A 2001, 105, 5393-5401.

24.Galland, N.; Caralp, F.; Hannachi, Y.; Bergeat, A.; Loison, J. C. Experimental and Theoretical Studies of the Methylidyne $\mathrm{CH}\left(\mathrm{X}^{2} \Pi\right)$ Radical Reaction with Ethane $\left(\mathrm{C}_{2} \mathrm{H}_{6}\right)$ : Overall Rate Constant and Product Channels. J. Phys. Chem. A 2003, 107, 5419-5426.

25.Coustenis, A.; Jennings, D. E.; Nixon, C. A.; Achterberg, R. K.; Lavvas, P.; Vinatier, S.; Teanby, N. A.; Bjoraker, G. L.; Carlson, R. C.; Piani, L.; et al. Titan Trace Gaseous Composition from CIRS at the End of the Cassini-Huygens Prime Mission. Icarus 2010, 207, 461-476.

26.Hoobler, R. J.; Opansky, B. J.; Leone, S. R. Low-Temperature Rate Coefficients for Reactions of Ethynyl Radical $\left(\mathrm{C}_{2} \mathrm{H}\right)$ with Propane, Isobutane, n-Butane, and Neopentane. J. Phys. Chem. A 1997, 101, 1338-1342. 
27.Murphy, J. E.; Vakhtin, A. B.; Leone, S. R. Laboratory Kinetics of $\mathrm{C}_{2} \mathrm{H}$ Radical Reactions with Ethane, Propane, and n-Butane at T=96-296 K: Implications for Titan. Icarus 2003, 163, 175-181.

28.Berteloite, C.; Le Picard, S. D.; Balucani, N.; Canosa, A.; Sims, I. R. Low Temperature Rate Coefficients for Reactions of the Butadiynyl Radical, $\mathrm{C} 4 \mathrm{H}$, with Various Hydrocarbons. Part I: Reactions with Alkanes $\left(\mathrm{CH}_{4}, \mathrm{C}_{2} \mathrm{H}_{6}, \mathrm{C}_{3} \mathrm{H}_{8}, \mathrm{C}_{4} \mathrm{H}_{10}\right)$. Phys. Chem. Chem. Phys. 2010, 12, 3666-3676.

29.Frisch, M. J.; Trucks, G. W.; Schlegel, H. B.; Scuseria, G. E.; Robb, M. A.; Cheeseman, J. R.; Scalmani, G.; Barone, V.; Mennucci, B.; Petersson, G. A.; et al. Gaussian 09, Revision B.01; Gaussian, Inc.: Wallingford, CT, 2010.

30.Becke, A. D. Density-Functional Thermochemistry. III. The Role of Exact Exchange. J. Chem. Phys. 1993, 98, 5648-5652.

31.Lee, C.; Yang, W.; Parr, R. G. Development of the Colle-Salvetti Correlation-Energy Formula into a Functional of the Electron Density. Phys. Rev. B 1988, 37, 785-789.

32-Krishnan, R.; Frisch, M.; Pople, J. A. Contribution of Triple Substitutions to the Electron Correlation Energy in Fourth Order Perturbation Theory. J. Chem. Phys. 1980, $72,4244-4245$.

33.Pople, J. A.; Head-Gordon, M.; Raghavachari, K. Quadratic Configuration Interaction. A General technique for Determining Electron Correlation Energies. J. Chem. Phys. 1987, $87,5968-5975$.

34.Merrick, J. P.; Moran, D.; Radom, L. An Evaluation of Harmonic Vibrational Frequency Scale Factors. J. Phys. Chem. A 2007, 111, 11683-11700.

35.Werner, H.-J.; Knowles, P. J.; Kinizia, G.; Manby, F. R.; Schutz, M. MOLPRO, version 2010.1, a package of ab initio programs, 2010.

36-.Peterson, K. A.; Dunning, T. H. Intrinsic Errors in Several ab Initio Methods: The Dissociation Energy of $\mathrm{N}_{2}$. J. Phys. Chem. 1995, 99, 3898-3901.

37.Dunning, T. H. Gaussian Basis Sets for Use in Correlated Molecular Calculations. I. The Atoms Boron through Neon and Hydrogen. J. Chem. Phys. 1989, 90, 1007-1023.

38.Purvis, G. D.; Bartlett, R. J. A Full Coupled-Cluster Singles and Doubles Model: The Inclusion of Disconnected Triples. J. Chem. Phys. 1982, 76, 1910-1918.

39.Eyring, H.; Lin, S. H.; Lin, S. M. Basic Chemical Kinetics; Wiley: New York, 1980. 
40.NIST Chemistry WebBook, NIST Standard Reference Database Number 69. http://webbook.nist.gov/chemistry/

41.Ruscic, B. Updated Active Thermochemical Tables (ATcT) values based on ver. 1.110 of the Thermochemical Network (2012); available at ATcT.anl.gov 
Table 3.1: Relative Energies for Select $\mathrm{C}_{4} \mathrm{H}_{9}$ Species. The relative energies for the various $\mathrm{C}_{4} \mathrm{H}_{9}$ reaction intermediates and products were calculated at the CCSD(T)/CBS//B3LYP/6$311 \mathrm{G}(\mathrm{d}, \mathrm{p})+\mathrm{ZPE}(\mathrm{B} 3 \mathrm{LYP} / 6-311 \mathrm{G}(\mathrm{d}, \mathrm{p}))$ level of theory and also taken from experimental thermochemical data. All values are in $\mathrm{kcal} / \mathrm{mol}$.

\begin{tabular}{|c|c|c|c|}
\hline Species & $\Delta \mathrm{E}_{\text {calc }}$ & $\Delta \mathrm{E}_{\exp }$ & $\begin{array}{c}\text { Absolute } \\
\text { Deviation }\end{array}$ \\
\hline 2-butyl radical & -99.4 & $-100.5^{\mathrm{a}}$ & 1.1 \\
\hline 1-butyl radical & -96.7 & $\mathrm{~N} / \mathrm{A}$ & -- \\
\hline isobutyl radical & -98.0 & $-100.2^{\mathrm{a}}$ & 2.2 \\
\hline tert-butyl radical & -103.1 & $-105.5^{\mathrm{a}}$ & 2.4 \\
\hline $\begin{array}{c}\text { propene }\left(\mathrm{C}_{3} \mathrm{H}_{6}\right)+ \\
\mathrm{CH}_{3}\end{array}$ & -77.1 & $-77.3^{\mathrm{b}}$ & 0.2 \\
\hline $\begin{array}{c}\text { ethene }\left(\mathrm{C}_{2} \mathrm{H}_{4}\right)+ \\
\mathrm{C}_{2} \mathrm{H}_{5}\end{array}$ & -75.2 & $-76.1^{\mathrm{b}}$ & 0.9 \\
\hline 1-butene $+\mathrm{H}$ & -64.6 & $-65.1^{\mathrm{b}}$ & 0.5 \\
\hline trans-2-butene $+\mathrm{H}$ & -67.4 & $-67.5^{\mathrm{b}}$ & 0.1 \\
\hline cis-2-butene $+\mathrm{H}$ & -66.2 & $-66.7^{\mathrm{b}}$ & 0.5 \\
\hline isobutene $+\mathrm{H}$ & -68.6 & $-69.2^{\mathrm{b}}$ & 0.6 \\
\hline$n$-propyl $+\mathrm{CH}_{2}\left({ }^{3} \mathrm{~B}_{1}\right)$ & 0.4 & $-0.5^{\mathrm{a}}$ & 0.9 \\
\hline isopropyl $+\mathrm{CH}_{2}\left({ }^{3} \mathrm{~B}_{1}\right)$ & -2.6 & $-2.7^{\mathrm{a}}$ & 0.1 \\
\hline
\end{tabular}

${ }^{\text {a }}$ Computed from room temperature enthalpies of formation from Ref. 37.

${ }^{\mathrm{b}}$ Computed from 0 Kelvin enthalpies of formation from Ref. 38. 
Table 3.2: Energy-Dependent Unimolecular Rate Coefficients, $k$. These were calculated using RRKM theory under single-collision conditions at collision energies of 0 and 1 $\mathrm{kcal} / \mathrm{mol}$.

\begin{tabular}{|c|c|c|}
\hline Reaction & $\mathrm{k}\left(\mathrm{s}^{-1}\right), 0 \mathrm{kcal} / \mathrm{mol}$ & $\mathrm{k}\left(\mathrm{s}^{-1}\right), 1 \mathrm{kcal} / \mathrm{mol}$ \\
\hline trans-2-butyl radical $\rightarrow 1$-butyl radical & $1.11 \times 10^{9}$ & $1.22 \times 10^{9}$ \\
\hline 1-butyl radical $\rightarrow$ trans-2-butyl radical & $2.55 \times 10^{9}$ & $2.76 \times 10^{9}$ \\
\hline $\begin{array}{c}\text { trans-2-butyl radical } \rightarrow \text { isobutyl } \\
\text { radical }\end{array}$ & $6.39 \times 10^{5}$ & $7.53 \times 10^{5}$ \\
\hline $\begin{array}{c}\text { isobutyl radical } \rightarrow \text { trans-2-butyl } \\
\text { radical }\end{array}$ & $5.25 \times 10^{6}$ & $6.17 \times 10^{6}$ \\
\hline $\begin{array}{c}\text { trans-2-butyl radical } \rightarrow \text { cis-2-butyl } \\
\text { radical }\end{array}$ & $1.56 \times 10^{12}$ & $1.56 \times 10^{12}$ \\
\hline $\begin{array}{c}\text { cis-2-butyl radical } \rightarrow \text { trans-2-butyl } \\
\text { radical }\end{array}$ & $2.59 \times 10^{12}$ & $2.59 \times 10^{12}$ \\
\hline isobutyl radical $\rightarrow$ tert-butyl radical & $2.02 \times 10^{9}$ & $2.17 \times 10^{9}$ \\
\hline tert-butyl radical $\rightarrow$ isobutyl radical & $2.88 \times 10^{9}$ & $3.12 \times 10^{9}$ \\
\hline $\begin{array}{c}\text { trans-2-butyl radical } \rightarrow \text { propene }+ \\
\mathrm{CH}_{3}\end{array}$ & $4.52 \times 10^{10}$ & $4.81 \times 10^{10}$ \\
\hline trans-2-butyl radical $\rightarrow 1$-butene $+\mathrm{H}$ & $6.21 \times 10^{9}$ & $6.73 \times 10^{9}$ \\
\hline $\begin{array}{c}\text { trans-2-butyl radical } \rightarrow \text { trans-2-butene } \\
+\mathrm{H}\end{array}$ & $9.81 \times 10^{9}$ & $1.06 \times 10^{10}$ \\
\hline 1-butyl radical $\rightarrow$ ethene $+\mathrm{C}_{2} \mathrm{H}_{5}$ & $1.45 \times 10^{11}$ & $1.55 \times 10^{11}$ \\
\hline 1-butyl radical $\rightarrow 1$-butene $+\mathrm{H}$ & $1.28 \times 10^{10}$ & $1.40 \times 10^{10}$ \\
\hline
\end{tabular}




\begin{tabular}{|c|c|c|}
\hline isobutyl radical $\rightarrow$ propene $+\mathrm{CH}_{3}$ & $1.01 \times 10^{11}$ & $1.09 \times 10^{11}$ \\
\hline isobutyl radical $\rightarrow$ isobutene $+\mathrm{H}$ & $4.93 \times 10^{9}$ & $5.32 \times 10^{9}$ \\
\hline tert-butyl radical $\rightarrow$ isobutene $+\mathrm{H}$ & $6.61 \times 10^{10}$ & $7.12 \times 10^{10}$ \\
\hline cis-2-butyl radical $\rightarrow$ cis-2-butene $+\mathrm{H}$ & $1.57 \times 10^{10}$ & $1.70 \times 10^{10}$ \\
\hline
\end{tabular}


Table 3.3: Propane + CH Radical Product Branching Ratio (0 kcal/mol).

\begin{tabular}{|c|c|c|c|c|c|}
\hline Products & $\begin{array}{c}\text { C-C } \\
\text { insertion }\end{array}$ & $\begin{array}{c}\text { terminal C- } \\
\text { H insertion }\end{array}$ & $\begin{array}{c}\text { mid C-H } \\
\text { insertion }\end{array}$ & $\begin{array}{c}\text { Net (including } \\
\text { C-C insertion) }\end{array}$ & $\begin{array}{c}\text { Net } \\
\text { (excluding } \\
\text { C-C } \\
\text { insertion) }\end{array}$ \\
\hline $\begin{array}{c}\text { propene + } \\
\text { methyl radical }\end{array}$ & 63.03 & 1.00 & 93.64 & 31.93 & 24.15 \\
\hline $\begin{array}{c}\text { ethene + ethyl } \\
\text { radical }\end{array}$ & 1.40 & 90.47 & 0.00 & 54.56 & 67.85 \\
\hline $\begin{array}{c}\text { 1-butene + H } \\
\text { trans-2-butene } \\
+ \text { H }\end{array}$ & 8.78 & 8.10 & 0.00 & 6.62 & 6.08 \\
\hline $\begin{array}{c}\text { cis-2-butene + } \\
\text { H }\end{array}$ & 13.11 & 0.21 & 0.00 & 2.75 & 0.16 \\
\hline isobutene + H & 0.00 & 0.00 & 6.36 & 1.27 & 1.59 \\
\hline
\end{tabular}


Table 3.4: Propane + CH Radical Product Branching Ratio (1 kcal/mol).

\begin{tabular}{|c|c|c|c|c|c|}
\hline Products & $\begin{array}{c}\text { C-C } \\
\text { insertion }\end{array}$ & $\begin{array}{c}\text { terminal C- } \\
\text { H insertion }\end{array}$ & $\begin{array}{c}\text { mid C-H } \\
\text { insertion }\end{array}$ & $\begin{array}{c}\text { Net } \\
\text { (including C- } \\
\text { C insertion) }\end{array}$ & $\begin{array}{c}\text { Net } \\
\text { (excluding } \\
\text { C-C insertion) }\end{array}$ \\
\hline $\begin{array}{c}\text { propene + } \\
\text { methyl radical }\end{array}$ & 62.63 & 1.01 & 93.64 & 31.87 & 24.17 \\
\hline $\begin{array}{c}\text { ethene + ethyl } \\
\text { radical }\end{array}$ & 1.43 & 90.28 & 0.00 & 54.45 & 67.71 \\
\hline $\begin{array}{c}\text { 1-butene + H } \\
\text { trans-2-butene } \\
+ \text { H }\end{array}$ & 13.80 & 0.22 & 0.00 & 2.89 & 6.20 \\
\hline $\begin{array}{c}\text { cis-2-butene + } \\
\text { H }\end{array}$ & 13.25 & 0.22 & 0.00 & 2.78 & 0.17 \\
\hline \begin{tabular}{c} 
isobutene + H \\
\hline
\end{tabular} & 0.00 & 0.00 & 6.36 & 1.27 & 1.58 \\
\hline
\end{tabular}


Figure 3.1: $\mathrm{C}_{4} \mathrm{H}_{9}$ PES. Surface was mapped at the CCSD(T)/CBS//B3LYP/6-311G(d,p) + ZPE(B3LYP/6-311G(d,p) level.

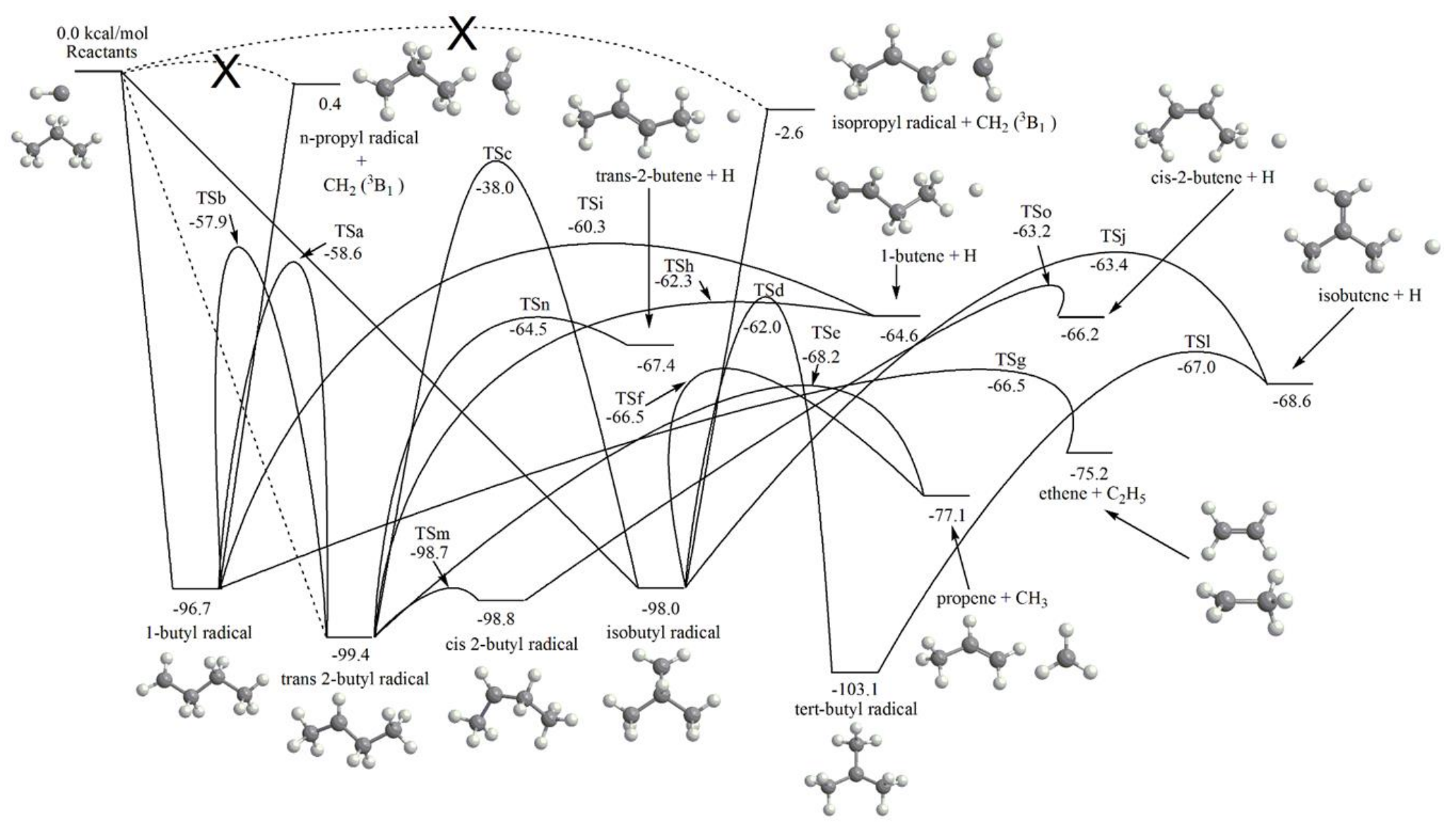


Figure 3.2: Optimized $\mathrm{C}_{4} \mathrm{H}_{9}$ PES Transition-State Structures. Critical bond lengths in $\AA$.

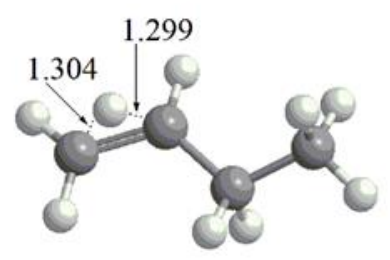

TSa

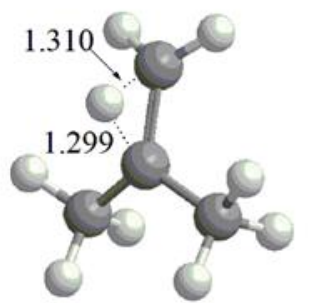

TSd

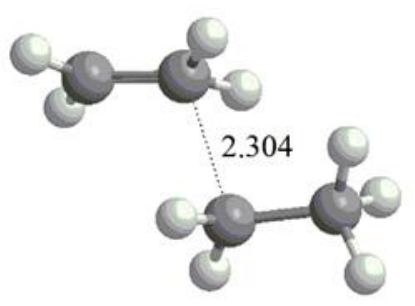

TSg

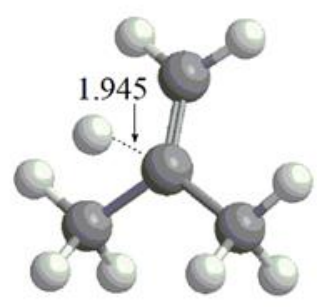

TSj

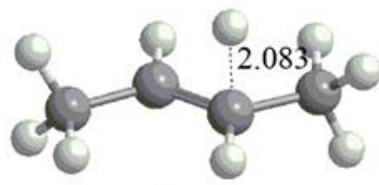

TSn
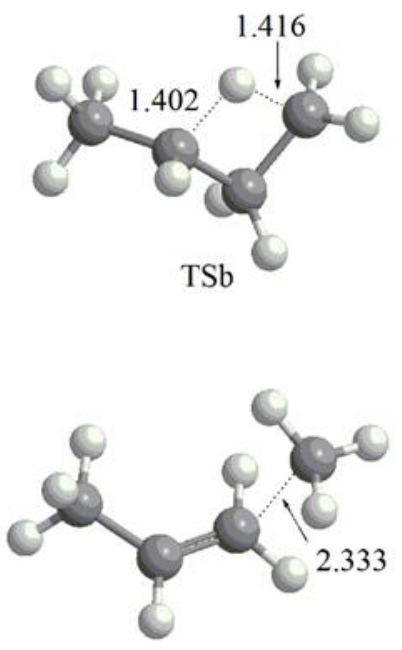

TSe

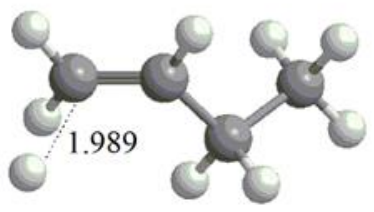

TSh

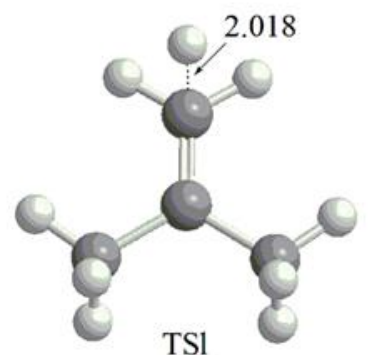

TSl
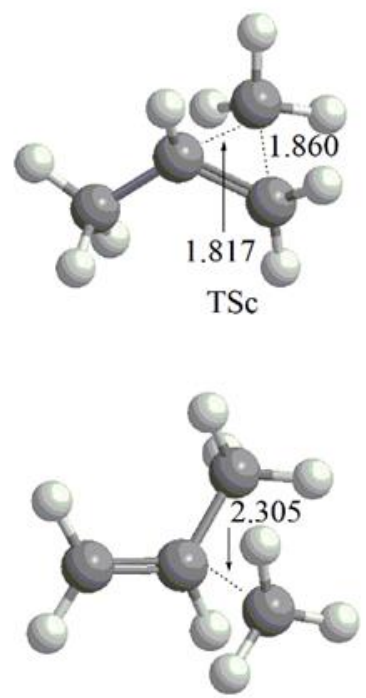

TSf

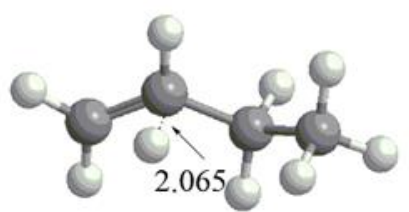

TSi
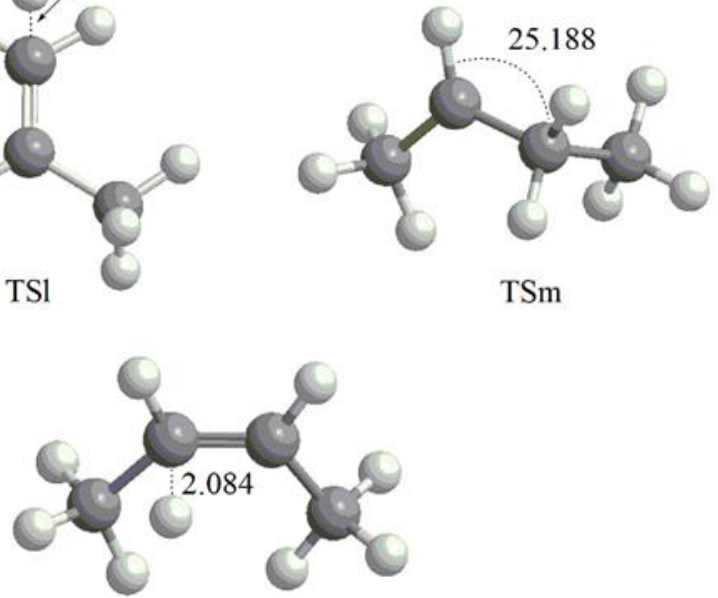

TSo 


\section{CHAPTER IV}

REACTION MECHANISM OF CH $\left(\mathrm{X}^{2} \Pi\right)+\mathrm{C}_{3} \mathrm{H}_{6} \mathrm{AND}_{4} \mathrm{H}_{7} \mathrm{PES}$ 
Introduction:

Methane is known to exist in appreciable amounts in interstellar clouds ${ }^{1}$ and in the atmosphere of Titan. $^{2}$ Upon methane fragmentation due to photon absorption or collision with energetic particles a complex chemical evolution is kick started in which longer carbon skeletons can be produced, or aromatic molecules like benzene can be formed, eventually leading to the formation of polycyclic aromatic hydrocarbons (PAH). ${ }^{1-4}$ Photochemical kinetic models of planetary atmospheres and chemical processes in interstellar clouds have tended to attribute the formation of benzene, the crucial PAH precursor, to ion-neutral reactions. ${ }^{5}$ However, using ab initio calculations and crossed molecular beam experiments, Jones et al. have recently shown that the reaction between the $\mathrm{C}_{2} \mathrm{H}$ radical and 1,3-butadiene could be a simple and important source of benzene in interstellar clouds. ${ }^{6}$ In addition, the model used in their study pointed to the potential importance of $\mathrm{CH}\left(\mathrm{X}^{2} \Pi\right)$ reactions within the neutral-neutral reaction network. ${ }^{6}$ In particular, the reaction between $\mathrm{CH}$ and propene was proposed as a possible major source of the 1,3-butadiene needed for the subsequent reaction with the $\mathrm{C}_{2} \mathrm{H}$ radical. ${ }^{6}$ The fact that low-temperature experimental rate constants for various $\mathrm{CH}$ reactions with hydrocarbons are typically in the order of $10^{-10} \mathrm{~cm}^{3}$ molecule ${ }^{-1} \mathrm{~s}^{-1}$ suggests that $\mathrm{CH}$ is indeed reactive enough for its reaction with propene to play an important role in both interstellar clouds and Titan's atmosphere. , $^{\text {, }}$

There has, to our knowledge, been two theoretical studies related to the $\mathrm{CH}+$ propene reaction: ${ }^{9,10}$ Miller located selected minima and saddle points on the $\mathrm{C}_{4} \mathrm{H}_{7}$ potential energy surface (PES), ${ }^{9}$ and later the PES relevant to the reaction was mapped out using G3B3 calculations. ${ }^{10}$ However, a comparison between the relative energies computed 
in the latter work and those based on experimental thermochemical tables, where available, shows a rather significant systematic deviation. ${ }^{10,11,12}$ Also, no attempt has been made so far to theoretically predict the product branching ratios in the reaction under different conditions, despite the fact that relative product yields were investigated in two recent experimental studies. ${ }^{13,14}$ Here we thus seek to re-examine the $\mathrm{C}_{4} \mathrm{H}_{7}$ PES relevant to the $\mathrm{CH}+$ propene reaction while extending the previous investigations to provide unimolecular rate constants and branching ratios, which will be compared to the experimental results of Loison and Bergeat ${ }^{13}$ and Trevitt et al. ${ }^{14}$

Methods:

All the relevant $\mathrm{C}_{4} \mathrm{H}_{7}$ minima and transition state structures were located using the GAUSSIAN 2009 software package. ${ }^{15}$ Minima as well as most transition states were optimized using the B3LYP hybrid density functional ${ }^{16,17}$ and the $6-311 \mathrm{G}(\mathrm{d}, \mathrm{p})$ basis set. $^{18}$ However, due to the fact that B3LYP calculations tend to underestimate barrier heights, certain transition states for $\mathrm{H}$ loss from $\mathrm{C}_{4} \mathrm{H}_{7}$ could not be found at the B3LYP/6-311G(d,p) level. In those cases, the transition state structures were searched for and located using the QCISD $^{19} / 6-311 G(d, p)$ method instead. Harmonic frequencies were calculated at the same level of theory as the corresponding optimized geometries to confirm that the structures were indeed minima or transition states; the frequencies were later used in rate constant calculations. To obtain a better description of the energetics the single-point energies of all optimized structures were refined at the $\operatorname{CCSD}(\mathrm{T})-\mathrm{F} 12 / \mathrm{CBS}$ level using the MOLPRO 2010 program package. ${ }^{20-23}$ The CBS limit was achieved using Dunning's correlationconsistent cc-pVnZ basis sets (cc-pVDZ, cc-pVTZ, and cc-pVQZ) and performing an exponential three-point infinite basis set extrapolation. ${ }^{24}$ 
Energy-dependent unimolecular rate constant calculations for the isomerization and dissociation reaction channels associated with the reaction of $\mathrm{CH}$ and propene were computed using Rice-Ramsperger-Kassel-Marcus (RRKM) ${ }^{25}$ theory under single-collision conditions at the zero-pressure limit relevant to crossed molecular beams experiments, interstellar clouds, and Titan's upper atmosphere. The RRKM expression for a rate constants $k(E)$ is

$$
k(E)=\frac{\sigma W^{\ddagger}\left(E-E^{\ddagger}\right)}{h \rho(E)}
$$

where $\sigma$ is the reaction path degeneracy, $h$ is Planck's constant, $\mathrm{W}^{\ddagger}\left(E-E^{\ddagger}\right)$ is the total number of states for the transition state and $\rho(E)$ represents the density of states of the energized reactants. $E$ was taken to be the sum of collisional and chemical activation energies of $\mathrm{CH}+$ propene under the assumption that a dominant fraction of the former is transferred into its internal normal modes. To obtain the zero-pressure limit product branching ratios we solved the first-order kinetic equations for unimolecular reactions formulated within the steady-state approximation, according to the kinetics scheme based on the ab initio PES diagram. In order to reproduce the conditions of the experiments, ${ }^{13,14}$ temperature and pressure dependent phenomenological rate coefficients and product branching ratios were additionally computed at $p=5$ Torr and $T=300 \mathrm{~K}$ by solving the one-dimensional master equation (ME) employing the PAPER software package. ${ }^{26,27}$ The density of states for all species were calculated within rigid-rotor harmonic oscillator approximation, except for soft normal modes corresponding to internal rotations, which were treated within a hindered rotor model ${ }^{28}$ Here, the potential of the hindered rotors were 
mapped out using partial geometry optimizations at various fixed torsional angles carried out at the B3LYP/6-311G(d,p) level. Lennard-Jones collision parameters were taken as $\left(\varepsilon / \mathrm{cm}^{-1}, \sigma / \AA\right)=(19.8,3.38)$ and $(44.2,3.43)$ for $\mathrm{N}_{2}$ bath gas and $\mathrm{C}_{3} \mathrm{H}_{6}$, respectively. ${ }^{29}$ Collisional energy transfer in the master equation was described using the "exponential down" model, ${ }^{30}$ with the temperature dependence of the range parameter $\alpha$ for the deactivating wing of the energy transfer expressed as $\alpha(T)=\alpha_{300}(T / 300 \mathrm{~K})^{n}$, with $n=0.86$ and $\alpha_{300}=228 \mathrm{~cm}^{-1} \cdot{ }^{29}$

Results and Discussion:

\section{Entrance Channels and depiction of PES}

Several bimolecular entrance reaction channels are available in principle to $\mathrm{CH}$ and propene, three of which are $\mathrm{H}$-abstractions and five of which are association reactions. All association reactions lead to wells on the $\mathrm{C}_{4} \mathrm{H}_{7}$ PES that lie well below the separated reactants (at least $82.4 \mathrm{kcal} / \mathrm{mol}$ below reactants); these associations include $\mathrm{CH}$ addition to propene's double bond, $\mathrm{CH}$ insertions into three nonequivalent $\mathrm{C}-\mathrm{H} \sigma$ bonds, and $\mathrm{CH}$ insertion into the $\mathrm{C}-\mathrm{C} \sigma$ bond. Here, because there is less steric hindrance due to a reduced number of hydrogens relative to the saturated systems of the previous chapters, the $\mathrm{C}-\mathrm{C} \sigma$ bond insertion path cannot be completely ruled out. Also, since $\mathrm{CH}$ is known to add to a double $\mathrm{C}=\mathrm{C}$ bond without a barrier ${ }^{31,32}$ and to insert into a $\mathrm{C}-\mathrm{H}$ bond via a barrierless path, both processes are able to account for the fast kinetics of $\mathrm{CH}$ reactions at low

temperatures $;^{7,8,13,33-36}$ to date, which of the entrance channels is more important and what the relative contribution of each is towards the overall reaction rate constant remains an unsolved problem. This problem can be addressed with calculations of the reaction 
dynamics, for instance, by running reactive trajectories initiated by the $\mathrm{CH}+\mathrm{C}_{3} \mathrm{H}_{6}$ encounters and counting the trajectories leading to the different addition or insertion $\mathrm{C}_{4} \mathrm{H}_{7}$ complexes. For example, our preliminary calculations using semiclassical trajectories to evaluate probabilities of different entrance channels of the $\mathrm{CH}+\mathrm{C}_{2} \mathrm{H}_{4}$ reaction thus far suggest that $\mathrm{CH}$ insertion into sp2 $\mathrm{C}-\mathrm{H}$ bonds is possible but much less probable than a double bond addition and gives an insertion/addition branching ratio close to 15:85. Transferring these qualitative results to propene, a $\mathrm{CH}_{3}$-substituted ethene molecule, we can anticipate that $\mathrm{CH}$ addition to propene's double bond should be the prevalent entrance channel, but insertions into all $\mathrm{C}-\mathrm{H}$ bonds in propene could be possible too. Hence, in this study our strategy will be to evaluate the overall $\mathrm{CH}+\mathrm{C}_{3} \mathrm{H}_{6}$ product branching ratios as functions of the initial $\mathrm{CH}$ addition or insertion complex and thus to predict the reaction outcome for each possible separate entrance channel. Then we can consider different weights for the entrance channels, recalculate the overall branching ratios and compare them with the available experimental data. This comparison would allow us to estimate the contributions of different barrierless entrance channels, at least qualitatively. To follow this approach, here we consider all possible $\mathrm{CH}$ addition and insertion $\mathrm{C}_{4} \mathrm{H}_{7}$ complexes, which is a larger set of the initial intermediates than that studied by Li et al. ${ }^{10}$ who included only the double bond addition and $\mathrm{sp}^{3} \mathrm{C}-\mathrm{H}$ bond insertions.

In the meantime, we ruled out the abstraction channels. The $\mathrm{H}$ abstractions generally result in products which are much less favorable in energy than the association products. For instance, $\mathrm{H}$ abstractions from $\mathrm{sp}^{2}$ carbons leading to vinylic radicals are endothermic. $\mathrm{H}$ abstraction from the $\mathrm{CH}_{3}$ group leads to $\mathrm{CH}_{2}\left({ }^{3} \mathrm{~B}_{1}\right)+\cdot \mathrm{CH}_{2} \mathrm{CHCH}_{2}$ (allyl radical), which are $12.7 \mathrm{kcal} / \mathrm{mol}$ exothermic due to the electron delocalization in allyl. 
However, we could not locate a transition state for this process. When $\mathrm{CH}$ approaches the methyl group in propene, an attractive minimal energy path leads to the insertion $\mathrm{C}_{4} \mathrm{H}_{7}$ complex residing in a deep potential well rather than to the abstraction $\mathrm{CH}_{2}\left({ }^{3} \mathrm{~B}_{1}\right)+$ $\cdot \mathrm{CH}_{2} \mathrm{CHCH}_{2}$ products.

In order to best depict and discuss the reaction mechanism we have chosen to break down the intermediates into three classes: 1) substituted three-membered ring structures first accessed via double bond addition, 2) open chain structures first accessed via insertion into one of propene's terminal $\mathrm{C}-\mathrm{H}$ bonds or into the single $\mathrm{C}-\mathrm{C}$ bond, and 3) branched structures first accessed via insertion into propene's sole middle C-H bond. In Figures 4.14.5 we illustrate each of these three portions of the $\mathrm{C}_{4} \mathrm{H}_{7}$ PES while also highlighting the structures that connect these different PES regions. Optimized geometries of various transition states are shown in Figures 4.6. The relative energies calculated here on the $\mathrm{C}_{4} \mathrm{H}_{7}$ PES are compared with experimental data obtained from enthalpies of formation of various species from Active Thermochemical Tables ${ }^{11}$ when available or NIST Chemistry WebBook $^{12}$ and are presented in Table 4.1. The results of this comparison suggest that the method used is accurate to within $1 \mathrm{kcal} / \mathrm{mol}$. Regarding the surface computed earlier at the G3B3 level, ${ }^{10}$ it appears that the energies reported in that work are uniformly shifted down by $12-13 \mathrm{kcal} / \mathrm{mol}$; in other words the differences in the energies amongst the intermediates and products seem to agree with our results, suggesting that the issue might stem from incorrect energy of one of the reactants, with the $\mathrm{CH}$ radical being a more probable culprit. 


\section{$\mathrm{CH}$ radical addition to the double bond}

Addition of $\mathrm{CH}$ to propene's double bond forms a methyl-substituted cyclopropyl radical labeled as $\mathrm{CH}_{3}-\mathrm{cCH} \cdot \mathrm{CHCH}_{2}$. Both a cis and a trans conformer exist. The $c i s-\mathrm{CH}_{3}-$ $\mathrm{cCH} \cdot \mathrm{CHCH}_{2}$ conformer is slightly more stable with a relative energy of $82.6 \mathrm{kcal} / \mathrm{mol}$ below the reactants, while trans $-\mathrm{CH}_{3}-\mathrm{cCH} \cdot \mathrm{CHCH}_{2}$ resides $82.4 \mathrm{kcal} / \mathrm{mol}$ lower in energy than the reactants. The barrier for cis-trans isomerization, via the transition state TSa, is only $1.6 \mathrm{kcal} / \mathrm{mol}$, so that the isomerization can be considered a very fast process even in interstellar clouds or Titan's atmosphere due to the large energy content in $\mathrm{CH}_{3}$ $\mathrm{cCH} \cdot \mathrm{CHCH}_{2}$ if it is produced in the $\mathrm{CH}+\mathrm{C}_{3} \mathrm{H}_{6}$ reaction. To each of these conformers two isomerization channels are available, one of which is a ring opening via a $\mathrm{C}-\mathrm{C}$ bond scission and the other of which is an $\mathrm{H}$ migration. Because the barrier towards ring opening is much lower than that for the $\mathrm{H}$ migration regardless of the conformation, we can expect the ring opening to be the dominant isomerization channel. The ring opening in cis- $\mathrm{CH}_{3}$ $\mathrm{cCH} \cdot \mathrm{CHCH}_{2}$ leads to the formation of trans $-\mathrm{CH}_{3} \mathrm{CHCH} \cdot \mathrm{CH}_{2}$, a chain species, while the analogous bond scission in trans $-\mathrm{CH}_{3}-\mathrm{cCH} \cdot \mathrm{CHCH}_{2}$ leads to the chain $\mathrm{cis}-\mathrm{CH}_{3} \mathrm{CHCH} \cdot \mathrm{CH}_{2}$ conformer. The barrier for the former process is $20.3 \mathrm{kcal} / \mathrm{mol}$, via TS1a, while the barrier for trans $-\mathrm{CH}_{3}-\mathrm{cCH} \cdot \mathrm{CHCH}_{2}$ ring opening is $21.4 \mathrm{kcal} / \mathrm{mol}$, via TS1b. Electronic delocalization over the $\mathrm{CHCHCH}_{2}$ skeleton of $\mathrm{CH}_{3} \mathrm{CHCH} \cdot \mathrm{CH}_{2}$ makes both of its conformers highly favorable in energy; trans $-\mathrm{CH}_{3} \mathrm{CHCH} \cdot \mathrm{CH}_{2}$, the most stable $\mathrm{C}_{4} \mathrm{H}_{7}$ species, has a relative energy of $112.4 \mathrm{kcal} / \mathrm{mol}$ below reactants, while $\mathrm{cis}-\mathrm{CH}_{3} \mathrm{CHCH} \cdot \mathrm{CH}_{2}$ resides $111.7 \mathrm{kcal} / \mathrm{mol}$ below reactants. Their interconversion, from trans to $c i s$ via TSb, requires a barrier of $14.7 \mathrm{kcal} / \mathrm{mol}$ to be overcome. 
The $\mathrm{H}$ migration available to $\mathrm{CH}_{3}-\mathrm{cCH} \cdot \mathrm{CHCH}_{2}$ depends on the conformation. Starting with trans- $\mathrm{CH}_{3}-\mathrm{cCH} \cdot \mathrm{CHCH}_{2}$ a migration between non-adjacent carbons can lead to the formation of $\mathrm{CH}_{2}-\mathrm{cCHCH}_{2} \mathrm{CH}_{2}, 92.6 \mathrm{kcal} / \mathrm{mol}$ below the reactants. The barrier associated with this migration is $37.1 \mathrm{kcal} / \mathrm{mol}$, via TS2. The migration available to cis$\mathrm{CH}_{3}-\mathrm{cCH} \cdot \mathrm{CHCH}_{2}$ is between adjacent carbons and leads to $\mathrm{CH}_{3}-\mathrm{c} \cdot \mathrm{CCH}_{2} \mathrm{CH}_{2}, 85.4$ $\mathrm{kcal} / \mathrm{mol}$ lower in energy than the reactants. The barrier for this migration, via TS3, is 43.1 $\mathrm{kcal} / \mathrm{mol}$. Both $\mathrm{H}$ migration products are more stable than their respective parent $\mathrm{CH}_{3}$ $\mathrm{cCH} \cdot \mathrm{CHCH}_{2}$. The migration barriers are at least $15 \mathrm{kcal} / \mathrm{mol}$ higher than those for ring openings, however, and are unlikely to compete. We therefore disregard a detailed discussion of the channels available after these migrations and mention only that their products may evolve similarly to the original $\mathrm{CH}_{3}-\mathrm{cCH} \cdot \mathrm{CHCH}_{2}$ structures, i.e., undergo either a ring opening or an $\mathrm{H}$ migration, with the ring opening again being much more favorable. The details associated with these channels are included in Figure 4.1.

The conformers of $\mathrm{CH}_{3}-\mathrm{cCH} \cdot \mathrm{CHCH}_{2}$ also have several exit channels available. A $\mathrm{CH}_{3}$-loss from trans- $\mathrm{CH}_{3}-\mathrm{cCH} \cdot \mathrm{CHCH}_{2}$ requires a barrier of $44.7 \mathrm{kcal} / \mathrm{mol}$, via TS20, and produces cyclopropene. It is also possible for trans $-\mathrm{CH}_{3}-\mathrm{cCH} \cdot \mathrm{CHCH}_{2}$ to emit $\mathrm{H}$ from two different locations. Upon $\mathrm{H}$ loss from the tert-carbon, $\mathrm{CH}_{3}-\mathrm{CCCHCH}_{2}$ is produced via TS2; the barrier for this process is $48.6 \mathrm{kcal} / \mathrm{mol}$. An $\mathrm{H}$ loss from the $\mathrm{CH}_{2}$ group can lead to $\mathrm{CH}_{3}$ cCHCHCH; the two $\mathrm{Hs}$ within this $\mathrm{CH}_{2}$ group are not equivalent. Consequently, one of the two transition states associated with $\mathrm{H}$ loss from this group, TS22a, originates from the trans isomer and its barrier is $49.8 \mathrm{kcal} / \mathrm{mol}$. On the other hand, TS22b corresponds to the $\mathrm{H}$ loss from $\mathrm{cis}-\mathrm{CH}_{3}-\mathrm{cCH} \cdot \mathrm{CHCH}_{2}$ and its barrier is $50.5 \mathrm{kcal} / \mathrm{mol}$. Once again, high barriers as compared to the simple ring openings via TS1a and TS1b suggest that the reacting 
behavior after $\mathrm{CH}$ addition will in fact depend on the portion of the PES containing chain $\mathrm{C}_{4} \mathrm{H}_{7}$ isomers, illustrated in detail in Figures 4.3 and 4.4.

\section{$\mathrm{CH}$ radical insertion into a terminal $\mathrm{C}-\mathrm{H}$ bond}

Two chain intermediates can be produced via insertion of $\mathrm{CH}$ into the terminal $\mathrm{C}$ $\mathrm{H}$ bonds of propene. The first, formed via insertion into propene's $\mathrm{CH}_{2}$ group, has two conformers, cis- $\mathrm{CH}_{3} \mathrm{CHCH} \cdot \mathrm{CH}_{2}$ and trans $-\mathrm{CH}_{3} \mathrm{CHCH} \cdot \mathrm{CH}_{2}$. These were introduced in the previous section. The second, formed via insertion into propene's $\mathrm{CH}_{3}$ group, is $\cdot \mathrm{CH}_{2} \mathrm{CH}_{2} \mathrm{CHCH}_{2}$. Although it has different conformations, we will consider only the most stable one since fast rotations around single bonds connect them via low barriers. The unpaired electron of $\cdot \mathrm{CH}_{2} \mathrm{CH}_{2} \mathrm{CHCH}_{2}$ cannot delocalize over multiple $\mathrm{C}$ - $\mathrm{C}$ bonds and hence this isomer, with a relative energy of $95.9 \mathrm{kcal} / \mathrm{mol}$ below the reactants, is less stable than $\mathrm{CH}_{3} \mathrm{CHCH} \cdot \mathrm{CH}_{2}$. The $\mathrm{CH}_{3} \mathrm{CHCH} \cdot \mathrm{CH}_{2}$ and $\cdot \mathrm{CH}_{2} \mathrm{CH}_{2} \mathrm{CHCH}_{2}$ intermediates are connected via $\mathrm{H}$ migrations; trans $-\mathrm{CH}_{3} \mathrm{CHCH} \cdot \mathrm{CH}_{2}$ and $\cdot \mathrm{CH}_{2} \mathrm{CH}_{2} \mathrm{CHCH}_{2}$ can interconvert via TS7a, while cis- $\mathrm{CH}_{3} \mathrm{CHCH} \cdot \mathrm{CH}_{2}$ and $\cdot \mathrm{CH}_{2} \mathrm{CH}_{2} \mathrm{CHCH}_{2}$ can interconvert via TS7b. The barrier from trans- $\mathrm{CH}_{3} \mathrm{CHCH} \cdot \mathrm{CH}_{2}$ to $\cdot \mathrm{CH}_{2} \mathrm{CH}_{2} \mathrm{CHCH}_{2}$ is $48.9 \mathrm{kcal} / \mathrm{mol}(32.4 \mathrm{kcal} / \mathrm{mol}$ in reverse) and that from $\mathrm{cis}-\mathrm{CH}_{3} \mathrm{CHCH} \cdot \mathrm{CH}_{2}$ to $\mathrm{CH}_{2} \mathrm{CH}_{2} \mathrm{CHCH}_{2}$ is $47.2 \mathrm{kcal} / \mathrm{mol}(31.4$ $\mathrm{kcal} / \mathrm{mol}$ ). The energetics of these channels are such that all other isomerizations available to $\mathrm{CH}_{3} \mathrm{CHCH} \cdot \mathrm{CH}_{2}$ are not likely to have significant contributions. This point will turn out to be important when we compare our results with experiment.

$\mathrm{CH}_{3} \mathrm{CHCH} \cdot \mathrm{CH}_{2}$ has several more $\mathrm{H}$ migration channels available. Three of them lead it to $\mathrm{CH}_{3} \mathrm{CH} \cdot \mathrm{CCH}_{3}$, which can exist in cis or trans conformations. Due to a loss of electronic delocalization both isomers are significantly less stable than $\mathrm{CH}_{3} \mathrm{CHCH} \cdot \mathrm{CH}_{2}$; trans $-\mathrm{CH}_{3} \mathrm{CH} \cdot \mathrm{CCH}_{3}$ has a relative energy of $91.8 \mathrm{kcal} / \mathrm{mol}$ below reactants while cis- 
$\mathrm{CH}_{3} \mathrm{CH} \cdot \mathrm{CCH}_{3}$ lies $91.0 \mathrm{kcal} / \mathrm{mol}$ below reactants. The barrier associated with their interconversion from trans to cis is $6.0 \mathrm{kcal} / \mathrm{mol}$, via TSc. The $\mathrm{H}$ migration which leads trans $-\mathrm{CH}_{3} \mathrm{CHCH} \cdot \mathrm{CH}_{2}$ to trans $-\mathrm{CH}_{3} \mathrm{CH} \cdot \mathrm{CCH}_{3}$ can be between adjacent or non-adjacent carbons. The non-adjacent migration has a lower barrier, $61.5 \mathrm{kcal} / \mathrm{mol}$, via TS8, while the $\mathrm{H}$ shift between adjacent centers has a barrier of $64.2 \mathrm{kcal} / \mathrm{mol}$, via TS9a. The conversion of cis- $\mathrm{CH}_{3} \mathrm{CHCH} \cdot \mathrm{CH}_{2}$ to $c i s-\mathrm{CH}_{3} \mathrm{CH} \cdot \mathrm{CCH}_{3}$, meanwhile, occurs by $\mathrm{H}$ migration between adjacent $\mathrm{C}$ atoms and exhibits a barrier of $64.0 \mathrm{kcal} / \mathrm{mol}$, via TS9b. Two other hydrogen migrations are available for the $\mathrm{CH}_{3} \mathrm{CHCH} \cdot \mathrm{CH}_{2}$ intermediate to form $\mathrm{CH}_{3} \mathrm{CH}_{2} \cdot \mathrm{CCH}_{2}$, which resides $89.5 \mathrm{kcal} / \mathrm{mol}$ below the reactants. Because low rotational barriers separate different conformations of $\mathrm{CH}_{3} \mathrm{CH}_{2} \cdot \mathrm{CCH}_{2}$, we disregard all of them but the most favorable one. The barrier for trans- $\mathrm{CH}_{3} \mathrm{CHCH} \cdot \mathrm{CH}_{2}$ to $\mathrm{CH}_{3} \mathrm{CH}_{2} \cdot \mathrm{CCH}_{2}$ is $64.8 \mathrm{kcal} / \mathrm{mol}$, via TS10a and the barrier from cis- $\mathrm{CH}_{3} \mathrm{CHCH} \cdot \mathrm{CH}_{2}$ is $63.1 \mathrm{kcal} / \mathrm{mol}$, via TS10b. The last $\mathrm{H}$ migration channel available for trans- $\mathrm{CH}_{3} \mathrm{CHCH} \cdot \mathrm{CH}_{2}$ leads to cis $-\mathrm{CH}_{3} \mathrm{CH}_{2} \mathrm{CH} \cdot \mathrm{CH}$. The relative energy for this intermediate is $86.1 \mathrm{kcal} / \mathrm{mol}$ below the reactants and the barrier associated with this channel is $64.0 \mathrm{kcal} / \mathrm{mol}$, via TS11. A trans conformer of this radical also exists and cis- $\mathrm{CH}_{3} \mathrm{CH}_{2} \mathrm{CH} \cdot \mathrm{CH}$ and trans $-\mathrm{CH}_{3} \mathrm{CH}_{2} \mathrm{CH} \cdot \mathrm{CH}$ can interconvert via TSd via a barrier of $4.0 \mathrm{kcal} / \mathrm{mol}$.

$\cdot \mathrm{CH}_{2} \mathrm{CH}_{2} \mathrm{CHCH}_{2}$ also has additional isomerization channels available, two of which are $\mathrm{H}$ migrations between non-adjacent carbons and one is $\mathrm{C}-\mathrm{C}$ bond formation leading to a four-membered ring. The first of the $\mathrm{H}$ migrations leads ${ }^{-} \mathrm{CH}_{2} \mathrm{CH}_{2} \mathrm{CHCH}_{2}$ to $\mathrm{CH}_{3} \mathrm{CH}_{2} \cdot \mathrm{CCH}_{2}$ and the barrier associated with this channel is $46.0 \mathrm{kcal} / \mathrm{mol}$, via TS12. The other $\mathrm{H}$ migration in turn leads to $c i s-\mathrm{CH}_{3} \mathrm{CH}_{2} \mathrm{CH} \cdot \mathrm{CH}$ and the barrier associated with this channel is $28.0 \mathrm{kcal} / \mathrm{mol}$, via TS13. $\mathrm{C}-\mathrm{C}$ bond formation between the terminal $\mathrm{CH}_{2}$ groups 
can lead to $\mathrm{c} \cdot \mathrm{CH}_{2} \mathrm{CH}_{2} \mathrm{CHCH}_{2}$ and a barrier of $33.8 \mathrm{kcal} / \mathrm{mol}$, via TS14, is associated with this channel. Notice that two of these barriers are quite low, at least as compared to most of the barriers for isomerizations of $\mathrm{CH}_{3} \mathrm{CHCH} \cdot \mathrm{CH}_{2}$. Based upon their energetics it is possible that these reaction channels could be viable so long as these are able to compete with the dissociation (exit) channels available to this intermediate.

The exit channels for the $\mathrm{CH}_{3} \mathrm{CHCH} \cdot \mathrm{CH}_{2}$ conformers are all simple $\mathrm{H}$ loss processes. $\mathrm{H}$ emission from the $\mathrm{CH}_{3}$ group of both cis and trans conformers leads to 1,3butadiene, whose conjugated $\pi$ bonds have a stabilizing effect making 1,3-butadiene $+\mathrm{H}$ the most stable products of the $\mathrm{CH}+\mathrm{C}_{3} \mathrm{H}_{6}$ reaction, $67.8 \mathrm{kcal} / \mathrm{mol}$ lower in energy than the reactants. The barrier associated with 1,3-butadiene formation is $47.0 \mathrm{kcal} / \mathrm{mol}$, via TS26a, from trans- $\mathrm{CH}_{3} \mathrm{CHCH} \cdot \mathrm{CH}_{2}$; and $49.1 \mathrm{kcal} / \mathrm{mol}$ starting with the cis conformer, via TS26b. An $\mathrm{H}$ loss from the $\mathrm{CH}$ group adjacent to $\mathrm{CH}_{2}$ produces 1,2-butadiene, with exothermicity of $55.8 \mathrm{kcal} / \mathrm{mol}$. The transition state corresponding to this process was found to be connected to the trans conformer and the barrier is $56.6 \mathrm{kcal} / \mathrm{mol}$, via TS27. - $\mathrm{CH}_{2} \mathrm{CH}_{2} \mathrm{CHCH}_{2}$ has two exit channels available. An $\mathrm{H}$ loss from the non-terminal $\mathrm{CH}_{2}$ group leads to 1,3-butadiene and the barrier associated with this channel is $33.2 \mathrm{kcal} / \mathrm{mol}$, via TS28. A C-C bond scission can also lead to the formation of ethene $+\mathrm{C}_{2} \mathrm{H}_{3}$, residing $62.7 \mathrm{kcal} / \mathrm{mol}$ below the reactants, via a barrier of $38.1 \mathrm{kcal} / \mathrm{mol}$ at TS29.

\section{$\mathrm{CH}$ radical insertion into the middle $\mathrm{C}-\mathrm{H}$ bond}

Insertion of the $\mathrm{CH}$ radical into propene's middle $\mathrm{C}-\mathrm{H}$ bond forms a branched intermediate denoted $\mathrm{CH}_{3} \mathrm{C}\left(\cdot \mathrm{CH}_{2}\right) \mathrm{CH}_{2}$. Electronic delocalization over the $\mathrm{CH}_{2} \mathrm{CCH}_{2}$ skeleton stabilizes the radical, and its relative energy is $111.9 \mathrm{kcal} / \mathrm{mol}$ below the reactants. Three isomerization channels are available to $\mathrm{CH}_{3} \mathrm{C}\left(\cdot \mathrm{CH}_{2}\right) \mathrm{CH}_{2}$. The first is ring closure via 
TS6 leading to $\mathrm{CH}_{3}-\mathrm{c} \cdot \mathrm{CCH}_{2} \mathrm{CH}_{2}$. The barrier associated with this channel is $49.4 \mathrm{kcal} / \mathrm{mol}$. Although this barrier is lower than those for the other two isomerization processes, this ring closure leads to a portion of the PES shown in Figure 4.1 which contains high barriers and is expected to represent a dead end on the surface. Therefore, in the low pressure and low temperature regime the ring closure is expected to have little net influence. The second available isomerization is an $\mathrm{H}$ shift between $\mathrm{CH}_{2}$ groups which leads to $\left(\mathrm{CH}_{3}\right)_{2} \mathrm{C} \cdot \mathrm{CH}$, another branched species. Loss of electronic delocalization destabilizes it relative to its parent intermediate and its relative energy is $89.1 \mathrm{kcal} / \mathrm{mol}$ below the reactants. The barrier for this $\mathrm{H}$ migration is $61.2 \mathrm{kcal} / \mathrm{mol}$, via TS16. The last available isomerization is $\mathrm{CH}_{3}$ migration from the tert-carbon to a $\mathrm{CH}_{2}$ group leading to $\mathrm{CH}_{3} \mathrm{CH}_{2} \cdot \mathrm{CCH}_{2}$. This is a chain intermediate that was discussed in the previous section. The barrier for this migration is $79.3 \mathrm{kcal} / \mathrm{mol}$, via TS17, and it should also be negligible.

The question as to whether $\mathrm{H}$ migration is a competitive reaction channel depends on the energetics of the exit channels available to $\mathrm{CH}_{3} \mathrm{C}\left(\cdot \mathrm{CH}_{2}\right) \mathrm{CH}_{2}$. In fact, only one exit channel relatively low in energy is found for this intermediate, producing $\mathrm{CH}_{2} \mathrm{CCH}_{2}+$ $\cdot \mathrm{CH}_{3}, 66.4 \mathrm{kcal} / \mathrm{mol}$ below the reactants, via TS26 and a barrier of $56.5 \mathrm{kcal} / \mathrm{mol}$. This barrier is $4.7 \mathrm{kcal} / \mathrm{mol}$ lower than that for the $\mathrm{H}$ migration and hence we may expect that the lower barrier, coupled with an unfavorable entropic factor for the H-migration, should make the allene production preferable. Other details regarding the reaction mechanism of $\left(\mathrm{CH}_{3}\right)_{2} \mathrm{C} \cdot \mathrm{CH}$ are illustrated in Figure 4.5.

\section{RRKM Rate Constants and Product Branching Ratios}

In Tables 4.2 and 4.3 we present the calculated rate constants for select unimolecular reactions on the $\mathrm{C}_{4} \mathrm{H}_{7} \mathrm{PES}$. The product branching ratios computed under the 
assumption that the $\mathrm{CH}$ reaction with propene begins with a single entrance channel are collected in Table 4.4 for different possible entrance channels; these have been calculated at the zero-pressure limit and zero collision energy, as well as at 5 Torr of pressure and $T$ $=300 \mathrm{~K}$. Notice first from Table 4.4 that the reaction outcome is rather insensitive as to whether $\mathrm{CH}_{3}-\mathrm{cCH} \cdot \mathrm{CHCH}_{2}$ or $\mathrm{CH}_{3} \mathrm{CHCH} \cdot \mathrm{CH}_{2}$ is the initial $\mathrm{C}_{4} \mathrm{H}_{7}$ intermediate formed, reflecting the fact that no other process available to $\mathrm{CH}_{3}-\mathrm{cCH} \cdot \mathrm{CHCH}_{2}$ can compete with ring opening, as was expected from the energetics of the PES, and is confirmed by the rate constants in Tables 4.2 and 4.3. Therefore, at least at low pressures, the initial $\mathrm{CH}$ double bond addition channel merges with the channels initiated by $\mathrm{CH}$ insertions into either a terminal $\mathrm{sp}^{2} \mathrm{C}-\mathrm{H}$ bond or $\mathrm{C}-\mathrm{C}$ bond. Then, 1,3-butadiene is expected to be the dominant product with a $\sim 85 \%$ relative yield. Notice also that although a minor process, the isomerization of $\mathrm{CH}_{3} \mathrm{CHCH} \cdot \mathrm{CH}_{2}$ to $\mathrm{CH}_{2} \mathrm{CH}_{2} \mathrm{CHCH}_{2}$ is not negligible and has to occur in order to account for the calculated $\sim 11 \%$ relative yield of ethene $+\mathrm{C}_{2} \mathrm{H}_{3}$ radical. The fact that this isomerization is faster than the $\mathrm{H}$ loss from $\mathrm{CH}_{3} \mathrm{CHCH} \cdot \mathrm{CH}_{2}$ leading to 1 ,2butadiene reflects its much lower barrier of $\sim 12 \mathrm{kcal} / \mathrm{mol}$; the fact that the middle $\mathrm{C}-\mathrm{C}$ bond cleavage in $\mathrm{CH}_{2} \mathrm{CH}_{2} \mathrm{CHCH}_{2}$ is preferential with respect to the $\mathrm{H}$ loss leading to 1,3 butadiene despite its higher barrier of $\sim 5 \mathrm{kcal} / \mathrm{mol}$ is due to the entropic factor; the $\mathrm{C}-\mathrm{C}$ cleavage transition state, TS29, is looser than TS28. Thus when the situation is reversed such that the initial $\mathrm{CH}$ insertion occurs into one of the $\mathrm{sp}^{3} \mathrm{C}-\mathrm{H}$ bonds the production of ethene $+\mathrm{C}_{2} \mathrm{H}_{3}$ radical becomes preferable, $\sim 67 \%$, which is more than double the relative yield of 1,3-butadiene, $\sim 30 \%$. Here, the product branching ratio depends on the competition between $\mathrm{C}-\mathrm{C}$ scission and $\mathrm{C}-\mathrm{H}$ scission and also between $\mathrm{C}-\mathrm{C}$ scission and $\mathrm{H}$ migration from $\cdot \mathrm{CH}_{2} \mathrm{CH}_{2} \mathrm{CHCH}_{2}$ to $\mathrm{CH}_{3} \mathrm{CHCH} \cdot \mathrm{CH}_{2}$ followed by $\mathrm{C}-\mathrm{H}$ bond scission from 
the $\mathrm{CH}_{3}$ group. For the last possible entrance channel, meanwhile, which is $\mathrm{CH}$ insertion into the middle $\mathrm{sp}^{2} \mathrm{C}-\mathrm{H}$ bond of propene, the production of allene $+\mathrm{CH}_{3}$ radical is predicted to be the almost exclusive reaction channel. Here the isomerization channels cannot compete with the immediate cleavage of the single $\mathrm{C}-\mathrm{C}$ bond in the initial $\mathrm{CH}_{3} \mathrm{C}\left(\cdot \mathrm{CH}_{2}\right) \mathrm{CH}_{2}$ intermediate; $\mathrm{CH}$ insertion into the middle $\mathrm{sp}^{2} \mathrm{C}-\mathrm{H}$ bond of propene is in a sense "disconnected" from the rest of the PES which the other entrance channels can access.

There have been two experimental measurements of product branching ratios reported for the reaction between $\mathrm{CH}$ and propene. While Loison and Bergeat found that $78 \pm 10 \%$ of the products formed are $\mathrm{C}_{4} \mathrm{H}_{6}$ species, ${ }^{13}$ Trevitt et al. observed exclusive $\mathrm{C}_{4} \mathrm{H}_{6}$ formation. ${ }^{14}$ In order for us to provide a better comparison with these experiments, we recomputed the branching ratios at 5 Torr and $300 \mathrm{~K}$ using the RRKM-ME approach. The results, it turns out, are similar to those at the zero-pressure limit except that under the experimental conditions $\sim 2 \%$ of 1,3-butadiene is redistributed to 1,2-butadiene. Our calculated maximum value of $\sim 4 \%$ for the 1,2-butadiene production after initial $\mathrm{CH}$ addition to the double bond or insertions into either a terminal $\mathrm{sp}^{2} \mathrm{C}-\mathrm{H}$ bond or the $\mathrm{C}-\mathrm{C}$ bond are thus much lower than the $25 \pm 5 \%$ for the 1,2-butadiene production reported by Trevitt et al. ${ }^{14}$ Our calculations, in addition, do not predict the formation of 1-butyne, whose branching ratio was measured to be $12 \pm 3 \% .{ }^{14}$ We have attempted to understand these disagreements in terms of our computed PES and rate constants. 1,2-butadiene formation is possible through the following three precursor molecules: $\mathrm{CH}_{3} \mathrm{CHCH} \cdot \mathrm{CH}_{2}$, $\mathrm{CH}_{3} \mathrm{CH} \cdot \mathrm{CCH}_{3}$, and $\mathrm{CH}_{3} \mathrm{CH}_{2} \cdot \mathrm{CCH}_{2}$. $\mathrm{H}$ elimination from $\mathrm{CH}_{3} \mathrm{CHCH}^{\circ} \mathrm{CH}_{2}$ has been discussed above; there, the ratio of the rate constants to form 1,3-butadiene and 1,2butadiene is large, $\sim 24$. On the other hand, 1,2-butadiene production from $\mathrm{CH}_{3} \mathrm{CH} \cdot \mathrm{CCH}_{3}$, 
and $\mathrm{CH}_{3} \mathrm{CH}_{2} \cdot \mathrm{CCH}_{2}$ as precursors should not be significant since their formation via the isomerization of $\mathrm{CH}_{3} \mathrm{CHCH} \cdot \mathrm{CH}_{2}$ and $\cdot \mathrm{CH}_{2} \mathrm{CH}_{2} \mathrm{CHCH}_{2}$ is not expected to be competitive with their exit channels, according to the respective rate constants. Thus, all but a negligible amount of the 1,2-butadiene predicted to be formed is via direct $\mathrm{H}$ loss in $\mathrm{CH}_{3} \mathrm{CHCH} \cdot \mathrm{CH}_{2}$ and not from the other two precursors. Deviation from a statistical behavior, however, would be expected to increase the formation of the $\mathrm{H}$ elimination products and, in particular, 1,2-butadiene: If we begin with $\mathrm{CH}$ addition to the double bond, subsequent ring opening forms the $\mathrm{CH}_{3} \mathrm{CHCH} \cdot \mathrm{CH}_{2}$ isomer in which 1) immediate $\mathrm{C}-\mathrm{H}$ bond cleavage should be preferable over 1,2-H shift to form $\cdot \mathrm{CH}_{2} \mathrm{CH}_{2} \mathrm{CHCH}_{2}$ since the latter requires a more complete energy randomization; 2) $\mathrm{H}$ loss from the former $\mathrm{CH}$ reactant to give 1,2butadiene should be favored over $\mathrm{H}$ loss to form 1,3-butadiene since in the latter energy must flow across three bonds in order to activate the $\mathrm{C}-\mathrm{H}$ bond in the terminal $\mathrm{CH}_{3}$ group. We may thus expect dynamical factors to somewhat increase the production of 1,2butadiene. By itself, however, this is not likely to fully reconcile the theoretical and experimental relative yields of 1,2-butadiene. Trevitt et al. mentioned that some non- $\mathrm{C}_{4} \mathrm{H}_{6}$ species might have been formed but distributed across different mass channels being below the experimental detection limit of $5 \% .{ }^{14}$ Should this be the case, the reported experimental branching ratios of $\mathrm{C}_{4} \mathrm{H}_{6}$ species, including that of 1,2-butadiene, would be reduced. Based on our calculations, ethene $+\mathrm{C}_{2} \mathrm{H}_{3}$ radical and allene $+\mathrm{CH}_{3}$ radical are the most probable channels which might have been below the detection limit in the experiment. In fact, it is possible to find weights for the entrance channels which, if coupled with a small but reasonable deviation from statistical reaction behavior, could bring the branching ratios of ethene $+\mathrm{C}_{2} \mathrm{H}_{3}$ radical and allene $+\mathrm{CH}_{3}$ radical close to the detection limit. This could 
better reconcile the theoretical and experimental predictions for 1,2-butadiene. For example, if we assume the contributions of the entrance channels to be $93 \%$ for the double bond addition/terminal $\mathrm{sp}^{2}$ bond insertion/C-C insertion, close to $0 \%$ for the terminal $\mathrm{sp}^{3}$ insertion, and $7 \%$ for the middle $\mathrm{sp}^{2}$ bond insertion, then the branching ratios of the ethene $+\mathrm{C}_{2} \mathrm{H}_{3}$ radical and allene $+\mathrm{CH}_{3}$ radical channels would take the respective values of $10.5 \%$ and $7 \%$, before accounting for dynamical factors. Also, incomplete randomization of the chemical activation energy in $\mathrm{CH}_{3}-\mathrm{cCH} \cdot \mathrm{CHCH}_{2}$, the very first cyclic intermediate formed as a result of the $\mathrm{CH}$ double addition, may somewhat increase the yield of cyclopropene + $\mathrm{CH}_{3}$ above the statistical value of $\sim 1 \%$ via a direct cleavage of the weakest bond in this complex.

Two precursor molecules are possible for 1-butyne, $\mathrm{CH}_{3} \mathrm{CH}_{2} \cdot \mathrm{CCH}_{2}$ and $\mathrm{CH}_{3} \mathrm{CH}_{2} \mathrm{CH} \cdot \mathrm{CH}$. The former is also a precursor for 1,2-butadiene formation and was discussed above; no reasonable energetic path exists for its formation and it is not expected to be sampled by the system. The latter, however, is accessible via a channel with favorable energetics. In particular, isomerization of $\cdot \mathrm{CH}_{2} \mathrm{CH}_{2} \mathrm{CHCH}_{2}$ can lead to cis- $\mathrm{CH}_{3} \mathrm{CH}_{2} \mathrm{CH} \cdot \mathrm{CH}$ and the barrier associated with this process is low, $28.0 \mathrm{kcal} / \mathrm{mol}$. Next, the cis$\mathrm{CH}_{3} \mathrm{CH}_{2} \mathrm{CH} \cdot \mathrm{CH}$ intermediate could undergo an $\mathrm{H}$ loss via a $36.3 \mathrm{kcal} / \mathrm{mol}$ barrier to form 1-butyne; however, the rate constant for the initial isomerization is $5.21 \times 10^{9} \mathrm{~s}^{-1}$, a value which is much lower than those for the two exit channels available to ${ }^{-} \mathrm{CH}_{2} \mathrm{CH}_{2} \mathrm{CHCH}_{2}$ to form ethene $+\mathrm{C}_{2} \mathrm{H}_{3}$ radical and 1,3-butadiene $\left(1.22 \times 10^{11}\right.$ and $2.95 \times 10^{10} \mathrm{~s}^{-1}$, respectively). The rate constants for the $\mathrm{C}-\mathrm{C}$ and $\mathrm{C}-\mathrm{H}$ scission steps are higher than that for the $\mathrm{H}$ migration because the respective transitions states TS29 and TS28 are much looser than TS13 leading to cis- $\mathrm{CH}_{3} \mathrm{CH}_{2} \mathrm{CH} \cdot \mathrm{CH}$. Therefore, the entropic factor hinders the production 
of the cis $-\mathrm{CH}_{3} \mathrm{CH}_{2} \mathrm{CH} \cdot \mathrm{CH}$ precursor and prevents the formation of 1-butyne. In this case, dynamical factors cannot explain the observation of a significant yield of 1-butyne as the formation of its precursor is a complex multi-step process. Here, an $\mathrm{H}$ assisted isomerization of 1,2-butadiene through a secondary reaction could be responsible; the two isomers are close in energy.

While it is possible to reconcile our results with those of Trevitt et al., ${ }^{14}$ our original computed $\mathrm{C}_{4} \mathrm{H}_{6}$ branching ratio agrees quite well with those of Loison and Bergeat. ${ }^{13}$ Indeed, if we transfer the results of the quasiclassical trajectories calculations for $\mathrm{CH}+$ ethene and: 1) assign a weight of 0.80 to the double bond addition; 2) assign a weight for the remaining entrance channels based upon the number of bonds available for the particular insertion, we would obtain a $\mathrm{C}_{4} \mathrm{H}_{6}$ branching ratio of $77 \%$, close to Loison and Bergeat's experimental value of $78 \pm 10 \%{ }^{13}$. Interestingly, in the isotope-labeled CD + propene experiment of Trevitt et al., it was determined that the D elimination channel leads to almost exclusive 1,2-butadiene $(97 \pm 20 \%)$ and that the $\mathrm{H}$ elimination gives both deuterated 1,3-butadiene $(89 \pm 18 \%)$ and 1-butyne $(11 \pm 2 \%) ;{ }^{14}$ these results strongly suggest double bond addition is the dominant entrance channel with $\mathrm{CH}_{3} \mathrm{CHCD} \cdot \mathrm{CH}_{2}$, formed by ring opening of $\mathrm{CH}_{3}-\mathrm{cCH} \cdot \mathrm{CDCH}_{2}$, being the decomposing complex. Even if, however, we assume that the sole entrance channel is the double bond addition, the calculated $\mathrm{C}_{4} \mathrm{H}_{6}$ relative yield, $87 \%$, would still be within the error bars of Loison and Bergeat's results. ${ }^{13}$

\section{References:}

1.Yeghikyan, A. G.; Viti, S.; Williams, D. A. The Formation of Heavy Hydrocarbons in Molecular Clouds. Mon. Not. R. Astron. Soc. 2001, 326, 313-316.

2.Raulin, F.; Brasse, C.; Poch O.; Coll, P. Prebiotic-Like Chemistry on Titan. Chem. Soc. Rev. 2012, 41, 5380-5393. 
3.Bennett, C. J.; Jamieson, C. S.; Osamura, Y.; Kaiser, R. I. Laboratory Studies on the Irradiation of Methane in Interstellar, Cometary, and Solar System Ices. Astrophys. J. 2006, $653,792-811$.

4.Waite Jr., J. H.; Young, D. T.; Cravens, T. E.; Coates, A. J.; Crary, F. J.; Magee, B.; Westlake, J. The Process of Tholin Formation in Titan's Upper Atmosphere. Science 2007, $316,870-875$.

5.Woods, P. M.; Millar, T. J.; Zijlstra, A. A.; Herbst, E. The Synthesis of Benzene in the Proto-Planetary Nebula CRL 618. Astrophys. J. Lett. 2002, 574, L167-L170.

6.Jones, B. M.; Zhang, F.; Kaiser, R. I.; Jamal, A.; Mebel, A. M.; Cordiner, M. A.; Charnley, S. B. Formation of Benzene in the Interstellar Medium. Proc. Nat. Acad. Sci. 2011, 108, 452-457.

7.Canosa, A.; Sims, I. R.; Travers, D.; Smith, I. W. M.; Rowe, B. R. Astron. Astrophys. 1997, 323, 644-651.

8.Daugey, N.; Caubet, P.; Retail, B.; Costes, M.; Bergeat A.; Dorthe, G. Kinetic Measurements on Methylidyne Radical Reactions with Several Hydrocarbons at Low Temperatures. Phys. Chem. Chem. Phys. 2005, 7, 2921-2927.

9.Miller, J. L. Theoretical Study of the Straight-Chain C4H7 Radical Isomers and Their Dissociation and Isomerization Transition States J. Phys. Chem. A 2004, 108, 2268-2277.

10.Li, Y.; Liu, H.; Zhou, Z.; Huang, X.; Sun, C. Reaction Mechanism of CH $+\mathrm{C}_{3} \mathrm{H}_{6}$ : A Theoretical Study. J. Phys. Chem. A 2010, 114, 9496-9506.

11.Ruscic, B. Updated Active Thermochemical Tables (ATcT) values based on ver. 1.112 of the Thermochemical Network (2013); available at ATcT.anl.gov.

12.NIST Chemistry WebBook, NIST Standard Reference Database Number 69; http://webbook.nist.gov/chemistry/.

13.Loison, J. C.; Bergeat, A. Rate Constants and the $\mathrm{H}$ Atom Branching Ratio of the Reactions of the Methylidyne $\mathrm{CH}\left(\mathrm{X}^{2} \Pi\right)$ radical with $\mathrm{C}_{2} \mathrm{H}_{2}, \mathrm{C}_{2} \mathrm{H}_{4}, \mathrm{C}_{3} \mathrm{H}_{4}$ (Methylacetylene and Allene), $\mathrm{C}_{3} \mathrm{H}_{6}$ (Propene) and $\mathrm{C}_{4} \mathrm{H}_{8}$ (trans-Butene). Phys. Chem. Chem. Phys. 2009, 11, 655-664.

14.Trevitt, A. J.; Prendergast, M. B.; Goulay, F.; Savee, J. D.; Osborn, D. L.; Taatjes, C. A.; Leone, S. R.; Product Branching Fractions of the $\mathrm{CH}+$ Propene Reaction from Synchrotron Photoionization Mass Spectrometry. J. Phys. Chem. A, 2013, 117, 6450-6457.

15.Frisch, M. J. et al. Gaussian 09, Revision B.01 (Gaussian, Inc., Wallingford CT, 2010). 
16.Becke, A. D. Density-functional thermochemistry. III. The role of exact exchange. $J$. Chem. Phys. 1993, 98, 5648-5652.

17.Lee, C.; Yang W.; Parr, R. G. Development of the Colle-Salvetti Correlation-Energy Formula into a Functional of the Electron Density. Phys. Rev. B 1988, 37, 785-789.

18.Krishnan, R.; Frisch, M.; Pople, J. A. Contribution of Triple Substitutions to the Electron Correlation Energy in Fourth Order Perturbation Theory J. Chem. Phys. 1980, 72, 4244-4245.

19.Pople, J. A. ; Head-Gordon, M.; Raghavachari, K. Quadratic configuration interaction. A general technique for determining electron correlation energies. J. Chem. Phys. 1987, 87, 5968-5975.

20.Purvis, G. D.; Bartlett, R. J. A Full Coupled-Cluster Singles and Doubles Model: The Inclusion of Disconnected Triples. J. Chem. Phys. 1982, 76, 1910-1918.

21.Knizia, G.; Adler, T. B.; Werner, H.-J. Simplified CCSD(T)-F12 methods: theory and benchmarks. J. Chem. Phys. 2009, 130, 054104.

22.Peterson, K. A.; Dunning, T. H. Intrinsic Errors in Several ab Initio Methods: The Dissociation Energy of $\mathrm{N}_{2}$. J. Phys. Chem. 1995, 99, 3898-3901.

23.Werner, H-J; Knowles, P. J.; Kinizia, G.; Manby, F. R.; Schutz, M. MOLPRO, version 2010.1, a package of ab initio programs, 2010.

24.Dunning, T. H. Gaussian Basis Sets for Use in Correlated Molecular Calculations. I. The Atoms Boron through Neon and Hydrogen. J. Chem. Phys. 1989, 90, 1007-1023.

25.Eyring, H.; Lin, S. H.; Lin, S. M. Basic Chemical Kinetics; Wiley: New York, 1980.

26.Georgievskii, Y.; Miller, J. A.; Burke, M. P.; Klippenstein, S. J. Reformulation and Solution of the Master Equation for Multiple-Well Chemical Reactions. J. Phys. Chem. A 2013, 117, 12146-12154.

27.Y. Georgievskii, A.W. Jasper, J. Zador, J.A. Miller, M. P. Burke, C.F. Goldsmith, S.J. Klippenstein, PAPER v1 (2014).

28.J.I. Steinfeld, J.S. Francisco, W.L. Hase, Chemical Kinetics and Dynamics, PrenticeHall, New Jersey (1999).

29.Jasper, A. W.; Miller, J. A. Lennard-Jones Parameters for Combustion and Chemical Kinetics Modeling from Full-Dimensional Intermolecular Potentials. Combust. Flame 2014, 161, 101-110. 
30.Troe, J. Theory of Thermal Unimolecular Reactions at Low Pressures. 1. Solutions of the Master Equation. J. Chem. Phys. 1977, 66, 4745-4757.

31.Goulay, F.; Trevitt, A. J.; Meloni, G.; Selby, T. M.; Osborn, D. L.; Taatjes, C. A.; Vereecken, L.; Leone, S. R. Cyclic Versus Linear Isomers Produced by Reaction of the Methylidyne Radical (CH) with Small Unsaturated Hydrocarbons. J. Am. Chem. Soc. 2009, 131, 993-1005.

32.Zhang, F.; Maksyutenko, P.; Kaiser, R. I. Chemical dynamics of the $\mathrm{CH}\left(\mathrm{X}^{2} \Pi\right)+$ $\mathrm{C}_{2} \mathrm{H}_{4}\left(\mathrm{X}^{1} \mathrm{~A}_{1 \mathrm{~g}}\right), \mathrm{CH}\left(\mathrm{X}^{2} \Pi\right)+\mathrm{C}_{2} \mathrm{D}_{4}\left(\mathrm{X}^{1} \mathrm{~A}_{1 \mathrm{~g}}\right)$, and $\mathrm{CD}\left(\mathrm{X}^{2} \Pi\right)+\mathrm{C}_{2} \mathrm{H}_{4}\left(\mathrm{X}^{1} \mathrm{~A}_{1 \mathrm{~g}}\right)$ reactions studied under single collision conditions. Phys. Chem. Chem. Phys. 2012, 14, 529-537.

33.Fleurat-Lessard, P.; Rayez, J. C.; Bergeat, A.; Loison, A. C. Reaction of Methylidyne $\mathrm{CH}\left(\mathrm{X}^{2} \Pi\right)$ Radical with $\mathrm{CH}_{4}$ and $\mathrm{H}_{2} \mathrm{~S}$ : Overall Rate Constant and Absolute Atomic Hydrogen Production. Chem. Phys. 2007, 279, 87-99.

34.Loison, J. C.; Bergeat, A.; Caralp, F.; Hannachi, Y. Rate Constants and H Atom Branching Ratios of the Gas-Phase Reactions of Methylidyne $\mathrm{CH}\left(\mathrm{X}^{2} \Pi\right)$ Radical with a Series of Alkanes. J. Phys. Chem. A 2006, 110, 13500-13506.

35.Mckee, K.; Blitz, M. A.; Hughes, K. J.; Pilling, M. J.; Qian, H. B.; Taylor, A.; Seakins, P. W. H Atom Branching Ratios from the Reactions of $\mathrm{CH}$ with $\mathrm{C}_{2} \mathrm{H}_{2}, \mathrm{C}_{2} \mathrm{H}_{4}, \mathrm{C}_{2} \mathrm{H}_{6}$, and neo- $\mathrm{C}_{5} \mathrm{H}_{12}$ at Room Temperature and 25 Torr. J. Phys. Chem. A 2003, 107, 5710.

36.Galland, N.; Caralp, F.; Hannachi, Y.; Bergeat, A.; Loison, J. C. Experimental and Theoretical Studies of the Methylidyne $\mathrm{CH}\left(\mathrm{X}^{2} \Pi\right)$ Radical Reaction with Ethane $\left(\mathrm{C}_{2} \mathrm{H}_{6}\right)$ : Overall Rate Constant and Product Channels. J. Phys. Chem. A 2003, 107, 5419-5426. 
Table 4.1: Relative Energies for Select $\mathrm{C}_{4} \mathrm{H}_{7}$ Species. It compares the calculated relative energies of select products at the CCSD(T)-F12/CBS//B3LYP/6-311G(d,p) + ZPE(B3LYP/6-311G(d,p)) level with reference values from thermochemical active tables. Relative energies computed at the G3B3//B3LYP/6-311G(d,p) level (Ref. 10) are also included. All values are in $\mathrm{kcal} / \mathrm{mol}$.

\begin{tabular}{|c|c|c|c|c|}
\hline Products & $\Delta \mathrm{E}_{\text {theo }}$ & $\Delta \mathrm{E}_{\text {exp }}$ & $\begin{array}{c}\text { Absolute } \\
\text { deviation }\end{array}$ & $\Delta \mathrm{E}_{\text {theo }}(\mathrm{G} 3 \mathrm{~B} 3)$ \\
\hline $\mathrm{c} \mathrm{CHCHCH}_{2}+\cdot \mathrm{CH}_{3}$ & -44.1 & $-44.3^{\mathrm{a}}$ & 0.2 & -57.1 \\
\hline $\mathrm{CH}_{2} \mathrm{CH}_{2}+\cdot \mathrm{CHCH}_{2}$ & -62.7 & $-63.5^{\mathrm{a}}$ & 0.8 & -76.9 \\
\hline $\mathrm{CHCH} \cdot \mathrm{CH}_{2} \mathrm{CH}_{3}$ & -62.9 & $-64.1^{\mathrm{a}}$ & 1.2 & -76.5 \\
\hline $\mathrm{CH}_{2} \mathrm{CCH}_{2}+\cdot \mathrm{CH}_{3}$ & -66.4 & $-67.1^{\mathrm{a}}$ & 0.7 & -80.8 \\
\hline $\mathrm{CH}_{3} \mathrm{CCH}+\cdot \mathrm{CH}_{3}$ & -67.4 & $-68.2^{\mathrm{a}}$ & 0.8 & -81.5 \\
\hline $\begin{array}{c}\text { trans }-\mathrm{CH}_{2} \mathrm{CHCHCH} \\
\cdot\end{array}$ & -67.8 & $-68.8^{\mathrm{b}}$ & 1.0 & -82.0 \\
\hline $\mathrm{CH}_{3} \mathrm{CHCCH}_{2}+\cdot \mathrm{H}$ & -55.8 & $-56.0^{\mathrm{b}}$ & 0.2 & -70.3 \\
\hline $\mathrm{CH}_{3} \mathrm{CCCH}_{3}+\cdot \mathrm{H}$ & -59.7 & $-60.6^{\mathrm{a}}$ & 0.9 & -74.2 \\
\hline $\mathrm{CH}_{3} \mathrm{CH}_{2} \mathrm{CCH}+\cdot \mathrm{H}$ & -54.6 & $-55.7^{\mathrm{a}}$ & 1.1 & -69.0 \\
\hline
\end{tabular}

${ }^{\mathrm{a}}$ Computed from $0 \mathrm{~K}$ enthalpies of formation from ref $11 .{ }^{\mathrm{b}} \mathrm{Computed}$ from room temperature enthalpies of formation from ref 12. 
Table 4.2: Energy-Dependent Isomerization Rate Coefficients, $k$. These were for select isomerization reactions and calculated at zero collision energy. The values of $k$ are in units of $\mathrm{s}^{-1}$. Reactions associated with portions of the $\mathrm{C}_{4} \mathrm{H}_{7}$ PES which are, for all practical purposes, not sampled by the system are not included.

\begin{tabular}{|c|c|c|}
\hline Reaction & Transition state & $k$ \\
\hline $\begin{array}{c}\text { cis- } \mathrm{CH}_{3}-\mathrm{cCH} \cdot \mathrm{CHCH}_{2} \text { to trans- } \mathrm{CH}_{3-} \\
\mathrm{cCH} \cdot \mathrm{CHCH}_{2}\end{array}$ & $\mathrm{TSa}$ & $1.05 \times 10^{13}$ \\
\hline $\begin{array}{c}\text { trans- } \mathrm{CH}_{3}-\mathrm{cCH} \cdot \mathrm{CHCH}_{2} \text { to } \mathrm{cis}-\mathrm{CH}_{3-} \\
\mathrm{cCH} \cdot \mathrm{CHCH}_{2}\end{array}$ & $\mathrm{TSa}$ & $1.16 \times 10^{13}$ \\
\hline $\begin{array}{c}\text { cis- } \mathrm{CH}_{3}-\mathrm{cCH} \cdot \mathrm{CHCH}_{2} \text { to trans- } \\
\mathrm{CH}_{3} \mathrm{CHCH} \cdot \mathrm{CH}_{2}\end{array}$ & TS1a & $6.59 \times 10^{11}$ \\
\hline $\begin{array}{c}\text { trans- } \mathrm{CH}_{3} \mathrm{CHCH} \cdot \mathrm{CH}_{2} \text { to } \text { cis- } \mathrm{CH}_{3-} \\
\mathrm{cCH} \cdot \mathrm{CHCH}_{2}\end{array}$ & TS1a & $8.61 \times 10^{8}$ \\
\hline $\begin{array}{c}\text { trans- } \mathrm{CH}_{3}-\mathrm{cCH} \cdot \mathrm{CHCH}_{2} \text { to cis- } \\
\mathrm{CH}_{3} \mathrm{CHCH} \cdot \mathrm{CH}_{2}\end{array}$ & TS1b & $3.68 \times 10^{11}$ \\
\hline $\begin{array}{c}\text { cis- } \mathrm{CH}_{3} \mathrm{CHCH} \cdot \mathrm{CH}_{2} \text { to trans }-\mathrm{CH}_{3}- \\
\mathrm{cCH} \cdot \mathrm{CHCH}_{2}\end{array}$ & TS1b & $2.18 \times 10^{8}$ \\
\hline cis- $\mathrm{CH}_{3}-\mathrm{cCH} \cdot \mathrm{CHCH}_{2}$ to $\mathrm{CH}_{3}-\mathrm{c} \cdot \mathrm{CCH}_{2} \mathrm{CH}_{2}$ & TS3 & $6.52 \times 10^{8}$ \\
\hline $\mathrm{CH}_{3}-\mathrm{c} \cdot \mathrm{CCH}_{2} \mathrm{CH}_{2}$ to $\mathrm{cis}-\mathrm{CH}_{3}-\mathrm{cCH} \cdot \mathrm{CHCH}_{2}$ & TS3 & $1.08 \times 10^{9}$ \\
\hline $\begin{array}{c}\text { trans- } \mathrm{CH}_{3}-\mathrm{cCH} \cdot \mathrm{CHCH}_{2} \text { to } \cdot \mathrm{CH}_{2^{-}} \\
\mathrm{cCHCH} \mathrm{CH}_{2} \\
\end{array}$ & TS2 & $3.46 \times 10^{9}$ \\
\hline $\begin{array}{c}\cdot \mathrm{CH}_{2}-\mathrm{cCHCH} \mathrm{CH}_{2} \text { to trans- } \mathrm{CH}_{3-} \\
\mathrm{cCH} \cdot \mathrm{CHCH}_{2}\end{array}$ & TS2 & $7.91 \times 10^{7}$ \\
\hline trans- $\mathrm{CH}_{3} \mathrm{CHCH} \cdot \mathrm{CH}_{2}$ to $\mathrm{cis}-\mathrm{CH}_{3} \mathrm{CHCH} \cdot \mathrm{CH}_{2}$ & $\mathrm{TSb}$ & $1.33 \times 10^{12}$ \\
\hline cis- $\mathrm{CH}_{3} \mathrm{CHCH} \cdot \mathrm{CH}_{2}$ to trans- $\mathrm{CH}_{3} \mathrm{CHCH} \cdot \mathrm{CH}_{2}$ & $\mathrm{TSb}$ & $6.66 \times 10^{11}$ \\
\hline trans $-\mathrm{CH}_{3} \mathrm{CHCH} \cdot \mathrm{CH}_{2}$ to $\cdot \mathrm{CH}_{2} \mathrm{CH}_{2} \mathrm{CHCH}_{2}$ & TS7a & $4.94 \times 10^{9}$ \\
\hline - $\mathrm{CH}_{2} \mathrm{CH}_{2} \mathrm{CHCH}_{2}$ to trans- $\mathrm{CH}_{3} \mathrm{CHCH} \cdot \mathrm{CH}_{2}$ & TS7a & $1.61 \times 10^{10}$ \\
\hline cis- $\mathrm{CH}_{3} \mathrm{CHCH} \cdot \mathrm{CH}_{2}$ to $\cdot \mathrm{CH}_{2} \mathrm{CH}_{2} \mathrm{CHCH}_{2}$ & TS7b & $2.09 \times 10^{9}$ \\
\hline$\cdot \mathrm{CH}_{2} \mathrm{CH}_{2} \mathrm{CHCH}_{2}$ to $\mathrm{cis}-\mathrm{CH}_{3} \mathrm{CHCH} \cdot \mathrm{CH}_{2}$ & TS7b & $1.37 \times 10^{10}$ \\
\hline trans $-\mathrm{CH}_{3} \mathrm{CHCH} \cdot \mathrm{CH}_{2}$ to trans $-\mathrm{CH}_{3} \mathrm{CH} \cdot \mathrm{CCH}_{3}$ & TS8 and TS9a & $1.13 \times 10^{8}$ \\
\hline trans $-\mathrm{CH}_{3} \mathrm{CH} \cdot \mathrm{CCH}_{3}$ to trans $-\mathrm{CH}_{3} \mathrm{CHCH} \cdot \mathrm{CH}_{2}$ & TS8 and TS9a & $5.79 \times 10^{9}$ \\
\hline trans $-\mathrm{CH}_{3} \mathrm{CHCH} \cdot \mathrm{CH}_{2}$ to $\mathrm{CH}_{3} \mathrm{CH}_{2} \cdot \mathrm{CCH}_{2}$ & TS10a & $2.45 \times 10^{7}$ \\
\hline $\mathrm{CH}_{3} \mathrm{CH}_{2} \cdot \mathrm{CCH}_{2}$ to trans $-\mathrm{CH}_{3} \mathrm{CHCH} \cdot \mathrm{CH}_{2}$ & TS10a & $2.01 \times 10^{9}$ \\
\hline trans $-\mathrm{CH}_{3} \mathrm{CHCH} \cdot \mathrm{CH}_{2}$ to $\mathrm{cis}-\mathrm{CH}_{3} \mathrm{CH}_{2} \mathrm{CH} \cdot \mathrm{CH}$ & TS11 & $1.99 \times 10^{7}$ \\
\hline cis- $\mathrm{CH}_{3} \mathrm{CH}_{2} \mathrm{CH} \cdot \mathrm{CH}$ to trans $-\mathrm{CH}_{3} \mathrm{CHCH} \cdot \mathrm{CH}_{2}$ & TS11 & $4.03 \times 10^{9}$ \\
\hline cis $-\mathrm{CH}_{3} \mathrm{CHCH} \cdot \mathrm{CH}_{2}$ to $\mathrm{cis}-\mathrm{CH}_{3} \mathrm{CH} \cdot \mathrm{CCH}_{3}$ & TS9b & $1.73 \times 10^{7}$ \\
\hline cis- $\mathrm{CH}_{3} \mathrm{CH} \cdot \mathrm{CCH}_{3}$ to $\mathrm{cis}-\mathrm{CH}_{3} \mathrm{CHCH} \cdot \mathrm{CH}_{2}$ & TS9b & $1.96 \times 10^{9}$ \\
\hline cis- $\mathrm{CH}_{3} \mathrm{CHCH} \cdot \mathrm{CH}_{2}$ to $\mathrm{CH}_{3} \mathrm{CH}_{2} \cdot \mathrm{CCH}_{2}$ & TS10b & $1.78 \times 10^{7}$ \\
\hline
\end{tabular}




\begin{tabular}{|c|c|c|}
\hline $\mathrm{CH}_{3} \mathrm{CH}_{2} \cdot \mathrm{CCH}_{2}$ to $\mathrm{cis}-\mathrm{CH}_{3} \mathrm{CHCH} \cdot \mathrm{CH}_{2}$ & TS10b & $2.89 \times 10^{9}$ \\
\hline$\cdot \mathrm{CH}_{2} \mathrm{CH}_{2} \mathrm{CHCH}_{2}$ to $\cdot \mathrm{CH}_{2}-\mathrm{cCHCH}_{2} \mathrm{CH}_{2}$ & TS5 & $1.16 \times 10^{11}$ \\
\hline$\cdot \mathrm{CH}_{2}-\mathrm{cCHCH}_{2} \mathrm{CH}_{2}$ to $\cdot \mathrm{CH}_{2} \mathrm{CH}_{2} \mathrm{CHCH}_{2}$ & TS5 & $2.76 \times 10^{12}$ \\
\hline$\cdot \mathrm{CH}_{2} \mathrm{CH}_{2} \mathrm{CHCH}_{2}$ to $\mathrm{CH}_{3} \mathrm{CH}_{2} \cdot \mathrm{CCH}_{2}$ & TS12 & $2.36 \times 10^{8}$ \\
\hline $\mathrm{CH}_{3} \mathrm{CH}_{2} \cdot \mathrm{CCH}_{2}$ to $\cdot \mathrm{CH}_{2} \mathrm{CH}_{2} \mathrm{CHCH}_{2}$ & TS12 & $5.89 \times 10^{9}$ \\
\hline$\cdot \mathrm{CH}_{2} \mathrm{CH}_{2} \mathrm{CHCH}_{2}$ to $\mathrm{cis}-\mathrm{CH}_{3} \mathrm{CH}_{2} \mathrm{CH} \cdot \mathrm{CH}$ & TS13 & $5.21 \times 10^{9}$ \\
\hline cis- $\mathrm{CH}_{3} \mathrm{CH}_{2} \mathrm{CH} \cdot \mathrm{CH}$ to $\cdot \mathrm{CH}_{2} \mathrm{CH}_{2} \mathrm{CHCH}_{2}$ & TS13 & $3.19 \times 10^{11}$ \\
\hline$\cdot \mathrm{CH}_{2} \mathrm{CH}_{2} \mathrm{CHCH}_{2}$ to c. $\mathrm{CH}_{2} \mathrm{CH}_{2} \mathrm{CHCH}_{2}$ & TS14 & $6.71 \times 10^{8}$ \\
\hline c. $\mathrm{CH}_{2} \mathrm{CH}_{2} \mathrm{CHCH}_{2}$ to $\cdot \mathrm{CH}_{2} \mathrm{CH}_{2} \mathrm{CHCH}_{2}$ & TS14 & $3.37 \times 10^{10}$ \\
\hline$\cdot \mathrm{CH}_{2}-\mathrm{cCHCH}_{2} \mathrm{CH}_{2}$ to $\mathrm{CH}_{3}-\mathrm{c} \cdot \mathrm{CCH}_{2} \mathrm{CH}_{2}$ & TS4 & $1.44 \times 10^{8}$ \\
\hline $\mathrm{CH}_{3}-\mathrm{c} \cdot \mathrm{CCH}_{2} \mathrm{CH}_{2}$ to $\cdot \mathrm{CH}_{2}-\mathrm{cCHCH}_{2} \mathrm{CH}_{2}$ & TS4 & $2.36 \times 10^{9}$ \\
\hline cis- $\mathrm{CH}_{3} \mathrm{CH}_{2} \mathrm{CH} \cdot \mathrm{CH}$ to trans $-\mathrm{CH}_{3} \mathrm{CH}_{2} \mathrm{CH} \cdot \mathrm{CH}$ & TSd & $9.70 \times 10^{12}$ \\
\hline trans $-\mathrm{CH}_{3} \mathrm{CH}_{2} \mathrm{CH} \cdot \mathrm{CH}$ to cis $-\mathrm{CH}_{3} \mathrm{CH}_{2} \mathrm{CH} \cdot \mathrm{CH}$ & TSd & $1.05 \times 10^{13}$ \\
\hline trans $-\mathrm{CH}_{3} \mathrm{CH}_{2} \mathrm{CH} \cdot \mathrm{CH}$ to $\mathrm{CH}_{3} \mathrm{CH}_{2} \cdot \mathrm{CCH}_{2}$ & TS15 & $2.91 \times 10^{9}$ \\
\hline $\mathrm{CH}_{3} \mathrm{CH}_{2} \cdot \mathrm{CCH}_{2}$ to trans $-\mathrm{CH}_{3} \mathrm{CH}_{2} \mathrm{CH} \cdot \mathrm{CH}$ & TS15 & $1.10 \times 10^{9}$ \\
\hline $\mathrm{CH}_{3} \mathrm{C}\left(\cdot \mathrm{CH}_{2}\right) \mathrm{CH}_{2}$ to $\mathrm{CH}_{3}-\mathrm{c} \cdot \mathrm{CCH}_{2} \mathrm{CH}_{2}$ & TS6 & $1.44 \times 10^{8}$ \\
\hline $\mathrm{CH}_{3}-\mathrm{c} \cdot \mathrm{CCH}_{2} \mathrm{CH}_{2}$ to $\mathrm{CH}_{3} \mathrm{C}\left(\cdot \mathrm{CH}_{2}\right) \mathrm{CH}_{2}$ & TS6 & $3.04 \times 10^{11}$ \\
\hline $\mathrm{CH}_{3} \mathrm{C}\left(\cdot \mathrm{CH}_{2}\right) \mathrm{CH}_{2}$ to $(\mathrm{CH} 3)_{2} \mathrm{C} \cdot \mathrm{CH}$ & TS16 & $1.37 \times 10^{7}$ \\
\hline$(\mathrm{CH} 3)_{2} \mathrm{C} \cdot \mathrm{CH}$ to $\mathrm{CH}_{3} \mathrm{C}\left(\cdot \mathrm{CH}_{2}\right) \mathrm{CH}_{2}$ & TS16 & $1.39 \times 10^{10}$ \\
\hline $\mathrm{CH}_{3} \mathrm{C}\left(\cdot \mathrm{CH}_{2}\right) \mathrm{CH}_{2}$ to $\mathrm{CH}_{3} \mathrm{CH}_{2} \cdot \mathrm{CCH}_{2}$ & TS17 & $3.71 \times 10^{4}$ \\
\hline $\mathrm{CH}_{3} \mathrm{CH}_{2} \cdot \mathrm{CCH}_{2}$ to $\mathrm{CH}_{3} \mathrm{C}\left(\cdot \mathrm{CH}_{2}\right) \mathrm{CH}_{2}$ & TS17 & $5.06 \times 10^{6}$ \\
\hline
\end{tabular}


Table 4.3: Energy-Dependent Dissociation Rate Coefficients, $k$. These were for select dissociation reactions calculated at zero collision energy. The values of $k$ are in units of $\mathrm{s}^{-}$ ${ }^{1}$. Reactions associated with portions of the $\mathrm{C}_{4} \mathrm{H}_{7} \mathrm{PES}$ which are, for all practical purposes, not sampled by the system are not included.

\begin{tabular}{|c|c|c|}
\hline Reaction & Transitions state & $k$ \\
\hline $\begin{array}{c}\text { trans- } \mathrm{CH}_{3}-\mathrm{cCH} \cdot \mathrm{CHCH}_{2} \text { to } \mathrm{cCHCHCH} \mathrm{CHC}_{2}+ \\
\cdot \mathrm{CH}_{3}\end{array}$ & TS20 & $1.12 \times 10^{10}$ \\
\hline $\begin{array}{c}\text { trans }-\mathrm{CH}_{3}-\mathrm{cCH} \cdot \mathrm{CHCH}_{2} \text { to } \mathrm{CH}_{3}-\mathrm{CCCHCH}_{2} \\
+\cdot \cdot \mathrm{H}\end{array}$ & TS21 & $5.04 \times 10^{8}$ \\
\hline $\begin{array}{c}\text { trans }-\mathrm{CH}_{3}-\mathrm{cCH} \cdot \mathrm{CHCH}_{2} \text { to } \mathrm{CH}_{3}-\mathrm{cCHCHCH} \\
+\cdot \mathrm{H}\end{array}$ & TS22a & $8.93 \times 10^{8}$ \\
\hline $\begin{array}{l}\text { cis- } \mathrm{CH}_{3}-\mathrm{cCH} \cdot \mathrm{CHCH}_{2} \text { to } \mathrm{CH}_{3}-\mathrm{cCHCHCH}+ \\
\cdot \mathrm{H}\end{array}$ & TS22b & $3.98 \times 10^{8}$ \\
\hline $\begin{array}{c}\text { trans }-\mathrm{CH}_{3} \mathrm{CHCH} \cdot \mathrm{CH}_{2} \text { to } \mathrm{CH}_{2} \mathrm{CHCHCH}_{2}+ \\
\cdot \mathrm{H}\end{array}$ & TS26a & $3.40 \times 10^{10}$ \\
\hline cis- $\mathrm{CH}_{3} \mathrm{CHCH} \cdot \mathrm{CH}_{2}$ to $\mathrm{CH}_{2} \mathrm{CHCHCH}_{2}+\cdot \mathrm{H}$ & TS26b & $6.95 \times 10^{9}$ \\
\hline trans- $\mathrm{CH}_{3} \mathrm{CHCH} \cdot \mathrm{CH}_{2}$ to $\mathrm{CH}_{3} \mathrm{CHCCH}_{2}+\cdot \mathrm{H}$ & TS27 & $8.53 \times 10^{8}$ \\
\hline$\cdot \mathrm{CH}_{2} \mathrm{CH}_{2} \mathrm{CHCH}_{2}$ to $\mathrm{CH}_{2} \mathrm{CHCHCH}_{2}+\cdot \mathrm{H}$ & TS28 & $2.95 \times 10^{10}$ \\
\hline$\cdot \mathrm{CH}_{2} \mathrm{CH}_{2} \mathrm{CHCH}_{2}$ to $\mathrm{CH}_{2} \mathrm{CH}_{2}+\cdot \mathrm{CHCH}_{2}$ & TS29 & $1.22 \times 10^{11}$ \\
\hline$\cdot \mathrm{CH}_{2}-\mathrm{cCHCH}_{2} \mathrm{CH}_{2}$ to $\mathrm{CH}_{2}-\mathrm{cCCH}_{2} \mathrm{CH}_{2}+\cdot \mathrm{H}$ & TS25 & $1.63 \times 10^{8}$ \\
\hline trans $-\mathrm{CH}_{3} \mathrm{CH}_{2} \mathrm{CH} \cdot \mathrm{CH}$ to $\mathrm{CHCH}+\cdot \mathrm{CH}_{2} \mathrm{CH}_{3}$ & TS30 & $9.838 \times 10^{11}$ \\
\hline cis- $\mathrm{CH}_{3} \mathrm{CH}_{2} \mathrm{CH} \cdot \mathrm{CH}$ to $\mathrm{CH}_{3} \mathrm{CH}_{2} \mathrm{CCH}+\cdot \mathrm{H}$ & TS31 & $2.556 \times 10^{10}$ \\
\hline c. $\mathrm{CH}_{2} \mathrm{CH}_{2} \mathrm{CHCH}_{2}$ to $\mathrm{cCH}_{2} \mathrm{CH}_{2} \mathrm{CHCH}+\cdot \mathrm{H}$ & TS32 & $3.732 \times 10^{10}$ \\
\hline $\mathrm{CH}_{3} \mathrm{C}\left(\cdot \mathrm{CH}_{2}\right) \mathrm{CH}_{2}$ to $\mathrm{CH}_{2} \mathrm{CCH}_{2}+\cdot \mathrm{CH}_{3}$ & TS38 & $1.23 \times 10^{9}$ \\
\hline
\end{tabular}


Table 4.4: Propene + CH Radical Product Branching Ratio. These product branching ratios (\%) for the different initial bimolecular entrance channels were calculated at the zero pressure limit and zero collision energy and at $p=5$ Torr and $T=300 \mathrm{~K}$ (in parentheses).

\begin{tabular}{|c|c|c|c|c|}
\hline Products & $\begin{array}{c}\text { Double Bond } \\
\text { Addition }\end{array}$ & $\begin{array}{c}\text { Terminal sp } \\
\text { C-H Insertion } \\
/ \\
\text { C-C Insertion }\end{array}$ & $\begin{array}{c}\text { Terminal sp } \text { C- }^{3} \\
\text { H Insertion }\end{array}$ & $\begin{array}{c}\text { Middle sp }{ }^{2} \text { C- } \\
\text { H insertion }\end{array}$ \\
\hline $\begin{array}{c}\mathrm{cCHCHCH} \\
\cdot \mathrm{CH}_{3}+\end{array}$ & $1.1 \%(1.0)$ & - & - & - \\
\hline $\begin{array}{c}\mathrm{CH}_{2} \mathrm{CHCHCH} \\
\cdot \mathrm{H}\end{array}$ & $85.9 \%(82.7)$ & $87.1 \%(83.7)$ & $29.9 \%(20.7)$ & - \\
\hline $\mathrm{CH}_{3} \mathrm{CHCCH}_{2}+\cdot \mathrm{H}$ & $1.5 \%(3.7)$ & $1.6 \%(3.7)$ & - & - \\
\hline $\begin{array}{c}\mathrm{CH} \mathrm{CH}_{2}+ \\
\cdot \mathrm{CHCH}_{2}\end{array}$ & $10.6 \%$ & $10.6 \%(11.4)$ & $67.4 \%(76.6)$ & - \\
\hline $\mathrm{CHCH}_{+} \cdot \mathrm{CH}_{2} \mathrm{CH}_{3}$ & - & - & $2.0 \%(1.7)$ & - \\
\hline $\mathrm{CH}_{2} \mathrm{CCH}_{2}+\cdot \mathrm{CH}_{3}$ & - & - & - & $98.3 \%(99.1)$ \\
\hline $\mathrm{CH}_{3} \mathrm{CCH}_{+} \cdot \mathrm{CH}_{3}$ & - & - & - & $1.1 \%(0.7)$ \\
\hline
\end{tabular}


Figure 4.1: $\mathrm{C}_{4} \mathrm{H}_{7}$ PES, Part 1. This portion describes the isomerization channels following $\mathrm{CH}$ addition to double bond calculated at the $\operatorname{CCSD}(\mathrm{T})-\mathrm{F} 12 / \mathrm{CBS} / / \mathrm{B} 3 \mathrm{LYP} / 6-311 \mathrm{G}(\mathrm{d}, \mathrm{p})+\mathrm{ZPE}(\mathrm{B} 3 \mathrm{LYP} / 6-311 \mathrm{G}(\mathrm{d}, \mathrm{p}))$ level of theory. All relative energies are given in $\mathrm{kcal} / \mathrm{mol}$.

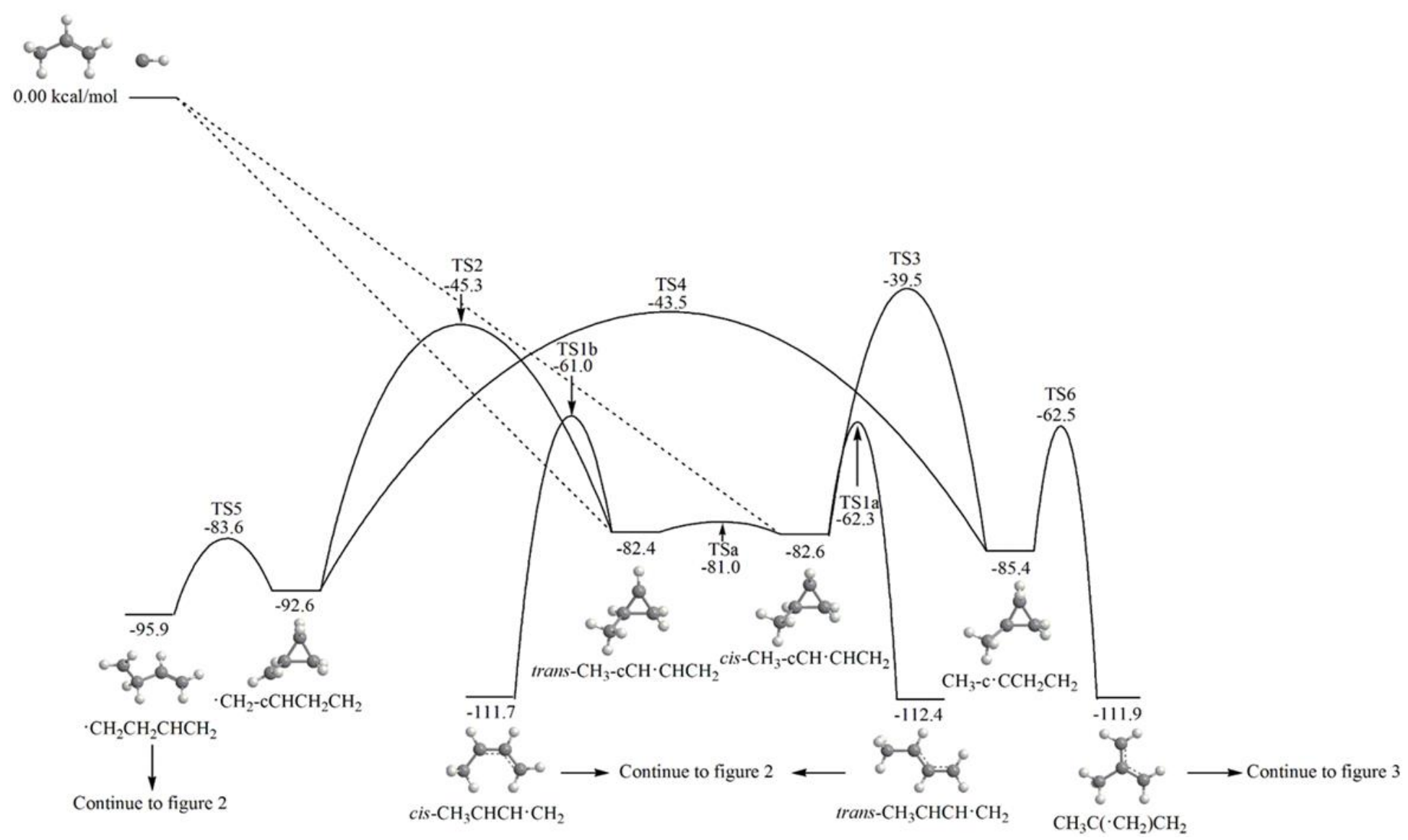


Figure 4.2: $\mathrm{C}_{4} \mathrm{H}_{7}$ PES, Part 2. This portion describes the dissociation channels following $\mathrm{CH}$ radical double bond addition calculated at the CCSD(T)-F12/CBS//B3LYP/6-311G(d,p) + ZPE(B3LYP/6-311G(d,p)) level of theory. All relative energies are given in $\mathrm{kcal} / \mathrm{mol}$.

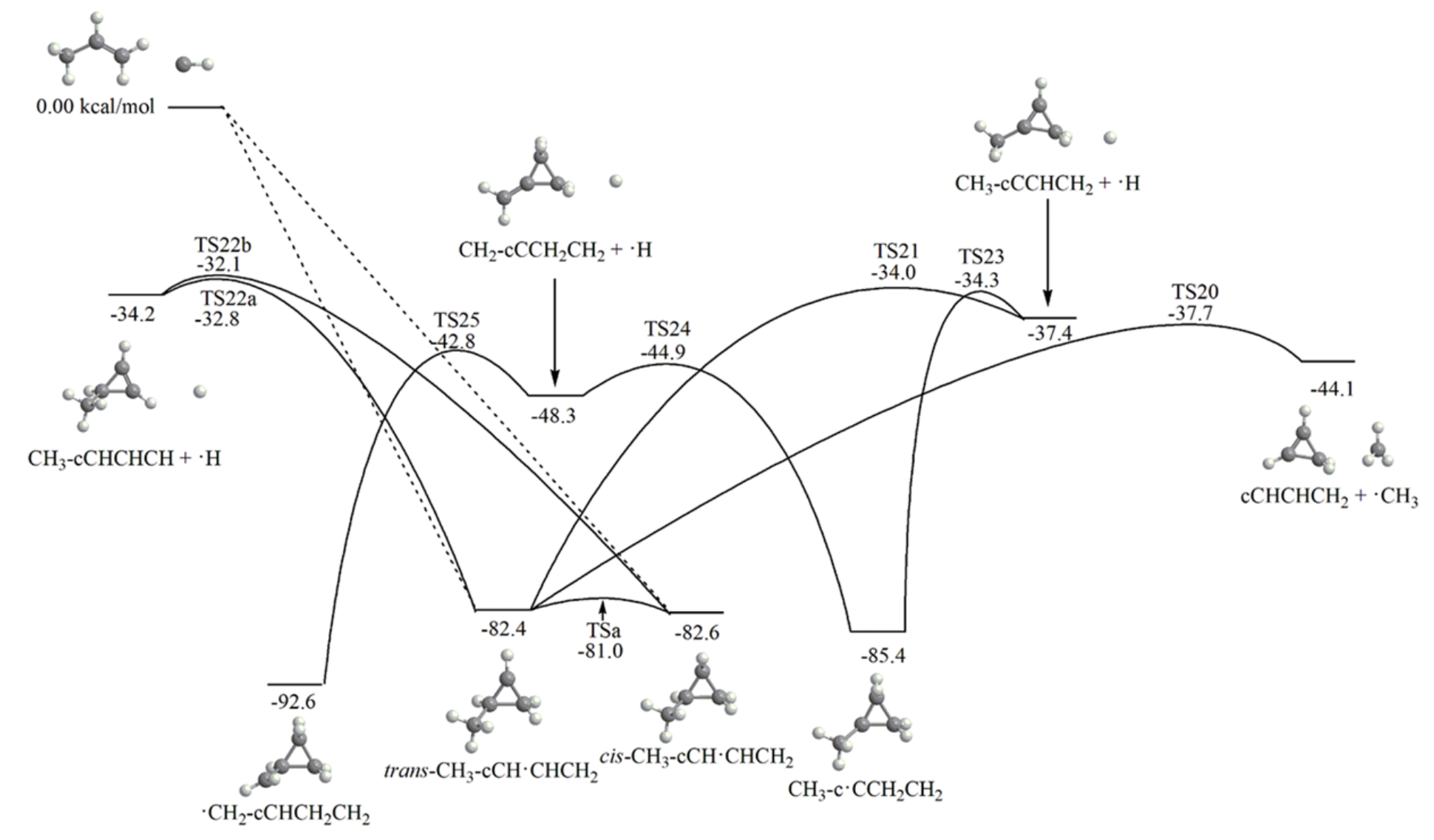


Figure 4.3: $\mathrm{C}_{4} \mathrm{H}_{7}$ PES, Part 3. This portions describes the isomerization channels following terminal $\mathrm{CH}$ radical insertions calculated at the CCSD(T)-F12/CBS//B3LYP/6-311G(d,p) + ZPE(B3LYP/6-311G(d,p)) level of theory. All relative energies are given in $\mathrm{kcal} / \mathrm{mol}$.

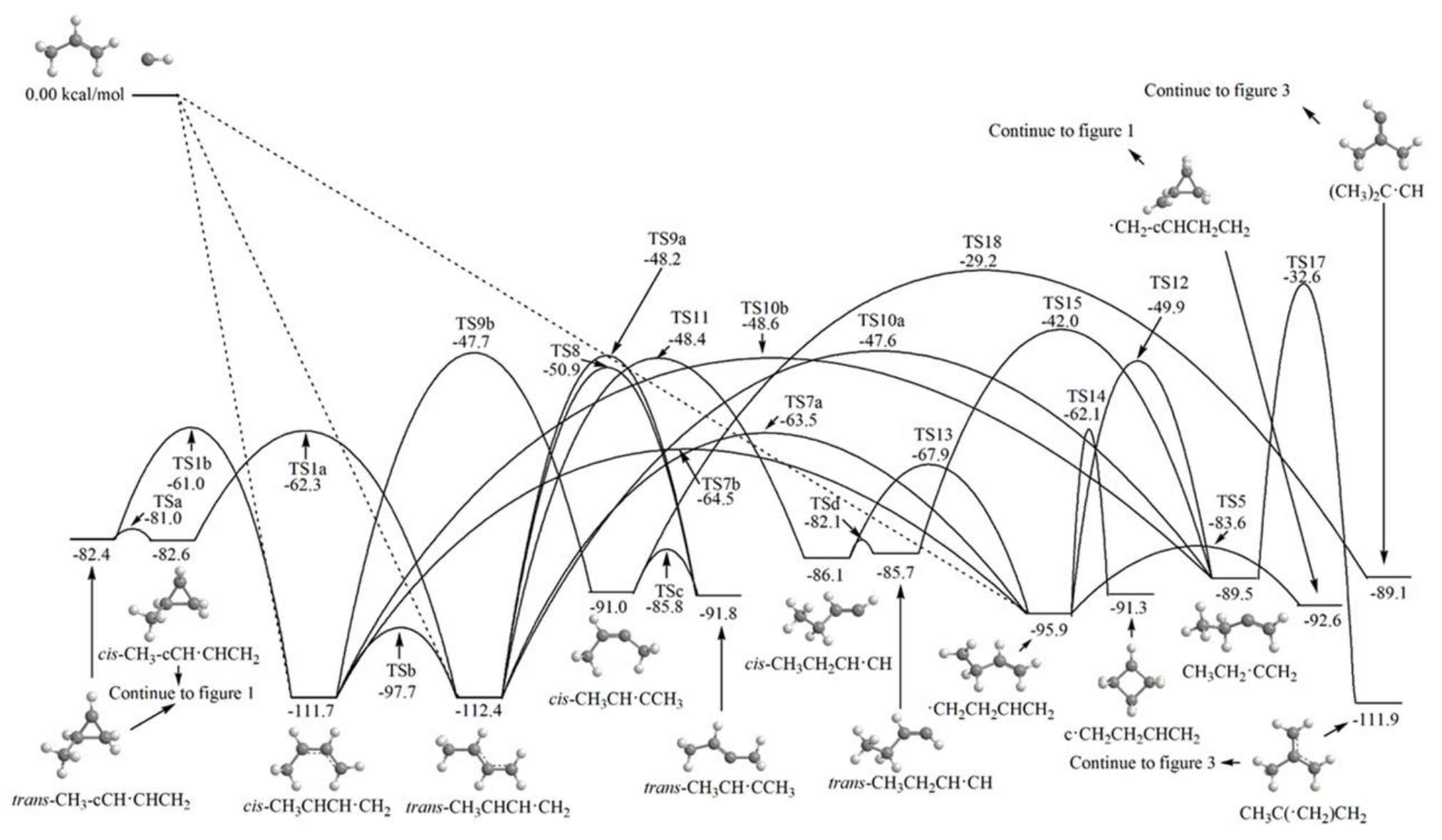


Figure 4.4: $\mathrm{C}_{4} \mathrm{H}_{7} \mathrm{PES}$, Part 4. This portion describes the dissociation channels following terminal $\mathrm{CH}$ radical insertions calculated at the CCSD(T)-F12/CBS//B3LYP/6-311G(d,p) + ZPE(B3LYP/6-311G(d,p)) level of theory. All relative energies are given in $\mathrm{kcal} / \mathrm{mol}$.

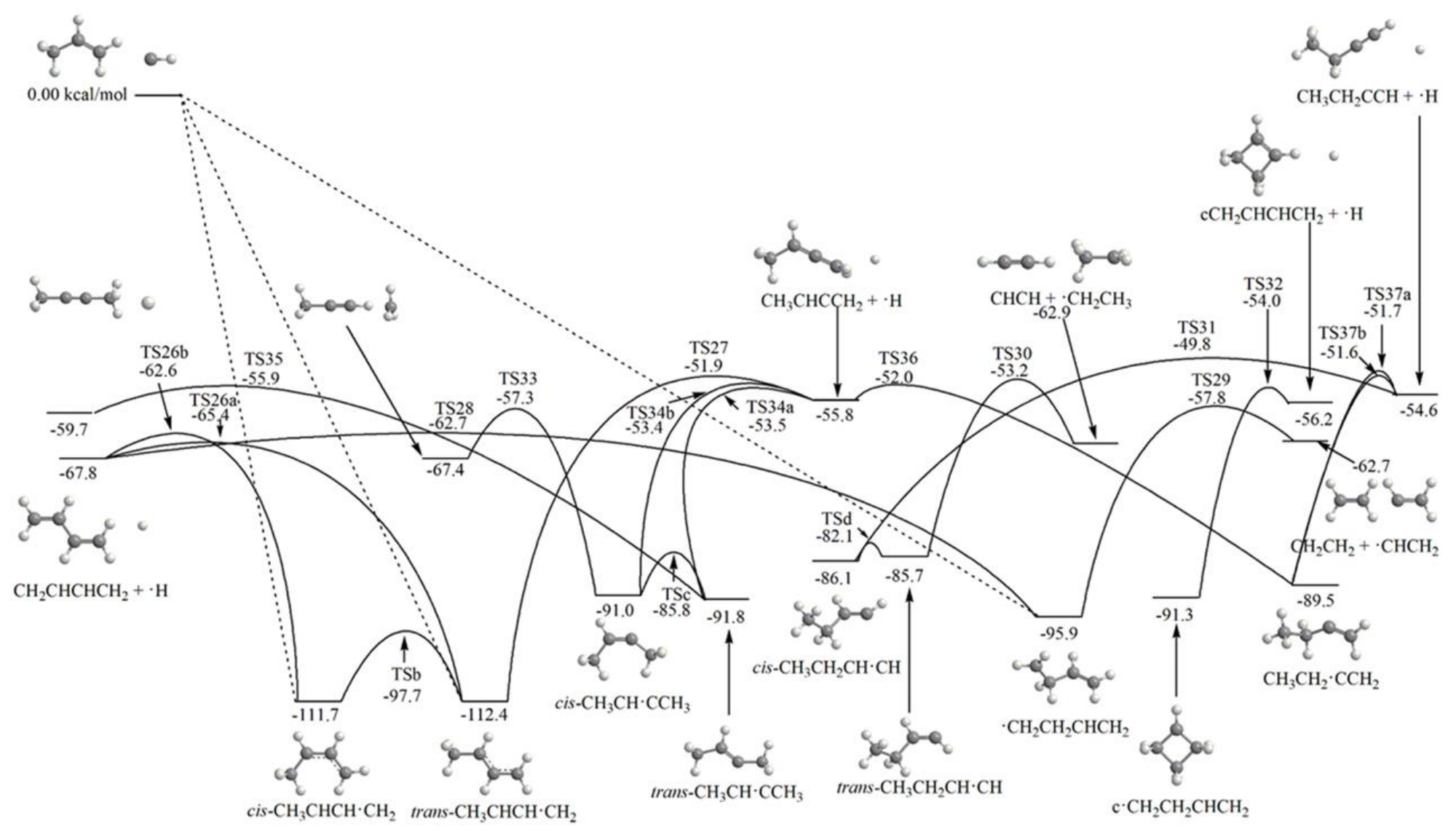


Figure 4.5: $\mathrm{C}_{4} \mathrm{H}_{7}$ PES, Part 5. This portion corresponds to $\mathrm{CH}$ radical insertion into the middle $\mathrm{C}-\mathrm{H}$ bond of propene calculated at the CCSD(T)-F12/CBS//B3LYP/6-311G(d,p) + ZPE(B3LYP/6-311G(d,p)) level of theory. All relative energies are given in $\mathrm{kcal} / \mathrm{mol}$.

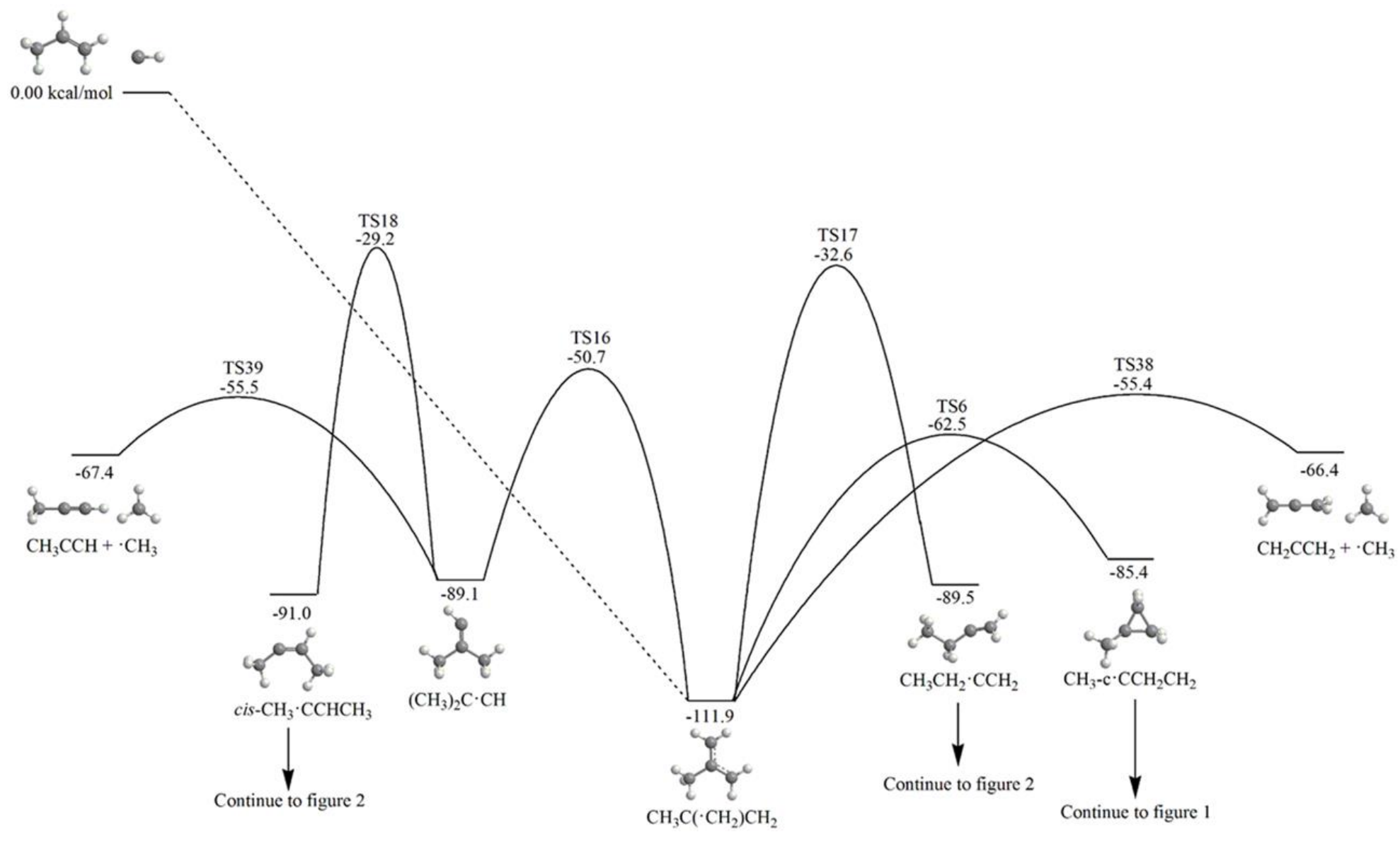


Figure 4.6: Optimized $\mathrm{C}_{4} \mathrm{H}_{7}$ Transition State Structures. Bond lengths are in $\AA$, angles in degrees.

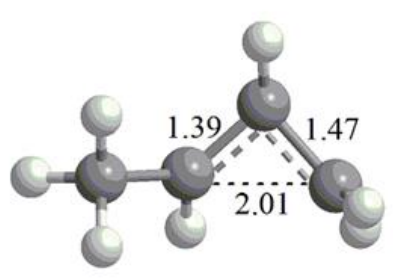

TS1a, $-62.3 \mathrm{kcal} / \mathrm{mol}$

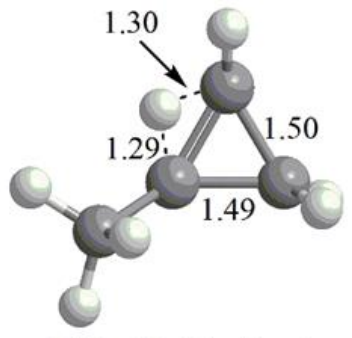

TS3, $-39.5 \mathrm{kcal} / \mathrm{mol}$

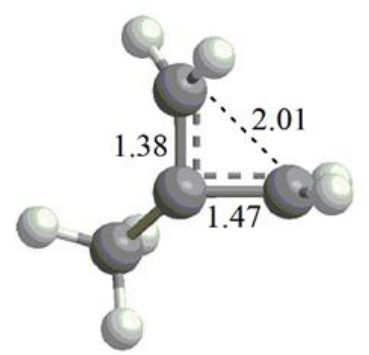

TS6, $-62.5 \mathrm{kcal} / \mathrm{mol}$

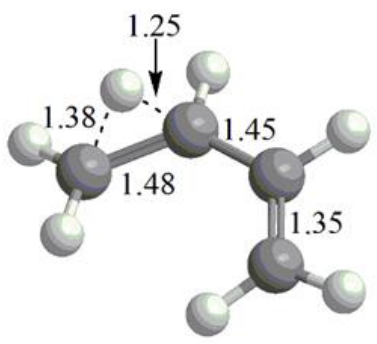

TS7b, $-64.5 \mathrm{kcal} / \mathrm{mol}$

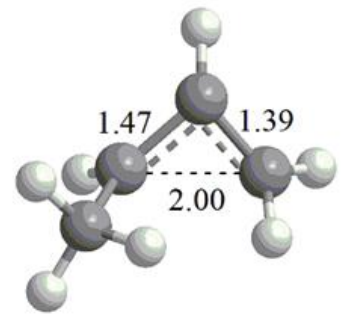

TS1b, $-61.0 \mathrm{kcal} / \mathrm{mol}$

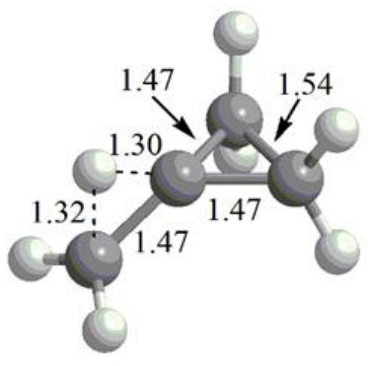

$\mathrm{TS} 4,-43.5 \mathrm{kcal} / \mathrm{mol}$

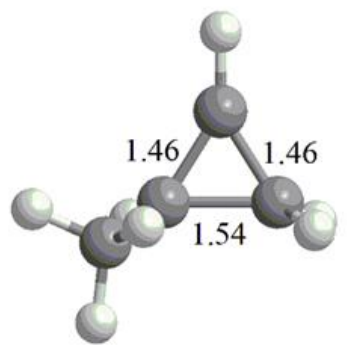

$\mathrm{TSa},-81.0 \mathrm{kcal} / \mathrm{mol}$

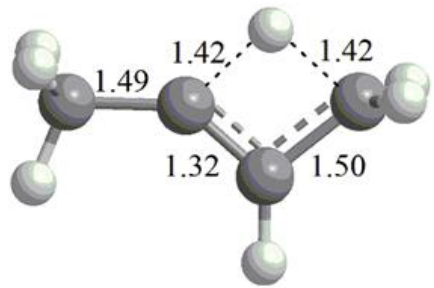

TS8, $-50.9 \mathrm{kcal} / \mathrm{mol}$

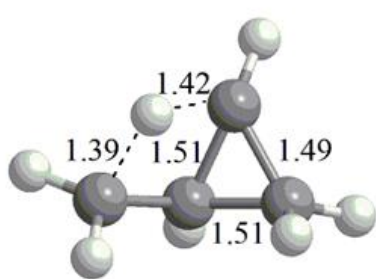

TS2, $-45.3 \mathrm{kcal} / \mathrm{mol}$

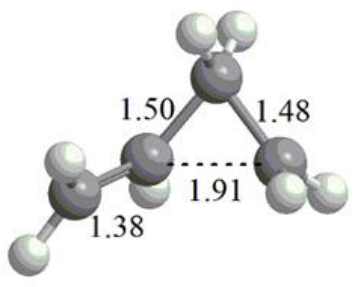

TS5, $-83.6 \mathrm{kcal} / \mathrm{mol}$

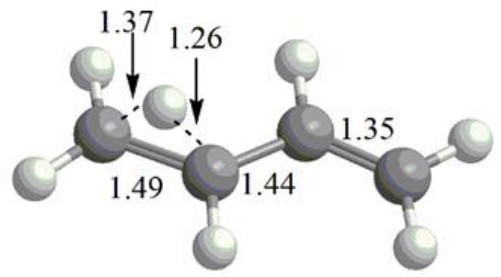

TS7a, $-63.5 \mathrm{kcal} / \mathrm{mol}$

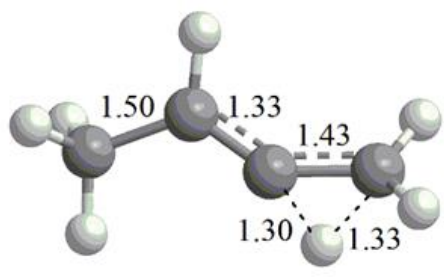

TS9a, $-48.2 \mathrm{kcal} / \mathrm{mol}$ 


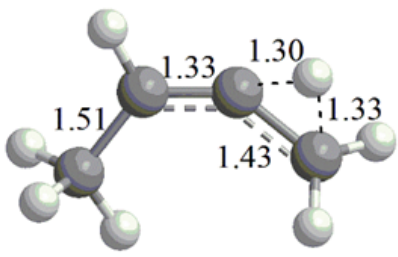

TS9b, $-47.7 \mathrm{kcal} / \mathrm{mol}$

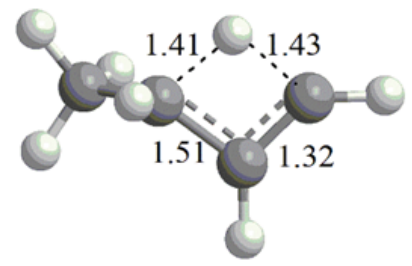

TS11, $-48.4 \mathrm{kcal} / \mathrm{mol}$

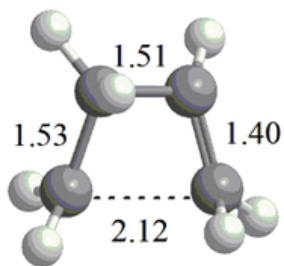

TS14, $-62.1 \mathrm{kcal} / \mathrm{mol}$

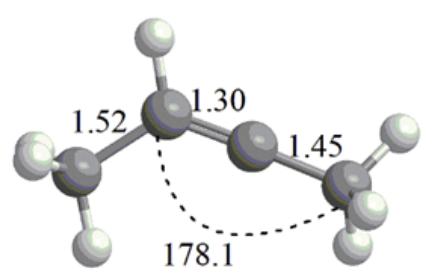

TSc, $-85.8 \mathrm{kcal} / \mathrm{mol}$

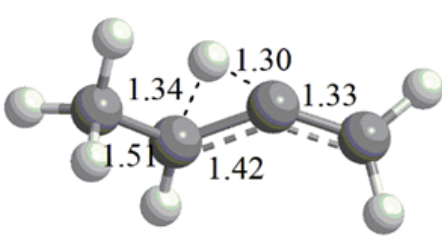

TS10a, $-47.6 \mathrm{kcal} / \mathrm{mol}$

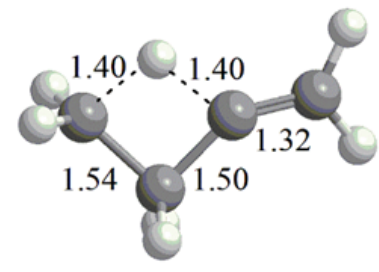

TS12, $-49.9 \mathrm{kcal} / \mathrm{mol}$

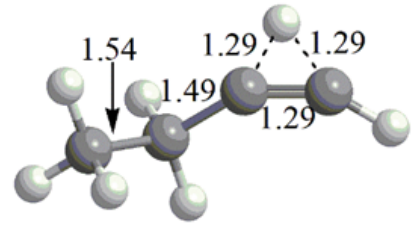

$\mathrm{TS} 15,-42.0 \mathrm{kcal} / \mathrm{mol}$

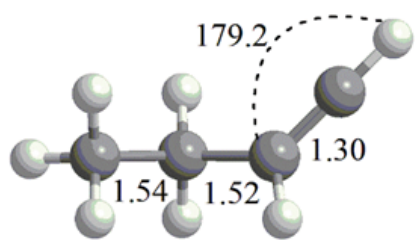

TSd, $-82.1 \mathrm{kcal} / \mathrm{mol}$

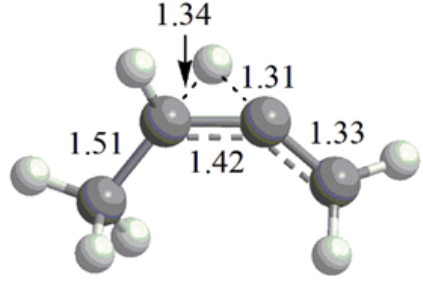

TS10b, $-48.6 \mathrm{kcal} / \mathrm{mol}$

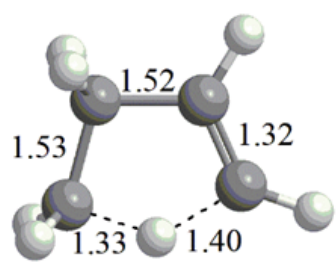

TS13, $-67.9 \mathrm{kcal} / \mathrm{mol}$

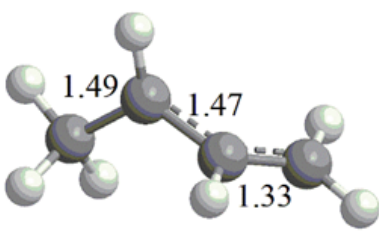

TSb, $-97.7 \mathrm{kcal} / \mathrm{mol}$

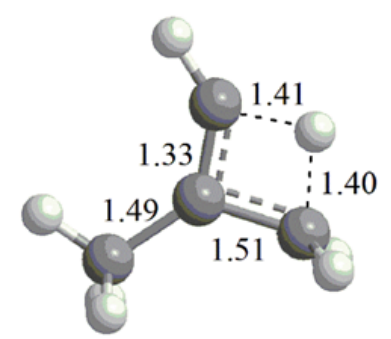

TS16, $-50.7 \mathrm{kcal} / \mathrm{mol}$ 


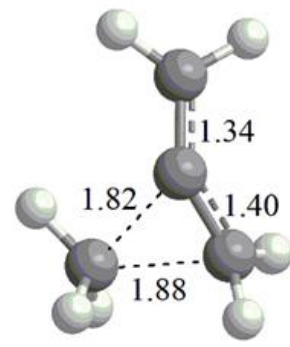

TS17, $-32.6 \mathrm{kcal} / \mathrm{mol}$

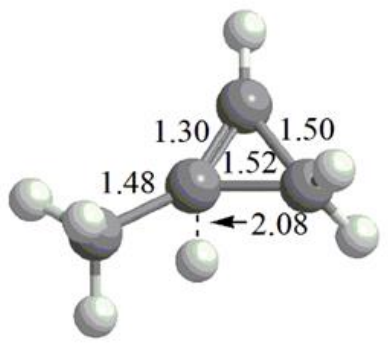

TS21, $-34.0 \mathrm{kcal} / \mathrm{mol}$

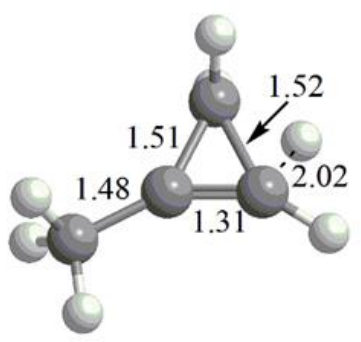

TS23, QCISD, - $-34.3 \mathrm{kcal} / \mathrm{mol}$

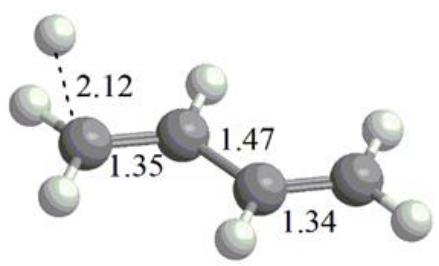

TS26a, QCISD, -65.4 kcal/mol

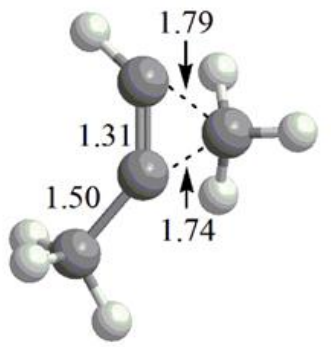

TS18, $-29.2 \mathrm{kcal} / \mathrm{mol}$

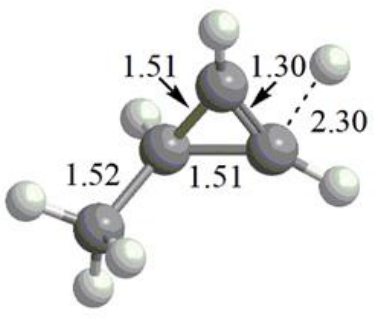

TS22a, $-32.8 \mathrm{kcal} / \mathrm{mol}$

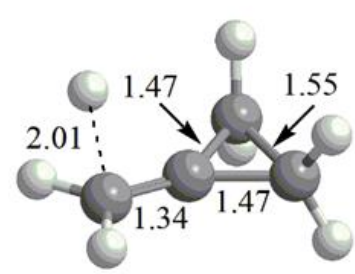

TS24, QCISD, -44.9 kcal/mol

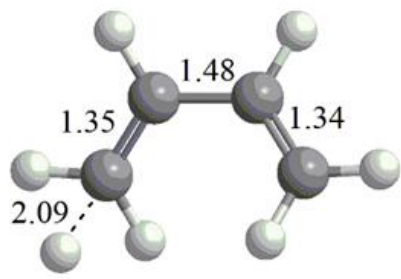

TS26b, QCISD, -62.6 kcal/mol

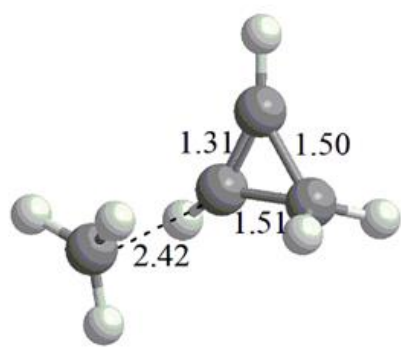

TS20, $-37.7 \mathrm{kcal} / \mathrm{mol}$

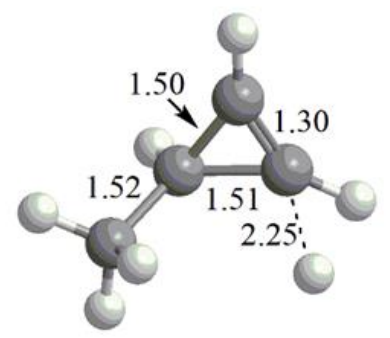

TS22b, $-32.1 \mathrm{kcal} / \mathrm{mol}$

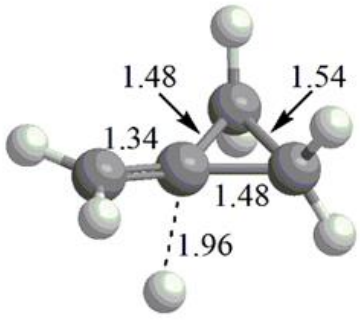

TS25, QCISD, $-42.8 \mathrm{kcal} / \mathrm{mol}$

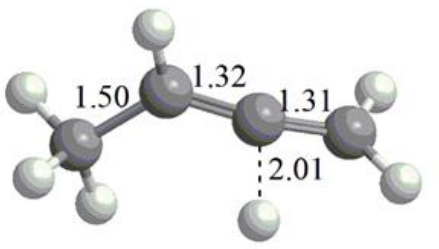

TS27, $-51.9 \mathrm{kcal} / \mathrm{mol}$ 


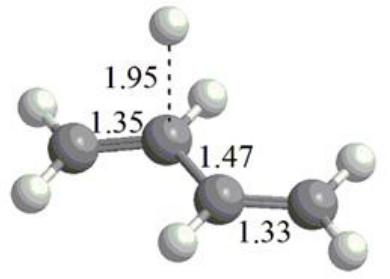

TS28, $-62.7 \mathrm{kcal} / \mathrm{mol}$

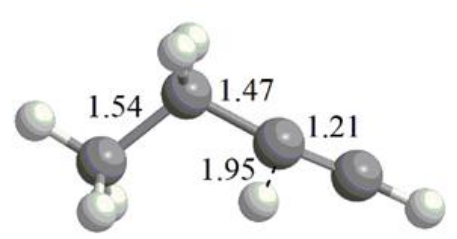

TS31, $-49.8 \mathrm{kcal} / \mathrm{mol}$

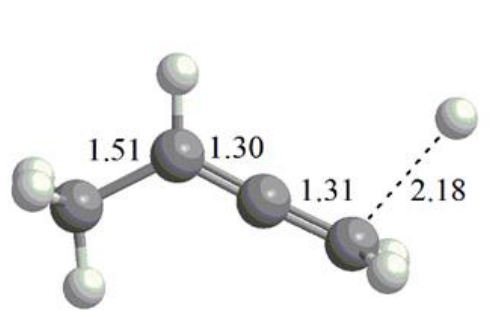

TS34a, $-53.5 \mathrm{kcal} / \mathrm{mol}$

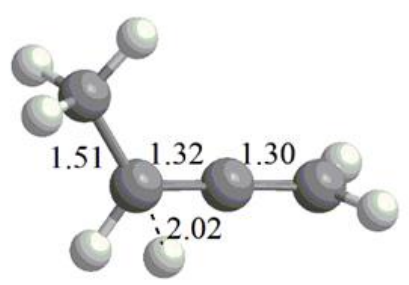

TS36, $-52.0 \mathrm{kcal} / \mathrm{mol}$

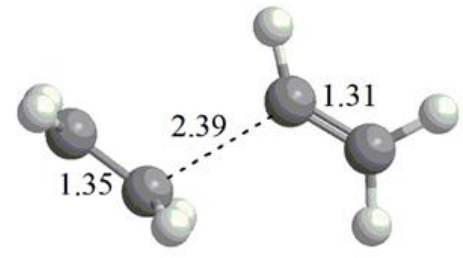

TS29, $-57.8 \mathrm{kcal} / \mathrm{mol}$

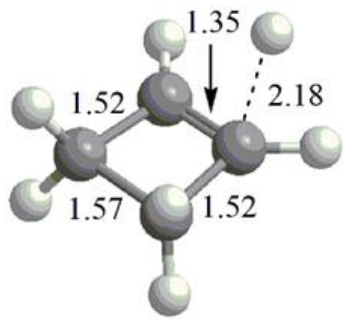

TS32, $-54.0 \mathrm{kcal} / \mathrm{mol}$

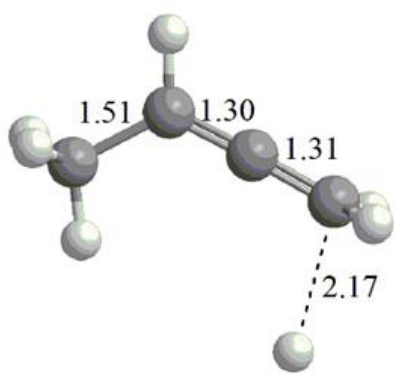

TS34b, $-53.4 \mathrm{kcal} / \mathrm{mol}$

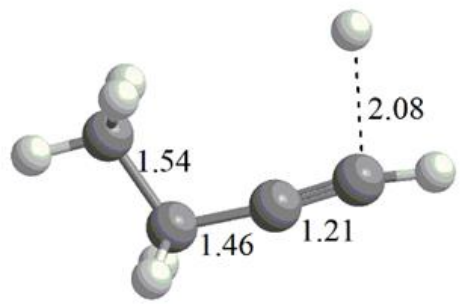

TS37a, $-51.7 \mathrm{kcal} / \mathrm{mol}$

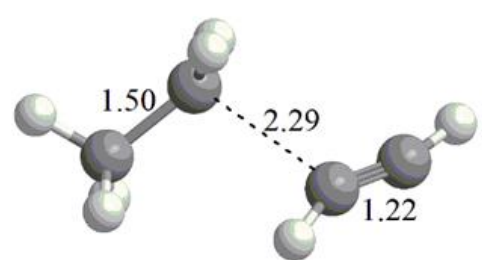

TS30, $-53.2 \mathrm{kcal} / \mathrm{mol}$
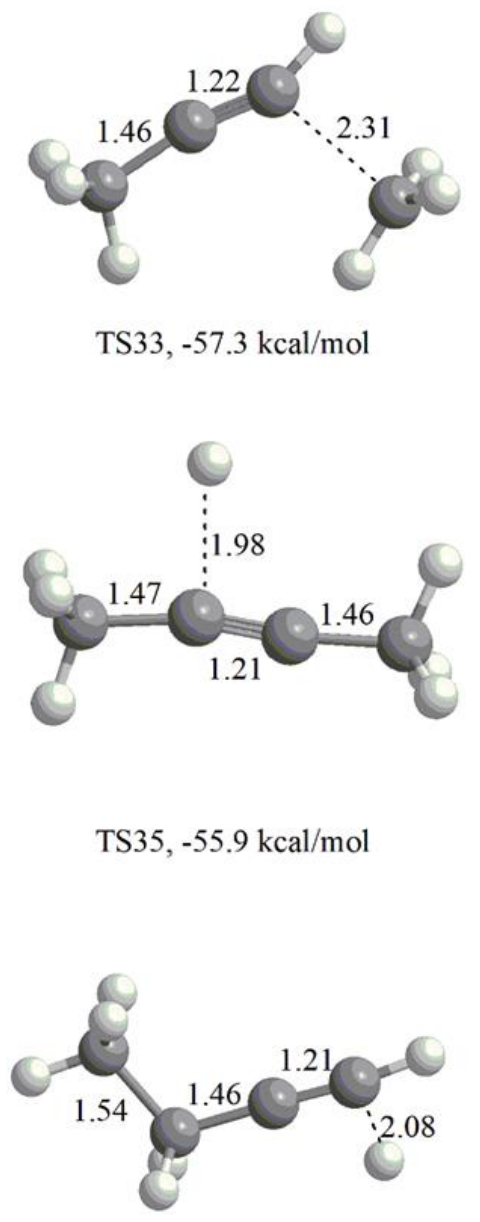

TS37b, $-51.6 \mathrm{kcal} / \mathrm{mol}$ 


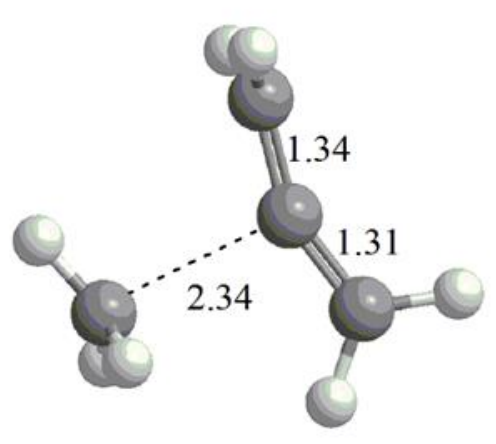

TS38, $-55.4 \mathrm{kcal} / \mathrm{mol}$

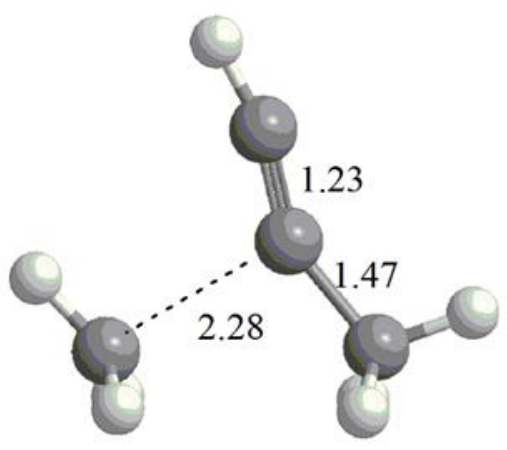

TS39, $-55.5 \mathrm{kcal} / \mathrm{mol}$ 


\section{CHAPTER V}

REACTION MECHANISM OF CH $\left(\mathrm{X}^{2} \Pi\right)+\mathrm{C}_{3} \mathrm{H}_{4}$ AND $\mathrm{C}_{4} \mathrm{H}_{5}$ PES 
Introduction:

Chemical reactions on the $\mathrm{C}_{4} \mathrm{H}_{5}$ PES are thought to be of practical importance to combustion modeling. ${ }^{1,2,3,4}$ In addition, $\mathrm{C}_{4} \mathrm{H}_{5}$ PES reactions might provide important paths towards the formation of complex chemical species in low temperature environments. 5,6 Regarding the former, three $\mathrm{C}_{4} \mathrm{H}_{5}$ isomers were identified in fuel-rich flames; ${ }^{2,3}$ also, a $\mathrm{C}_{4} \mathrm{H}_{5}+\mathrm{C}_{2} \mathrm{H}_{2}$ reaction could be important to the formation of benzene, a PAH precursor. ${ }^{2,3,4}$ Amongst other contributing factors, the details of the $\mathrm{C}_{4} \mathrm{H}_{5} \mathrm{PES}$ itself influences the time evolution of $\mathrm{C}_{4} \mathrm{H}_{5}$ isomers in complex mixtures. Meanwhile, in low temperature environments, where reactive species drive forward the growth of the carbon-chain, $\mathrm{CH}$ and $\mathrm{C}_{2} \mathrm{H}$ reactions are often important. ${ }^{6,7,8,9}$ Relative to the $\mathrm{C}_{4} \mathrm{H}_{5} \mathrm{PES}, \mathrm{C}_{2} \mathrm{H}$ can react with ethene while $\mathrm{CH}$ can react with allene or methylacetylene. Although a detailed theoretical investigation of the $\mathrm{C}_{2} \mathrm{H}+\mathrm{C}_{2} \mathrm{H}_{4}$ reaction has been conducted, ${ }^{6}$ a detailed theoretical investigation into both the unimolecular kinetics and product distribution of the aforementioned $\mathrm{CH}$ reactions has not, to our knowledge, been performed. In a sense, this is a continuation of previous mechanistic studies we have performed regarding the reactions between $\mathrm{CH}$ with propene and propane. ${ }^{10,11}$ Using a similar procedure as for those studies, we will look into the mechanisms behind the final product distribution for each $\mathrm{C}_{4} \mathrm{H}_{5}$ isomer that, at least in principle, can be accessed from the entrance channels. These include all the $\mathrm{C}_{4} \mathrm{H}_{5}$ isomers that have been detected in fuel rich flames. A comparison of these results will be made with previous experimental branching ratio studies. ${ }^{12,13}$ In addition, however, we have also generated a thorough $\mathrm{C}_{4} \mathrm{H}_{5}$ PES in the form of a PAPER $^{14,15}$ input file so that the pressure and temperature dependence of various $\mathrm{C}_{4} \mathrm{H}_{5}$ 
reactions could be studied after quick extension and/or modification and/or cutting of this file.

Methods:

The optimizations on the $\mathrm{C}_{4} \mathrm{H}_{5}$ PES all used the $\mathrm{B} 3 \mathrm{LY} \mathrm{Y}^{16,17}$ hybrid functional and the $6-311++\mathrm{G}(\mathrm{d}, \mathrm{p})$ basis set. ${ }^{18}$ In order to characterize the nature of these structures (i.e. minima vs. saddle points), harmonic frequencies were calculated at the B3LYP/6$311++\mathrm{G}(\mathrm{d}, \mathrm{p})$ level as well. Zero-point energies for all structures are thus B3LYP/6$311++\mathrm{G}(\mathrm{d}, \mathrm{p})$ level corrections. Last, these B3LYP/6-311++G(d,p) level harmonic frequencies were used in rate constant and master equation calculations.

The energies for all chemical species, meanwhile, underwent further refinement; in most cases, this was done using complete basis set limit $\operatorname{CCSD}(\mathrm{T})-\mathrm{F} 12^{19,20}$ energies. The extrapolations were based on a two-point extrapolation technique ${ }^{21}$ using the VTZ-F12 and VQZ-F12 basis sets. ${ }^{22}$ In order to describe the behavior of the adducts which stem from an initial addition of the $\mathrm{CH}$ radical to a carbon atom, however, whose available transition state structures showed some quite large t amplitudes, CASPT2 ${ }^{23}$ calculations using a $3 \times 3$ active space were performed.

The approach to calculating the product branching ratios resulting from the reactions involved one-dimensional master equation calculations using the PAPER software package ${ }^{14,15}$ Here, the rigid-rotor harmonic oscillator approximation was used for the density of state of all species, except for soft internal rotations which were treated using the hindered rotor model. ${ }^{24}$ To model these hindered rotations, their potential were mapped at the B3LYP/6-311G(d,p) level. Meanwhile, in order to describe the collisional energy transfer in the master equation, an "exponential down" model ${ }^{25}$ was used, with the 
temperature dependence of the range parameter $\alpha$ for the deactivating wing of the energy transfer expressed as $\alpha(T)=\alpha_{300}(T / 300 K)^{n}$ where $\alpha_{300}=228 \mathrm{~cm}^{-1}$ and $n=0.86 .^{26}$ The Lennard-Jones collision parameters were $\left(\varepsilon / \mathrm{cm}^{-1}, \sigma / \AA\right)=(19.8,3.38)$ and $(44.2,3.43) .{ }^{26}$ The unimolecular rate constants presented in this publication, meanwhile, were calculated at the zero-pressure limit, without treatment of hindered rotations. These E-dependent rate constants were calculated using the Rice-Ramsperger-Kassel-Marcus (RRKM) method, ${ }^{27}$ whose expression is

$$
k(E)=\frac{\sigma W^{\ddagger}\left(E-E^{\ddagger}\right)}{h \rho}
$$

where $\sigma$ is the reaction path degeneracy, $h$ is Planck’s constant, $W^{\ddagger}\left(E-E^{\ddagger}\right)$ is the total number of states of the transition state, and $\rho(E)$ represents the density of states of the energized reactants. Here, the internal energy was taken as a sum of the energy of chemical activation in the $\mathrm{CH}+\mathrm{C}_{3} \mathrm{H}_{4}$ reaction and a collision energy, with the assumption that a dominant fraction of the latter is converted to the internal vibrational energy.

Results and Discussion:

Entrance Channels:

The two $\mathrm{CH}$ radical reactions available on the $\mathrm{C}_{4} \mathrm{H}_{5}$ PES exhibit a particular difference as compared to the analogous reaction on the $\mathrm{C}_{4} \mathrm{H}_{7} \mathrm{PES}$; while on the $\mathrm{C}_{4} \mathrm{H}_{5} \mathrm{PES}$ it is possible to locate a well corresponding to $\mathrm{CH}$ addition to a carbon atom, it does not appear that such a well exists on the $\mathrm{C}_{4} \mathrm{H}_{7}$ PES. ${ }^{10}$ An analogous behavior is exhibited on the $\mathrm{C}_{3} \mathrm{H}_{3}$ PES and $\mathrm{C}_{3} \mathrm{H}_{5}$ PES. Regarding the reactions between $\mathrm{CH}$ and ethene/propene $\left(\mathrm{C}_{3} \mathrm{H}_{5} / \mathrm{C}_{4} \mathrm{H}_{7} \mathrm{PES}\right)$, current experimental observations coupled to theoretical treatments suggest that $\mathrm{CH}$ addition to the double bond is the major entrance channel reaction and that 
the available $\mathrm{C}-\mathrm{H} \sigma$ bond insertions together add up to minor (although non-negligible) reaction paths. ${ }^{10,13}$ Picturing the PES, this means that a large surface area on the 3-D slice describing mutual fragment approach acts as a steep funnel towards the double bond addition well. It is important to mention that for the reaction between $\mathrm{C}_{2} \mathrm{H}_{2}$ and $\mathrm{CH}$, where both a $\mathrm{CH}$ radical addition to a carbon atom and a $\mathrm{CH}$ radical addition to a triple bond are possible, the results from semi-classical trajectories run in our group suggests that both of these additions together dominate the possible $\mathrm{CH}$ radical $\mathrm{C}-\mathrm{H} \sigma$ bond insertion entrance channel which are minor, but observed nonetheless. Although these results are in a qualitative stage at the moment, it suggests that for the present publication, and in order to understand the reactions of the $\mathrm{CH}$ radical with unsaturated species as a whole, it is important to know if the existence of a carbon addition well on the $\mathrm{C}_{4} \mathrm{H}_{5}$ PES will amount to a simple two-step double/triple bond addition via a fast ring close or if it will have a large "dispersing" effect on how the $\mathrm{C}_{4} \mathrm{H}_{5}$ PES is sampled after initial reactive encounter. If the former is true, it is quite possible then the product distributions for all $\mathrm{CH}$ radical reactions with $\mathrm{C} 2$ and $\mathrm{C} 3$ unsaturated species can all be thought of as depending in large part on the evolution of the original double/triple bond addition intermediate.

Methylacetylene + CH, Carbon Addition:

There exist two important conformers that correspond to an addition to the terminal carbon; these will be labelled trans- $\mathrm{CH}_{3} \cdot \mathrm{CCHCH}$ and cis- $\mathrm{CH}_{3} \cdot \mathrm{CCHCH}$. The structures have similar energies, with the cis isomer being somewhat more exothermic; cis$\mathrm{CH}_{3} \cdot \mathrm{CCHCH}$ is $22.5 \mathrm{kcal} / \mathrm{mol}$ exothermic while the trans isomer lies $20.1 \mathrm{kcal} / \mathrm{mol}$ below reactants. In the context of $\mathrm{CH}$ radical reactions, where intermediates often lie in deep wells, these thus correspond to metastable configurations. Figure 5.1 below depicts the PES 
corresponding to these isomers; in addition, we summarize below the isomerization channels available to these adducts along with their respective barrier heights:

$\begin{array}{ll}\text { cis }-\mathrm{CH}_{3} \cdot \mathrm{CCHCH} \rightarrow \text { trans }-\mathrm{CH}_{3} \cdot \mathrm{CCHCH} & 3.6 \mathrm{kcal} / \mathrm{mol}(\mathrm{TS} 1 \mathrm{a}) \\ \text { trans }-\mathrm{CH}_{3} \cdot \mathrm{CCHCH} \rightarrow \mathrm{CH}_{3}-\mathrm{cCCH} \cdot \mathrm{CH} & \text { No barrier } \\ \text { trans }-\mathrm{CH}_{3} \cdot \mathrm{CCHCH} \rightarrow \mathrm{CH}_{3} \mathrm{CC} \cdot \mathrm{CH}_{2} & 2.8 \mathrm{kcal} / \mathrm{mol}(\mathrm{TS} 1 \mathrm{~b}) \\ \text { cis }-\mathrm{CH}_{3} \cdot \mathrm{CCHCH} \rightarrow \cdot \mathrm{CH}_{2} \mathrm{CHCCH} & \\ \text { cis }-\mathrm{CH}_{3} \cdot \mathrm{CCHCH} \rightarrow \mathrm{CH}_{2} \mathrm{CHCH} \cdot \mathrm{CH} & 6.4 \mathrm{kcal} / \mathrm{mol}(\mathrm{TS} 1 \mathrm{c})\end{array}$

First, a bending motion leading to ring close is the favorable energetic path. It leads to the species formed via direct $\mathrm{CH}$ addition to the triple bond. On the other hand, the $\mathrm{H}$ shift between adjacent carbon centers (TS1d) is endothermic and might not be expected to contribute at lower temperatures. Also, the energetics associated with conformational change (TS1a) suggests that it might be possible for the product distribution to differ depending on whether the cis or trans isomer is formed from the initial addition reaction. As can be seen in Table 5.2, this turns out not to be the case, except to a small degree: Beginning first with trans- $\mathrm{CH}_{3} \cdot \mathrm{CCHCH}$, the major product is 1,2,3-butatriene, accounting for $60 \%$ of the total products, while vinylacetylene accounts for $23 \%$; assuming the cis isomer first, close to $4 \%$ of the previous 1,2,3-butatriene is re-distributed as vinylacetylene. In both cases, $\mathrm{CH}_{2}-\mathrm{cCCHCH}$ accounts for $17 \%$ of the total products.

Methylacetylene $+\mathrm{CH}$, Triple Bond Addition:

$\mathrm{CH}$ addition to a triple bond leads to a three-membered ring, labeled $\mathrm{CH}_{3}$ $\mathrm{cCCH} \cdot \mathrm{CH}$, which has two important conformations. $\mathrm{CH}_{3}-\mathrm{cCCH} \cdot \mathrm{CH}\left(\mathrm{C}_{\mathrm{s}}\right)$, belonging to the $\mathrm{C}_{\text {s }}$ point group, is $-77.2 \mathrm{kcal} / \mathrm{mol}$ exothermic while $\mathrm{CH}_{3}-\mathrm{cCCH} \cdot \mathrm{CH}\left(\mathrm{C}_{1}\right)$ is $80.1 \mathrm{kcal} / \mathrm{mol}$ below reactants. Figure 5.2 contains the relevant PES to both species. The barrier height 
towards simple conformational change, via TS2a, is $\sim 30 \mathrm{kcal} / \mathrm{mol}$ lower than all remaining barriers indicating that the triple bond adduct will sample both conformations before reacting further (pseudo-equilibrium). Below are the remaining channels available to $\mathrm{CH}_{3}$ $\mathrm{cCCH} \cdot \mathrm{CH}$.

$$
\begin{array}{ll}
\mathrm{CH}_{3}-\mathrm{cCCH} \cdot \mathrm{CH}\left(\mathrm{C}_{1}\right) \rightarrow \mathrm{CH}_{3} \mathrm{C}(\mathrm{C}) \cdot \mathrm{CH}_{2} & 35.4 \mathrm{kcal} / \mathrm{mol}(\mathrm{TS} 2 \mathrm{~b}) \\
\mathrm{CH}_{3}-\mathrm{cCCH} \cdot \mathrm{CH}\left(\mathrm{C}_{1}\right) \rightarrow \mathrm{CH}_{2} \mathrm{CHCH} \cdot \mathrm{CH} & 55.8 \mathrm{kcal} / \mathrm{mol}(\mathrm{TS} 2 \mathrm{c}) \\
\mathrm{CH}_{3}-\mathrm{cCCH} \cdot \mathrm{CH}\left(\mathrm{C}_{1}\right) \rightarrow \mathrm{CH}_{3} \cdot \mathrm{CHCCH} & 56.4 \mathrm{kcal} / \mathrm{mol}(\mathrm{TS} 2 \mathrm{~d}) \\
\mathrm{CH}_{3}-\mathrm{cCCH} \cdot \mathrm{CH}\left(\mathrm{C}_{1}\right) \rightarrow \mathrm{CH}_{3} \cdot \mathrm{CCHCH} & \text { No barrier } \\
\mathrm{CH}_{3}-\mathrm{cCCH} \cdot \mathrm{CH}\left(\mathrm{C}_{\mathrm{s}}\right) \rightarrow \cdot \mathrm{CH}_{2}-\mathrm{cCHCHCH} & 48.0 \mathrm{kcal} / \mathrm{mol}(\mathrm{TS} 2 \mathrm{e}) \\
\mathrm{CH}_{3}-\mathrm{cCCH} \cdot \mathrm{CH}\left(\mathrm{C}_{\mathrm{s}}\right) \rightarrow \mathrm{CH}_{2}-\mathrm{cCCHCH}+\mathrm{H} & 38.1 \mathrm{kcal} / \mathrm{mol}(\mathrm{TS} 2 \mathrm{f})
\end{array}
$$

From the energetics above it might be expected that the evolution of $\mathrm{CH}_{3}-\mathrm{cCCH} \cdot \mathrm{CH}$ will depend on the competition between two channels: One is a concerted 1,3 $\mathrm{H}$ shift + ring opening leading to $\mathrm{CH}_{3} \mathrm{C}(\mathrm{C}) \cdot \mathrm{CH}_{2}$, a branched species, the other an $\mathrm{H}$ loss. Although the barrier height towards $\mathrm{H}$ loss is higher, its corresponding transition state structure is looser. Rate coefficients in Table 5.1 confirm that these two channels indeed dominate. Further, it indicates that the isomerization channel is somewhat favored over the $\mathrm{H}$ loss at low temperatures. The product distribution is given in Table 5.2 and is similar to the distribution observed after the initial carbon addition described above reflecting the fact that ring closure is the major channel available to the $\mathrm{CH}_{3} \cdot \mathrm{CCHCH}$ adduct: $1,2,3$-butatriene's branching ratio is $57.3 \%$, vinylacetylene $22.0 \%$, and methylenecyclopropene $20.4 \%$. Methylacetylene $+\mathrm{CH}$, Insertions:

$\mathrm{CH}$ radical insertion into the sp $\mathrm{C}-\mathrm{H}$ bond leads to the $\mathrm{CH}_{3} \cdot \mathrm{CCCH}_{2}$ species; at 110.3 $\mathrm{kcal} / \mathrm{mol}$ below reactants, it is the most exothermic species on the $\mathrm{C}_{4} \mathrm{H}_{5}$ PES. Several 
channels are available to $\mathrm{CH}_{3} \cdot \mathrm{CCCH}_{2}$, all of which are depicted in Figure 5.3 and also below:

$$
\begin{array}{lr}
\mathrm{CH}_{3} \cdot \mathrm{CCCH}_{2} \rightarrow \mathrm{CH}_{3}-\mathrm{c} \cdot \mathrm{CCCH}_{2} & 46.8 \mathrm{kcal} / \mathrm{mol}(\mathrm{TS} 3 \mathrm{a}) \\
\mathrm{CH}_{3} \cdot \mathrm{CCCH}_{2} \rightarrow \cdot \mathrm{CH}_{2} \mathrm{CHCCH}{ }_{2} & 55.4 \mathrm{kcal} / \mathrm{mol}(\mathrm{TS} 3 \mathrm{~b}) \\
\mathrm{CH}_{3} \cdot \mathrm{CCCH}_{2} \rightarrow \mathrm{CH}_{3} \mathrm{C}(\mathrm{C}) \cdot \mathrm{CH}_{2} & 58.9 \mathrm{kcal} / \mathrm{mol}(\mathrm{TS} 3 \mathrm{c}) \\
\mathrm{CH}_{3} \cdot \mathrm{CCCH}_{2} \rightarrow \mathrm{CH}_{3} \cdot \mathrm{CCHCH} & 93.0 \mathrm{kcal} / \mathrm{mol}(\mathrm{TS} 1 \mathrm{~b}) \\
\mathrm{CH}_{3} \cdot \mathrm{CCCH}_{2} \rightarrow \mathrm{CH}_{3} \mathrm{CHC} \cdot \mathrm{CH} & 106.4 \mathrm{kcal} / \mathrm{mol}(\mathrm{TS} 3 \mathrm{~d}) \\
\mathrm{CH}_{3} \cdot \mathrm{CCCH}_{2} \rightarrow 1,2,3-\text { butatriene }+\mathrm{H} & 55.1 \mathrm{kcal} / \mathrm{mol}(\mathrm{TS} 3 \mathrm{e})
\end{array}
$$

A C-C-C bend leading to $\mathrm{CH}_{3}-\mathrm{c} \cdot \mathrm{CCCH}_{2}$, a three-membered ring species, is available and this channel has the most favorable energetics. An $\mathrm{H}$ loss producing 1,2,3-butatriene is also available. The $\mathrm{H}$ loss barrier height is $\sim 8 \mathrm{kcal} / \mathrm{mol}$ higher than the bend, but it is also much looser. The RRKM rate coefficients in Table 5.1 shows that in fact direct $\mathrm{H}$ loss is the major channel $\left(1.3 \times 10^{9} \mathrm{~s}^{-1}\right.$ vs. $\left.2.4 \times 10^{8} \mathrm{~s}^{-1}\right)$. It also shows that the $1,2 \mathrm{H}$ shift leading to $\cdot \mathrm{CH}_{2} \mathrm{CHCCH}_{2}$ is a non-negligible channel. The $\cdot \mathrm{CH}_{2} \mathrm{CHCCH}_{2}$ molecule will be discussed in detail in the context of allene reaction with $\mathrm{CH}$ but regions of PES it samples are given in figure 5.8). Overall, the final product distribution is $76.7 \%$ 1,2,3-butatriene and $23.0 \%$ vinylacetylene.

A $\mathrm{CH}$ radical insertion into a $\mathrm{sp}^{3} \mathrm{C}-\mathrm{H}$ bond, meanwhile, leads to $\cdot \mathrm{CH}_{2} \mathrm{CH}_{2} \mathrm{CCH}$, which was investigated and discussed in detail in the context of ethene reaction with $\mathrm{C}_{2} \mathrm{H} .{ }^{6}$ The following discussion will thus be brief. A simplified PES relevant to the radical is given in Figure 5.4. There are two important channels governing the radical's evolution. An $\mathrm{H}$ shift leading to $\mathrm{CH}_{3} \mathrm{CHC} \cdot \mathrm{CH}$ is available, as is an $\mathrm{H}$ loss. The RRKM rate coefficients from Krishtal et. al. for both channels are quite similar, indicating both 
channels are $~$ equiprobable. In the context of $\mathrm{CH}$ radical reactions, where the wells and saddle points are much more exothermic, the looser nature of the $\mathrm{H}$ loss transition state structure enhances its rate coefficient (relative to the $\mathrm{H}$ shift). Overall, Krishtal et al. found exclusive vinylacetylene production, both from direct $\cdot \mathrm{CH}_{2} \mathrm{CH}_{2} \mathrm{CCH} \mathrm{H}$ loss and also from the $\mathrm{H}$ shift to $\mathrm{CH}_{3} \mathrm{CHC} \cdot \mathrm{CH}$ which then loses an $\mathrm{H}$. Table 5.2 contains our final predicted product distribution, which sees a slight modification as $\sim 5 \%$ of the products are recast as acetylene. This stems from a $\sim 4 \mathrm{kcal} / \mathrm{mol}$ lowering of the barrier height connecting $\cdot \mathrm{CH}_{2} \mathrm{CH}_{2} \mathrm{CCH}$ to $\mathrm{CH}_{2} \mathrm{CHCH} \cdot \mathrm{CH}$ which can then undergo $\mathrm{C}-\mathrm{C}$ cleavage.

Last is the possible insertion of a $\mathrm{CH}$ radical into a $\mathrm{C}-\mathrm{C} \sigma$ bond, which would produce the $\mathrm{CH}_{3} \mathrm{CHC} \cdot \mathrm{CH}$ molecule, an exothermic intermediate which lies $107.6 \mathrm{kcal} / \mathrm{mol}$ below reactants. It was suggested in the previous paragraph that its major reaction channel might be just a simple $\mathrm{H}$ loss to produce vinylacetylene. Indeed this is the case and master equation calculations predict its branching ratio to be $99.1 \%$. Figure 5.5 shows its available isomerizations and exit channels, and shows that the barrier heights to isomerization are too high.

Allene $+\mathrm{CH}$, Carbon Additions:

The addition of the $\mathrm{CH}$ radical onto either the middle or terminal carbon of allene is possible, as both exist as wells on the $\mathrm{C}_{4} \mathrm{H}_{5}$ PES. The middle addition, however, has no available channel except to ring close to the double bond addition intermediate, which is treated in the following section, and can thus be ignored. The terminal addition intermediate on the other hand is not so trivial, and it contains several reaction channels. First, it is important to mention that there are two important conformations of the $\mathrm{CH}_{2} \cdot \mathrm{CCH}_{2} \mathrm{CH}$ as can be seen in Figure 5.6; however, a search for the transition state 
structure was not successful. Thus the approach here was to average the branching ratios for each isomer since they are very similar in stability and might be formed in roughly equal amounts from the entrance channel. The channels available are summarized below:
(1) $\mathrm{CH}_{2} \cdot \mathrm{CCH}_{2} \mathrm{CH} \rightarrow \mathrm{CH}_{2}-\mathrm{cC} \cdot \mathrm{CHCH}_{2} \quad$ No barrier
(1) $\mathrm{CH}_{2} \cdot \mathrm{CCH}_{2} \mathrm{CH} \rightarrow \cdot \mathrm{CH}_{2} \mathrm{CH}_{2} \mathrm{CCH}$
$1.40 \mathrm{kcal} / \mathrm{mol}(\mathrm{TSa} 1)$
(2) $\mathrm{CH}_{2} \cdot \mathrm{CCH}_{2} \mathrm{CH} \rightarrow \cdot \mathrm{CH}_{2} \mathrm{CHCCH}_{2}$
No barrier
(2) $\mathrm{CH}_{2} \cdot \mathrm{CCH}_{2} \mathrm{CH} \rightarrow \cdot \mathrm{CH}_{2} \mathrm{CHCH} \cdot \mathrm{CH}$
$8.80 \mathrm{kcal} / \mathrm{mol}(\mathrm{TSa} 2)$

Thus each of the isomers has a barrierless path available as well as a channel with a barrier. The barrierless processes produce the intermediates available to allene $+\mathrm{CH}$ directly from addition to the double bond and $\mathrm{C}-\mathrm{H}$ insertion and will be discussed next. TSa1 is a 1,4 H shift which is very entropically hindered and thus the system after carbon addition should evolve simply according to the intermediates in the following sections.

\section{Allene + CH, Double Bond Addition:}

With an addition of the $\mathrm{CH}$ radical onto a double bond of allene a three-membered ring species is generated, $\mathrm{CH}_{2}-\mathrm{cC} \cdot \mathrm{CHCH}_{2}$, which is an exothermic species lying 92.7 $\mathrm{kcal} / \mathrm{mol}$ below reactants. Its evolution is governed, in principle, via the competition between six reaction paths; of these, five are isomerization channels and one is an exit channel. These paths are summarized below, along with their relevant barrier heights:

$$
\begin{aligned}
& \mathrm{CH}_{2}-\mathrm{cC} \cdot \mathrm{CHCH}_{2} \rightarrow \cdot \mathrm{CH}_{2} \mathrm{CHCCH}_{2} \quad 16.5 \mathrm{kcal} / \mathrm{mol} \text { (TSb1) } \\
& \mathrm{CH}_{2}-\mathrm{cC} \cdot \mathrm{CHCH}_{2} \rightarrow \mathrm{CH}_{3} \mathrm{C}(\mathrm{C}) \cdot \mathrm{CH}_{2} \quad 39.5 \mathrm{kcal} / \mathrm{mol}(\mathrm{TSb} 2) \\
& \mathrm{CH}_{2}-\mathrm{cC} \cdot \mathrm{CHCH}_{2} \rightarrow \mathrm{bicCH}_{2} \mathrm{CHCCH}_{2} \quad 49.6 \mathrm{kcal} / \mathrm{mol}(\mathrm{TSb} 3) \\
& \mathrm{CH}_{2}-\mathrm{cC} \cdot \mathrm{CHCH}_{2} \rightarrow \mathrm{CH}_{2} \mathrm{CHCH} \cdot \mathrm{CH} \quad 80.4 \mathrm{kcal} / \mathrm{mol}(\mathrm{TSb} 4) \\
& \mathrm{CH}_{2}-\mathrm{cC} \cdot \mathrm{CHCH}_{2} \rightarrow \mathrm{bicCH}_{2} \mathrm{CHCHCH} \quad 81.3 \mathrm{kcal} / \mathrm{mol} \text { (TSb5) }
\end{aligned}
$$




$$
\mathrm{CH}_{2}-\mathrm{cC} \cdot \mathrm{CHCH}_{2} \rightarrow \mathrm{CH}_{2}-\mathrm{cCCHCH}+\mathrm{H} \quad 52.4 \mathrm{kcal} / \mathrm{mol}(\mathrm{TSb} 6)
$$

Two of the isomerization channels above, from energetic considerations alone, can be ruled out as uncompetitive channels; both channels describe some fashion of an $\mathrm{H}$ shift + ring open/close, a concerted process. RRKM rate constants in Table 5.3 confirm that both are indeed negligible. The channel describing a simple ring opening, meanwhile, shows the most favorable energetics of the remaining channels, at least $23.0 \mathrm{kcal} / \mathrm{mol} \mathrm{so}$, and might be expected to be the dominant channel. Rate constants in table 5.3 show that simple ring opening of the three-membered ring is indeed orders of magnitude faster than the remaining channels $\left(3.80 \times 10^{12} \mathrm{~s}^{-1}\right.$ vs. $1.01 \times 10^{10} \mathrm{~s}^{-1}$ for the next faster $\left.k\right)$. The net result is that the $\mathrm{CH}_{2}-\mathrm{cC} \cdot \mathrm{CHCH}_{2}$ radical, regardless of the temperature, "merges" with the $\cdot \mathrm{CH}_{2} \mathrm{CHCCH}_{2}$ radical through ring opening; since the $\mathrm{CH}_{2} \mathrm{CHCCH}_{2}$ radical is the configuration accessible via direct $\mathrm{C}-\mathrm{H}$ bond insertion, the double bond addition entrance channel is "merged" with the entrance channel corresponding to $\mathrm{C}-\mathrm{H}$ bond insertion, which is discussed next. This is similar behavior as what was shown in the reaction between propene and the $\mathrm{CH}$ radical (i.e. initial addition forms three-membered ring which undergoes a fast ring opening to produce the " $\mathrm{sp}^{2} \mathrm{C}-\mathrm{H} \sigma$ bond insertion intermediate"). The final product branching ratios give $96.4 \%$ vinylacetylene.

\section{Allene $+\mathrm{CH}, \mathrm{C}-\mathrm{H}$ Bond Insertion:}

The $\cdot \mathrm{CH}_{2} \mathrm{CHCCH}_{2}$ radical, labelled $i-\mathrm{C}_{4} \mathrm{H}_{5}$ in Miller's et al. 2000 publication, is $108.9 \mathrm{kcal} / \mathrm{mol}$ exothermic, at least in part due to electronic delocalization of its unpaired electron. Its time evolution depends on the competition between eight available channels, six of which are isomerization reactions and two of which are simple $\mathrm{H}$ loss processes:

$$
\cdot \mathrm{CH}_{2} \mathrm{CHCCH}_{2} \rightarrow \mathrm{CH}_{2}-\mathrm{cC} \cdot \mathrm{CHCH}_{2} \quad 32.7 \mathrm{kcal} / \mathrm{mol}(\mathrm{TSb} 1)
$$




$$
\begin{array}{cc}
\cdot \mathrm{CH}_{2} \mathrm{CHCCH}_{2} \rightarrow \mathrm{CH}_{3} \cdot \mathrm{CCCH}_{2} & 53.0 \mathrm{kcal} / \mathrm{mol}(\mathrm{TS} 3 \mathrm{~b}) \\
\cdot \mathrm{CH}_{2} \mathrm{CHCCH}_{2} \rightarrow \mathrm{CH}_{2} \mathrm{CHCH} \cdot \mathrm{CH} & 55.1 \mathrm{kcal} / \mathrm{mol}(\mathrm{TSc} 1) \\
\cdot \mathrm{CH}_{2} \mathrm{CHCCH}_{2} \rightarrow \mathrm{CH}_{2} \mathrm{CHCH} \cdot \mathrm{CH} & 55.2 \mathrm{kcal} / \mathrm{mol}(\mathrm{TSc} 2) \\
\cdot \mathrm{CH}_{2} \mathrm{CHCCH}_{2} \rightarrow \mathrm{cCH}_{2} \mathrm{CHCCH}_{2} & 50.0 \mathrm{kcal} / \mathrm{mol}(\mathrm{TSc} 3) \\
\cdot \mathrm{CH}_{2} \mathrm{CHCCH}_{2} \rightarrow \mathrm{CH}_{3} \mathrm{CHC} \cdot \mathrm{CH} & 62.4 \mathrm{kcal} / \mathrm{mol}(\mathrm{TSc} 4) \\
\cdot \mathrm{CH}_{2} \mathrm{CHCCH}_{2} \rightarrow \text { Vinylacetylene }+\cdot \mathrm{H} & 45.3 \mathrm{kcal} / \mathrm{mol}(\mathrm{TSc} 5) \\
\cdot \mathrm{CH}_{2} \mathrm{CHCCH} & \rightarrow 1,2,3-\mathrm{Butatriene}+\cdot \mathrm{H}
\end{array}
$$

As can be seen, the path with the most favorable energetics, via TSb1, ring closes the $\cdot \mathrm{CH}_{2} \mathrm{CHCCH}_{2}$ species and forms $\mathrm{CH}_{2}-\mathrm{CC} \cdot \mathrm{CHCH}_{2}$, which was discussed in the previous section. Also, most of the remaining available channels to $\cdot \mathrm{CH}_{2} \mathrm{CHCCH}_{2}$ have quite similar barrier heights, except for a terminal carbon $\mathrm{H}$ loss, via $\mathrm{TSc} 5$, which produces vinylacetylene. The RRKM rate constants show this direct $\mathrm{H}$ loss dominates while isomerization to $\mathrm{CH}_{2}-\mathrm{cC} \cdot \mathrm{CHCH}_{2}$ is minor $\left(7.64 \times 10^{11} \mathrm{~s}^{-1}\right.$ vs. $\left.1.40 \times 10^{11} \mathrm{~s}^{-1}\right)$. Although the barrier height to $\mathrm{H}$ loss is higher, the reaction channels are all quite exothermic; thus an entropic contribution to the rate constant is significant. A final vinylacetylene product branching ratio of $96.5 \%$ confirms this.

Comparison with previous studies:

The product distribution results show that for both $\mathrm{CH}$ radical reactions on the $\mathrm{C}_{4} \mathrm{H}_{5}$ PES, the $\mathrm{H}$ loss exit channels are dominant, and this finding agrees with previous branching ratio measurements. According to the results of Ref. 12, although $100 \% \mathrm{H}$ loss product formation is within the error bar for both reactions, the measured $\mathrm{H}$ atom branching ratios leaves a small window for a few percent of non- $\mathrm{H}$ loss product formation. Based on the present results, these non $\mathrm{H}$ loss products would both stem from $\mathrm{C}-\mathrm{C}$ cleavage to produce 
acetylene along with a vinyl radical. This is only possible if the system samples the $\mathrm{CH}_{2} \mathrm{CHCH} \cdot \mathrm{CH}$ configuration. In the case of methylacetylene $+\mathrm{CH}$, starting with initial sp3 $\mathrm{C}-\mathrm{H}$ bond insertion to produce $\cdot \mathrm{CH}_{2} \mathrm{CH}_{2} \mathrm{CCH}$, an $\mathrm{H}$ shift produces the $\mathrm{CH}_{2} \mathrm{CHCH} \cdot \mathrm{CH}$ species which then undergoes C-C cleavage. As can be seen in Table 5.2, initial sp3 C-H insertion would then predict $5.1 \%$ acetylene formation. As for the reaction between allene and $\mathrm{CH}$, the $\mathrm{CH}_{2} \mathrm{CHCH} \cdot \mathrm{CH}$ configuration can be accessed after an initial carbon to addition to produce the $\mathrm{CH}_{2} \cdot \mathrm{CCH}_{2} \mathrm{CH}$, which can then directly reach the $\mathrm{CH}_{2} \mathrm{CHCH} \cdot \mathrm{CH}$ configuration, or isomerize first to $\mathrm{CH}_{2} \mathrm{CH}_{2} \mathrm{CCH}$, which then follows the same scheme as was mentioned above. From Table 5.4 it can be seen that after initial carbon addition for the allene $+\mathrm{CH}$ reaction, again $5.3 \%$ of acetylene would be produced.

An interesting result from this study is that for the reaction between methylacetylene and the $\mathrm{CH}$ radical, there is a significant production of $\mathrm{CH}_{2}-\mathrm{cCCHCH}$ which is in qualitative agreement with the results in Ref. 13, which predicted its branching ratio to be between $24-36 \%$. There is some disagreement in the specifics, however, since the $\mathrm{CH}_{2}-\mathrm{cCCHCH}$ upper bound presently is $20.5 \%$. This upper bound would depend on all bimolecular entrance channels proceeding through an initial triple bond addition. While such an extreme is unlikely, it does again suggest that $\mathrm{CH}$ radical reactions with unsaturated hydrocarbons proceed in large part through this double/triple bond addition, and that the remaining channels are make-up minor reaction paths. In addition to the $30 \% \mathrm{CH}_{2}$ $\mathrm{cCCHCH}$ formation, Goulay et al. ${ }^{13}$ also found $33 \%$ and $37 \%$ 1,2,3-butatriene and vinylacetylene formation respectively for the methylacetylene $+\mathrm{CH}$ reaction. Again, if we were to assume only triple bond addition entrance channel reactions, the results from this study would be $57.3 \%$ and $22.0 \%$ 1,2,3-butatriene and vinylacetylene respectively. In 
particular, the 1,2,3-butatriene production would be the largest source of disagreement. The discrepancy can be made smaller by assigning proper weights to each of the possible entrance channels in a sensible way. From Table 5.2 we can see that the best way to increase the production of vinylacetylene is to assume $\sim 60 \%$ triple bond insertion, $\sim 28 \%$ carbon addition and $~ 12 \%$; this would result in $31.5 \%$ vinylacetylene production which would fall within the error bar of the experiments, $16.5 \% \mathrm{CH}_{2}-\mathrm{cCCHCH}$ production and $51.0 \%$ 1,2,3-butatriene. In such a case, $\mathrm{CH}_{2}$-cCCHCH would fall to $~ 7.5 \%$ from the error bar of the experiments and the 1,2,3-butatriene about $12 \%$. Also, if dynamical effects should be important after a triple bond addition, such an effect would increase $\mathrm{CH}_{2-}$ $\mathrm{cCCHCH}$ production and decreasing the production of both 1,2,3-butatriene and vinylacetylene, and thus could be one possible explanation to bringing the system these results to within the experimental values.

In the case of allene $+\mathrm{CH}$, Goulay et al. were not able to detect any cyclic structures in their experiments, being able only to detect vinylacetylene and 1,2,3-butatriene (77\% and $23 \%$ to be exact). Once again the results here can explain certain aspects of their findings. For instance, our results also do not predict the production of cyclic structures as the $\mathrm{CH}_{2}-\mathrm{cC} \cdot \mathrm{CHCH}_{2}$ is expected to quickly ring open based on our results. Our results also predict dominant vinylacetylene production, which all stem from an $\mathrm{H}$ loss from the $\cdot \mathrm{CH}_{2} \mathrm{CHCCH}_{2}$ species, which is easily accessible via all entrance channels. Our results, however, predict vinylacetylene production to be roughly $95 \%$ which is outside the error bars of Ref. 13 by about $13 \%$. 


\section{References:}

1. Miller, J. A.; Klippenstein, S. J.; Robertson, S. H. A Theoretical Analysis of the Reaction between Vinyl and Acetylene: Quantum Chemistry and Solution of the Master Equation. J. Phys. Chem. A 2000, 104, 7525-7536.

2. Hansen, N.; Klippenstein, S. J.; Taatjes, C. A.; Miller, J. A.; Wang, J.; Cool, T. A.; Yang, B.; Yang, R.; Wei, L.; Huang, C.; Wang, J.; Qi, F.; Law, M. E.; Westmoreland, P. R. Identification and Chemistry of $\mathrm{C}_{4} \mathrm{H}_{3}$ and $\mathrm{C}_{4} \mathrm{H}_{5}$ Isomers in Fuel-Rich Flames. J. Phys. Chem. A 2006, 110, 3670-3678.

3. Atakan, B.; Lamprecht, A.; Kohse-Hoinghaus, K. An experimental study of fuel-rich 1,3-pentadiene and acetylene/propene flames. Combust. Flame 2003, 133, 431-440.

4. Senosiain, J. P.; Miller, J. A. The Reaction of $n$ - and $i-\mathrm{C}_{4} \mathrm{H}_{5}$ Radicals with Acetylene. $J$. Phys. Chem. A 2007, 111, 3740-3747.

5. Kaiser, R. I.; Stranges, D.; Bevsek, H. M.; Lee, Y. T.; Suits A. G. Crossed-beam reaction of carbon atoms with hydrocarbon molecules. IV. Chemical dynamics of methylpropargyl radical formation, $\mathrm{C} 4 \mathrm{H} 5$, from reaction of $\mathrm{C}(3 \mathrm{Pj})$ with propylene, $\mathrm{C} 3 \mathrm{H} 6(\mathrm{X} \mathrm{1A})$. J. Chem. Phys. 1997, 106, 4945-4953.

6. Krishtal, S. P.; Mebel, A. M.; Kaiser, R. I. A Theoretical Study of the Reaction Mechanism and Product Branching Ratios of $\mathrm{C}_{2} \mathrm{H}+\mathrm{C}_{2} \mathrm{H}_{4}$ and Related Reactions on the $\mathrm{C}_{4} \mathrm{H}_{5}$ Potential Energy Surface. J. Phys. Chem. A 2009, 113, 11112-11128.

7. Bezard, B. Composition and chemistry of Titan's stratosphere. Phil. Trans. R. Soc. A 2009, 367, 683-695.

8. Peng, Z; Dobrijevic, M.; Hebrard, E.; Nathalie, C.; Pernot, P. Photochemical modeling of Titan atmosphere at the " 10 percent uncertainty horizon." Faraday Discuss. 2010, 147, $137-153$.

9. Jones, B. M.; Zhang, F.; Kaiser, R. I.; Jamal, A.; Mebel, A. M.; Cordiner, M. A.; Charnley, S. B. Formation of Benzene in the Interstellar Medium. Proc. Natl. Acad. Sci. U.S. A. 2011, 108, $452-457$.

10. Ribeiro, J. M.; Mebel, A. M. Reaction Mechanism and Product Branching Ratios of the $\mathrm{CH}+\mathrm{C}_{3} \mathrm{H}_{6}$ Reaction: A Theoretical Study. J. Phys. Chem. A 2016, 120, $1800-1812$.

11. Ribeiro, J. M.; Mebel, A. M. Reaction Mechanism and Product Branching Ratios of the $\mathrm{CH}+\mathrm{C}_{3} \mathrm{H}_{8}$ Reaction: A Theoretical Study. J. Phys. Chem. A 2014, 118, $9080-9086$. 
12. Loison, J. C; Bergeat, A. Rate Constants and the $\mathrm{H}$ Atom Branching Ratio of the Reactions of the Methylidyne $\mathrm{CH}\left(\mathrm{X}^{2} \Pi\right)$ Radical with $\mathrm{C}_{2} \mathrm{H}_{2}, \mathrm{C}_{2} \mathrm{H}_{4}, \mathrm{C}_{3} \mathrm{H}_{4}$ (Methylacetylene and Allene), $\mathrm{C}_{3} \mathrm{H}_{6}$ (Propene) and $\mathrm{C}_{4} \mathrm{H}_{8}$ (Trans-Butene). Phys. Chem. Chem. Phys., 2009, $11,655-664$.

13. Goulay, F.; Trevitt, A. J.; Meloni, G.; Selby, T. M.; Osborn, D. L.; Taatjes, C. A.; Vereecken, L.; Leone, S. R. Cyclic Versus Linear Isomers Produced by Reaction of the Methylidyne Radical (CH) with Small Unsaturated Hydrocarbons. J. Am. Chem. Soc. 2009, $131,993-1005$.

14. Georgievskii, Y.; Miller, J. A.; Burke, M. P.; Klippenstein, S. J. Reformulation and Solution of the Master Equation for Multiple-Well Chemical Reactions. J. Phys. Chem. A 2013, $117,12146-12154$.

15. Georgievskii, Y.; Jasper, A. W.; Zador, J.; Miller, J. A.; Burke, M. P.; Goldsmith, C. F.; Klippenstein, S. J. PAPER, v1; 2014.

16. Becke, A. D. Density-Functional Thermochemistry. III. The Role of Exact Exchange. J. Chem. Phys. 1993, 98, 5648-5652.

17. Lee, C.; Yang, W.; Parr, R. G. Development of the Colle-Salvetti Correlation-Energy Formula into a Functional of the Electron Density. Phys. Rev. B: Condens. Matter Mater. Phys. 1988, 37, $785-789$.

18. Krishnan, R.; Frisch, M.; Pople, J. A. Contribution of Triple Substitutions to the Electron Correlation Energy in Fourth Order Perturbation Theory. J. Chem. Phys. 1980, $72,4244-4245$.

19. Purvis, G. D.; Bartlett, R. J. A Full Coupled-Cluster Singles and Doubles Model: The Inclusion of Disconnected Triples. J. Chem. Phys. 1982, 76, 1910- 1918.

20. Knizia, G.; Adler, T. B.; Werner, H.-J. Simplified CCSD(T)-F12 Methods: Theory and Benchmarks. J. Chem. Phys. 2009, 130, 054104.

21. Peterson, K. A.; Dunning, T. H. Intrinsic Errors in Several ab Initio Methods: The Dissociation Energy of N2. J. Phys. Chem. 1995, 99, $3898-3901$.

22. Peterson, K . A.; Adler, T. B.; Werner, H.-J. Systematically Convergent Basis Sets for Explicitly Correlated Wavefunctions: The Atoms H, He, B-Ne, and Al-Ar. J. Chem. Phys. 2008, 128, 084102 
23. Werner, H. J. Third Order Multireference Perturbation Theory The CASPT3 Method. Mol. Phys. 1996, 89, 645-661.

24. Steinfeld, J.I.; Francisco, J.S.; Hase, W.L. Chemical Kinetics and Dynamics; PrenticeHall: Upper Saddle River, NJ, 1999.

25. Troe, J. Theory of Thermal Unimolecular Reactions at Low Pressures. 1. Solutions of the Master Equation. J. Chem. Phys. 1977, 66, 4745 - 4757.

26. Jasper, A. W.; Miller, J. A. Lennard-Jones Parameters for Combustion and Chemical Kinetics Modeling from Full-Dimensional Intermolecular Potentials. Combust. Flame 2014, 161, $101-110$.

27. Eyring, H.; Lin, S. H.; Lin, S. M. Basic Chemical Kinetics; Wiley: New York, 1980. 
Table 5.1: Methylacetylene $+\mathrm{CH}$ Radical Unimolecular Rate Coefficients, $k$. These are RRKM rate coefficients at $0 \mathrm{kcal} / \mathrm{mol}$ collision energy relevant to methylacetylene $+\mathrm{CH}$ radical reaction.

\begin{tabular}{|c|c|c|}
\hline cis $-\mathrm{CH}_{3} \cdot \mathrm{CCHCH} \rightarrow$ trans $-\mathrm{CH}_{3} \cdot \mathrm{CCHCH}$ & $2.2 \times 10^{12}$ & TS1a \\
\hline trans $-\mathrm{CH}_{3} \cdot \mathrm{CCHCH} \rightarrow$ cis $-\mathrm{CH}_{3} \cdot \mathrm{CCHCH}$ & $5.1 \times 10^{12}$ & TS1a \\
\hline trans $-\mathrm{CH}_{3} \cdot \mathrm{CCHCH} \rightarrow \mathrm{CH}_{3} \mathrm{CC} \cdot \mathrm{CH}_{2}$ & $4.3 \times 10^{11}$ & $\mathrm{TS} 1 \mathrm{~b}$ \\
\hline $\mathrm{CH}_{3} \mathrm{CC} \cdot \mathrm{CH}_{2} \rightarrow$ trans $-\mathrm{CH}_{3} \cdot \mathrm{CCHCH}$ & $4.8 \times 10^{4}$ & TS1b \\
\hline cis- $\mathrm{CH}_{3} \cdot \mathrm{CCHCH} \rightarrow \cdot \mathrm{CH}_{2} \mathrm{CHCCH}_{2}$ & $2.7 \times 10^{11}$ & TS1c \\
\hline$\cdot \mathrm{CH}_{2} \mathrm{CHCCH}_{2} \rightarrow$ cis $-\mathrm{CH}_{3} \cdot \mathrm{CCHCH}$ & $3.6 \times 10^{3}$ & TS1c \\
\hline cis $-\mathrm{CH}_{3} \cdot \mathrm{CCHCH} \rightarrow \mathrm{CH}_{2} \mathrm{CHCH} \cdot \mathrm{CH}$ & $8.1 \times 10^{4}$ & TS1d \\
\hline $\mathrm{CH}_{2} \mathrm{CHCH} \cdot \mathrm{CH} \rightarrow$ cis $-\mathrm{CH}_{3} \cdot \mathrm{CCHCH}$ & $7.4 \times 10^{-3}$ & TS1d \\
\hline $\mathrm{CH}_{3}-\mathrm{cCCH} \cdot \mathrm{CH}\left(\mathrm{C}_{1}\right) \rightarrow \mathrm{CH}_{3}-\mathrm{cCCH} \cdot \mathrm{CH}\left(\mathrm{C}_{\mathrm{s}}\right)$ & $5.9 \times 10^{12}$ & TS2a \\
\hline $\mathrm{CH}_{3}-\mathrm{cCCH} \cdot \mathrm{CH}\left(\mathrm{C}_{\mathrm{s}}\right) \rightarrow \mathrm{CH}_{3}-\mathrm{cCCH} \cdot \mathrm{CH}\left(\mathrm{C}_{1}\right)$ & $9.9 \times 10^{12}$ & TS2a \\
\hline $\mathrm{CH}_{3}-\mathrm{cCCH} \cdot \mathrm{CH}\left(\mathrm{C}_{1}\right) \rightarrow \mathrm{CH}_{3} \mathrm{C}(\mathrm{C}) \cdot \mathrm{CH}_{2}$ & $3.2 \times 10^{10}$ & $\mathrm{TS} 2 \mathrm{~b}$ \\
\hline $\mathrm{CH}_{3} \mathrm{C}(\mathrm{C}) \cdot \mathrm{CH}_{2} \rightarrow \mathrm{CH}_{3}-\mathrm{cCCH} \cdot \mathrm{CH}\left(\mathrm{C}_{1}\right)$ & $2.9 \times 10^{11}$ & $\mathrm{TS} 2 \mathrm{~b}$ \\
\hline $\mathrm{CH}_{3}-\mathrm{cCCH} \cdot \mathrm{CH}\left(\mathrm{C}_{1}\right) \rightarrow \mathrm{CH}_{2} \mathrm{CHCH} \cdot \mathrm{CH}$ & $2.4 \times 10^{7}$ & TS2c \\
\hline $\mathrm{CH}_{2} \mathrm{CHCH} \cdot \mathrm{CH} \rightarrow \mathrm{CH}_{3}-\mathrm{cCCH} \cdot \mathrm{CH}\left(\mathrm{C}_{1}\right)$ & $1.7 \times 10^{6}$ & TS2c \\
\hline $\mathrm{CH}_{3}-\mathrm{cCCH} \cdot \mathrm{CH}\left(\mathrm{C}_{1}\right) \rightarrow \mathrm{CH}_{3} \mathrm{CHC} \cdot \mathrm{CH}$ & $8.9 \times 10^{7}$ & TS2d \\
\hline $\mathrm{CH}_{3} \mathrm{CHC} \cdot \mathrm{CH} \rightarrow \mathrm{CH}_{3}-\mathrm{cCCH} \cdot \mathrm{CH}\left(\mathrm{C}_{1}\right)$ & $2.1 \times 10^{5}$ & TS2d \\
\hline $\mathrm{CH}_{3}-\mathrm{cCCH} \cdot \mathrm{CH}\left(\mathrm{C}_{\mathrm{s}}\right) \rightarrow \cdot \mathrm{CH}_{2}-\mathrm{cCHCHCH}$ & $1.1 \times 10^{9}$ & TS2e \\
\hline$\cdot \mathrm{CH}_{2}-\mathrm{cCHCHCH} \rightarrow \mathrm{CH}_{3}-\mathrm{cCCH} \cdot \mathrm{CH}\left(\mathrm{C}_{\mathrm{s}}\right)$ & $2.4 \times 10^{8}$ & TS2e \\
\hline $\mathrm{CH}_{3}-\mathrm{cCCH} \cdot \mathrm{CH}\left(\mathrm{C}_{\mathrm{s}}\right) \rightarrow \mathrm{CH}_{2}-\mathrm{cCCHCH}+\mathrm{H}$ & $3.3 \times 10^{10}$ & TS2f \\
\hline $\mathrm{CH}_{3} \cdot \mathrm{CCCH}_{2} \rightarrow \mathrm{CH}_{3}-\mathrm{cC} \cdot \mathrm{CCH}_{2}$ & $2.4 \times 10^{8}$ & TS3a \\
\hline
\end{tabular}




\begin{tabular}{|c|c|c|}
\hline $\mathrm{CH}_{3} \cdot \mathrm{cC} \cdot \mathrm{CCH}_{2} \rightarrow \mathrm{CH}_{3} \cdot \mathrm{CCCH}_{2}$ & $1.4 \times 10^{13}$ & TS3a \\
\hline $\mathrm{CH}_{3} \cdot \mathrm{CCCH}_{2} \rightarrow \cdot \mathrm{CH}_{2} \mathrm{CHCCH}_{2}$ & $5.1 \times 10^{8}$ & TS3b \\
\hline $\mathrm{CH}_{2} \mathrm{CHCCH}_{2} \rightarrow \mathrm{CH}_{3} \cdot \mathrm{CCCH}_{2}$ & $1.9 \times 10^{10}$ & TS3b \\
\hline $\mathrm{CH}_{3} \cdot \mathrm{CCCH}_{2} \rightarrow \mathrm{CH}_{3} \mathrm{C}(\mathrm{C}) \cdot \mathrm{CH}_{2}$ & $1.9 \times 10^{7}$ & TS3c \\
\hline $\mathrm{CH}_{3} \mathrm{C}(\mathrm{C}) \cdot \mathrm{CH}_{2} \rightarrow \mathrm{CH}_{3} \cdot \mathrm{CCCH}$ & \\
\hline $\mathrm{CH}_{3} \cdot \mathrm{CCCH}_{2} \rightarrow \mathrm{CH}_{3} \mathrm{CHC} \cdot \mathrm{CH}$ & $4.0 \times 10^{12}$ & TS3c \\
\hline $\mathrm{CH}_{3} \mathrm{CHC} \cdot \mathrm{CH} \rightarrow \mathrm{CH}_{3} \cdot \mathrm{CCCH}$ & $6.4 \times 10^{-1}$ & TS3d \\
\hline $\mathrm{CH}_{3} \cdot \mathrm{CCCH}_{2} \rightarrow 1,2,3-$ butatriene $+\mathrm{H}$ & $8.8 \times 10^{0}$ & TS3d \\
\hline
\end{tabular}


Table 5.2: Methylacetylene + $\mathrm{CH}$ Radical Product Branching Ratio. These are given as \%

\begin{tabular}{|c|c|c|c|c|c|}
\hline \multirow{2}{*}{ Products } & Terminal & Triple & sp C-H & sp3 C-H & sp3 C-C \\
& Carbon & Bond & Insertion & Insertion & Insertion \\
\hline $\mathrm{CH}_{2}$-cCCHCH + & 15.2 & 20.4 & 0.1 & 0.0 & 0.0 \\
$\mathrm{H}$ & & & & & \\
\hline $1,2,3$-butatriene + & 59.3 & 57.3 & 76.7 & 0.0 & 0.0 \\
$\mathrm{H}$ & & & & & \\
\hline Vinylacetylene + & 25.1 & 22.0 & 23.0 & 93.9 & 99.1 \\
$\mathrm{H}$ & & & & & \\
\hline Acetylene $+\mathrm{C}_{2} \mathrm{H}_{3}$ & 0.4 & 0.4 & 0.3 & 5.1 & 0.8 \\
\hline Ethene $+\mathrm{C}_{2} \mathrm{H}$ & 0.0 & 0.0 & 0.0 & 0.9 & 0.1 \\
\hline
\end{tabular}


Table 5.3: Allene + CH Radical Unimolecular Rate Coefficients, $k$. These are RRKM rate coefficients at $0 \mathrm{kcal} / \mathrm{mol}$ collision energy relevant to allene $+\mathrm{CH}$ radical reaction.

\begin{tabular}{|c|c|c|}
\hline $\mathrm{CH}_{2}-\mathrm{cC} \cdot \mathrm{CHCH}_{2} \rightarrow \cdot \mathrm{CH}_{2} \mathrm{CHCCH}_{2}$ & TSb1 & $3.80 \times 10^{12}$ \\
\hline$\cdot \mathrm{CH}_{2} \mathrm{CHCCH}_{2} \rightarrow \mathrm{CH}_{2}-\mathrm{cC} \cdot \mathrm{CHCH}_{2}$ & TSb1 & $1.40 \times 10^{11}$ \\
\hline $\mathrm{CH}_{2}-\mathrm{cC} \cdot \mathrm{CHCH}_{2} \rightarrow \mathrm{CH}_{3} \mathrm{C}(\mathrm{C}) \cdot \mathrm{CH}_{2}$ & TSb2 & $1.01 \times 10^{10}$ \\
\hline $\mathrm{CH}_{3} \mathrm{C}(\mathrm{C}) \cdot \mathrm{CH}_{2} \rightarrow \mathrm{CH}_{2}-\mathrm{cC} \cdot \mathrm{CHCH}_{2}$ & TSb2 & $6.42 \times 10^{11}$ \\
\hline $\mathrm{CH}_{2}-\mathrm{cC} \cdot \mathrm{CHCH}_{2} \rightarrow \mathrm{bicCH}_{2} \mathrm{CHCCH}_{2}$ & TSb3 & $2.61 \times 10^{8}$ \\
\hline $\mathrm{bicCH}_{2} \mathrm{CHCCH}_{2} \rightarrow \mathrm{CH}_{2}-\mathrm{cC} \cdot \mathrm{CHCH}_{2}$ & TSb3 & $7.15 \times 10^{10}$ \\
\hline $\mathrm{CH}_{2}-\mathrm{cC} \cdot \mathrm{CHCH}_{2} \rightarrow \mathrm{CH}_{2} \mathrm{CHCH} \cdot \mathrm{CH}$ & TSb4 & $1.10 \times 10^{4}$ \\
\hline $\mathrm{CH}_{2} \mathrm{CHCH} \cdot \mathrm{CH} \rightarrow \mathrm{CH}_{2}-\mathrm{cC} \cdot \mathrm{CHCH}_{2}$ & TSb4 & $2.96 \times 10^{3}$ \\
\hline $\mathrm{CH}_{2}$-cC $\cdot \mathrm{CHCH}_{2} \rightarrow \mathrm{bicCH}_{2} \mathrm{CHCHCH}$ & TSb5 & $6.24 \times 10^{3}$ \\
\hline $\mathrm{bicCH}_{2} \mathrm{CHCHCH} \rightarrow \mathrm{CH}_{2}-\mathrm{cC} \cdot \mathrm{CHCH}_{2}$ & TSb5 & $2.01 \times 10^{5}$ \\
\hline $\mathrm{CH}_{2}-\mathrm{cC} \cdot \mathrm{CHCH}_{2} \rightarrow \mathrm{CH}_{2}-\mathrm{cCCHCH}+\mathrm{H}$ & TSb6 & $6.33 \times 10^{9}$ \\
\hline$\cdot \mathrm{CH}_{2} \mathrm{CHCCH}_{2} \rightarrow \mathrm{CH}_{2} \mathrm{CHCH} \cdot \mathrm{CH}$ & $\mathrm{TSc} 1+\mathrm{TSc} 2$ & $6.45 \times 10^{9}$ \\
\hline $\mathrm{CH}_{2} \mathrm{CHCH} \cdot \mathrm{CH} \rightarrow \cdot \mathrm{CH}_{2} \mathrm{CHCCH}_{2}$ & $\mathrm{TSc} 1+\mathrm{TSc} 2$ & $4.69 \times 10^{10}$ \\
\hline$\cdot \mathrm{CH}_{2} \mathrm{CHCCH}_{2} \rightarrow \mathrm{CH}_{3} \cdot \mathrm{CCCH}_{2}$ & TS3b & $2.10 \times 10^{10}$ \\
\hline $\mathrm{CH}_{3} \cdot \mathrm{CCCH}_{2} \rightarrow \cdot \mathrm{CH}_{2} \mathrm{CHCCH}_{2}$ & TS3b & $5.64 \times 10^{8}$ \\
\hline$\cdot \mathrm{CH}_{2} \mathrm{CHCCH}_{2} \rightarrow \mathrm{cCH}_{2} \mathrm{CHCCH}_{2}$ & TSc3 & $4.66 \times 10^{8}$ \\
\hline $\mathrm{cCH}_{2} \mathrm{CHCCH}_{2} \rightarrow \cdot \mathrm{CH}_{2} \mathrm{CHCCH}_{2}$ & TSc3 & $2.37 \times 10^{11}$ \\
\hline$\cdot \mathrm{CH}_{2} \mathrm{CHCCH}_{2} \rightarrow$ vinylacetylene $+\mathrm{H}$ & TSc5 & $7.64 \times 10^{11}$ \\
\hline $\mathrm{CH}_{2} \mathrm{CHCCH}_{2} \rightarrow 1,2,3$-butatriene $+\mathrm{H}$ & TSc6 & $1.26 \times 10^{10}$ \\
\hline
\end{tabular}


Table 5.4: Allene + CH Radical Product Branching Ratio. These are given as $\%$.

\begin{tabular}{|c|c|c|c|}
\hline Products & Terminal Carbon & Double Bond & sp2 C-H Insertion \\
& Addition & Addition & \\
\hline $\mathrm{CH}_{2}$-cCCHCH + & 0.0 & 0.1 & 0.0 \\
$\mathrm{H}$ & 1.3 & 2.5 & 2.4 \\
$\mathrm{H}$ & & & 96.5 \\
\hline $\mathrm{H}$ & 93.0 & 96.4 & 1.0 \\
\hline Vinylacetylene + & & & 0.0 \\
\hline Acetylene $+\mathrm{C}_{2} \mathrm{H}_{3}$ & 5.3 & 1.0 & \\
\hline Ethene $+\mathrm{C}_{2} \mathrm{H}$ & 0.4 & 0.0 & \\
\hline
\end{tabular}


Figure 5.1: $\mathrm{C}_{4} \mathrm{H}_{5}$ PES, Part 1. This portion of CCSD(T)-F12/CBS//B3LYP/6-311++G(d,p) $\mathrm{C}_{4} \mathrm{H}_{5}$ PES is relevant to the $\mathrm{CH}_{3} \cdot \mathrm{CCHCH}$ molecule formed after initial $\mathrm{CH}$ addition to the terminal carbon of methylacetylene.

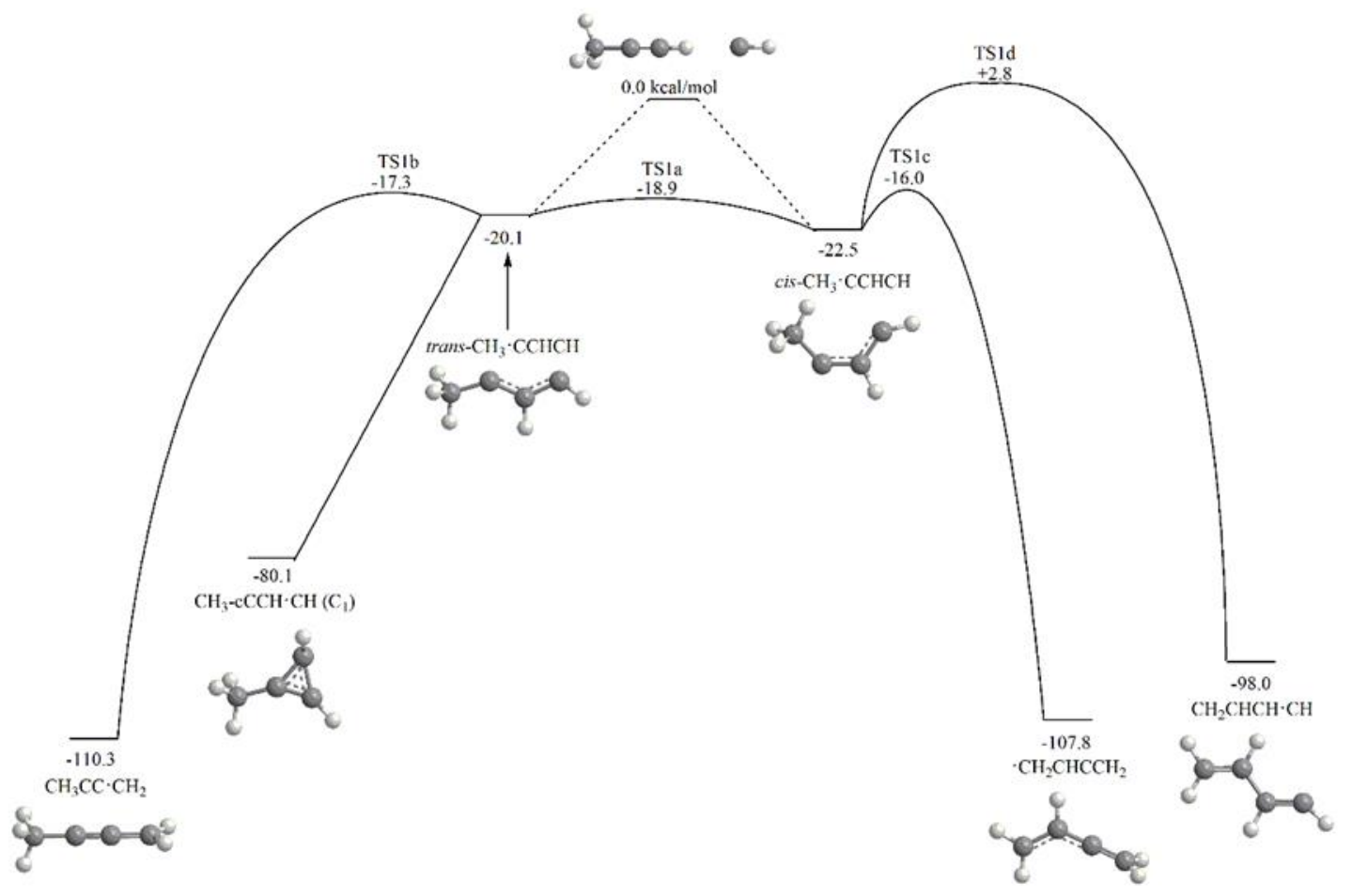


Figure 5.2: $\mathrm{C}_{4} \mathrm{H}_{5}$ PES, Part 2. This portion of CCSD(T)-F12/CBS//B3LYP/6-311++G(d,p) $\mathrm{C}_{4} \mathrm{H}_{5} \mathrm{PES}$ is relevant to the $\mathrm{CH}_{3}-\mathrm{cCCH} \cdot \mathrm{CH}$ molecule formed after initial $\mathrm{CH}$ addition to the triple bond of methylacetylene.

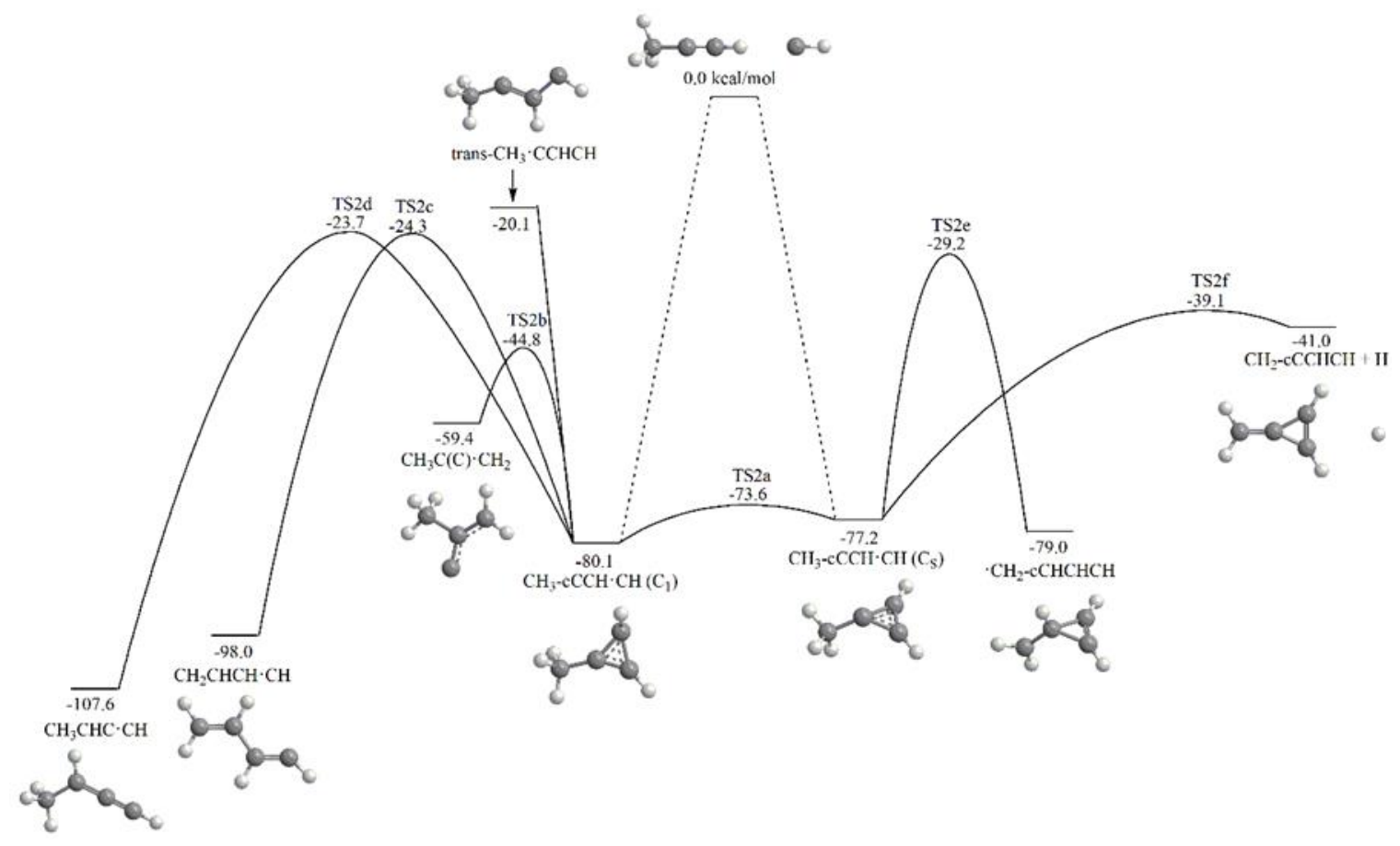


Figure 5.3: $\mathrm{C}_{4} \mathrm{H}_{5}$ PES, Part 3. This portion of CCSD(T)-F12/CBS//B3LYP/6-311++G(d,p) $\mathrm{C}_{4} \mathrm{H}_{5}$ PES is relevant to the $\mathrm{CH}_{3} \mathrm{CC} \cdot \mathrm{CH}_{2}$ molecule formed after initial $\mathrm{CH}$ insertion into the sp hybridized C-H bond of methylacetylene.

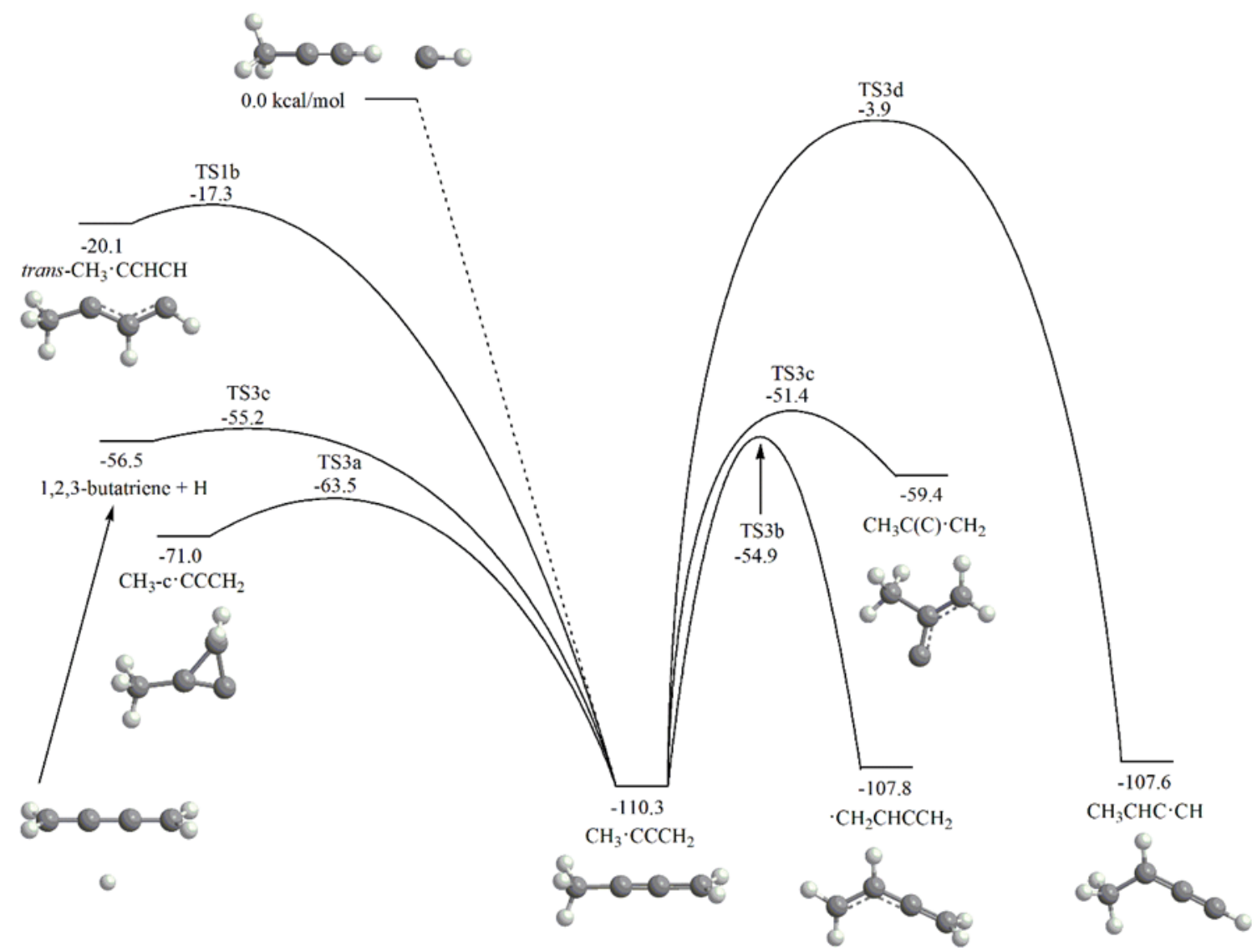


Figure 5.4: $\mathrm{C}_{4} \mathrm{H}_{5}$ PES, Part 4. This portion of CCSD(T)-F12/CBS//B3LYP/6-311++G(d,p) $\mathrm{C}_{4} \mathrm{H}_{5} \mathrm{PES}$ is relevant to the $\cdot \mathrm{CH}_{2} \mathrm{CH}_{2} \mathrm{CCH}$ molecule formed after initial $\mathrm{CH}$ insertion into sp3 hybridized $\mathrm{C}-\mathrm{H}$ bond of methylacetylene.

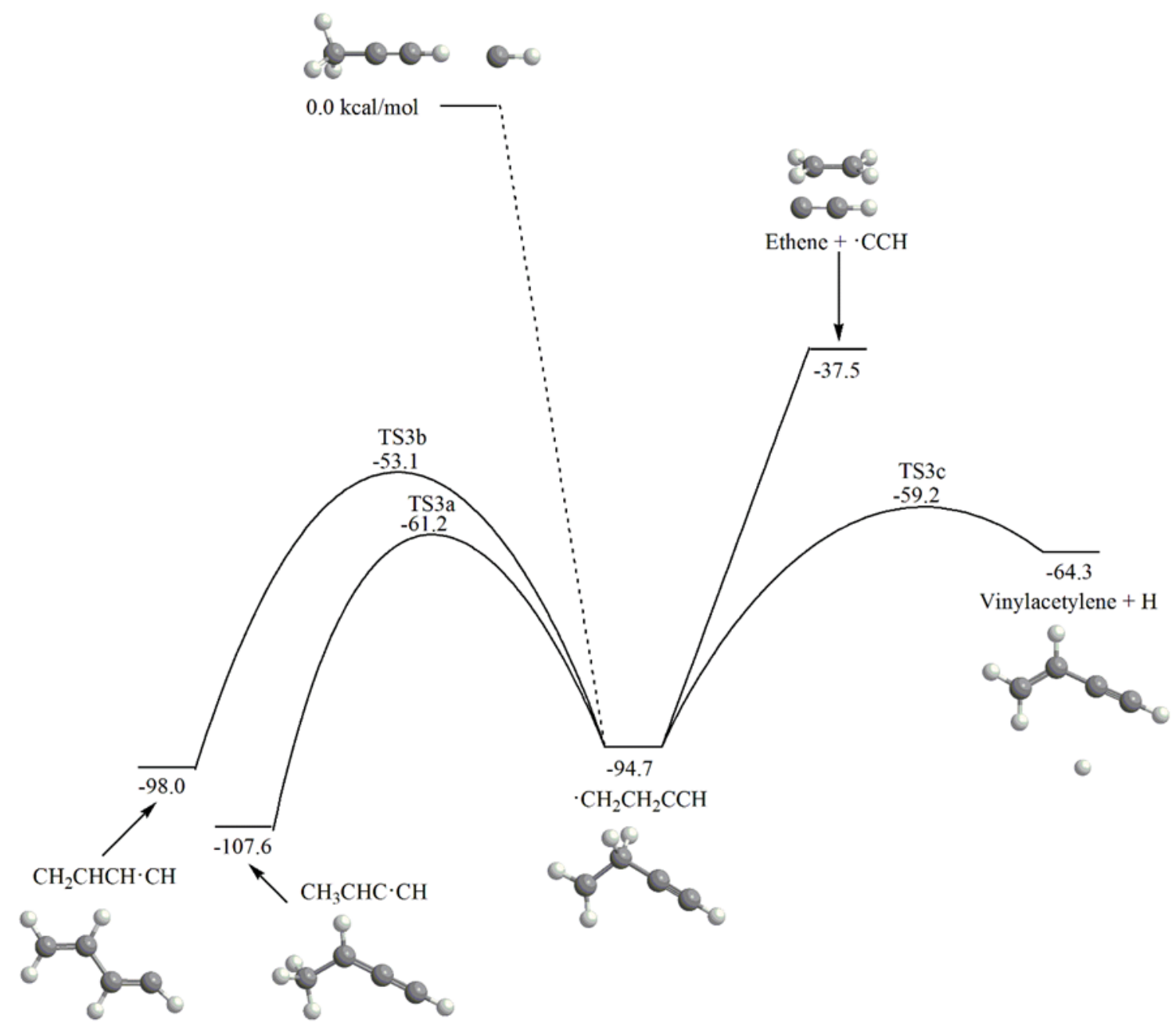


Figure 5.5: $\mathrm{C}_{4} \mathrm{H}_{5}$ PES, Part 5. This portion of $\mathrm{CCSD}(\mathrm{T})-\mathrm{F} 12 / \mathrm{CBS} / / \mathrm{B} 3 \mathrm{LYP} / 6-311++\mathrm{G}(\mathrm{d}, \mathrm{p})$ $\mathrm{C}_{4} \mathrm{H}_{5}$ PES is relevant to the $\mathrm{CH}_{3} \mathrm{CHC} \cdot \mathrm{CH}$ molecule formed after initial $\mathrm{CH}$ insertion into sp3 hybridized C-C bond of methylacetylene.

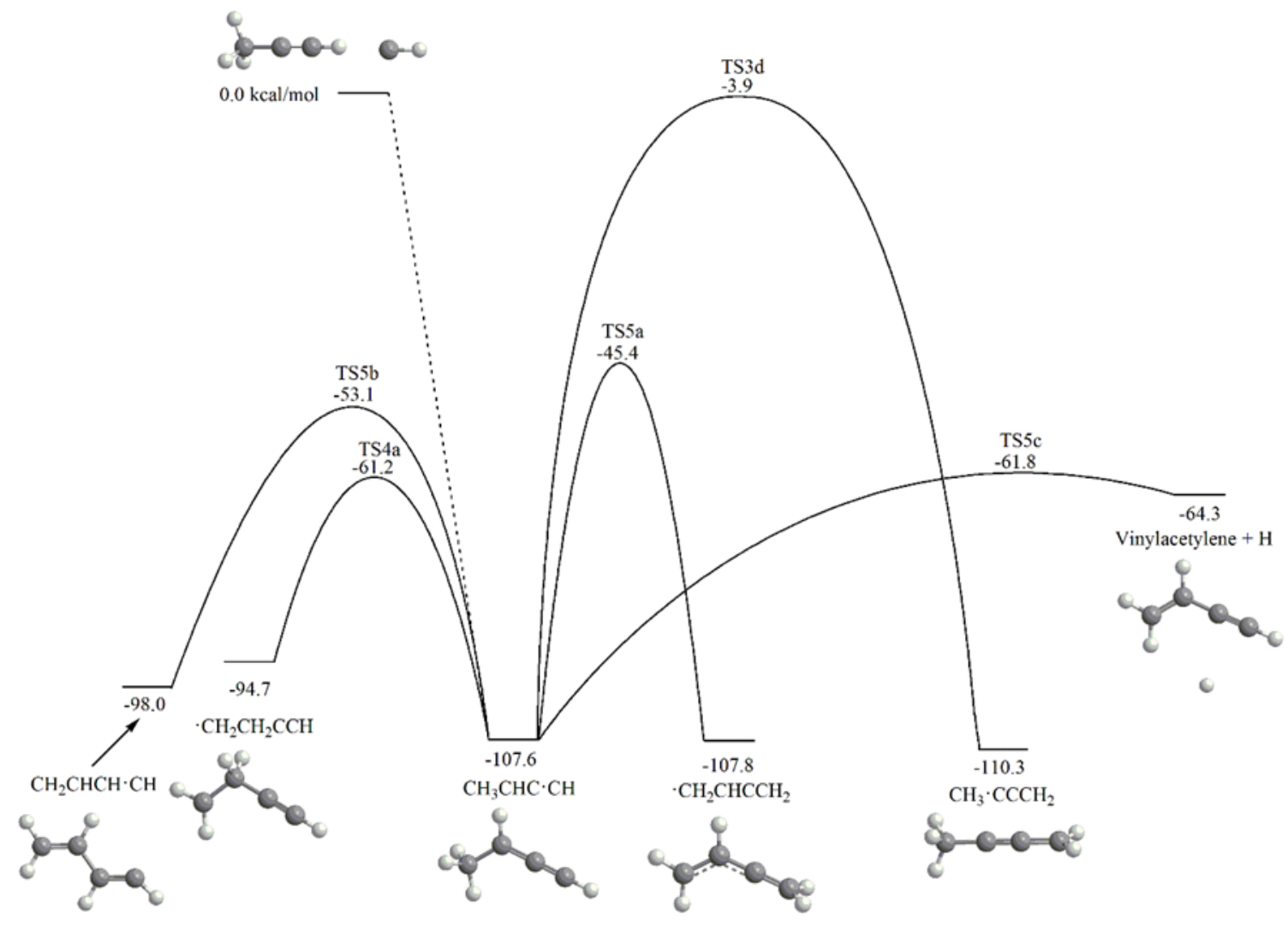


Figure 5.6: $\mathrm{C}_{4} \mathrm{H}_{5}$ PES, Part 6. This portion of CCSD(T)-F12/CBS//B3LYP/6-311++G(d,p) $\mathrm{C}_{4} \mathrm{H}_{5} \mathrm{PES}$ is relevant to the $\mathrm{CH}_{2} \cdot \mathrm{CCH}_{2} \mathrm{CH}$ molecule formed after initial $\mathrm{CH}$ addition to the terminal carbon of allene.

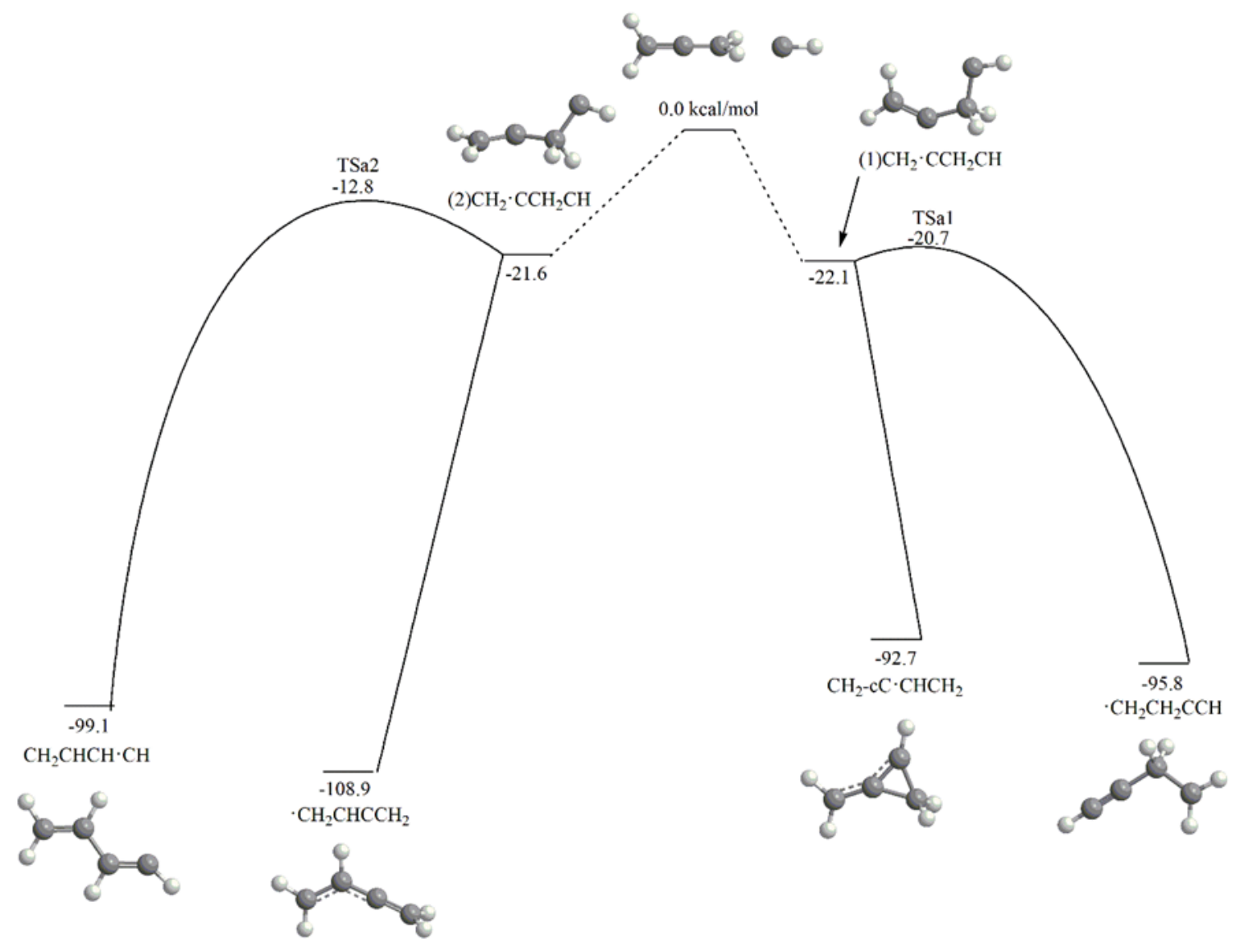


Figure 5.7: $\mathrm{C}_{4} \mathrm{H}_{5}$ PES, Part 7. This portion of CCSD(T)-F12/CBS//B3LYP/6-311++G(d,p) $\mathrm{C}_{4} \mathrm{H}_{5} \mathrm{PES}$ is relevant to the $\mathrm{CH}_{2}-\mathrm{cCCH} \cdot \mathrm{CH}_{2}$ molecule formed after initial $\mathrm{CH}$ addition to the double bond of allene.

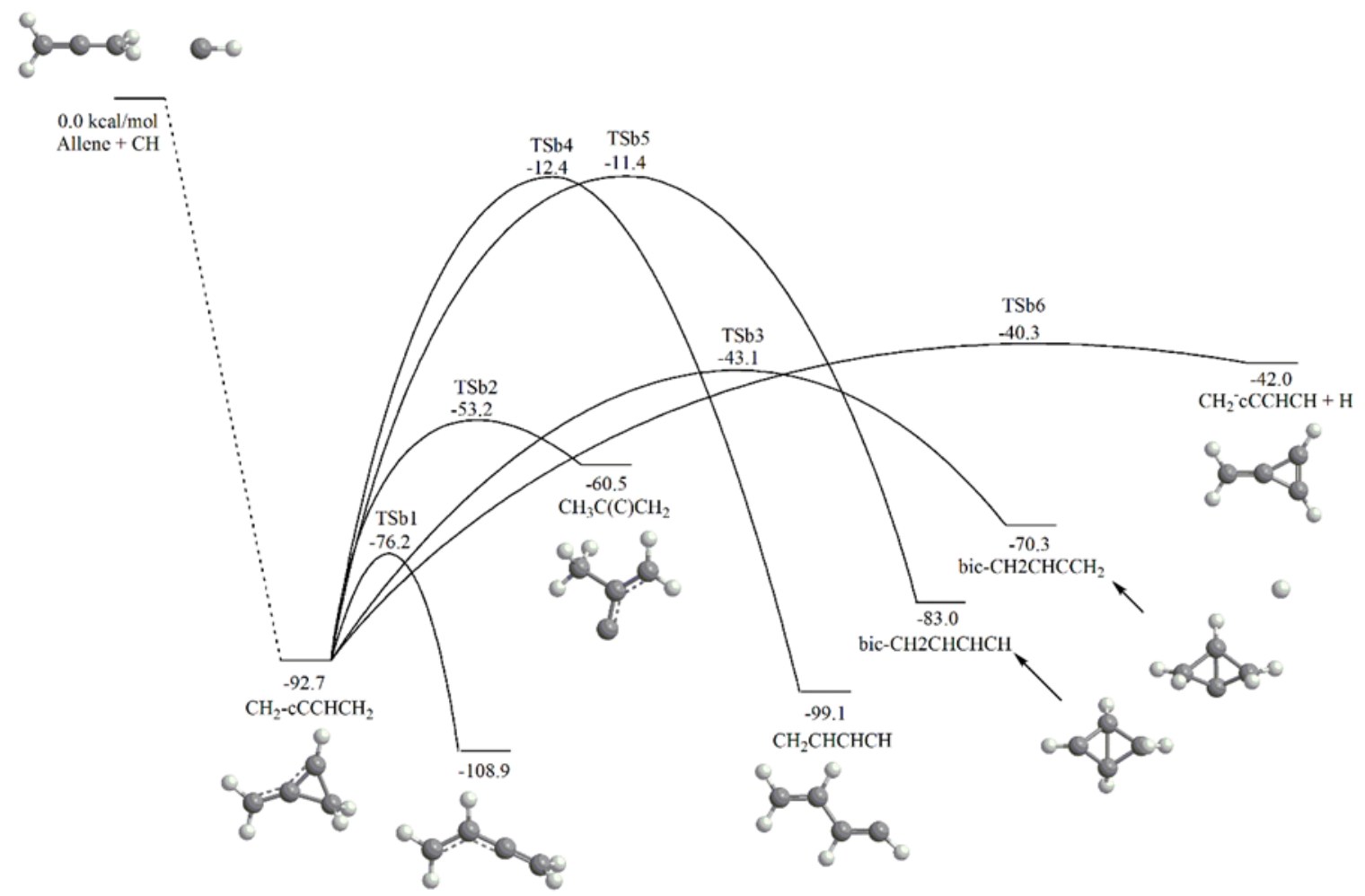


Figure 5.8: $\mathrm{C}_{4} \mathrm{H}_{5}$ PES, Part 8. This portion of CCSD(T)-F12/CBS//B3LYP/6-311++G(d,p) $\mathrm{C}_{4} \mathrm{H}_{5} \mathrm{PES}$ is relevant to the $\mathrm{CH}_{2} \mathrm{CHCCH}_{2}$ molecule formed after initial $\mathrm{CH}$ insertion into $\mathrm{sp} 2$ hybridized $\mathrm{C}-\mathrm{H}$ bond of allene.

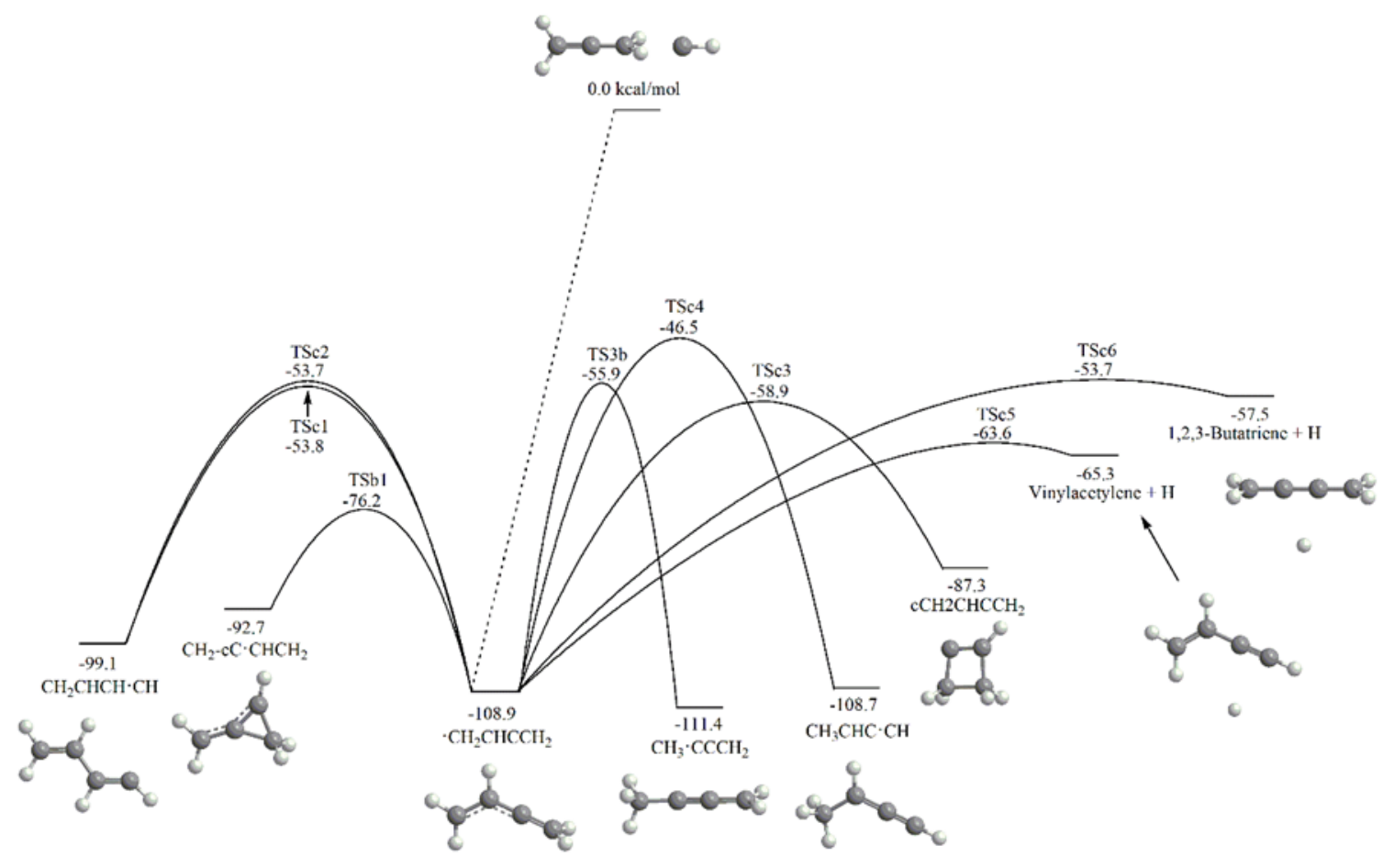


CHAPTER VI

CONCLUSIONS 
The reactions between methane and ethane with the $\mathrm{CH}$ radical, through high-level theoretical rate coefficient calculations, have been shown to be fast at all temperatures, which has important implications for the chemical evolution within interstellar clouds and low temperature atmospheres such as Titan's. Even though it was known from experiments that these reactions were fast even at low temperatures, previous theoretical studies were able to provide only a qualitative explanation for this behavior with the mapping of a submerged saddle point along the initial bimolecular $\mathrm{C}-\mathrm{H} \sigma$ bond insertion reaction path. Results in this publication, meanwhile, are more quantitative, beginning with high-level calculations along the initial reaction path, which suggests an attractive potential showing a monotonic decrease in the potential as the reactants approach one another. In addition, the rate coefficient results here are close to quantitative agreement with experiments for the reaction between methane and the $\mathrm{CH}$ radical while for the reaction between ethane and the $\mathrm{CH}$ radical the results are quantitative. These results indicate that the kinetics of the $\mathrm{CH}$ radical reactions with methane and ethane is a two transition-state reaction where in the lower temperatures its rate is governed at large separations while in the higher temperatures the rate is governed in an inner transition state where concerted incipient bond formation and bond cleavage are occurring. The results here suggest the ab initio and kinetic scheme which should be used to investigate the kinetics of $\mathrm{CH}$ radical reactions with higher alkanes.

Meanwhile, regarding the reaction mechanisms of reactions between alkanes and the $\mathrm{CH}$ radical, the present results provide the first concrete theoretical evidence that the initial bimolecular entrance channel proceeds through the $\mathrm{C}-\mathrm{H} \sigma$ bond insertion reaction and does not undergo $\mathrm{C}-\mathrm{C} \sigma$ bond insertion. The MEP leading to the latter was found to be 
repulsive at interfragment distances greater than $\sim 1.70 \AA$, with a potential along this reaction path well above the separated reactants in the range of 1.70-2.10 $\AA$ fragment separation. In addition, the predicted product distributions in this dissertation for the reactions between the $\mathrm{CH}$ radical with ethane and propane provide further, although indirect, evidence that the $\mathrm{C}-\mathrm{H} \sigma$ bond insertion path could be the exclusive initial reaction: In the case of ethane $+\mathrm{CH}$, the assumption that the reaction must evolve from the $n$-propyl radical provides propene $+\cdot \mathrm{H}$ branching ratios which are in quantitative agreement with the sole previous experimental branching ratio measurements; as for the case of propane + $\mathrm{CH}$ reaction, assumption that the reaction must proceed through either the $n$-butyl or secbutyl radicals leads to product distributions that are close to experimental error of the $\mathrm{H}$ atom branching ratio. Based upon the $\mathrm{H}$ shift and $\mathrm{H}$ loss transition state energies calculated for both the $\mathrm{C}_{2} \mathrm{H}_{5}$ and $\mathrm{C}_{3} \mathrm{H}_{7}$ PESs, it seems plausible that this small disagreement stems from errors in ab initio energies due to the theoretical method and not from lack of inclusion of a $\mathrm{C}-\mathrm{C} \sigma$ bond insertion path.

All of the product distributions calculated for this dissertation may have important implications for interstellar clouds and low temperature atmospheres. Of special interest here is the competition between the growth and degradation of the carbon chain in these environments. First, beginning with the reaction between methane and the $\mathrm{CH}$ radical, it is clear that the exclusive exit channel is an $\mathrm{H}$ loss that leads to ethene production, which can be explained by the fact that the sole $\beta$-scission available to the initial energized radical is the $\mathrm{H}$ loss, and not a $\mathrm{C}-\mathrm{C}$ cleavage. Meanwhile, a different product distribution behavior is seen for the reaction regarding the ethane molecule, where the dominant exit channel is $\mathrm{CH}_{3}$ loss; here, the mechanism is governed from the competition between the available C- 
$\mathrm{C}$ and $\mathrm{C}-\mathrm{H} \beta$-scissions of the $n$-propyl radical. Moving on to the reaction between propane with the $\mathrm{CH}$ radical, once again $\mathrm{C}-\mathrm{C}$ cleavage to degrade the molecule again dominates, though in this case the available $\mathrm{C}-\mathrm{C} \beta$-scissions can result in $\mathrm{CH}_{3}$ or $\mathrm{C}_{2} \mathrm{H}_{5}$ radical formation. Thus, except for the reaction between methane and the $\mathrm{CH}$ radical, which grows the carbon-chain, both the reactions between the $\mathrm{CH}$ radical with ethane and propane have the net effect of degrading the carbon-chain. It seems plausible to expect that reactions with large alkanes will follow a similar pattern as the $\mathrm{C}_{2} \mathrm{H}_{6}+\mathrm{CH}$ and $\mathrm{C}_{3} \mathrm{H}_{8}+\mathrm{CH}$ reactions, with degradation being dominant.

In regards to the reactions between the $\mathrm{CH}$ radical with the unsaturated $\mathrm{C}_{3} \mathrm{H}_{6}$ and $\mathrm{C}_{3} \mathrm{H}_{4}$ species, the predicted product distributions suggest a much different behavior than for the alkanes. Here, $\mathrm{H}$ loss products dominate the reaction between propene and the $\mathrm{CH}$ radical and are close to exclusive for both of the reactions available with the $\mathrm{C}_{3} \mathrm{H}_{4}$ molecules. For the former, the $\mathrm{H}$ loss dominates in large part due to the resonancestabilization of the $\mathrm{H}$ loss transition state from the $\cdot \mathrm{CH}_{2} \mathrm{CH}_{2} \mathrm{CHCH}_{2}$ configuration, which is expected to be sampled often during this reaction. Thus production of 1,3-butadiene is the major product here, meaning the reaction works to grow the carbon-chain. This fact might have important implications to certain interstellar clouds. As for the $\mathrm{C}_{3} \mathrm{H}_{4}+\mathrm{CH}$ reactions, because of the high degree of unsaturation in the initial energized radical, there are not energetically feasible $\mathrm{C}-\mathrm{C}$ cleavage exit channels; the one feasible such channel is C-C cleavage to produce acetylene and this could be a competitive exit channel except the these $\mathrm{CH}$ radical reaction do not readily access the only configuration necessary for it to take place, the $\mathrm{CH}_{2} \mathrm{CHCH} \cdot \mathrm{CH}$ species. 
The proper description of the entrance channels available to the reactions between the $\mathrm{CH}$ radical with either $\mathrm{C}_{3} \mathrm{H}_{6}$ or $\mathrm{C}_{3} \mathrm{H}_{4}$ are very difficult to investigate theoretically and there are, in principle, many such channels which need to be considered. It is simpler, although not as direct, to try and understand the competition amongst the entrance channel reactions from final product distribution calculations. An important result in the context of the above reactions is that the product branching ratio results can all be qualitatively explained if it is assumed that an initial addition is assumed. It has been suggested that this channel should dominate from entropic considerations, as compared to $\mathrm{C}-\mathrm{H} \sigma$ bond insertions. Thus the results from this publication, through a complete mapping of the respective PESs, provides more indirect evidence that addition is the dominant pathway. Furthermore, the quantitative disagreements in the product distributions with respect to experimental results suggest that $\mathrm{C}-\mathrm{H} \sigma$ bond insertions for the $\mathrm{C} 3$ unsaturated hydrocarbon species cannot be neglected. Thus to completely understand these reactions in a predictive manner would thus require an understanding of the quantitative nature of the competition between addition and insertion processes. 


\section{VIT A}

\section{JOAO MARCELO LAMIM RIBEIRO}

Born, Sao Paulo, Brazil

2011

B.S., Chemistry

Florida International University

Miami, Florida

2015

Visiting Doctoral Scholar

Argonne National Laboratory

Lemont, Illinois

2015

Doctoral Evidence Acquisition Fellow

University Graduate School

Florida International University

Miami, Florida

2008-2016

Teaching Assistant

Florida International University

Miami, Florida

\section{PUBLICATIONS AND PRESENTATIONS}

Ribeiro, J. M. L.; Mebel, A. M., Predictive theoretical kinetics for $\mathrm{CH}_{4}, \mathrm{C}_{2} \mathrm{H}_{6}$ and $\mathrm{C}_{3} \mathrm{H}_{8}$ reaction with $\mathrm{CH}\left(\mathrm{X}^{2} \Pi\right)$. In preparation (Draft available).

Ribeiro, J. M. L.; Mebel, A.M., Reaction mechanism and product branching ratios of the $\mathrm{CH}+\mathrm{C}_{3} \mathrm{H}_{4}$ reaction: a theoretical study. In preparation (Draft available).

Zhao, L.; Yang, T.; Kaiser, R.; Troy, T.; Ahmed, M.; Belisario-Lara, D.; Ribeiro, J. M. L.; Mebel, A. A Combined Experimental and Computational Study on the Unimolecular Decomposition of JP-8 Jet Fuel Surrogates I: Decane $\left(\mathrm{C}_{10} \mathrm{H}_{22}\right)$. J. Phys. Chem. A. Submitted.

Zhao, L.; Yang, T.; Kaiser, R.; Troy, T.; Ahmed, M.; Belisario-Lara, D.; Ribeiro, J. M. L.; Mebel, A. A Combined Experimental and Computational Study on the Unimolecular Decomposition of JP-8 Jet Fuel Surrogates II: Dodecane $\left(\mathrm{C}_{12} \mathrm{H}_{26}\right)$. Submitted.

Ribeiro, J. M. L.; Mebel, A. M., Reaction mechanism and product branching ratios of the $\mathrm{CH}+\mathrm{C}_{3} \mathrm{H}_{6}$ reaction: a theoretical study. J. Phys. Chem. A 2016, 120 (11), 1800-1812.

Ribeiro, J. M. L.; Mebel, A. M., Reaction mechanism and rate constants of the $\mathrm{CH}+\mathrm{CH}_{4}$ reaction: a theoretical study. Molecular Physics 2015, 113 (13-14), 1865-1872. 
Ribeiro, J. M. L.; Mebel, A. M., Reaction mechanism and product branching ratios of the $\mathrm{CH}+\mathrm{C}_{3} \mathrm{H}_{8}$ reaction: a theoretical study. J. Phys. Chem. A 2014, 118 (39), 9080-9086.

Ribeiro, J. M. L.; Mebel, A. M., Reaction mechanisms and branching ratios between $\mathrm{CH}$ $\left(\mathrm{X}^{2} \Pi\right)$ and $\mathrm{C}_{3} \mathrm{H}_{8}, \mathrm{C}_{3} \mathrm{H}_{6}$ and $\mathrm{C}_{3} \mathrm{H}_{4}$ : An ab initio study. 250 th ACS National Meeting and Exposition, Boston, Ma., August 16-20, 2015 (Poster).

Ribeiro, J. M. L.; Mebel, A. M., Low temperature dynamics and kinetics of the bimolecular reactions between $\mathrm{CH}\left(\mathrm{X}^{2} \Pi\right)$ and $\mathrm{CH}_{4}, \mathrm{C}_{2} \mathrm{H}_{6}, \mathrm{C}_{2} \mathrm{H}_{4}, \mathrm{C}_{2} \mathrm{H}_{2}$ : An ab initio study. $248^{\text {th }}$ ACS National Meeting and Exposition, San Francisco, Ca., August 10-14, 2014 (Poster).

Ribeiro, J. M. L.; Mebel, A. M., Reaction mechanisms between $\mathrm{CH}\left(\mathrm{X}^{2} \Pi\right)$ and $\mathrm{CH}_{4}, \mathrm{C}_{2} \mathrm{H}_{6}$, $\mathrm{C}_{2} \mathrm{H}_{4}, \mathrm{C}_{2} \mathrm{H}_{2}$ : An ab initio study. $247^{\text {th }}$ ACS National Meeting and Exposition, Dallas, Tx., March 16-20, 2014 (Poster). 